\title{
African natural products with potential antioxidants and hepatoprotectives properties: a review
}

\author{
Bashir Lawal $^{1 *}$ D, Oluwatosin K. Shittu ${ }^{1,2}$, Florence I. Oibiokpa ${ }^{1}$, Eustace B. Berinyuy ${ }^{3}$ and Hadiza Mohammed ${ }^{1}$
}

\begin{abstract}
Free radicals are highly reactive molecules generated during oxidation reactions which in turn initiate chain reactions resulting to cellular damage. There is substantial evidence implicating free radicals especially reactive oxygen species (ROS) in the etiology of more than one hundred degenerative disorders in humans including, arthritis, atherosclerosis, ischemia and reperfusion injury of many tissues, gastritis, diabetics, central nervous system injury, acquired immunodeficiency syndrome (AIDS) and cancer. Scientific evidence postulates that bioactive compounds especially from natural products are capable of providing protection against free radicals. Consequently, few decades have witnessed a surfeit of research geared towards validating the antioxidant and hepatoprotective potential of the natural products. In this review, African natural products whose antioxidants activities were scientifically validated either in their crude extracts and/or derived products have been discussed. A total 1076 plants species representing 287 family, 132 isolated compounds and 7 insect/mollusk secreation were found. The plant species from the following families; Fababceae, Asteraceae, Lamiaceae, Moraceae, Euphorbiaceae, Combretaceae and Malvaceae have received more scientific attention than others. Analysis of the reports revealed that Combretum apiculatum, Telfaria occidentalis, Acalypha racemosa, Garcinia lucida were the most active plant extracts from African flora. The most active ROS-detoxifying phytochemicals were moracin T, U, S and R (84-87), oleanolic acid (54), 5,7,4'-trihydroxy-3,8,3',5'-tetramethoxyflavone (89), 5,7,3'-trihydroxy-3,8,4',5'-trimethoxyflavone (88), luteolin (3',4',5,7-tetrahydroxy flavone) (117) and genistein (4',5,7-trihydroxyisoflavone) (116). The significant antioxidant potential demonstrated by some crude extracts and their constituent compounds render them good candidates for the development of new drugs. Although, the study of the mechanisms of actions as well as clinical validation of some of these isolated compounds is lacking. It is hoped that pertinent scientist and stakeholders will look further into some of these compounds for detailed authentification and subsequent commercialization.
\end{abstract}

Keywords: Antioxidants, DPPH, Hepatoprotective, Africa, Plants, Natural products

\section{Introduction}

Oxidation is a chemical reaction that transfers electrons or hydrogen from a substance to an oxidizing agent. Free radicals are generated during this oxidation reaction especially during oxidative respiration when there is a mitochondria leakage of activated oxygen [1], which in turn initiate a chain of reactions that results in cellular damage. Antioxidants terminate this chain of reactions by removing free radical intermediates, thus inhibiting

\footnotetext{
* Correspondence: bashirlawal12@gmail.com

'Department of Biochemistry, Tropical Disease Research Unit, Federal

University of Technology, P.M.B. 65 Minna, Nigeria

Full list of author information is available at the end of the article
}

further oxidation reactions [2]. They include reducing agents such as $\beta$-carotene, vitamin $\mathrm{C}, \mathrm{E}$ and ascorbic acid, as well as enzymes like superoxide dismutase (SOD), catalase (CAT), glutathione and peroxidases [3], and therefore exert their protective role by being oxidized themselves. Furthermore, many antioxidants compounds have been characterized form plants including flavonoids. Flavonoids are phenolic compounds with importants roles in scavenging free radicals and thus play vital roles in preventing oxidative stress associated disorders [4]. Among the common ROS are superoxide $\left(\mathrm{O}^{--}\right)$, hydroxyl $(\mathrm{OH})$, and peroxyl $(\mathrm{OOH}$, ROO) radicals [5]. Enzymes capable of producing 
superoxide are xanthine oxidase, reduced nicotinamide adenine dinucleotide phosphate oxidases and cytochrome $\mathrm{P}_{450}$ [1]. The imbalance between the production of these free radicals and the detoxifying capacity of the antioxidants results in oxidative stress which is among the major implicative factors in etiology of certain degenerative and chronic diseases including diabetes, atherosclerosis, parkinson's disease [6], renal disorders [7], cardiovascular, inflammatory, cancer, autoimmune, neurodegenerative diseases [8], and several other human ailments [9].

The liver is the major regulatory organ responsible for the metabolism, storage, detoxification, secretions and excretions of various exogenous and endogenous molecules including xenobiotics [10]. It plays a vital role in maintaining cellular homeostasis and protects the body against deleterious effect of chemicals, drugs, toxin, organism and parasite [5]. Therefore, the healthy performance of the organ reflects the health status of human $[11,12]$. However, during these protective roles this organ is susceptible to a numbers of diseases and disorders [13], from chemical drugs and other agents due to its distinctive metabolic roles and the proximal affiliation with the gastrointestinal tract (GIT) [14]. Hepatic injury may also results from excessive alcohol and paracetamol consumptions, exposure to infectious agents, xenobiotics and over the-counter drugs in western countries [15].

Hepatic diseases are a worldwide predicament often involving free radicals induced oxidative stress which if left untreated may advance from steatosis to chronic hepatitis, fibrosis and hepatocellular carcinoma [16]. The conventional drugs commonly used to combat the diseases and disorders associated with the liver are beset with different undesirable effects on biological systems [17]. As a result considerable attentions has been geared towards finding alternative, less toxic and effective antioxidants and hepatocurative agents from Africa natural product for the prevention, managements and treatment of diseases and disorders associated with the liver [18]. The natural products with medicinal reputation could serve as lead sources of natural antioxidants for development of novel drugs [12].

Africa is blessed with enormous biodiversity of natural product for healing practices [19]. From time immemorial Africa medicinal plants have been used by virtually all cultures to meet their health care needs. Evolutions have made plants to harbor a numbers of antioxidant chemicals (phytochemical or secondary metabolites) as natural means of surviving in hostile environments [20]. Consequently, few decades have witnessed a glut of research geared towards validating the quality, quantity, protective roles as well as therapeutic effectiveness of these antioxidant in African plants against oxidative stress induced diseases and disorders.
However, available reviews on the antioxidant potencies of African natural products; focused only on medicinal plants [21], published decade ago with emphasis only on 38 plants [22], others are limited to Cameroonian medicinal plants, [23], few African vegetables, fruits and mushrooms [24], and hepatoprotective activities of medicinal plants [25]. This review is intended to serve as scientific baseline information for the documented African natural products with antioxidants and hepatoprotectve reputation as well as a starting point for future studies.

\section{Methodology (Search strategy)}

To identify natural products from African flora and fauna with antioxidant and hepatoprotective potentials, a review was compiled based on scientific literature from various sources including; Google Scholar, Science Direct, PubMed, Medline, Science domain [19, 22, 26, 27]. The keywords used for identification of relevant data included the following terms; antioxidant, radical scavenging activities, anti-aging principles, reactive oxygen species, free radicals, African medicinal plants, natural product, 2,2-Diphenyl-1-picrylhydrazyl radical scavenging assay $(\mathrm{DPPH})$, reducing properties and lipid peroxidations. All relevant data previously published in English were retrieved. However, data for natural products from sources other than African countries were completely excluded from this review paper. Using the specified procedure for acquisition of necessary data, 641 articles were retrieved, out of which 315 , mainly in the form of journal articles, books and reviews; were used for compilation of the current review.

The information obtained from these research articles, captured in the current review paper includes; scientific names, that is the family, genus and specific names, parts of plants or mollusk used, solvent system used for the extraction procedure, the bioassay test carried out, whether in vitro or in vivo, as well as the antioxidant and hepatoprotective potencies of natural products originating from African flora and fauna (Tables 1, 2, 3, 4, 5 and 6). Information was also obtained from authenticated post graduate theses, conference proceedings with literature on antioxidant and hepatoprotective assay results of flora and fauna endemic or naturalized in Africa.

\section{Results and discussion}

A total 1076 plants species representing 287 family and 7 other natural products were identified. Previous phytochemical studies of ethnomedicinal plants of African origin used as antioxidants and for hepatoprotective properties led to characterization of approximately 132 compounds reviewed in this study. A map of Africa indicating the subregions of the continent as used in this review is presented in Fig. 1. From the reviewed plants with antioxidant and related data; $31.33 \%$ originate from 
Table 1 Antioxidants activities of West African plants

\begin{tabular}{|c|c|c|c|c|c|c|c|}
\hline Plants & Family & Part used & Solvents & Assay Methods & Inhibition/IC 50 & $\begin{array}{l}\text { Country of } \\
\text { origin }\end{array}$ & References \\
\hline Abrus precatorius $\mathrm{L}$. & Leguminosae & Leaf & $\mathrm{MeOH}$ & DPPH & $72.48 \%$ at $5 \mathrm{mg} / \mathrm{mL}$ & Nigeria & [136] \\
\hline Abrus precatorius $\mathrm{L}$. & Leguminosae & Seed/Shell & Oil & DPPH/ABTS/LP/NO & 52.9.1.9,2.1/3,3,1.4,1.2 mg/mL & Nigeria & {$[137]$} \\
\hline Artemisia absinthii L. & Asteraceae & Not stated & $\mathrm{H}_{2} \mathrm{O}$ & FRAP & $2228 \mu \mathrm{Mol} / \mathrm{L}$ & Not stated & {$[30]$} \\
\hline Acacia ataxacantha DC. & Fabaceae & Bark & $\mathrm{CH}_{2} \mathrm{Cl}_{2} / \mathrm{EtOAC}$ & $\mathrm{DPPH}$ & $65 / 54 \%$ at $62.5 \mu \mathrm{g} / \mathrm{mL}$ & Benin & [138] \\
\hline Acacia macrostachya Rchb. ex DC. & Verbenaceae & Root & $\mathrm{MeOH}$ & DPPH & $4.30 \mu \mathrm{g} / \mathrm{mL}$ & Burkina Faso & [139] \\
\hline Acalypha segetalis Mull. & Euphorbiaceae & Leaf & $\mathrm{MeOH}$ & $\mathrm{DPPH}$ & $>200 \mu \mathrm{g} / \mathrm{mL}$ & Nigeria & [140] \\
\hline Acalypha torta L. & Euphorbiaceae & Leaf & $\mathrm{MeOH}$ & DPPH & $>200 \mu \mathrm{g} / \mathrm{mL}$ & Nigeria & [140] \\
\hline Acanthospermum hispidium DC. & Asteraceae & Aerial parts & $\mathrm{MeOH}$ & DPPH & - & Benin & [141] \\
\hline Adansonia digitata $\mathrm{L}$. & Bombacaceae & Fruit & $\mathrm{MeOH}$ & $\mathrm{DPPH}$ & $77.36 \%$ & Guinea & [142] \\
\hline Adansonia digitata $\mathrm{L}$. & Bombacaceae & Leaf & $\mathrm{BtOH}$ & FRAP & $78 \%$. at $500 \mu \mathrm{g} / \mathrm{mL}$ & Nigeria & [143] \\
\hline Adansonia digitata $\mathrm{L}$. & Bombacaceae & Fruit & $\mathrm{MeOH}$ & FRAP & $24.50 \mathrm{mmol} A E A C / 100 \mathrm{~g}$ & Burkina Faso & [144] \\
\hline Aframomum melegueta K.Schum. & Zingiberaceae & Fruit & $\mathrm{MeOH}$ & $\mathrm{DPPH}$ & $111.12 \%$ & Guinea & [142] \\
\hline Aframomum melegueta K.Schum. & Zingiberaceae & - & $\left(\mathrm{CH}_{3}\right)_{2} \mathrm{CO}$ & DPPH/SAS & $0.11 / 0.105 \mathrm{mg} / \mathrm{mL}$ & Nigeria & [145] \\
\hline Albizia chevalieri Harms. & Fabaceae & Leaf & $\mathrm{MeOH}$ & $\mathrm{DPPH}$ & $94.732 \%$ at $250 \mu \mathrm{g} / \mathrm{mL}$ & Nigeria & {$[146]$} \\
\hline Alchornea laxiflora Pax \& K. Hoffm. & Euphorbiaceae & Leaf & $\mathrm{BtOH}$ & FRAP & & Nigeria & [143] \\
\hline Alchornea ordifolia Mull. Arg. & Euphorbiaceae & Leaf & $\begin{array}{l}\mathrm{EtOAC} /\left(\mathrm{CH}_{3}\right) \\
{ }_{2} \mathrm{CO}\end{array}$ & DPPH & $99.4 / 79 \%$ at $1.56 \mathrm{mg} / \mathrm{mL}$ & Nigeria & [147] \\
\hline Allium sativum $\mathrm{L}$. & Alliaceae & Spice & $\mathrm{H}_{2} \mathrm{O}$ & DPPH/ABTS & $1.4 / 0.66 \mathrm{mg} / \mathrm{mL}$ & Nigeria & {$[148]$} \\
\hline Alstonia boonei De wild. & Apocynaceae & $\begin{array}{l}\text { Cortex/Folium/ } \\
\text { Radix }\end{array}$ & $\mathrm{MeOH}$ & DPPH & $++/++$ & Nigeria & {$[38]$} \\
\hline Alstonia boonei De wild. & Apocynaceae & Stem & $\mathrm{MeOH}$ & DPPH/FRAP & $68.5 / 1.40 \%$ at $400 \mu \mathrm{g} / \mathrm{mL}$ & Nigeria & [149] \\
\hline Althaeae radix $\mathrm{L}$. & Malvaceae & Not stated & $\mathrm{H}_{2} \mathrm{O}$ & FRAP & $59 \mu \mathrm{Mol} / \mathrm{L}$ & Not stated & {$[30]$} \\
\hline Amaranthus hybridus $\mathrm{L}$. & Amaranthaceae & Leaf & $\mathrm{MeOH}$ & $\mathrm{DPPH}$ & $9.0 \pm 2.1 \mu \mathrm{g} / \mathrm{mL}$ & Nigeria & Adetutu et al., 2013 [150] \\
\hline Amaranthus viridis $\mathrm{L}$. & Amaranthaceae & Leaf & $\mathrm{MeOH}$ & $\mathrm{DPPH}$ & $3.4 \pm 0.25 \mu \mathrm{g} / \mathrm{mL}$ & Nigeria & Adetutu et al., 2015 \\
\hline Anarcadium occidentale L. & Anacardaceae & Bark & $\mathrm{MeOH}$ & DPPH/FRAP & $43.5 / 0.70$ at $400 \mu \mathrm{g} / \mathrm{mL}$ & Nigeria & [149] \\
\hline Anisopus mannii N.E.Br. & Aslepiadaceae & Stem/Leaf/Root & $\mathrm{H}_{2} \mathrm{O}$ & RSA & $0.2 / 0.15 / 0.19 \mathrm{mM}$ & Nigeria & [151] \\
\hline $\begin{array}{l}\text { Anogeissus leiocarpus (DC.) Guill. \& } \\
\text { Perr. }\end{array}$ & Combretaceae & Leaf & $\mathrm{MeOH}$ & DPPH & 79.09 at $5 \mathrm{mg} / \mathrm{mL}$ & Nigeria & [136] \\
\hline $\begin{array}{l}\text { Anogeissus leiocarpus (DC.) Guill. \& } \\
\text { Perr. }\end{array}$ & Combretaceae & Root & $\mathrm{H}_{2} \mathrm{O}$ & $\mathrm{H}_{2} \mathrm{O}_{2} / \mathrm{Fe}^{3+}$ & $0.53 / 0.39 \%$ & Nigeria & {$[152]$} \\
\hline Antidesma venosum E. Mey. ex Tul. & Euphorbiaceae & Fruit & $\mathrm{MeOH}$ & $\mathrm{DPPH}$ & $9.53 \%$ & Guinea & [142] \\
\hline Arctostasphylos uva-ursi L. (Spreng). & Ericaceae & Not stated & $\mathrm{H}_{2} \mathrm{O}$ & FRAP & $13207 \mu \mathrm{Mol} / \mathrm{L}$ & Not stated & {$[30]$} \\
\hline Argemone Mexicana L. & Papaveraceaea & Entire plant & $\mathrm{MeOH}$ & DPPH & $1.73 \mu \mathrm{g} / \mathrm{mL}$ & Benin & [141] \\
\hline
\end{tabular}


Table 1 Antioxidants activities of West African plants (Continued)

\begin{tabular}{|c|c|c|c|c|c|c|c|}
\hline Asperulae herba $\mathrm{L}$. & Rubiaceae & Not stated & $\mathrm{H}_{2} \mathrm{O}$ & FRAP & $2557 \mu \mathrm{Mol} / \mathrm{L}$ & Not stated & [30] \\
\hline Balanites aegyptiaca (L.) Delile. & Balantiaceae & Leaf & $\mathrm{MeOH}$ & DPPH & $52.53 \mu \mathrm{g} / \mathrm{mL}$ & Togo & [153] \\
\hline Bardanae folium & Asteraceae & Not stated & $\mathrm{H}_{2} \mathrm{O}$ & FRAP & $2337 \mu \mathrm{Mol} / \mathrm{L}$ & Not stated & [30] \\
\hline Basilici herba L. & Lamiaceae & Not stated & $\mathrm{H}_{2} \mathrm{O}$ & FRAP & $5314 \mu \mathrm{Mol} / \mathrm{L}$ & Not stated & [30] \\
\hline Bauhinia rufescens Lam. & Caesalpiniaceae & Leaf & $\mathrm{MeOH}$ & $\mathrm{DPPH}$ & $74.65 \%$ at $50 \mu \mathrm{g} / \mathrm{mL}$ & Nigeria & [154] \\
\hline Besella alba $\mathrm{L}$. & Basellaceae & Leaf/Stem & $\mathrm{MeOH}$ & DPPH & $+/-$ & Nigeria & [39] \\
\hline Betulae folium L. & Betulaceae & Not stated & $\mathrm{H}_{2} \mathrm{O}$ & FRAP & $3896 \mu \mathrm{Mol} / \mathrm{L}$ & Not stated & [30] \\
\hline Blepharis lineariifolia Pers. & Acanthaceae & Stem/Leaf & $\mathrm{H}_{2} \mathrm{O}$ & $\mathrm{DPPH}$ & $44 \mu \mathrm{g} / \mathrm{mL}$ & Burkina Faso & [155] \\
\hline Blighia sapida K.D. Koenig & Sapindaceae & Fruit & $\mathrm{MeOH}$ & DPPH & $38.54 \%$ & Guinea & [142] \\
\hline Boerhavia diffusa $\mathrm{L}$. & Nyctaginaceae & Leaf & $\mathrm{MeOH}$ & $\mathrm{DPPH}$ & ++ & Nigeria & [156] \\
\hline Boswellia dalzielii Hutch. & Burceraceae & Stem back & $\mathrm{EtOH}$ & $\mathrm{DPPH}$ & $83 \%$ at $10 \mu \mathrm{g} / \mathrm{mL}$ & Benin & [157] \\
\hline Brachystegia eurycoma Harms. & Fabaceae & Seed & $\mathrm{EtOH}$ & $\mathrm{DPPH}$ & $59.70 \mu \mathrm{g} / \mathrm{mL}$ & Nigeria & [158] \\
\hline Brassica juncea (L.) Coss. & Brassicaceae & Seed & $\mathrm{MeOH}$ & DPPH/FRAP & $68.9 / 1.30 \%$ at $400 \mu \mathrm{g} / \mathrm{mL}$ & Nigeria & [149] \\
\hline Bridelia ferruginea Benth. & Euphorbiaceae & Fruit & $\mathrm{MeOH}$ & $\mathrm{DPPH}$ & $13.30 \%$ & Guinea & [142] \\
\hline Bridelia micrantha Baill. & Phyllanthaceae & Leaf & $\mathrm{MeOH}$ & DPPH/FRAP & $97.70 / 1.39$ at $400 \mu \mathrm{g} / \mathrm{mL}$ & Nigeria & [149] \\
\hline Bursae pastoris herba & Brassicaceae & Not stated & $\mathrm{H}_{2} \mathrm{O}$ & FRAP & $654 \mu \mathrm{Mol} / \mathrm{L}$ & Not stated & [30] \\
\hline $\begin{array}{l}\text { Byrsocarpus coccineus Schumach. \& } \\
\text { Thonn. }\end{array}$ & Connraceae & Folium/Radix & $\mathrm{MeOH}$ & $\mathrm{DPPH}$ & $++/++$ & Nigeria & {$[38]$} \\
\hline $\begin{array}{l}\text { Byrsocarpus coccineus Schumach. \& } \\
\text { Thonn }\end{array}$ & Connaraceae & Root & $\mathrm{MeOH}$ & DPPH & - & Benin & [141] \\
\hline Calendulae flos $L$. & Asteraceae & Not stated & $\mathrm{H}_{2} \mathrm{O}$ & FRAP & $1347 \mu \mathrm{Mol} / \mathrm{L}$ & Not stated & {$[30]$} \\
\hline Calliandria surinamensis Engl. & Fabaceae & Flower & $\mathrm{MeOH}$ & $\mathrm{DPPH}$ & $<30 \%$ at $0.1 \mathrm{mg} / \mathrm{mL}$ & Nigeria & [159] \\
\hline Canarium schweinfurthii Engl. & Burseraceae & Cortex & $\mathrm{MeOH}$ & DPPH & ++++ & Nigeria & [38] \\
\hline Cantaurii herba Rafn. & Gentianaceae & & $\mathrm{H}_{2} \mathrm{O}$ & FRAP & $1347 \mu \mathrm{Mol} / \mathrm{L}$ & Not stated & {$[30]$} \\
\hline Cantharelle cibarius Fr. & Cantherallaceae & Mushroom & - & LPO & $49.74 \mathrm{nM}$ & Nigeria & [160] \\
\hline Cantharellus cibarius Fr. & Cantharellaceae & Fruit & $\mathrm{MeOH} / \mathrm{EtOH}$ & DPPH & $2.68 / 3.12 \mathrm{mg} / \mathrm{mL}$ & Nigeria & [161] \\
\hline Canthium setosum Hiern. & Rubiaceae & Aerial parts & $\mathrm{MeOH}$ & $\mathrm{DPPH}$ & $3.47 \mu \mathrm{g} / \mathrm{mL}$ & Benin & [141] \\
\hline Capsicum frutescens $\mathrm{L}$. & Solanaceae & Spice & $\mathrm{H}_{2} \mathrm{O}$ & DPPH/ABTS & $1.55 / 0.45 \mathrm{mg} / \mathrm{mL}$ & Nigeria & [148] \\
\hline Carica papaya L. & Caricaceae & Leaf & $\mathrm{EtOH}$ & $\mathrm{DPPH}$ & $0.58 \mathrm{mg} / \mathrm{mL}$ & Nigeria & [162] \\
\hline Cassia sieberiana DC. & Fabaceae & Leaf & $\mathrm{MeOH}$ & $\mathrm{DPPH}$ & $50 \mu \mathrm{g} / \mathrm{mL}$ & Nigeria & [163] \\
\hline Cassia sieberiana DC. & Fabaceae & Stem & $\mathrm{MeOH}$ & DPPH/FRAP & $40.1 / 0.83$ at $400 \mu \mathrm{g} / \mathrm{mL}$ & Nigeria & [149] \\
\hline Casstha filiformis mill. & Lauraceae & Stem & $\mathrm{MeOH}$ & DPPH/FRAP & $75.8 / 1.61$ at $400 \mu \mathrm{g} / \mathrm{mL}$ & Nigeria & [149] \\
\hline Casuarina equisetifolia L. & Casuarinaceae & Fruit & $\mathrm{MeOH}$ & DPPH & $88.97 \%$ at $100 \mu \mathrm{g} / \mathrm{mL}$ & Benin & [164] \\
\hline Ceratotheca sesamoides Endl. & Pedaliaceae & Leaf & $\mathrm{MeOH}$ & DPPH & $2.9 \mu \mathrm{g} / \mathrm{mL}$ & Ivory coast & [165] \\
\hline
\end{tabular}


Table 1 Antioxidants activities of West African plants (Continued)

\begin{tabular}{|c|c|c|c|c|c|c|c|}
\hline Cetrariae lichen (L.) Ach. & Parmeliaceae & Not stated & $\mathrm{H}_{2} \mathrm{O}$ & FRAP & $125 \mu \mathrm{Mol} / \mathrm{L}$ & Not stated & [30] \\
\hline Chamomillae flos L. & Asteraceae & Not stated & $\mathrm{H}_{2} \mathrm{O}$ & FRAP & $2856 \mu \mathrm{Mol} / \mathrm{L}$ & Not stated & [30] \\
\hline Chellidonii herba L. & Papaveraceae & Not stated & $\mathrm{H}_{2} \mathrm{O}$ & FRAP & $3401 \mu \mathrm{Mol} / \mathrm{L}$ & Not stated & {$[30]$} \\
\hline Cichorii herba L. & Asteraceae & Not stated & $\mathrm{H}_{2} \mathrm{O}$ & FRAP & $1408 \mu \mathrm{Mol} / \mathrm{L}$ & Not stated & {$[30]$} \\
\hline Citrus sinensis Pers. & Rutaceae & Leaf & $\mathrm{MeOH}$ & DPPH/FRAP & $69.7 / 1.22$ at $400 \mu \mathrm{g} / \mathrm{mL}$ & Nigeria & [149] \\
\hline Cleome gynandra L. & Capparidaceae & Leaf & $\mathrm{CH}_{2} \mathrm{Cl}_{2}$ & DPPH & $>38.4 \mu \mathrm{g} / \mathrm{mL}$ & Ivory coast & {$[165]$} \\
\hline Clerodendrum formicarum Gurke. & Lamiacea & Leaf & $\mathrm{MeOH}$ & $\mathrm{DPPH}$ & $>200 \mu \mathrm{g} / \mathrm{mL}$ & Cameroo & [140] \\
\hline Clitocybe odora (Fr) P. Kumm. & Tricholometaceae & Mushroom & - & LPO & $52.10 \mathrm{nM}$ & Nigeria & {$[160]$} \\
\hline Cnestis ferruginea DC. & Connaraceae & Leaf & $\mathrm{H}_{2} \mathrm{O}$ & $\mathrm{Fe}^{2} / \mathrm{RP} / \mathrm{DPPH}$ & $45.25 / 121.5 / 21.55 \mu \mathrm{g} / \mathrm{mL}$ & Ivory coast & {$[166]$} \\
\hline Cnestis ferruginea DC. & Connaraceae & $\begin{array}{l}\text { Cortex/Folium/ } \\
\text { Radix }\end{array}$ & $\mathrm{MeOH}$ & DPPH & $++++/++++/++++$ & Nigeria & {$[38]$} \\
\hline $\begin{array}{l}\text { Cnidoscolus acontifolius (Mill.) I.M. } \\
\text { Johnst. }\end{array}$ & Euphorbiaceae & Leaf & $\mathrm{BtOH}$ & FRAP & $76 \%$ at $500 \mu \mathrm{g} / \mathrm{mL}$ & Nigeria & [143] \\
\hline Cola lepidota K. Schum. & Sterculiaceae & Leaf & $\mathrm{MeOH} / \mathrm{CHCl}_{3}$ & $\mathrm{DPPH}$ & $190 / 50 \mu \mathrm{g} / \mathrm{mL}$ & Nigeria & [167] \\
\hline Combretum micranthum G. Don. & Combretaceae & Leaf & $\mathrm{H}_{2} \mathrm{O}$ & ABTS & 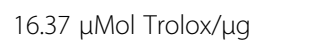 & Burkina Faso & {$[168]$} \\
\hline Crataegi flos L. & Rosaceae & Not stated & $\mathrm{H}_{2} \mathrm{O}$ & FRAP & $3025 \mu \mathrm{Mol} / \mathrm{L}$ & Not stated & {$[30]$} \\
\hline Crateva adansonii Forst. F. & Capparaceae & Leaf & $\mathrm{MeOH}$ & DPPH & $1562.52 \mathrm{mg} / \mathrm{mL}$ & Nigeria & Tsado et al., 2016b [169] \\
\hline Crinum jagus (J.Thomps.) Dandy. & Amarllidaceae & Bulb & $\mathrm{MeOH}$ & DPPH/FRAP & $85.78 / 1.86$ at $400 \mu \mathrm{g} / \mathrm{mL}$ & Nigeria & [149] \\
\hline Crinum purpurascen Herbs. & Liliaceae & Folium/Radix & $\mathrm{MeOH}$ & DPPH & $++/++$ & Nigeria & {$[38]$} \\
\hline Croton lobatus L. & Euphorbiaceae & Aerial parts & $\mathrm{MeOH}$ & DPPH & $1.96 \mu \mathrm{g} / \mathrm{mL}$ & Benin & [141] \\
\hline Cymbopogon citrates Stapf. & Poaceae & Leaf & Oil & $\mathrm{DPPH}$ & 7.48 at $0.1 \%$ oil & Burkina Faso & {$[170]$} \\
\hline Cymbopogon giganteus Chiov. & Poaceae & Leaf & Oil & DPPH & 18.76 at $0.1 \%$ oil & Burkina Faso & {$[170]$} \\
\hline Detarium microcarpum Guill. & Caesalpiniaceae & Seed & $\mathrm{EtOH}$ & DPPH & $89.00 \mu \mathrm{g} / \mathrm{mL}$ & Nigeria & [158] \\
\hline Detarium microcarpum Guill. & Caesalpiniaceae & Fruit & $\mathrm{MeOH}$ & FRAP & $48.45 \mathrm{mmol}$ AEAC/100 g & Burkina Faso & [144] \\
\hline Detarium senegalense J.F. Gmel. & Caesalpiniaceae & Fruit & $\mathrm{MeOH}$ & DPPH & $94.26 \%$ & Guinea & [142] \\
\hline Dialium dinklagei Harms. & Caesalpiniaceae & Leaf & $\mathrm{H}_{2} \mathrm{O}$ & $\mathrm{Fe}^{2} / \mathrm{RP} / \mathrm{DPPH}$ & $14.75 / 133.5 / 21.85 \mu \mathrm{g} / \mathrm{mL}$ & Ivory coast & [166] \\
\hline Dialium guineense Willd & Caesalpiniaceae & Fruit & $\mathrm{MeOH}$ & DPPH & $82.44 \%$ & Guinea & [142] \\
\hline Dialium guineense Willd & Caesalpiniaceae & Fruit & $\mathrm{MeOH}$ & FRAP & $<17.57 \mathrm{mmol}$ AEAC/100 g & Burkina Faso & [144] \\
\hline Dichapetalum guineense (DC.) Keay. & Dichapetalaceae & Leaf & $\mathrm{MeOH}$ & DPPH & - & Benin & [141] \\
\hline Dicliptera verticillata C. Chr. & Acanthaceae & Stem/Leaf & $\mathrm{H}_{2} \mathrm{O}$ & DPPH & $785 \mu \mathrm{g} / \mathrm{mL}$ & Burkina Faso & {$[155]$} \\
\hline $\begin{array}{l}\text { Diospyros mespiliformis Hochst. ex } \\
\text { A. DC. }\end{array}$ & Ebenaceae & Fruit & $\mathrm{MeOH}$ & DPPH & $111.75 \%$ & Guinea & {$[142]$} \\
\hline $\begin{array}{l}\text { Diospyros mespiliformis Hochst. ex } \\
\text { A. DC. }\end{array}$ & Ebenaceae & Fruit & $\mathrm{MeOH}$ & FRAP & $<17.57 \mathrm{mmol}$ AEAC/100 g & Burkina Faso & {$[144]$} \\
\hline Diospyros monbuttensis Gurke. & Fabaceae & Leaf & $\mathrm{H}_{2} \mathrm{O}$ & $\mathrm{Fe}^{2+} / \mathrm{RP} / \mathrm{DPPH}$ & $9.41 />200 / 22.25 \mu \mathrm{g} / \mathrm{mL}$ & Ivory coast & {$[166]$} \\
\hline
\end{tabular}


Table 1 Antioxidants activities of West African plants (Continued)

\begin{tabular}{|c|c|c|c|c|c|c|c|}
\hline Duranta repens $L$. & Verbenaceae & Leaf & $\mathrm{MeOH}$ & DPPH/FRAP & $72.61 / 1.71$ at $400 \mu \mathrm{g} / \mathrm{mL}$ & Nigeria & {$[149]$} \\
\hline $\begin{array}{l}\text { Dyschoriste perrottetii (Nees) } \\
\text { Kuntze. }\end{array}$ & Acanthaceae & Stem/Leaf & $\mathrm{H}_{2} \mathrm{O}$ & DPPH & $45 \mu \mathrm{g} / \mathrm{mL}$ & Burkina Faso & {$[155]$} \\
\hline Ehinaceae purpurea L. (Monench) & Asteraceae & Not stated & $\mathrm{H}_{2} \mathrm{O}$ & FRAP & $4033 \mu \mathrm{Mol} / \mathrm{L}$ & Not stated & {$[30]$} \\
\hline Ekebergia senegalansis A. Juss. & Meliaceae & Leaf & $\mathrm{MeOH}$ & DPPH & $13.33 \mu \mathrm{g} / \mathrm{mL}$ & Nigeria & $\begin{array}{l}\text { Aladesanmi et al., } 2007 \\
\text { [156] }\end{array}$ \\
\hline Entada Africana Guill. \& Per. & Fabaceae & Stem back & $\mathrm{n}-\mathrm{C}_{6} \mathrm{H}_{12}$ & $\mathrm{DPPH} / \beta-C L A M S / M L P$ & $81.08 / 235.30 / 3.53 \mu \mathrm{g} / \mathrm{mL}$ & Nigeria & {$[83]$} \\
\hline Entada africana Guill. \& Per. & Fabaceae & Leaf & $\mathrm{MeOH}$ & $\mathrm{DPPH}$ & $0.40 \mu \mathrm{g} / \mathrm{mL}$ & Togo & [153] \\
\hline Entada Africana Guill. \& Per. & Fabaceae & $\begin{array}{l}\text { Leaf/Stem bark/ } \\
\text { Leaf }\end{array}$ & $\mathrm{H}_{2} \mathrm{O}$ & DPPH & $3.36 / 1.36 / 1.4 \mu \mathrm{g} / \mathrm{mL}$ & Burkina Faso & {$[171]$} \\
\hline Entandrophragma angolense C. DC. & Meliaceae & Stem & $\mathrm{MeOH}$ & DPPH & 70.34 at $5 \mathrm{mg} / \mathrm{mL}$ & Nigeria & {$[136]$} \\
\hline Epilobii herba & Rosaceae & Not stated & $\mathrm{H}_{2} \mathrm{O}$ & FRAP & $7899 \mu \mathrm{Mol} / \mathrm{L}$ & Not stated & [30] \\
\hline Equiseti herba & Equisetaceae & Not stated & $\mathrm{H}_{2} \mathrm{O}$ & FRAP & $2222 \mu \mathrm{Mol} / \mathrm{L}$ & Not stated & {$[30]$} \\
\hline Erythrina sigmoidea pobeg. & Fabaceae & Stem Bark & $\mathrm{MeOH}$ & DPPH & $>200 \mu \mathrm{g} / \mathrm{mL}$ & Nigeria & [140] \\
\hline Ethulia conyzoides L.F. & Asteraceae & Leaf & $\mathrm{MeOH}$ & DPPH & $46.16 \pm 1.52 \mu \mathrm{g} / \mathrm{mL}$ & Nigeria & [172] \\
\hline Eucalyptus camaldulensis Dehnh. & Myrtaceae & Leaf & Oil & DPPH & 3.68 at $0.1 \%$ oil & Burkina Faso & {$[170]$} \\
\hline Euphrasiae herba & Orobandiaceae & Leaf & $\mathrm{H}_{2} \mathrm{O}$ & FRAP & $3107 \mu \mathrm{Mol} / \mathrm{L}$ & Not stated & {$[30]$} \\
\hline Farfarae folium & Asteraceae & Leaf & $\mathrm{H}_{2} \mathrm{O}$ & FRAP & $5350 \mu \mathrm{Mol} / \mathrm{L}$ & Not stated & {$[30]$} \\
\hline Felicia muricata Nees. & Asteraceae & Leaf & $\begin{array}{l}\mathrm{MeOH} /\left(\mathrm{CH}_{3}\right) \\
{ }_{2} \mathrm{CO}\end{array}$ & DPPH & $70 / 410 / 120 \mu \mathrm{g} / \mathrm{mL}$ & Nigeria & {$[173]$} \\
\hline Ficus asperifolia Miq. & Moraceae & Leaf & $\mathrm{H}_{2} \mathrm{O}$ & $\mathrm{DPPH} / \mathrm{Fe}^{2} / \mathrm{FRAP} / \mathrm{NO} / \mathrm{OH}$ & $\begin{array}{l}78.65 / 59.27 / 44.05 / 47.03 / 29.25 \text { at } \\
5 \mathrm{mg} / \mathrm{mL}\end{array}$ & Nigeria & {$[174]$} \\
\hline Ficus capensis Thunb & Moraceae & Fruit & $\mathrm{MeOH}$ & DPPH & $13.05 \%$ & Guinea & [142] \\
\hline Ficus dicranostyla Mildbr. & Moraceae & Leaf & $\mathrm{CH}_{2} \mathrm{Cl}_{2}$ & DPPH & $>38.4 \mu \mathrm{g} / \mathrm{mL}$ & Côte & {$[165]$} \\
\hline Ficus exasperate Roxb. & Moraceae & Leaf & $\mathrm{EtOH}$ & DPPH & $23 \%$ at $10 \mu \mathrm{g} / \mathrm{mL}$ & Benin & {$[157]$} \\
\hline Ficus platyphylla Delile. & Moraceae & Stem bark & $\mathrm{MeOH}$ & $\mathrm{DPPH}$ & $1.93 \mu \mathrm{g} / \mathrm{mL}$ & Burkina Faso & [139] \\
\hline Ficus sycomorus L. & Moraceae & Fruit & $\mathrm{MeOH}$ & FRAP & $<17.57 \mathrm{mmol} A E A C / 100 \mathrm{~g}$ & Burkina Faso & [144] \\
\hline Flacourtia flavescens Willd. & Flacourtiaceae & Leaf & $\mathrm{EtOH}$ & DPPH & $>70 \%$ at $100 \mu \mathrm{g} / \mathrm{mL}$ & Benin & {$[157]$} \\
\hline Foeniculi fructus B.P. & Apiaceae & Not stated & $\mathrm{H}_{2} \mathrm{O}$ & FRAP & $142 \mu \mathrm{Mol} / \mathrm{L}$ & Not stated & {$[30]$} \\
\hline Fragariae vesca $\mathrm{L}$. & Rosaceae & Not stated & $\mathrm{H}_{2} \mathrm{O}$ & FRAP & $11022 \mu \mathrm{Mol} / \mathrm{L}$ & Not stated & {$[30]$} \\
\hline Fraxini excelsior $\mathrm{L}$. & Lamiaceae & Not stated & $\mathrm{H}_{2} \mathrm{O}$ & FRAP & $7129 \mu \mathrm{Mol} / \mathrm{L}$ & Not stated & {$[30]$} \\
\hline Funtumia elastic (Preuss) Stapf. & Apocynaceae & Folium & $\mathrm{MeOH}$ & DPPH & +++ & Nigeria & {$[38]$} \\
\hline Garcina kola Heckel. & Clusiaceae & Seed & $\mathrm{MeOH}$ & DPPH/FRAP & $69.65 / 1.33$ at $400 \mu \mathrm{g} / \mathrm{mL}$ & Nigeria & [149] \\
\hline Gardenia erubescens Stapf \& Hutch. & Rubiaceae & Fruit & $\mathrm{MeOH}$ & FRAP & $<17.57 \mathrm{mmol}$ AEAC/100 g & Burkina Faso & {$[144]$} \\
\hline Geranium robertianum L. & Geraniaceae & Not stated & $\mathrm{H}_{2} \mathrm{O}$ & FRAP & $10696 \mu \mathrm{Mol} / \mathrm{L}$ & Not stated & {$[30]$} \\
\hline
\end{tabular}


Table 1 Antioxidants activities of West African plants (Continued)

\begin{tabular}{|c|c|c|c|c|c|c|c|}
\hline Gnetum africanum Welw. & Gnetaceae & Leaf & $\mathrm{MeOH}$ & & & Nigeria & [175] \\
\hline $\begin{array}{l}\text { Gongronema latifolia Bush Buck } \\
\text { (En). }\end{array}$ & Asclepiadaceae & Leaf/Stem & $\mathrm{MeOH}$ & DPPH & $+++/+++$ & Nigeria & [39] \\
\hline $\begin{array}{l}\text { Gongronema latifolia Bush Buck } \\
\text { (En). }\end{array}$ & Asclepiadaceae & Leaf & $\mathrm{CH}_{2} \mathrm{Cl}_{2}$ & DPPH & $90.70 \mu \mathrm{g} / \mathrm{mL}$ & Nigeria & [158] \\
\hline $\begin{array}{l}\text { Gongronema latifolia Bush Buck } \\
\text { (En). }\end{array}$ & Asclepiadaceae & Leaf & $\mathrm{BtOH} / \mathrm{H}_{2} \mathrm{O}$ & DPPH & $0.082 / 0.245 \mathrm{mg} / \mathrm{mL}$ & Nigeria & [176] \\
\hline Gossypium arboretum L. & Malvaceae & Back & $\mathrm{MeOH}$ & $\mathrm{DPPH}$ & ++ & Nigeria & Aladesanmi et al., 2012 \\
\hline Guiera senegalensis Lam. & Combretaceae & Stem/Leaf/Root & $\mathrm{H}_{2} \mathrm{O}$ & DPPH & 15.4/20/17 $\mu \mathrm{L} / 3 \mathrm{~mL}$ & Nigeria & [151] \\
\hline Harungana madagascariensis Poir. & Hypericaceae & Root & $\mathrm{MeOH}$ & DPPH/FRAP & $85 / 1.95$ at $400 \mu \mathrm{g} / \mathrm{mL}$ & Nigeria & [149] \\
\hline Hederae folium & Araliaceae & & $\mathrm{H}_{2} \mathrm{O}$ & FRAP & $5100 \mu \mathrm{Mol} / \mathrm{L}$ & Nigeria & [30] \\
\hline Hedranthera barteri (Hook.f.). & Apocynaceae & Folium & $\mathrm{MeOH}$ & DPPH & ++ & Nigeria & [38] \\
\hline Hericium erinaceus (Bull.) Persoon. & Hericiaceae & Mushroom & - & LPO & $36.31 \mathrm{nM}$ & Nigeria & [160] \\
\hline Hibisci flos L. & Malvaceae & Not stated & $\mathrm{H}_{2} \mathrm{O}$ & FRAP & $3157 \mu \mathrm{Mol} / \mathrm{L}$ & Not stated & [30] \\
\hline Hibiscus sabdariffa L. & Malvaceae & Leaf & $\mathrm{MeOH}$ & DPPH & 140.9 & Nigeria & [177] \\
\hline $\begin{array}{l}\text { Hybanthus enneaspermus (L.) F. } \\
\text { Muell. }\end{array}$ & Violaceae & Leaf & $\mathrm{EtOH}$ & DPPH & $>70 \%$ at $100 \mu \mathrm{g} / \mathrm{mL}$ & Benin & [157] \\
\hline $\begin{array}{l}\text { Hygrophila auriculata (schumach.) } \\
\text { Heine. }\end{array}$ & Acanthaceae & Stem/leaf & $\mathrm{H}_{2} \mathrm{O}$ & $\mathrm{DPPH}$ & $20 \mu \mathrm{g} / \mathrm{mL}$ & Burkina Faso & [155] \\
\hline Hymenocadia acida Tul. & Phllanthacea & Leaf & $\mathrm{MeOH}$ & DPPH/FRAP & $66.9 / 1.48$ at $400 \mu \mathrm{g} / \mathrm{mL}$ & Nigeria & [149] \\
\hline Hypericum perforatum L. & Hypericaceae & & $\mathrm{H}_{2} \mathrm{O}$ & FRAP & $5127 \mu \mathrm{Mol} / \mathrm{L}$ & Not stated & [30] \\
\hline Icacina trichantha Oliv. & Icacinaceae & Cortex & $\mathrm{MeOH}$ & DPPH & ++ & Nigeria & [38] \\
\hline Ipomoea asarifolia Roem. & Convolvulaceae & Stem/Leaf/Root & $\mathrm{H}_{2} \mathrm{O}$ & DPPH & $50 / 42 / 65 \mu \mathrm{L} / \mathrm{mL}$ & Nigeria & [151] \\
\hline Irvingia gabonensis Baill. ex Lanen. & Irvingiaceae & Seed & $\mathrm{EtOH}$ & DPPH & $15.30 \mu \mathrm{g} / \mathrm{mL}$ & Nigeria & [158] \\
\hline $\begin{array}{l}\text { Justicia galeopsis T. Anderson ex } \\
\text { C.B. Clarke. }\end{array}$ & Acanthaceae & Leaf & $\mathrm{CH}_{2} \mathrm{Cl}_{2}$ & DPPH & $>38.4 \mu \mathrm{g} / \mathrm{mL}$ & Ivory Coast & [165] \\
\hline Khaya grandifoliola C.DC. & Meliaceae & Stem back & $n-C_{6} H_{12}$ & DPPH/ß-CLAMS/MLP & $50.00 / 13.86 / 2.99 \mu \mathrm{g} / \mathrm{mL}$ & Nigeria & [83] \\
\hline Khaya senegalensis A. Juss. & Meliaceae & Stem bark & $\mathrm{MeOH}$ & DPPH & 42.58 at $5 \mathrm{mg} / \mathrm{mL}$ & Nigeria & [136] \\
\hline Khaya senegalensis A. Juss. & Meliaceae & Leaf & $\mathrm{H}_{2} \mathrm{O}$ & ABTS & 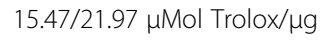 & Burkina Faso & [168] \\
\hline Kigelia Africana (Lam.) Benth. & Bignoniaceae & Leaf/Stem bark & $\mathrm{MeOH}$ & DPPH & 56.9 and $13.7 \mu \mathrm{g} / \mathrm{mL}$ & Ghana & [178] \\
\hline Laccaria amethystine (Huds) Cook. & Hydnangiaceae & Mushroom & - & LPO & $53.64 \mathrm{nM}$ & Nigeria & [160] \\
\hline Laccaria laccata (Scop) Cook. & Hydnangiaceae & Mushroom & - & LPO & $34.77 \mathrm{nM}$ & Nigeria & [160] \\
\hline $\begin{array}{l}\text { Lactarius deliciousus (L. ex Fr) S.F. } \\
\text { Gray. }\end{array}$ & Russulaceae & Mushroom & - & LPO & $34.46 \mathrm{nM}$ & Nigeria & [160] \\
\hline Lactuca taraxicofolia (Wild.) Schum. & Asteraceae & Leaf & $\mathrm{MeOH}$ & DPPH & $2.0 \pm 0.3 \mu \mathrm{g} / \mathrm{mL}$ & Nigeria & Adetutu et al., 2015 \\
\hline Landolfia owariensis P. Beauv. & Apocynaceae & Folium & $\mathrm{MeOH}$ & DPPH & +++ & Nigeria & [38] \\
\hline
\end{tabular}


Table 1 Antioxidants activities of West African plants (Continued)

\begin{tabular}{|c|c|c|c|c|c|c|c|}
\hline Landolphia heudelotii A. DC. & Apocynaceae & Fruit & $\mathrm{MeOH}$ & DPPH & $8.34 \mathrm{~s} \%$ & Guinea & [142] \\
\hline Lannea acida A. Rich. & Anacardiaceae & Fruit & $\mathrm{MeOH}$ & DPPH & $29.77 \%$ & Guinea & [142] \\
\hline $\begin{array}{l}\text { Lannea microcarpa Engl. \& K. } \\
\text { Krause. }\end{array}$ & Anacardiaceae & Fruit & $\mathrm{MeOH}$ & FRAP & $<17.57 \mathrm{mmol}$ AEAC/100 g & Burkina Faso & [144] \\
\hline Lannea nigritana (scott Elliot) Keay. & Anacardiaceae & Fruit & $\mathrm{MeOH}$ & $\mathrm{DPPH}$ & $7.53 \%$ & Guinea & [142] \\
\hline Lantana ukambensis (Vatke) Verdc. & Verbenaceae & Stem & $\mathrm{MeOH}$ & DPPH & $5.96 \mu \mathrm{g} / \mathrm{mL}$ & Burkina Faso & [139] \\
\hline Lapaca spp & Lapacaceae & Leaf & $\mathrm{MeOH}$ & DPPH/FRAP & $51.15 / 1.01$ at $400 \mu \mathrm{g} / \mathrm{mL}$ & Nigeria & Chinaka et al., 2013 \\
\hline Laportea Aestuans (L.) Chew. & Urticaceae & Leaf & $\mathrm{EtOH}$ & $\begin{array}{l}\mathrm{DPPH} / \mathrm{O}_{2} / \mathrm{OH} / \mathrm{NO} / \mathrm{H}_{2} \mathrm{O}_{2} / \\
\text { ABTS/LPO }\end{array}$ & $\begin{array}{l}15.0 / 247.0 / 84.3 / 67.3 / 230.7 / 81.0 / \\
82.7\end{array}$ & Nigeria & [179] \\
\hline Laurus nobilis L. & Lauraceae & Not stated & $\mathrm{H}_{2} \mathrm{O}$ & FRAP & $1260 \mu \mathrm{Mol} / \mathrm{L}$ & Not stated & [30] \\
\hline Lavandulae angustifolia Mill. & Lamiaceae & Not stated & $\mathrm{H}_{2} \mathrm{O}$ & FRAP & $7377 \mu \mathrm{Mol} / \mathrm{L}$ & Not stated & [30] \\
\hline Leea guinensis L. & Leeceae & Lignum & $\mathrm{MeOH}$ & DPPH & ++ & Nigeria & [38] \\
\hline Lepidagathis anobrya Nees. & Acanthaceae & Stem/Leaf & $\mathrm{H}_{2} \mathrm{O}$ & DPPH & $16.33 \mu \mathrm{g} / \mathrm{mL}$ & Burkina Faso & [155] \\
\hline Lepista nuda (Bull.) Cook. & Tricholometaceae & Mushroom & - & LPO & $53.65 \mathrm{nM}$ & Nigeria & [160] \\
\hline Lepista saeva (Fr) Cook. & Tricholometaceae & Mushroom & - & LPO & $34.46 \mathrm{nM}$ & Nigeria & [160] \\
\hline Lippia multiflora Moldeuke. & Verbanaceae & Leaf & Oil & $\mathrm{DPPH}$ & 39.29 at $0.1 \%$ oil & Burkina Faso & [170] \\
\hline Luglandis folium & Lamiaceae & Not stated & $\mathrm{H}_{2} \mathrm{O}$ & FRAP & $7432 \mu \mathrm{Mol} / \mathrm{L}$ & Not stated & [30] \\
\hline $\begin{array}{l}\text { Macrolepiotata procera }(\mathrm{Scp}) \\
\text { Singer. }\end{array}$ & Lepiotaceae & Mushroom & - & LPO & $38.75 \mathrm{nM}$ & Nigeria & [160] \\
\hline Majoranae folium Mull. Arg. & Lamiaceae & Not stated & $\mathrm{H}_{2} \mathrm{O}$ & FRAP & $4453 \mu \mathrm{Mol} / \mathrm{L}$ & Not stated & [30] \\
\hline $\begin{array}{l}\text { Mallotus oppositifolius (Geiseler) } \\
\text { Mull. Arg. }\end{array}$ & Euphorbiaceae & Leaf & $\mathrm{MeOH}$ & DPPH/FRAP & $78.92 / 1.69$ at $400 \mu \mathrm{g} / \mathrm{mL}$ & Nigeria & [149] \\
\hline Malvae herba L. & Malvaceae & Not stated & $\mathrm{H}_{2} \mathrm{O}$ & FRAP & $927 \mu \mathrm{Mol} / \mathrm{L}$ & Not stated & [30] \\
\hline Mangifera indica Blume. & Anacardiacea & Leaf & $\mathrm{EtOH}$ & DPPH & $0.313 \mathrm{mg} / \mathrm{mL}$ & Nigeria & [162] \\
\hline $\begin{array}{l}\text { Markhamia tomentosa K. schum. ex } \\
\text { Engl }\end{array}$ & Bignoniaceae & Leaf & $\mathrm{MeOH}$ & DPPH & $16.50 \mu \mathrm{g} / \mathrm{mL}$ & Nigeria & [156] \\
\hline Marrubium vulgare L. & Lamiaceae & Not stated & $\mathrm{H}_{2} \mathrm{O}$ & FRAP & $1653 \mu \mathrm{Mol} / \mathrm{L}$ & Not stated & [30] \\
\hline $\begin{array}{l}\text { Massularia acuminata (G.Don) } \\
\text { Bullock. }\end{array}$ & Rubiaceae & Leaf & $\mathrm{MeOH}$ & DPPH & $4.00 \mu \mathrm{g} / \mathrm{mL}$ & Nigeria & [156] \\
\hline Melissa officinalis L. & Lamiaceae & Not stated & $\mathrm{H}_{2} \mathrm{O}$ & FRAP & $25234 \mu \mathrm{Mol} / \mathrm{L}$ & Not stated & [30] \\
\hline Mentha piperita L. & Lamiaceae & Not stated & $\mathrm{H}_{2} \mathrm{O}$ & FRAP & $8987 \mu \mathrm{Mol} / \mathrm{L}$ & Not stated & [30] \\
\hline Achille Millefolium L. & Asteraceae & Not stated & $\mathrm{H}_{2} \mathrm{O}$ & FRAP & $3228 \mu \mathrm{Mol} / \mathrm{L}$ & Not stated & [30] \\
\hline Monodora myristica Blanco. & Annonaceae & Seed & $\mathrm{CH}_{2} \mathrm{Cl}_{2}$ & DPPH & $54.50 \mu \mathrm{g} / \mathrm{mL}$ & Nigeria & [158] \\
\hline Morinda lucida Benth. & Rubiacae & Leaf/Root & Oil & DPPH/ABTS/LP & $\begin{array}{l}7.82,6.20,0.08 / 7.82,8.82 \text { and } \\
0.02 \mathrm{mg} / \mathrm{mL}\end{array}$ & Nigeria & [137] \\
\hline Morus nigra L. & Moraceae & Not stated & $\mathrm{H}_{2} \mathrm{O}$ & FRAP & $2360 \mu \mathrm{Mol} / \mathrm{L}$ & Not stated & [30] \\
\hline
\end{tabular}


Table 1 Antioxidants activities of West African plants (Continued)

\begin{tabular}{|c|c|c|c|c|c|c|c|}
\hline Mucuna pruriens (L) DC. & Fabaceae & Leaf & $\mathrm{H}_{2} \mathrm{O} / \mathrm{EtOH}$ & $\mathrm{DPPH}$ & $32.63 / 41.40$ at $10 \mathrm{mg} / \mathrm{mL}$ & Nigeria & [180] \\
\hline Mucuna pruriens (L) DC. & Fabaceae & Seed & $\mathrm{EtOH}$ & DPPH & $7.30 \mu \mathrm{g} / \mathrm{mL}$ & Nigeria & [158] \\
\hline Murraya koenigi (L.) Sprenge & Rutaceae & Leaf & $\mathrm{MeOH}$ & DPPH/FRAP & $31.30 / 0.58$ at $400 \mu \mathrm{g} / \mathrm{mL}$ & Nigeria & [149] \\
\hline Myrianthus arboreus P. Beauv & Cecropiaceae & Leaf & $\mathrm{CH}_{2} \mathrm{Cl}_{2}$ & $\mathrm{DPPH}$ & $15.20 \mu \mathrm{g} / \mathrm{mL}$ & Ivory coast & [165] \\
\hline Myristica fragrans Houtt. & Myristicaceae & - & $\left(\mathrm{CH}_{3}\right)_{2} \mathrm{CO}$ & DPPH/SAS & $0.10 / 0.135 \mathrm{mg} / \mathrm{mL}$ & Nigeria & [145] \\
\hline Myrtilli fructus & Ericaceae & Not stated & $\mathrm{H}_{2} \mathrm{O}$ & FRAP & $7539 \mu \mathrm{Mol} / \mathrm{L}$ & Not stated & {$[30]$} \\
\hline Nauclea latifolia Blanco. & Rubiaceae & Fruit & $\mathrm{MeOH}$ & DPPH & $79.61 \%$ & Guinea & [142] \\
\hline Nauclea latifolia Blanco. & Rubiaceae & Root & $\mathrm{MeOH}$ & $\mathrm{DPPH}$ & $1.56 \mu \mathrm{g} / \mathrm{mL}$ & Benin & [141] \\
\hline Nelsonia canescens spreng. & Acanthaceae & Stem/Leaf & $\mathrm{H}_{2} \mathrm{O}$ & $\mathrm{DPPH}$ & $24.33 \mu \mathrm{g} / \mathrm{mL}$ & Burkina Faso & {$[155]$} \\
\hline Newbouldia laevis (P.Beauv.) & Bignoniaceae & Leaf & $\mathrm{H}_{2} \mathrm{O}$ & $\mathrm{Fe}^{2} / \mathrm{RP} / \mathrm{DPPH}$ & $7.28 / 148 / 19.5 \mu \mathrm{g} / \mathrm{mL}$ & Ivory coast & [166] \\
\hline Newbouldia laevis (P.Beauv.) & Bignoniaceae & Leaf & $\mathrm{BtOH}$ & FRAP & $72 \%$ at $500 \mu \mathrm{g} / \mathrm{mL}$ & Nigeria & [143] \\
\hline Newbouldia laevis (P.Beauv.) & Bignoniaceae & Leaf & $\mathrm{H}_{2} \mathrm{O}$ & $\mathrm{RP} / \mathrm{DPPH}$ & $148.0 / 19.5$ & Ivory coast & [166] \\
\hline Newbouldia laevis (P.Beauv.) & Bignoniaceae & Leaf & $\mathrm{MeOH}$ & $\mathrm{DPPH}$ & $155.17 \mathrm{mg} / \mathrm{mL}$ & Nigeria & Tsado et al., 2016b [169] \\
\hline Nymphaea lotus L. & Nympheaceae & Fruit & $\mathrm{MeOH}$ & DPPH & $82.99 \%$ & Guinea & {$[142]$} \\
\hline Ocimum basilicum L. & Lamiaceae & Leaf & Oil & DPPH & $3.82 \mu \mathrm{g} / \mathrm{mL}$ & Burkina Faso & {$[170]$} \\
\hline Ocimum canum L. & Lamiaceae & Leaf & Oil & DPPH & 4.20 at $0.1 \%$ oil & Burkina Faso & {$[170]$} \\
\hline Ocimum gratissimum L. & Lamiaceae & Leaf & $\mathrm{CH}_{2} \mathrm{Cl}_{2}$ & DPPH & $55.70 \mu \mathrm{g} / \mathrm{mL}$ & Nigeria & [158] \\
\hline Olax varidis $L$ & Olaceae & Leaf & $\mathrm{MeOH}$ & DPPH/FRAP & $58.19 / 1.19$ at $400 \mu \mathrm{g} / \mathrm{mL}$ & Nigeria & [149] \\
\hline Oleae folium Hoffmans. \& Link & Oleaceae & Not stated & $\mathrm{H}_{2} \mathrm{O}$ & FRAP & $3945 \mu \mathrm{Mol} / \mathrm{L}$ & Not stated & {$[30]$} \\
\hline Oncoba spinosa Forssk. & Flacourtiaceae & Fruit & $\mathrm{MeOH}$ & DPPH & $13.52 \%$ & Guinea & {$[142]$} \\
\hline Oxalis corniculata L. & Oxalidaceae & Leaf & $\mathrm{MeOH}$ & DPPH & $95.68 \%$ at $100 \mu \mathrm{g} / \mathrm{mL}$ & Benin & [164] \\
\hline Ozoroa insignis Delile. & Anacardiaceae & Stem & $\mathrm{MeOH}$ & $\mathrm{DPPH}$ & $7.53 \mu \mathrm{g} / \mathrm{mL}$ & Burkina Faso & [139] \\
\hline $\begin{array}{l}\text { Parinari curatelifolia Planch. Ex } \\
\text { Benth. }\end{array}$ & Chrysobalanaceae & Leaf & $\mathrm{MeOH}$ & $\mathrm{DPPH}$ & $0.20 \mu \mathrm{g} / \mathrm{mL}$ & Togo & [153] \\
\hline $\begin{array}{l}\text { Parinari curatelifolia Planch. Ex } \\
\text { Benth. }\end{array}$ & Chrysobalanaceae & Stem & $\mathrm{MeOH}$ & $\mathrm{DPPH}$ & $10.5 \mu \mathrm{g} / \mathrm{mL}$ & Burkina Faso & [139] \\
\hline Parinari excelsa Sabina. & Chrysobalanaceae & Fruit & $\mathrm{MeOH}$ & DPPH & $77.52 \%$ & Guinea & {$[142]$} \\
\hline Parkia biglobosa Benth. & Fabaceae & Fruit & $\mathrm{MeOH}$ & $\mathrm{DPPH}$ & $92.25 \%$ & Guinea & [142] \\
\hline Parkia biglobosa Benth. & Fabaceae & Stalk & $\mathrm{MeOH}$ & DPPH/FRAP & $59.01 / 1.24$ at $400 \mu \mathrm{g} / \mathrm{mL}$ & Nigeria & [149] \\
\hline Parkia biglobosa Benth. & Fabaceae & Leaf & $\mathrm{MeOH} / \mathrm{EtOH}$ & $\mathrm{DPPH}$ & $56.83 / 58.17 \%$ at $0.1 \mathrm{mg} / \mathrm{mL}$ & Ghana. & [181] \\
\hline Parkia biglobosa Benth. & Fabaceae & Fruit & $\mathrm{MeOH}$ & FRAP & $<17.57 \mathrm{mmol}$ AEAC/100 g & Burkina Faso & {$[144]$} \\
\hline Pavetta corymbosa F.N. Williams. & Rubiaceae & Leaf & $\mathrm{EtOH}$ & DPPH & 75.34 at $10 \mu \mathrm{g} / \mathrm{mL}$ & Benin & [157] \\
\hline Pavetta crassipes K. schum. & Rubiaceae & Leaf & $\mathrm{MeOH}$ & DPPH & 82.35 at $5 \mathrm{mg} / \mathrm{mL}$ & Nigeria & {$[136]$} \\
\hline Petroselini crispum (Mill) & Apiaceae & Not stated & $\mathrm{H}_{2} \mathrm{O}$ & FRAP & $1318 \mu \mathrm{Mol} / \mathrm{L}$ & Not stated & {$[30]$} \\
\hline
\end{tabular}


Table 1 Antioxidants activities of West African plants (Continued)

\begin{tabular}{|c|c|c|c|c|c|c|c|}
\hline Phaseoli pericarpum & Fabaceae & Not stated & $\mathrm{H}_{2} \mathrm{O}$ & FRAP & $319 \mu \mathrm{Mol} / \mathrm{L}$ & Not stated & [30] \\
\hline Phaseolus lunatus Haberle. & Fabaceae & Seed coat & - & DPPH & $0.37 \mathrm{mg} / \mathrm{mL}$ & Nigeria & [182] \\
\hline Picralima nitida Th. \& H. Dur. & Apocynaceae & Seed & $\mathrm{MeOH}$ & DPPH/FRAP & $55.3 / 1.38$ at $400 \mu \mathrm{g} / \mathrm{mL}$ & Nigeria & [149] \\
\hline Piper guineense Thonn. & Piperaceae & Leaf & $\mathrm{EtOH}$ & DPPH & $36.90 \mu \mathrm{g} / \mathrm{mL}$ & Nigeria & [158] \\
\hline Plantago lancfolium & Plantaginaceae & Not stated & $\mathrm{H}_{2} \mathrm{O}$ & FRAP & $1727 \mu \mathrm{Mol} / \mathrm{L}$ & Not stated & [30] \\
\hline Plantago majorfolium & Plantaginaceae & Not stated & $\mathrm{H}_{2} \mathrm{O}$ & FRAP & $2733 \mu \mathrm{Mol} / \mathrm{L}$ & Not stated & [30] \\
\hline Pleioceras barteri Baill. & Apocynaceae & Leaf & $\mathrm{MeOH}$ & DPPH & - & Nigeria & Aladesanmi et al., 2012 \\
\hline $\begin{array}{l}\text { Pleurotus ostreatus (Jacq. ex Fr) P. } \\
\text { Kumm }\end{array}$ & Pleuntaceae & Mushroom & - & LPO & $45.84 \mathrm{nM}$ & Nigeria & [160] \\
\hline Plumbago zeylanica L. & Plumbaginaceae & Root & $\mathrm{MeOH}$ & DPPH & - & Nigeria & Aladesanmi et al., 2012 \\
\hline Polygonum aviculare L. & Polygonaceae & Not stated & $\mathrm{H}_{2} \mathrm{O}$ & FRAP & $1210 \mu \mathrm{Mol} / \mathrm{L}$ & Not stated & [30] \\
\hline Primulae radix $\mathrm{L}$. & Primulaceae & Not stated & $\mathrm{H}_{2} \mathrm{O}$ & FRAP & $2197 \mu \mathrm{Mol} / \mathrm{L}$ & Not stated & [30] \\
\hline Psidium guajava L. (GCL). & Myrtaceae & Leaf & $\mathrm{EtOH}$ & DPPH & $0.04 \mathrm{mg} / \mathrm{mL}$ & Nigeria & [162] \\
\hline Psidium guajava L. (GCL). & Myrtaceae & Bark & $\mathrm{MeOH}$ & DPPH & ++ & Nigeria & [156] \\
\hline Psidium guayava L. (GCL). & Myrtaceae & Stem bark & $\mathrm{EtOH}$ & DPPH & $>70 \%$ at $100 \mu \mathrm{g} / \mathrm{mL}$ & Benin & [157] \\
\hline Psorospermum febrifugum Spach. & Hypericaceae & Leaf & $\mathrm{MeOH}$ & $\mathrm{DPPH}$ & $2.3 \mu \mathrm{g} / \mathrm{mL}$ & Ivory Coast & [165] \\
\hline Pterocarpus erinaceus Lam. & Papilionaceae & Aerial parts & $\mathrm{MeOH}$ & DPPH & $3.37 \mu \mathrm{g} / \mathrm{mL}$ & Benin & [141] \\
\hline Pterocarpus erinaceus Lam. & Fabaceae & Stem bark & $\mathrm{H}_{2} \mathrm{O}$ & DPPH & $0.80 \mu \mathrm{g} / \mathrm{mL}$ & Burkina Faso & [183] \\
\hline Pterocarpus erinaceus Lam. & Fabaceae & Leaf/Stem bark & $\mathrm{H}_{2} \mathrm{O}$ & ABTS & 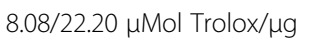 & Burkina Faso & [168] \\
\hline Pterocarpus midbraedii Jacq. & Fabaceae & Leaf & $\mathrm{MeOH}$ & & & Nigeria & {$[175]$} \\
\hline Pterocarpus milbraedii Jacq. & Fabaceae & Leaf & $\mathrm{EtOH}$ & DPPH & $20.30 \mu \mathrm{g} / \mathrm{mL}$ & Nigeria & [158] \\
\hline $\begin{array}{l}\text { Pterocarpus santalinoides L'He'r. ex } \\
\text { DC. }\end{array}$ & Fabaceae & Fruit & $\mathrm{MeOH}$ & DPPH & $8.18 \%$ & Guinea & [142] \\
\hline Raphia sudanica A. Chev. & Arecaceae & Fruit & $\mathrm{MeOH}$ & DPPH & $93.98 \%$ & Guinea & [142] \\
\hline $\begin{array}{l}\text { Raphiostylis beninensis Planch. ex } \\
\text { Benth. }\end{array}$ & Icacinaceae & Fruit & $\mathrm{MeOH}$ & DPPH & $43.33 \%$ & Guinea & [142] \\
\hline Rhynchosia buettneri Harms. & Fabaceae & Leaf & $\mathrm{MeOH}$ & DPPH & $7.5 \mu \mathrm{g} / \mathrm{mL}$ & Ivory Coast & [165] \\
\hline Ricinus communis L. & Euphorbiaceae & Root & $\mathrm{MeOH}$ & DPPH/FRAP & $60.8 / 1.43$ at $400 \mu \mathrm{g} / \mathrm{mL}$ & Nigeria & [149] \\
\hline Rosmarini officinalis $\mathrm{L}$. & Lamiaceae & Not stated & $\mathrm{H}_{2} \mathrm{O}$ & FRAP & $1277 \mu \mathrm{Mol} / \mathrm{L}$ & Not stated & [30] \\
\hline Puccinia rubi Schumach. & Phragmidiaceae & Not stated & $\mathrm{H}_{2} \mathrm{O}$ & FRAP & $12211 \mu \mathrm{Mol} / \mathrm{L}$ & Not stated & [30] \\
\hline Puccinia rubi-idaei (DC.) P. Karst. & Phragmidiaceae & Not stated & $\mathrm{H}_{2} \mathrm{O}$ & FRAP & $10025 \mu \mathrm{Mol} / \mathrm{L}$ & Not stated & [30] \\
\hline Saba senegalensis (A.D.C) Pichon. & Apocynaceae & Stem/Leaf & $\mathrm{H}_{2} \mathrm{O}$ & DPPH & $18.4 \mu \mathrm{g} / \mathrm{mL}$ & Burkina Faso & $\begin{array}{l}\text { Yougbaré-Ziébrou et al., } \\
2015 \text { [184] }\end{array}$ \\
\hline Saba senegalensis (A.D.C) Pichon. & Apocynaceae & Fruit & $\mathrm{MeOH}$ & FRAP & $<17.57 \mathrm{mmol}$ AEAC/100 g & Burkina Faso & [144] \\
\hline $\begin{array}{l}\text { Sacocephalus } \\
\text { latifolius Afzel. Ex R. Br. }\end{array}$ & Rubiaceae & Leaf & $\mathrm{MeOH}$ & DPPH/FRAP & $66.2 / 1.49$ at $400 \mu \mathrm{g} / \mathrm{mL}$ & Nigeria & [149] \\
\hline
\end{tabular}


Table 1 Antioxidants activities of West African plants (Continued)

\begin{tabular}{|c|c|c|c|c|c|c|c|}
\hline Salicis cortex Senna occidentalis & Saliaceae & Not stated & $\mathrm{H}_{2} \mathrm{O}$ & FRAP & $10892 \mu \mathrm{Mol} / \mathrm{L}$ & Not stated & {$[30]$} \\
\hline Salviae officinalis $\mathrm{L}$. & Lamiaceae & Not stated & $\mathrm{H}_{2} \mathrm{O}$ & FRAP & $7603 \mu \mathrm{Mol} / \mathrm{L}$ & Not stated & {$[30]$} \\
\hline Sanbuci flos L. & Caprifoliaceae & Not stated & $\mathrm{H}_{2} \mathrm{O}$ & FRAP & $4055 \mu \mathrm{Mol} / \mathrm{L}$ & Not stated & {$[30]$} \\
\hline Satureja herba Mill. & Lamiaceae & Not stated & $\mathrm{H}_{2} \mathrm{O}$ & FRAP & $5339 \mu \mathrm{Mol} / \mathrm{L}$ & Not stated & {$[30]$} \\
\hline Schrankia leptocarpa DC. & Mimosaceae & Entire Plant & $\mathrm{MeOH}$ & DPPH & $1.35 \mu \mathrm{g} / \mathrm{mL}$ & Benin & [141] \\
\hline Sclerocarya birrea HO Chst. & Anacardiaceae & Fruit & $\mathrm{MeOH}$ & FRAP & $<17.57 \mathrm{mmol}$ AEAC/100 g & Burkina Faso & [144] \\
\hline $\begin{array}{l}\text { Secamone afzelii (Roem. \& Schut.) } \\
\text { K. Schum. }\end{array}$ & Asclepiadaceae & Aerial parts & $\mathrm{MeOH}$ & DPPH & $1.74 \mu \mathrm{g} / \mathrm{mL}$ & Benin & [141] \\
\hline Senae folium $\mathrm{L}$. & Fabaceae & Not stated & $\mathrm{H}_{2} \mathrm{O}$ & FRAP & $1078 \mu \mathrm{Mol} / \mathrm{L}$ & Not stated & {$[30]$} \\
\hline Serpylli herba & Lamiaceae & Not stated & $\mathrm{H}_{2} \mathrm{O}$ & FRAP & $10868 \mu \mathrm{Mol} / \mathrm{L}$ & Not stated & {$[30]$} \\
\hline Sesanum indicum $\mathrm{L}$. & Pedallaceae & Leaf & $\mathrm{CH}_{2} \mathrm{Cl}_{2}$ & $\mathrm{DPPH}$ & $43.10 \mu \mathrm{g} / \mathrm{mL}$ & Nigeria & {$[158]$} \\
\hline Senna occidentalis (L.) Link. & Fabaceae & Leaf & $\mathrm{MeOH}$ & DPPH & $263.53 \mu \mathrm{g} / \mathrm{mL}$ & Nigeria & [185] \\
\hline Sida acuta Burm. F. & Malvaceae & Whole plant & $\mathrm{H}_{2} \mathrm{O}$ & ABTS & $6.12 \mu \mathrm{Mol}$ Trolox/mg & Burkina Faso & {$[168]$} \\
\hline Solanium aethiopicum L. & Solanaceae & Leaf & $\mathrm{MeOH}$ & DPPH & $5.2 \mu \mathrm{g} / \mathrm{mL}$ & Nigeria & Adetutu et al., 2015 \\
\hline Solanum melongena $\mathrm{L}$. & Solanaceae & Leaf & $\mathrm{MeOH}$ & & & Nigeria & {$[175]$} \\
\hline Solidaginis virgaurea L. & Asteraceae & Not stated & $\mathrm{H}_{2} \mathrm{O}$ & FRAP & $4256 \mu \mathrm{Mol} / \mathrm{L}$ & Not stated & {$[30]$} \\
\hline Sphenocentrum jollyanum Pierre. & Menispermaceae & Folium & $\mathrm{MeOH}$ & DPPH & +++ & Nigeria & {$[38]$} \\
\hline Sphenoceutrum jollyanum Pierre. & Menispermaceae & Root & $\mathrm{MeOH}$ & DPPH & ++ & Nigeria & {$[156]$} \\
\hline Spiraea herba L. & Rosaceae & Not stated & $\mathrm{H}_{2} \mathrm{O}$ & FRAP & $15256 \mu \mathrm{Mol} / \mathrm{L}$ & Not stated & {$[30]$} \\
\hline Spondias mombin Jacq. & Anacardiaceae & Fruit & $\mathrm{MeOH}$ & $\mathrm{DPPH}$ & $93.83 \%$ & Guinea & {$[142]$} \\
\hline Stigmata maydis $\mathrm{L}$. & Poaceae & Not stated & $\mathrm{H}_{2} \mathrm{O}$ & FRAP & $1009 \mu \mathrm{Mol} / \mathrm{L}$ & Not stated & {$[30]$} \\
\hline Strobilus lupuli L. & Cannabidaceae & Not stated & $\mathrm{H}_{2} \mathrm{O}$ & FRAP & $2204 \mu \mathrm{Mol} / \mathrm{L}$ & Not stated & {$[30]$} \\
\hline Strophanthus hispidus DC. & Apocynaceae & Leaf, root & $\mathrm{MeOH}$ & $\mathrm{DPPH}$ & 49.8 and $45.1 \mu \mathrm{g} / \mathrm{mL}$ & Ghana & [178] \\
\hline Strychnos spinosa Lam. & Loganiaceae & Fruit & $\mathrm{MeOH}$ & $\mathrm{DPPH}$ & $111.71 \%$ & Guinea & [142] \\
\hline Tamarindus indica $\mathrm{L}$. & Caesalpiniaceae & Fruit & $\mathrm{MeOH}$ & $\mathrm{DPPH}$ & $116.75 \%$ & Guinea & [142] \\
\hline Tamarindus indica $\mathrm{L}$. & Caesalpiniaceae & Fruit & $\mathrm{MeOH}$ & FRAP & $12.42 \mathrm{mmol}$ AEAC/100 g & Burkina Faso & {$[144]$} \\
\hline Telfairia occidentalis Hook. F. & Cucurbitaceae & Leaf/Stem & $\mathrm{MeOH}$ & DPPH & $+/-$ & Nigeria & {$[39]$} \\
\hline Telfaria occidentalis Hook. F. & Cucurbitaceae & Leaf & $\mathrm{MeOH}$ & $\mathrm{DPPH}$ & $1.8 \pm 0.2 \mu \mathrm{g} / \mathrm{mL}$ & Nigeria & {$[150]$} \\
\hline Teraxaci folium & Asteraceae & Not stated & $\mathrm{H}_{2} \mathrm{O}$ & FRAP & $4600 \mu \mathrm{Mol} / \mathrm{L}$ & Not stated & {$[30]$} \\
\hline $\begin{array}{l}\text { Terminalia avicennioides Guill. \& } \\
\text { Perr. }\end{array}$ & Combretaceae & Root & $\mathrm{H}_{2} \mathrm{O}$ & $\mathrm{H}_{2} \mathrm{O}_{2} / \mathrm{Fe}^{3+}$ & $0.58 / 0.66$ & Nigeria & {$[152]$} \\
\hline Terminalia catappa L. & Combretaceae & Leaf & Oil & DPPH & $0.084 \mathrm{mg} / \mathrm{mL}$ & Nigeria & {$[186]$} \\
\hline Terminalia catappa L. & Combretaceae & Leaf & $\mathrm{MeOH}$ & DPPH/FRAP & $58.19 / 1.30$ at $400 \mu \mathrm{g} / \mathrm{mL}$ & Nigeria & [149] \\
\hline Tetrapleura tetraptera Taub. & Fabaceae & Fruit & $\mathrm{EtOH}$ & DPPH & $12.70 \mu \mathrm{g} / \mathrm{mL}$ & Nigeria & [158] \\
\hline
\end{tabular}


Table 1 Antioxidants activities of West African plants (Continued)

\begin{tabular}{|c|c|c|c|c|c|c|c|}
\hline Tetrapleura tetraptera Taub. & Fabaceaee & Leaf & $\mathrm{MeOH} / \mathrm{EtOH}$ & $\mathrm{DPPH}$ & $68.35 / 69.49 \%$ at $0.1 \mathrm{mg} / \mathrm{mL}$ & Ghana. & [181] \\
\hline Thymi herba & Lamiaceae & Not stated & $\mathrm{H}_{2} \mathrm{O}$ & FRAP & $9069 \mu \mathrm{Mol} / \mathrm{L}$ & Not stated & [30] \\
\hline Tiliae flos Mill. & Malvaceae & Not stated & $\mathrm{H}_{2} \mathrm{O}$ & FRAP & $3807 \mu \mathrm{Mol} / \mathrm{L}$ & Not stated & {$[30]$} \\
\hline Trema orientalis (L.) Blume. & Cannabaceae & Leaf & $\mathrm{H}_{2} \mathrm{O}$ & $\mathrm{Fe}^{2} / \mathrm{RP} / \mathrm{DPPH}$ & 24.55/24.3/22.75 $\mu \mathrm{g} / \mathrm{mL}$ & Ivory Coast & [166] \\
\hline Trichilia heudeloti. Planch. & Meliaceae & Leaf & $\mathrm{MeOH}$ & $\mathrm{DPPH}$ & $6.50 \mu \mathrm{g} / \mathrm{mL}$ & Nigeria & Aladesanmi et al., 2012 \\
\hline Urticae folium $\mathrm{L}$. & Urticaceae & Not stated & $\mathrm{H}_{2} \mathrm{O}$ & FRAP & $3168 \mathrm{~mol} / \mathrm{L}$ & Not stated & {$[30]$} \\
\hline Uvaria chamae P. Beauv. & Annonaceae & Fruit & $\mathrm{MeOH}$ & DPPH & $13.52 \%$ & Guinea & [142] \\
\hline Uvaria chanae P. Beauv. & Annonaceae & Root & $\mathrm{MeOH}$ & DPPH/FRAP & $95.08 / 1.9$ at $400 \mu \mathrm{g} / \mathrm{mL}$ & Nigeria & [149] \\
\hline Verbasi flos L. & Scrophulariaceae & Not stated & $\mathrm{H}_{2} \mathrm{O}$ & FRAP & $603 \mu \mathrm{Mol} / \mathrm{L}$ & Not stated & {$[30]$} \\
\hline Verbenae herba & Verbinaceaae & Not stated & $\mathrm{H}_{2} \mathrm{O}$ & FRAP & $2089 \mu \mathrm{Mol} / \mathrm{L}$ & Not stated & [30] \\
\hline Vernonia amygdalina Delile. & Asteracea & Leaf & $\mathrm{EtOH}$ & DPPH & $19.33 \mu \mathrm{g} / \mathrm{mL}$ & Nigeria & [158] \\
\hline Vernonia Amygdalina Delile. & Astereacea & Leaf & $\mathrm{MeOH}$ & DPPH & 85.8 at $20 \mu \mathrm{g} / \mathrm{mL}$ & Nigeria & [187] \\
\hline Vernonia amygdalina Delile. & Asteracea & Leaf & $\mathrm{EtOH}$ & $\mathrm{DPPH}$ & $2.30 \mathrm{mg} / \mathrm{mL}$ & Nigeria & [162] \\
\hline Veronicae officinalis L. & Plantaginaceae & Not stated & $\mathrm{H}_{2} \mathrm{O}$ & FRAP & $6514 \mu \mathrm{Mol} / \mathrm{L}$ & Not stated & [30] \\
\hline Violae tricolor L. & Violaceae & Not stated & $\mathrm{H}_{2} \mathrm{O}$ & FRAP & $846 \mu \mathrm{Mol} / \mathrm{L}$ & Not stated & [30] \\
\hline Visci albi L. & Santalaceae & Not stated & $\mathrm{H}_{2} \mathrm{O}$ & FRAP & $727 \mu \mathrm{Mol} / \mathrm{L}$ & Not stated & [30] \\
\hline Vitellaria paradoxa C.FGaertn & Sapotaceae & Fruit & $\mathrm{MeOH}$ & FRAP & $<17.57 \mathrm{mmol}$ AEAC/100 g & Burkina Faso & [144] \\
\hline Vitex doniana Sweet. & Verbenaceae & Fruit & $\mathrm{MeOH}$ & DPPH & $82.99 \%$ & Guinea & [142] \\
\hline Vitex doniana Sweet. & Verbenaceae & Leaf & $\mathrm{H}_{2} \mathrm{O} / \mathrm{EtOH}$ & DPPH & $87.52 / 3.30$ at $10 \mathrm{mg} / \mathrm{mL}$ & Nigeria & [180] \\
\hline $\begin{array}{l}\text { Voacanga Africana Stapf ex Scott } \\
\text { Elliot. }\end{array}$ & Liliaceae & Folium & $\mathrm{MeOH}$ & DPPH & ++++ & Nigeria & [38] \\
\hline Xeoderris sthulmannii L. & Fabaceae & Stem bark & $\mathrm{MeOH}$ & $\mathrm{DPPH}$ & $2.36 \mu \mathrm{g} / \mathrm{mL}$ & Burkina Faso & [139] \\
\hline Ximenia Americana L. & Olacaceae & Fruit & $\mathrm{MeOH}$ & FRAP & $17.57 \mathrm{mmol} A E A C / 100 \mathrm{~g}$ & Burkina Faso & [144] \\
\hline Xylopia aethiopica A. Rich. & Annonaceae & Fruit & $\mathrm{MeOH}$ & $\mathrm{DPPH}$ & $13.70 \%$ & Guinea & [142] \\
\hline Xylopia aethiopica A. Rich. & Annonaceae & Seed & $\mathrm{EtOH}$ & $\mathrm{DPPH}$ & $10.70 \mu \mathrm{g} / \mathrm{mL}$ & Nigeria & [158] \\
\hline Zingiber officinale Roscoe. & Zingebracea & Spice & $\mathrm{H}_{2} \mathrm{O}$ & DPPH/ABTS & $1.21, / 0.04 \mathrm{mg} / \mathrm{mL}$ & Nigeria & [148] \\
\hline Zingiber officinale Roscoe. & Zingiberaceae & - & $\left(\mathrm{CH}_{3}\right)_{2} \mathrm{CO}$ & DPPH/SAS & $0.075 / 0070 \mathrm{mg} / \mathrm{mL}$ & Nigeria & [145] \\
\hline Ziziphus mauritiana Lam. & Rhamnaceae & Fruit & $\mathrm{MeOH}$ & FRAP & $18.28 \mathrm{mmol}$ AEAC/100 g & Burkina Faso & [144] \\
\hline
\end{tabular}

Key: +++ Strong intensity of yellow colouration, ++ Intermediate intensity of yellow colouration, + Weak intensity of yellow colouration, - No yellow colouration, +++- Antioxidant in low quantity, +++- Antioxidant in moderate quantity, ++++- Antioxidant in large quantity, $R S A$ radical scavenging activity, $R C$ reducing power capacity, $\mathrm{OH}$ hydroxyl ion, $\mathrm{NO}$ nitric oxide radical inhibition, $\mathrm{H}_{2} \mathrm{O}_{2}$ hydrogen peroxide inhibition activity, LPO lipid peroxidation inhibition activity, $A B T S^{+}$2,2'-azinobis-3-ethylbenzothiozolin-6-sulfonic acid cation decolourization test, $B$-CLAMS 3 -carotene-linoleic acid model system, MLP microsomal lipid peroxydation, FRAP $\mathrm{fe}^{2+}$ chelating ability and ferric reducing antioxidant properties, $\mathrm{DPPH}$ 1,1-dipheyl-2-picry-hydrazyl, $\mathrm{ORAC}$ oxygen radical absorbance capacity, $T E A C$ trolox equivalent antioxidant capacity, $\mathrm{MeOH}_{\mathrm{O}}$ methanol, $\mathrm{CH}_{2} \mathrm{Cl}_{2}$

dichloromethane, EtOH ethanol, EtOAc ethyl acetate, $n-\mathrm{C}_{6} \mathrm{H}_{12}$ hexane, $\left.\mathrm{CH}_{3}\right)_{2} \mathrm{CO}$ acetone, $\mathrm{H}_{2} \mathrm{O}$ aqueous, $\mathrm{BtOH}$ butanol 
Table 2 Antioxidants activities of Northern Africa African plants

\begin{tabular}{|c|c|c|c|c|c|c|c|}
\hline Plants & Family & Part used & Solvents & $\begin{array}{l}\text { Assay } \\
\text { Methods }\end{array}$ & Inhibition/EC 50 & $\begin{array}{l}\text { Country } \\
\text { of origin }\end{array}$ & References \\
\hline Acacia arabica (Lam) Wild. & Fabaceae & Leaf & $\mathrm{MeOH}$ & $\mathrm{DPPH}$ & $61.20 \%$ at $50 \mu \mathrm{g} / \mathrm{mL}$ & Sudan & [188] \\
\hline Acacia nilotica Delile. & Mimosaceae & Bark & $\mathrm{EtOH}$ & SORSA & $75 \%$ at $1 \mu \mathrm{g} / \mathrm{mL}$ & Sudan & {$[45]$} \\
\hline Acacia nilotica Delile. & Mimosaceae & Pod & $\mathrm{MeOH}$ & DPPH & $37.57 \mu \mathrm{M}$ & Sudan & [189] \\
\hline Acalypha marginata Spreng. & Euphorbiaceae & Leaf & $\mathrm{CHCl}_{3} / \mathrm{MeOH}$ & $\mathrm{DPPH}$ & $29 / 89$ at $50 \mu \mathrm{g} / \mathrm{mL}$ & Egypt & [42] \\
\hline Achillea millefolium L. & Asteraceae & Leaf & $\mathrm{EtOH}$ & $\mathrm{DPPH} / \mathrm{TBA}$ & $\begin{array}{l}58.11 / 51.2 \text { at } \\
100 \mu \mathrm{g} / \mathrm{mL}\end{array}$ & Egypt & [190] \\
\hline Adansonia digitata $\mathrm{L}$. & Malvaceae & Leaf & $\mathrm{EtOH}$ & DPPH & $13 \%$ & Sudan & [191] \\
\hline Adhatoda vasica Nees. & Acauthaceae & Leaf & $\mathrm{CHCl}_{3} / \mathrm{MeOH}$ & $\mathrm{DPPH}$ & $3 / 13$ at $50 \mu \mathrm{g} / \mathrm{mL}$ & Egypt & [42] \\
\hline Adhatoda vasica Nees. & Acanthaceae & Aerial parts & $\mathrm{MeOH}$ & $\mathrm{DPPH}$ & $>100 \mu \mathrm{g} / \mathrm{mL}$ & Egypt & [192] \\
\hline Ajuga iva (L.) Schreb. & Lamiaceae & Aerial parts & $\mathrm{MeOH}$ & $\mathrm{DPPH}$ & $486.60 \mu \mathrm{g} / \mathrm{mL}$ & Algeria & [193] \\
\hline Albezzia anthelmintica Benth. & Loganiaceae & Leaf & $\mathrm{CHCl}_{3} / \mathrm{MeOH}$ & DPPH & $20 / 49$ at $50 \mu \mathrm{g} / \mathrm{mL}$ & Egypt & [42] \\
\hline Albezzia stipulate (DC.) Bovin. & Mimosaceae & Leaf & $\mathrm{CHCl}_{3} / \mathrm{MeOH}$ & DPPH & $1 / 18$ at $50 \mu \mathrm{g} / \mathrm{mL}$ & Egypt & [42] \\
\hline Albizzia anthelmintica Benth. & Mimosaceae & - & $\mathrm{EtOH}$ & SOCA & $<50$ at $1 \mu \mathrm{g} / \mathrm{mL}$ & Sudan & [45] \\
\hline Alhagi maurorum Medik. & Leguminosae & Leaf & $\mathrm{H}_{2} \mathrm{O}$ & $\mathrm{DPPH}$ & $0.47 \mathrm{mmol}$ TEAC/g & Libya & [194] \\
\hline Aloe vera $\mathrm{L}$. & Xanthorrhoeaceae & Juice & $\mathrm{MeOH}$ & DPPH & $>100 \mu \mathrm{g} / \mathrm{mL}$ & Egypt & [192] \\
\hline Alternanthera versicolor Forssk. & Amaranthaceae & Leaf & $\mathrm{CHCl}_{3} / \mathrm{MeOH}$ & DPPH & $0.5 / 71$ at $50 \mu \mathrm{g} / \mathrm{mL}$ & Egypt & [42] \\
\hline Althaea rosea Hohen. & Malvaceae & Leaf & $\mathrm{CHCl}_{3} / \mathrm{MeOH}$ & $\mathrm{DPPH}$ & $19 / 58$ at $50 \mu \mathrm{g} / \mathrm{mL}$ & Egypt & [42] \\
\hline Amaranthus tricolor $\mathrm{L}$. & Amaranthaceae & Leaf & $\mathrm{CHCl}_{3} / \mathrm{MeOH}$ & DPPH & $1 / 0$ at $50 \mu \mathrm{g} / \mathrm{mL}$ & Egypt & [42] \\
\hline Anabasis articulata L. & Chenopodiaceae & Whole plant & $\mathrm{EtOH} / \mathrm{H}_{2} \mathrm{O}$ & $\mathrm{DPPH}$ & $\begin{array}{l}40 / 42 \% \text { at } 100 \mu \mathrm{g} / \\
\mathrm{mL}\end{array}$ & Egypt & [41] \\
\hline Anacyclus clavatus Pers. & Asteraceae & Aerial parts & $\mathrm{MeOH}$ & DPPH & $27.20 \mu \mathrm{g} / \mathrm{mL}$ & Algeria & [193] \\
\hline Anacyclus pyrethrum L (DC). & Asteraceae & Root & $\mathrm{MeOH}$ & DPPH & $26.3 \mu \mathrm{g} / \mathrm{mL}$ & Egypt & [192] \\
\hline Anastatica hierochuntica L. & Brassicaceae & Leaf & $\mathrm{EtOH}$ & DPPH & $150.85 \mu \mathrm{g} / \mathrm{mL}$ & Egypt & [195] \\
\hline $\begin{array}{l}\text { Anogeisus leiocarpus (DC.) Guill. } \\
\text { \& Perr. }\end{array}$ & Combretaceae & Leaf & $\mathrm{MeOH}$ & FRAP & $92 \%$ & Sudan & [196] \\
\hline Anthorium scherzerianum Schott. & Araceae & Leaf & $\mathrm{CHCl}_{3} / \mathrm{MeOH}$ & $\mathrm{DPPH}$ & $14 / 37$ at $50 \mu \mathrm{g} / \mathrm{mL}$ & Egypt & [42] \\
\hline Antigonon leptopus Hook \& Arm. & Polygonaceae & Leaf & $\mathrm{EtOH}$ & $\mathrm{DPPH}$ & $89 \%$ & Sudan & [197] \\
\hline Arbutus Pavarii Pamp. & Ericaceae & Leaf & $\mathrm{MeOH}$ & DPPH & $4.55 \mu \mathrm{g} / \mathrm{mL}$ & Algeria & [198] \\
\hline Arbutus unedo L. & Ericaceae & Aerial parts & $\mathrm{MeOH}$ & DPPH/ABTS & $3.8 / 4.2 \mu \mathrm{g} / \mathrm{mL}$ & Algeria & [199] \\
\hline Argemone mexicana $\mathrm{L}$. & Papaveraceae & Not stated & $\mathrm{EtOH}$ & SORSA & $<50$ at $1 \mu \mathrm{g} / \mathrm{mL}$ & Sudan & [45] \\
\hline Aristolochia bracteolata $\mathrm{L}$. & Aristolochiaceae & Not stated & $\mathrm{EtOH}$ & SORSA & $<50$ at $1 \mu \mathrm{g} / \mathrm{mL}$ & Sudan & [45] \\
\hline Artemisia absinthium L. & Compositae & Leaf & $\mathrm{H}_{2} \mathrm{O}$ & $\mathrm{DPPH}$ & $0.89 \mathrm{mmol} \mathrm{TEAC} / \mathrm{g}$ & Libya & [194] \\
\hline Artemisia annua $\mathrm{L}$. & Asteraceae & Leaf & $\mathrm{EtOH}$ & DPPH/TBA & $\begin{array}{l}37.97 / 49.6 \text { at } \\
100 \mu \mathrm{g} / \mathrm{mL}\end{array}$ & Egypt & [190] \\
\hline Arum palaestinum Boiss. & Araceae & Leaf & $\mathrm{EtOH} / \mathrm{H}_{2} \mathrm{O}$ & DPPH & $\begin{array}{l}12 / 43 \% \text { at } 100 \mu \mathrm{g} / \\
\mathrm{mL}\end{array}$ & Egypt & [41] \\
\hline Asparagus plumosus Baker. & Liliaceae & Leaf & $\mathrm{CHCl}_{3} / \mathrm{MeOH}$ & $\mathrm{DPPH}$ & $0 / 16$ at $50 \mu \mathrm{g} / \mathrm{mL}$ & Egypt & [42] \\
\hline Asparagus setaceus Jessop. & Liliaceae & Leaf & $\mathrm{CHCl}_{3} / \mathrm{MeOH}$ & DPPH & $5 / 15$ at $50 \mu \mathrm{g} / \mathrm{mL}$ & Egypt & [42] \\
\hline Asparagus stipularis Rch. D. & Liliaceae & Whole plant & $\mathrm{EtOH} / \mathrm{H}_{2} \mathrm{O}$ & $\mathrm{DPPH}$ & $\begin{array}{l}72 / 70 \% \text { at } 100 \mu \mathrm{g} / \\
\mathrm{mL}\end{array}$ & Egypt & [41] \\
\hline Asphodelus microcarpus Rch. D. & Liliaceae & Whole plant & $\mathrm{EtOH} / \mathrm{H}_{2} \mathrm{O}$ & DPPH & $\begin{array}{l}60 / 49 \% \text { at } 100 \mu \mathrm{g} / \\
\mathrm{mL}\end{array}$ & Egypt & [41] \\
\hline Aspidistra lurida Ker Gawl. & Convallariaceae & Leaf & $\mathrm{CHCl}_{3} / \mathrm{MeOH}$ & DPPH & $0 / 39$ at $50 \mu \mathrm{g} / \mathrm{mL}$ & Egypt & [42] \\
\hline Astragalus pinosus L. & Leguminosae & Whole plant & $\mathrm{EtOH} / \mathrm{H}_{2} \mathrm{O}$ & $\mathrm{DPPH}$ & $\begin{array}{l}28 / 19 \% \text { at } 100 \mu \mathrm{g} / \\
\mathrm{mL}\end{array}$ & Egypt & [41] \\
\hline Atriplex halimus L. & Chenopodiaceae & Whole plant & $\mathrm{EtOH} / \mathrm{H}_{2} \mathrm{O}$ & $\mathrm{DPPH}$ & $\begin{array}{l}\text { 70/50\% at } 100 \mu \mathrm{g} / \\
\mathrm{mL}\end{array}$ & Egypt & [41] \\
\hline
\end{tabular}


Table 2 Antioxidants activities of Northern Africa African plants (Continued)

\begin{tabular}{|c|c|c|c|c|c|c|c|}
\hline Balanites aegyptiaca Delile. & Balanitaceae & Bark & $\mathrm{EtOH}$ & SORSA & $72 \%$ at $1 \mu \mathrm{g} / \mathrm{mL}$ & Sudan & [45] \\
\hline Balanites aegyptiaca Delile. & Balanitaceae & Seed & Oil & & $17 \%$ & Sudan & [200] \\
\hline Bauhenia variegata & Leguminosae & Leaf & $\mathrm{CHCl}_{3} / \mathrm{MeOH}$ & $\mathrm{DPPH}$ & $18 / 94$ at $50 \mu \mathrm{g} / \mathrm{mL}$ & Egypt & [42] \\
\hline Bauhinia alba Buch. & Caesalpiniaceae & Leaf & $\mathrm{MeOH}$ & DPPH/ABTS & $74.32 / 25.29 \mu \mathrm{g} / \mathrm{mL}$ & Egypt & [201] \\
\hline Beta vulgaris $\mathrm{L}$. & Amaranthaceae & Leaf & $\begin{array}{l}\text { Cold } \mathrm{H}_{2} \mathrm{O} / \text { hot } \\
\mathrm{H}_{2} \mathrm{O} / \mathrm{MeOH}\end{array}$ & DPPH & $0.5 / 22 / 0.48 \mathrm{mg} / \mathrm{mL}$ & Egypt & [202] \\
\hline Beta vulgaris $\mathrm{L}$. & Amaranthaceae & Whole plant & $\mathrm{EtOH} / \mathrm{H}_{2} \mathrm{O}$ & $\mathrm{DPPH}$ & $\begin{array}{l}41 / 30 \% \text { at } 100 \mu \mathrm{g} / \\
\mathrm{mL}\end{array}$ & Egypt & [41] \\
\hline Bombax malabaricum DC. & Bombacaceae & Leaf & $\mathrm{CHCl}_{3} / \mathrm{MeOH}$ & DPPH & $2 / 96$ at $50 \mu \mathrm{g} / \mathrm{mL}$ & Egypt & [42] \\
\hline Boswellia sacra Flueck. & Burseraceae & Gum & $\mathrm{MeOH}$ & DPPH & $>100 \mu \mathrm{g} / \mathrm{mL}$ & Egypt & [192] \\
\hline Bougainvillea glabra Choisy. & Nyctaginaceae & Leaf & $\mathrm{CHCl}_{3} / \mathrm{MeOH}$ & DPPH & $20 / 50$ at $50 \mu \mathrm{g} / \mathrm{mL}$ & Egypt & [42] \\
\hline Bougainvillea pixie-pink & Nyctaginaceae & Leaf & $\mathrm{CHCl}_{3} / \mathrm{MeOH}$ & $\mathrm{DPPH}$ & $22 / 39$ at $50 \mu \mathrm{g} / \mathrm{mL}$ & Egypt & [42] \\
\hline Bougainvillea spectabilis Wild. & Nyctaginaceae & Leaf & $\mathrm{CHCl}_{3} / \mathrm{MeOH}$ & DPPH & $12 / 38$ at $50 \mu \mathrm{g} / \mathrm{mL}$ & Egypt & [42] \\
\hline Brachichton acerifolium & Sterculiaceae & Leaf & $\mathrm{CHCl}_{3} / \mathrm{MeOH}$ & DPPH & $16 / 22$ at $50 \mu \mathrm{g} / \mathrm{mL}$ & Egypt & [42] \\
\hline Brassica nigra W.D.J. Koch. & Brassicaceae & Seed & $\mathrm{MeOH}$ & DPPH & $32.82 \mu \mathrm{ML}$ & Sudan & [189] \\
\hline Brassica nigra W.D.J. Koch. & Brassicaceae & Seed & $\mathrm{MeOH}$ & DPPH & $>100 \mu \mathrm{g} / \mathrm{mL}$ & Egypt & [192] \\
\hline Brassica rapa $\mathrm{L}$. & Brassicaceae & Root & $\mathrm{MeOH}$ & DPPH & $>100 \mu \mathrm{g} / \mathrm{mL}$ & Egypt & [192] \\
\hline Buddleia davidii Franch & Loganiaceae & Leaf & $\mathrm{CHCl}_{3} / \mathrm{MeOH}$ & DPPH & $10 / 50$ at $50 \mu \mathrm{g} / \mathrm{mL}$ & Egypt & [42] \\
\hline Buddleja rufescens & Caesalpiniodeae & Leaf & $\mathrm{MeOH}$ & DPPH & $81 \%$ at $500 \mu \mathrm{g} / \mathrm{mL}$ & Sudan & [203] \\
\hline Caesalpinia pulcherrima (L.) Sw. & Loganiaceae & Leaf & $\mathrm{CHCl}_{3} / \mathrm{MeOH}$ & DPPH & $25 / 27$ at $50 \mu \mathrm{g} / \mathrm{mL}$ & Egypt & [42] \\
\hline Cakile maritime Scop. & Cruciferae & Whole plant & $\mathrm{EtOH} / \mathrm{H}_{2} \mathrm{O}$ & $\mathrm{DPPH}$ & $\begin{array}{l}58 / 55 \% \text { at } 100 \mu \mathrm{g} / \\
\mathrm{mL}\end{array}$ & Egypt & [41] \\
\hline Calendula officinalis $L$. & Asteraceae & Leaf & $\mathrm{EtOH}$ & $\mathrm{DPPH} / \mathrm{TBA}$ & $\begin{array}{l}22.08 / 2.60 \text { at } \\
100 \mu \mathrm{g} / \mathrm{mL}\end{array}$ & Egypt & [190] \\
\hline Calendula officinalis L. & Asteraceae & Leaf & $\mathrm{H}_{2} \mathrm{O}$ & DPPH & $0.67 \mathrm{mmol}$ TEAC/g & Libya & [194] \\
\hline Calicotome spinosa L. & Fabaceae & Leaf & $\mathrm{MeOH}$ & DPPH & $29.20 \mu \mathrm{g} / \mathrm{mL}$ & Algeria & [193] \\
\hline Calicotome villosa Poir. & Fabaceae & Leaf & $\mathrm{MeOH}$ & B-CLAMS & $29.8 \mu \mathrm{g} / \mathrm{mL}$ & Tunisia. & [204] \\
\hline $\begin{array}{l}\text { Caliistemon lanceolatus } \\
\text { (Curtis) Dum.Cours. }\end{array}$ & Myrtaceae & Leaf & $\mathrm{CHCl}_{3} / \mathrm{MeOH}$ & $\mathrm{DPPH}$ & $23 / 78$ at $50 \mu \mathrm{g} / \mathrm{mL}$ & Egypt & [42] \\
\hline Calliandra haematocephala Hassk. & Mimosaceae & Leaf & $\mathrm{CHCl}_{3} / \mathrm{MeOH}$ & DPPH & $10 / 23$ at $50 \mu \mathrm{g} / \mathrm{mL}$ & Egypt & [42] \\
\hline Camellia sinensis (L). Kuntze. & Theaceae & Leaf & $\mathrm{H}_{2} \mathrm{O}$ & $\mathrm{DPPH}$ & $\begin{array}{l}17.044 \mathrm{mmol} \text { TEAC/ } \\
\mathrm{g}\end{array}$ & Libya & [194] \\
\hline Camellia sinensis (L). Kuntze. & Theaceae & Leaf & $\mathrm{EtOH} / \mathrm{H}_{2} \mathrm{O}$ & DPPH & $\begin{array}{l}85 / 70 \% \text { at } 100 \mu \mathrm{g} / \\
\mathrm{mL}\end{array}$ & Egypt & [41] \\
\hline Camellia sinensis (L). Kuntze. & Theaceae & Leaf & Tea & $\mathrm{DPPH}$ & $3.0 \mu \mathrm{g} / \mathrm{mL}$ & Algeria & [205] \\
\hline Capparis Spinosa L. & Capparidaceae & Leaf & $\mathrm{MeOH}$ & DPPH & $57.75 \mu \mathrm{g} / \mathrm{mL}$ & Algeria & [198] \\
\hline Capsicum annuum L. & Solanaceae & Fruit & $\mathrm{EtOH} / \mathrm{H}_{2} \mathrm{O}$ & $\mathrm{DPPH}$ & $\begin{array}{l}57 / 25 \% \text { at } 100 \mu \mathrm{g} / \\
\mathrm{mL}\end{array}$ & Egypt & [41] \\
\hline Capsicum annuum L. & Solanaceae & Whole plant & $\mathrm{EtOH} / \mathrm{H}_{2} \mathrm{O}$ & $\mathrm{DPPH}$ & $\begin{array}{l}90 / 81 \% \text { at } 100 \mu \mathrm{g} / \\
\mathrm{mL}\end{array}$ & Egypt & [41] \\
\hline Capsicum frutescens $\mathrm{L}$. & Solanaceae & Leaf & $\begin{array}{l}\text { Cold } \mathrm{H}_{2} \mathrm{O} / \text { hot } \\
\mathrm{H}_{2} \mathrm{O} / \mathrm{MeOH}\end{array}$ & DPPH & $\begin{array}{l}0.69 / 22.2 / 0.57 \mathrm{mg} / \\
\mathrm{mL}\end{array}$ & Egypt & [202] \\
\hline Carissa grandiflora A.DC. & Apocynaceae & Leaf & $\mathrm{CHCl}_{3} / \mathrm{MeOH}$ & DPPH & $2 / 0$ at $50 \mu \mathrm{g} / \mathrm{mL}$ & Egypt & [42] \\
\hline Cassia acutifolia L. & Fabaceae & Leaf & $\begin{array}{l}\text { Cold } \mathrm{H}_{2} \mathrm{O} / \text { hot } \\
\mathrm{H}_{2} \mathrm{O} / \mathrm{MeOH}\end{array}$ & $\mathrm{DPPH}$ & $0.58 / 39 / 0.59 \mathrm{mg} / \mathrm{mL}$ & Egypt & [202] \\
\hline Cassia didymobotrya Delile. & Fabaceae & Leaf & $\mathrm{CHCl}_{3} / \mathrm{MeOH}$ & $\mathrm{DPPH}$ & $19.5 / 12$ at $50 \mu \mathrm{g} / \mathrm{mL}$ & Egypt & [42] \\
\hline Cassia fistula L. & Fabaceae & Leaf & $\mathrm{CHCl}_{3} / \mathrm{MeOH}$ & $\mathrm{DPPH}$ & $21.6 / 45$ at $50 \mu \mathrm{g} / \mathrm{mL}$ & Egypt & [42] \\
\hline Cassia fistula $\mathrm{L}$. & Fabaceae & Fruit & $\mathrm{MeOH}$ & DPPH & $75 \mu \mathrm{g} / \mathrm{mL}$ & Egypt & [192] \\
\hline
\end{tabular}


Table 2 Antioxidants activities of Northern Africa African plants (Continued)

\begin{tabular}{|c|c|c|c|c|c|c|c|}
\hline Cassia nigricans Vahl. & Caesalpinaceae & Not stated & $\mathrm{EtOH}$ & SORSA & $<50$ at $1 \mu \mathrm{g} / \mathrm{mL}$ & Sudan & [45] \\
\hline Cassia senna L. & Ceasalpiniaceae & leaf & $\mathrm{MeOH}$ & DPPH & $33.56 \mu \mathrm{M}$ & Sudan & [189] \\
\hline Centaurea calcitrapa L. & Asteraceae & Aerial parts & $\mathrm{MeOH}$ & DPPH & $231.70 \mu \mathrm{g} / \mathrm{mL}$ & Algeria & [193] \\
\hline Ceratonia siliqua L. & Fabaceae & Pod & $\mathrm{H}_{2} \mathrm{O}$ & DPPH/ABTS & $7.7 / 9.7 \%$ & Morocco & [206] \\
\hline Cestrum diurnum ex Dunal. & Solonaceae & Leaf & $\mathrm{CHCl}_{3} / \mathrm{MeOH}$ & DPPH & $30 / 20$ at $50 \mu \mathrm{g} / \mathrm{mL}$ & Egypt & [42] \\
\hline $\begin{array}{l}\text { Chrysanthemum frutesence (L.) } \\
\text { Sch. Bip. }\end{array}$ & Compositae & Leaf & $\mathrm{CHCl}_{3} / \mathrm{MeOH}$ & DPPH & $0 / 87$ at $50 \mu \mathrm{g} / \mathrm{mL}$ & Egypt & [42] \\
\hline Chrysanthemum red $\mathrm{L}$. & Asteraceae & Leaf & $\mathrm{CHCl}_{3} / \mathrm{MeOH}$ & DPPH & 15.53 at $50 \mu \mathrm{g} / \mathrm{mL}$ & Egypt & [42] \\
\hline Cistanche phelypaea L. & Orobanchaceae & Whole plant & $\mathrm{EtOH} / \mathrm{H}_{2} \mathrm{O}$ & DPPH & $\begin{array}{l}50 / 85 \% \text { at } 100 \mu \mathrm{g} / \\
\mathrm{mL}\end{array}$ & Egypt & [41] \\
\hline Cistus incanus L. & Cistaceae & Leaf & $\mathrm{MeOH}$ & $\mathrm{DPPH}$ & $17.75 \mu \mathrm{g} / \mathrm{mL}$ & Algeria & [198] \\
\hline Cistus Parviflorus Gaterau. & Cistaceae & Leaf & $\mathrm{MeOH}$ & DPPH & $4.75 \mu \mathrm{g} / \mathrm{mL}$ & Algeria & [198] \\
\hline Citrullus colocynthis (L) Schrad. & Cucurbitaceae & Not stated & $\mathrm{EtOH}$ & SORSA & $<50$ at $1 \mu \mathrm{g} / \mathrm{mL}$ & Sudan & [45] \\
\hline Citrus limon (L) Osbeck & Rutaceae & Fruit & $\mathrm{EtOH} / \mathrm{H}_{2} \mathrm{O}$ & DPPH & $\begin{array}{l}91 / 70 \% \text { at } 100 \mu \mathrm{g} / \\
\mathrm{mL}\end{array}$ & Egypt & [41] \\
\hline $\begin{array}{l}\text { Cochlospermum planchonii } \\
\text { Hook. F. ex Planach. }\end{array}$ & Cochlospermaceae & Root & $\mathrm{MeOH}$ & DPPH/FRAP & $01.83 / 06.50 \mathrm{mg} / \mathrm{mL}$ & Egypt & [207] \\
\hline Colocasia antiquorum Schott. & Araceae & Leaf & $\begin{array}{l}\text { Cold } \mathrm{H}_{2} \mathrm{O} / \text { hot } \\
\mathrm{H}_{2} \mathrm{O} / \mathrm{MeOH}\end{array}$ & $\mathrm{DPPH}$ & $\begin{array}{l}0.49 / 49.7 / 0.27 \mathrm{mg} / \\
\mathrm{mL}\end{array}$ & Egypt & [202] \\
\hline Combretum aculeatum Vent. & Combretaceae & Leaf & $\mathrm{MeOH}$ & FRAP & $98 \%$ & Sudan & [196] \\
\hline $\begin{array}{l}\text { Combretum hartmannianum } \\
\text { Schweinf. }\end{array}$ & Combretaceae & Leaf & $\mathrm{EtOH} / \mathrm{MeOH} / \mathrm{H}_{2} \mathrm{O}$ & DPPH & $146 / 14 / 967 \mu \mathrm{g} / \mathrm{mL}$ & Sudan & [208] \\
\hline $\begin{array}{l}\text { Combretum } \\
\text { hartmannianum Schweinf. }\end{array}$ & Combretaceae & Leaf & $\mathrm{MeOH}$ & RSA/FRAP & $86 / 11 \%$ & Sudan & [208] \\
\hline $\begin{array}{l}\text { Combretum } \\
\text { hartmannianum Schweinf. }\end{array}$ & Combretaceae & Leaf & $\mathrm{MeOH}$ & FRAP & $99 \%$ & Sudan & [196] \\
\hline Conocarpus erectus L. & Combretaceae & Leaf & $\mathrm{CHCl}_{3} / \mathrm{MeOH}$ & $\mathrm{DPPH}$ & $15 / 45$ at $50 \mu \mathrm{g} / \mathrm{mL}$ & Egypt & [42] \\
\hline Coratonia siliqua L. & Loganiaceae & Leaf & $\mathrm{CHCl}_{3} / \mathrm{MeOH}$ & $\mathrm{DPPH}$ & $1.5 / 40$ at $50 \mu \mathrm{g} / \mathrm{mL}$ & Egypt & [42] \\
\hline Cordia africana Lam. & Boraginaceae & $\begin{array}{l}\text { Leaf/Stem } \\
\text { bark/Fruit }\end{array}$ & $\mathrm{MeOH}$ & DPPH & $80 / 88 / 74 / 37 \%$ & Sudan & [209] \\
\hline Cordia sebestena Andrew. & Boraginaceae & Leaf & $\mathrm{CHCl}_{3} / \mathrm{MeOH}$ & DPPH & $15 / 42$ at $50 \mu \mathrm{g} / \mathrm{mL}$ & Egypt & [42] \\
\hline Cordyline fruticosa Gopp. & Laxmamiaceae & Leaf & $\mathrm{CHCl}_{3} / \mathrm{MeOH}$ & $\mathrm{DPPH}$ & $18 / 21$ at $50 \mu \mathrm{g} / \mathrm{mL}$ & Egypt & [42] \\
\hline Crinum longifolium L. & Amaryllidaceae & Leaf & $\mathrm{CHCl}_{3} / \mathrm{MeOH}$ & DPPH & $6 / 21$ at $50 \mu \mathrm{g} / \mathrm{mL}$ & Egypt & [42] \\
\hline Cryptostegia grandiflora R. Br. & Asclpiadaceae & Leaf & $\mathrm{CHCl}_{3} / \mathrm{MeOH}$ & DPPH & $0 / 35$ at $50 \mu \mathrm{g} / \mathrm{mL}$ & Egypt & [42] \\
\hline Cucurbita maxima Duchesne. & Cucurbitaceae & Seed & $\mathrm{EtOH}$ & DPPH & $38 \%$ & Sudan & [191] \\
\hline Cucurbita pepo Vell. & Cucurbitaceae & Leaf & $\mathrm{MeOH} / \mathrm{H}_{2} \mathrm{O}$ & DPPH & $>0.19 \mathrm{mg} / \mathrm{mL}$ & Algeria & [210] \\
\hline Cupressus sempervirens L. & Cupressaceae & Leaf & $\mathrm{CHCl}_{3} / \mathrm{MeOH}$ & DPPH & $6 / 65$ at $50 \mu \mathrm{g} / \mathrm{mL}$ & Egypt & [42] \\
\hline Cupressus sempervirens L. & Cupressacea & Leaf & $\mathrm{MeOH}$ & $\mathrm{DPPH}$ & $29.20 \mu \mathrm{g} / \mathrm{mL}$ & Algeria & [193] \\
\hline Cymbopogon citratus Stapf. & Poaceae & Leaf & $\mathrm{EtOH}$ & $\mathrm{DPPH} / \mathrm{TBA}$ & $\begin{array}{l}24.79 / 2.7 \text { at } \\
100 \mu \mathrm{g} / \mathrm{mL}\end{array}$ & Egypt & [190] \\
\hline Cymbopogon citratus Stapf. & Poaceae & Leaf & $\mathrm{MeOH}$ & DPPH & $30.64 \mu \mathrm{M}$ & Sudan & [189] \\
\hline $\begin{array}{l}\text { Cymbopogon } \\
\text { schoenanthus Spreng. }\end{array}$ & Poaceae & Leaf & $\mathrm{MeOH}$ & DPPH & $34.28 \mu \mathrm{ML}$ & Sudan & [189] \\
\hline Cynara scolymus L. & Asteraceae & Rizhome & $\mathrm{MeOH} /$ flavonoid & $\mathrm{DPPH}$ & $17.7 / 13.3 \mu \mathrm{g} / \mathrm{mL}$ & Libya & [211] \\
\hline Cyperus alternifolius Stend. & Cyperaceae & Leaf & $\mathrm{CHCl}_{3} / \mathrm{MeOH}$ & DPPH & $2 / 31$ at $50 \mu \mathrm{g} / \mathrm{mL}$ & Egypt & [42] \\
\hline Cypressus macrocarpa & Cupressaceae & Leaf & $\mathrm{CHCl}_{3} / \mathrm{MeOH}$ & DPPH & $3 / 49$ at $50 \mu \mathrm{g} / \mathrm{mL}$ & Egypt & [42] \\
\hline Datura arborea L. & Solonaceae & Leaf & $\mathrm{CHCl}_{3} / \mathrm{MeOH}$ & $\mathrm{DPPH}$ & $17 / 56$ at $50 \mu \mathrm{g} / \mathrm{mL}$ & Egypt & [42] \\
\hline Daucus carota L. & Umbelliferae & Whole plant & $\mathrm{EtOH} / \mathrm{H}_{2} \mathrm{O}$ & DPPH & $\begin{array}{l}85 / 81 \% \text { at } 100 \mu \mathrm{g} / \\
\mathrm{mL}\end{array}$ & Egypt & [41] \\
\hline $\begin{array}{l}\text { Derris rubosta } \\
\text { (Roxb. ex DC.) Benth. }\end{array}$ & Fabaceae & Leaf & $\mathrm{MeOH}$ & DPPH/ABTS & $138 / 294 \mu \mathrm{g} / \mathrm{mL}$ & Egypt & [201] \\
\hline
\end{tabular}


Table 2 Antioxidants activities of Northern Africa African plants (Continued)

\begin{tabular}{|c|c|c|c|c|c|c|c|}
\hline Didonia viscose Jacq. & Sapindaceae & Leaf & $\mathrm{CHCl}_{3} / \mathrm{MeOH}$ & $\mathrm{DPPH}$ & $0 / 90$ at $50 \mu \mathrm{g} / \mathrm{mL}$ & Egypt & [42] \\
\hline Dracaena fragrans Ker Gawl. & Moraceae & Leaf & $\mathrm{CHCl}_{3} / \mathrm{MeOH}$ & $\mathrm{DPPH}$ & $15 / 33$ at $50 \mu \mathrm{g} / \mathrm{mL}$ & Egypt & {$[42]$} \\
\hline Dracaena marginata $\mathrm{L}$. & Agavaceae & Leaf & $\mathrm{CHCl}_{3} / \mathrm{MeOH}$ & DPPH & $15 / 13$ at $50 \mu \mathrm{g} / \mathrm{mL}$ & Egypt & {$[42]$} \\
\hline Duranta repens $\mathrm{L}$. & Verbenaceae & Leaf & $\mathrm{CHCl}_{3} / \mathrm{MeOH}$ & DPPH & $16 / 44$ at $50 \mu \mathrm{g} / \mathrm{mL}$ & Egypt & {$[42]$} \\
\hline Eichhornia azurea $\mathrm{K}$ & Pontederiaceae & Fruit & $\mathrm{EtOH} / \mathrm{H}_{2} \mathrm{O}$ & DPPH & $\begin{array}{l}54 / 50 \% \text { at } 100 \mu \mathrm{g} / \\
\mathrm{mL}\end{array}$ & Egypt & [41] \\
\hline Elaeagnus macrophylla Thunb. & Elaeagnaceae & Leaf & $\mathrm{CHCl}_{3} / \mathrm{MeOH}$ & $\mathrm{DPPH}$ & $45 / 8$ at $50 \mu \mathrm{g} / \mathrm{mL}$ & Egypt & [42] \\
\hline Emblica officinalis Gaetn. & Euphorbiaceae & Fruit & $\mathrm{MeOH}$ & DPPH & $63 \mu \mathrm{g} / \mathrm{mL}$ & Egypt & [192] \\
\hline Erica arborea L. & Ericaceae & Aerial parts & $\mathrm{MeOH}$ & $\mathrm{DPPH} / \mathrm{ABTS}$ & $5.7 / 6.8 \mu \mathrm{g} / \mathrm{mL}$ & Algeria & [199] \\
\hline Erica multiflora $\mathrm{L}$. & Ericaceae & Aerial parts & $\mathrm{MeOH}$ & $\mathrm{DPPH} / \mathrm{ABTS}$ & $10.2 / 9.0 \mu \mathrm{g} / \mathrm{mL}$ & Algeria & [199] \\
\hline Eucalyptus globules Labill. & Myrtaceae & Leaf & $\mathrm{MeOH}$ & $\mathrm{DPPH} / \mathrm{H}_{2} \mathrm{O}_{2}$ & - & Algeria & [212] \\
\hline Eucalyptus rostrata Cav. & Myrtaceae & Leaf & $\mathrm{CHCl}_{3} / \mathrm{MeOH}$ & DPPH & $9 / 90$ at $50 \mu \mathrm{g} / \mathrm{mL}$ & Egypt & {$[42]$} \\
\hline Eugenia uniflora $\mathrm{L}$. & Myrtaceae & Leaf & $\mathrm{CHCl}_{3} / \mathrm{MeOH}$ & DPPH & $13 / 16$ at $50 \mu \mathrm{g} / \mathrm{mL}$ & Egypt & {$[42]$} \\
\hline Euonymus japonicus Thunb. & Celastraceae & Leaf & $\mathrm{CHCl}_{3} / \mathrm{MeOH}$ & $\mathrm{DPPH}$ & $3 / 66$ at $50 \mu \mathrm{g} / \mathrm{mL}$ & Egypt & {$[42]$} \\
\hline Euphorbia paralias L. & Euphorbiaceae & Whole plant & $\mathrm{EtOH} / \mathrm{H}_{2} \mathrm{O}$ & $\mathrm{DPPH}$ & $\begin{array}{l}81 / 51 \% \text { at } 100 \mu \mathrm{g} / \\
\mathrm{mL}\end{array}$ & Egypt & [41] \\
\hline Euphorbia serrata L. & Euphorbiaceae & Leaf & $\mathrm{MeOH}$ & $\mathrm{DPPH}$ & $40 \mu \mathrm{g} / \mathrm{mL}$ & Libya & [213] \\
\hline $\begin{array}{l}\text { Euphorbia splendens Bojer ex } \\
\text { Hook. }\end{array}$ & Euphorbiaceae & Leaf & $\mathrm{CHCl}_{3} / \mathrm{MeOH}$ & DPPH & $5.5 / 31$ at $50 \mu \mathrm{g} / \mathrm{mL}$ & Egypt & {$[42]$} \\
\hline Ferula assafoetida L. & Apiaceae & Gum & $\mathrm{MeOH}$ & $\mathrm{DPPH}$ & $>100 \mu \mathrm{g} / \mathrm{mL}$ & Egypt & [192] \\
\hline Ficus alii $\mathrm{L}$. & Moraceae & Leaf & $\mathrm{CHCl}_{3} / \mathrm{MeOH}$ & DPPH & $1 / 3$ at $50 \mu \mathrm{g} / \mathrm{mL}$ & Egypt & {$[42]$} \\
\hline Ficus benjamina $\mathrm{L}$. & Moraceae & Leaf & $\mathrm{CHCl}_{3} / \mathrm{MeOH}$ & $\mathrm{DPPH}$ & $2 / 3$ at $50 \mu \mathrm{g} / \mathrm{mL}$ & Egypt & [42] \\
\hline Ficus carica L. & Moracea & Whole plant & $\mathrm{EtOH} / \mathrm{H}_{2} \mathrm{O}$ & DPPH & $\begin{array}{l}84 / 80 \% \text { at } 100 \mu \mathrm{g} / \\
\mathrm{mL}\end{array}$ & Egypt & [41] \\
\hline Ficus carica L. & Moraceae & Leaf & $\mathrm{MeOH}$ & $\mathrm{DPPH}$ & $113.30 \mu \mathrm{g} / \mathrm{mL}$ & Algeria & [193] \\
\hline Ficus elastica Roxb. & Moraceae & Leaf & $\mathrm{CHCl}_{3} / \mathrm{MeOH}$ & $\mathrm{DPPH}$ & $11.5 / 41$ at $50 \mu \mathrm{g} / \mathrm{mL}$ & Egypt & [42] \\
\hline Ficus enfictoria $\mathrm{L}$. & Moraceae & Leaf & $\mathrm{CHCl}_{3} / \mathrm{MeOH}$ & DPPH & $3.5 / 31$ at $50 \mu \mathrm{g} / \mathrm{mL}$ & Egypt & {$[42]$} \\
\hline Ficus hawaii L. & Moraceae & Leaf & $\mathrm{CHCl}_{3} / \mathrm{MeOH}$ & $\mathrm{DPPH}$ & $3 / 25$ at $50 \mu \mathrm{g} / \mathrm{mL}$ & Egypt & {$[42]$} \\
\hline Ficus natalensis Hochst. & Moraceae & Leaf & $\mathrm{CHCl}_{3} / \mathrm{MeOH}$ & DPPH & $5 / 16$ at $50 \mu \mathrm{g} / \mathrm{mL}$ & Egypt & {$[42]$} \\
\hline Ficus nitida Miq. & Moraceae & Leaf & $\mathrm{CHCl}_{3} / \mathrm{MeOH}$ & DPPH & $5 / 25$ at $50 \mu \mathrm{g} / \mathrm{mL}$ & Egypt & {$[42]$} \\
\hline Ficus religiosa $\mathrm{L}$. & Moraceae & Leaf & $\mathrm{CHCl}_{3} / \mathrm{MeOH}$ & DPPH & $3 / 24$ at $50 \mu \mathrm{g} / \mathrm{mL}$ & Egypt & [42] \\
\hline Ficus vasta Forss $\mathrm{K}$. & Moraceae & Leaf & $\mathrm{MeOH}$ & $\begin{array}{l}\text { RSA/Iron } \\
\text { chelating }\end{array}$ & $88 / 03 \%$ & Sudan & [208] \\
\hline Foeniculum vulgare Mill. & Apiaceae & Leaf & $\mathrm{CHCl}_{3} / \mathrm{MeOH}$ & $\mathrm{DPPH}$ & $46 / 16$ at $50 \mu \mathrm{g} / \mathrm{mL}$ & Egypt & {$[42]$} \\
\hline Fraxinus latifolia Benth. & Oleaceae & Leaf & $\mathrm{EtOH}$ & $\mathrm{OH}$ & $79.76 \mu \mathrm{g} / \mathrm{mL}$ & Algeria & [214] \\
\hline Gazania splendens Hort. Angl & Compositae & Leaf & $\mathrm{CHCl}_{3} / \mathrm{MeOH}$ & $\mathrm{DPPH}$ & $0 / 89$ at $50 \mu \mathrm{g} / \mathrm{mL}$ & Egypt & [42] \\
\hline Geigeria alata Benth \& Hook. F. & Asteraceae & - & $\mathrm{EtOH}$ & SORSA & $<50$ at $1 \mu \mathrm{g} / \mathrm{mL}$ & Sudan & {$[45]$} \\
\hline Globularia alypum L. & Globulariaceae & Leaf & $\mathrm{MeOH}$ & DPPH & $39.30 \mu \mathrm{g} / \mathrm{mL}$ & Algeria & [193] \\
\hline Globularia alypum L. & Globulariaceae & Leaf & $\begin{array}{l}\mathrm{MeOH} / \mathrm{H}_{2} \mathrm{O} / \\
\mathrm{EtOAC}\end{array}$ & DPPH & $\begin{array}{l}33.32 / 36.12 / \\
38.29 \mu \mathrm{g} / \mathrm{mL}\end{array}$ & Algeria & {$[215]$} \\
\hline $\begin{array}{l}\text { Globularia Arabica Jaub \& } \\
\text { Spach. }\end{array}$ & Globulariaceae & Leaf & $\mathrm{MeOH}$ & DPPH & $7.65 \mu \mathrm{g} / \mathrm{mL}$ & Algeria & [198] \\
\hline Glycyrrhiza glabra L. & Galegeae & Seed & $\mathrm{EtOH} / \mathrm{H}_{2} \mathrm{O}$ & DPPH & $\begin{array}{l}47 / 84 \% \text { at } 100 \mu \mathrm{g} / \\
\mathrm{mL}\end{array}$ & Egypt & [41] \\
\hline Grass L. & Poaceae & Leaf & $\mathrm{CHCl}_{3} / \mathrm{MeOH}$ & DPPH & $5 / 30$ at $50 \mu \mathrm{g} / \mathrm{mL}$ & Egypt & {$[42]$} \\
\hline Guiera senegalensis Lam. & Combretaceae & Leaf & $\mathrm{MeOH}$ & $\begin{array}{l}\text { RSA/Iron } \\
\text { chelating }\end{array}$ & $90 / 05 \%$ & Sudan & [208] \\
\hline Hammada scoparia (Pomel) Iljin. & Chenopodiaceae & Leaf & $\mathrm{MeOH}$ & DPPH & $8 \mu \mathrm{g} / \mathrm{mL}$ & Libya & [211] \\
\hline
\end{tabular}


Table 2 Antioxidants activities of Northern Africa African plants (Continued)

\begin{tabular}{|c|c|c|c|c|c|c|c|}
\hline Helianthemum lippii Mill. & Cistaceae & Leaf & $\mathrm{MeOH}$ & $\mathrm{DPPH} / \mathrm{OH}$ & $58.98 / 324.84 \mu \mathrm{g} / \mathrm{mL}$ & Algeria & [216] \\
\hline Helianthemum lippii Mill. & Cistaceae & Leaf & $\mathrm{MeOH}$ & DPPH & $45.2 \mu \mathrm{g} / \mathrm{mL}$ & Algeria & [198] \\
\hline Helianthus annuus L. & Asteraceae & Seed & Oil & DPPH & $52 \%$ & Sudan & [200] \\
\hline Helychrysum stoechas L. & Asteraceae & Aerial parts & $\mathrm{MeOH}$ & DPPH & $46.30 \mu \mathrm{g} / \mathrm{mL}$ & Algeria & [193] \\
\hline Herniaria glabra Mill. & Caropllaceae & Aerial parts & $\mathrm{MeOH}$ & DPPH & $332.5 \mu \mathrm{g} / \mathrm{mL}$ & Algeria & [193] \\
\hline Hibiscus mutabilic L. & Malvaceae & Leaf & $\mathrm{CHCl}_{3} / \mathrm{MeOH}$ & DPPH & $0 / 40$ at $50 \mu \mathrm{g} / \mathrm{mL}$ & Egypt & [42] \\
\hline Hibiscus sabdariffa L. & Malvaceae & Leaf & $\mathrm{H}_{2} \mathrm{O}$ & DPPH & $5.62 \mathrm{mmol} \mathrm{TEAC} / \mathrm{g}$ & Libya & [194] \\
\hline Hibiscus sabdariffa L. & Malvaceae & Calyces & $\mathrm{MeOH}$ & DPPH & $33.24 \mu \mathrm{M}$ & Sudan & [189] \\
\hline Hydnora abyssinica A. Braun. & Hydnoraceae & Leaf & $\mathrm{EtOH}$ & SORSA & $59 \%$ at $1 \mu \mathrm{g} / \mathrm{mL}$ & Sudan & [45] \\
\hline Hydnora abyssinica A. Braun. & Hydnoraceae & Rhizome & $\mathrm{MeOH}$ & $\begin{array}{l}\text { RSA/lron } \\
\text { chelating }\end{array}$ & $77 / 02 \%$ & Sudan & [208] \\
\hline Hydrangea red $\mathrm{L}$. & Saxifragaceae & Leaf & $\mathrm{CHCl}_{3} / \mathrm{MeOH}$ & DPPH & $4 / 29$ at $50 \mu \mathrm{g} / \mathrm{mL}$ & Egypt & [42] \\
\hline Hyoscyamus albus L. & Rhamnacea & Leaf & $\mathrm{MeOH}$ & DPPH & $60 \mu \mathrm{g} / \mathrm{mL}$ & Libya & [213] \\
\hline Hyphaene thebaica Mark. & Arecacea & Not stated & $\mathrm{EtOH}$ & SORSA & $<50$ at $1 \mu \mathrm{g} / \mathrm{mL}$ & Sudan & [45] \\
\hline Inula viscosa $\mathrm{L}$. & Asteraceae & Leaf & Oil & $\begin{array}{l}\text { DPPH, } \\
\text { ABTS/ } H_{2} \mathrm{O}_{2}\end{array}$ & - & Algeria & [217] \\
\hline Jacarandas acutifolia L. & Bignoniaceae & Leaf & $\mathrm{CHCl}_{3} / \mathrm{MeOH}$ & $\mathrm{DPPH}$ & $18 / 55$ at $50 \mu \mathrm{g} / \mathrm{mL}$ & Egypt & [42] \\
\hline Jasminum grandiflorum L. & Oleaceae & Flower & $\mathrm{H}_{2} \mathrm{O}$ & DPPH/ABTS & $14.35 / 10.2 \%$ & Morocco & [206] \\
\hline Jasminum grandiflorum L. & Oleaceae & Leaf & $\mathrm{CHCl}_{3} / \mathrm{MeOH}$ & DPPH & $39 / 52$ at $50 \mu \mathrm{g} / \mathrm{mL}$ & Egypt & [42] \\
\hline Jasminum primulinum ex Baker. & Oleaceae & Leaf & $\mathrm{CHCl}_{3} / \mathrm{MeOH}$ & DPPH & $6 / 30$ at $50 \mu \mathrm{g} / \mathrm{mL}$ & Egypt & {$[42]$} \\
\hline Jatropha curcas L. & Euphorbiaceae & Root/Leaf & $\mathrm{EtOH}$ & DPPH & $0.048 / 0.063$ & Egypt & [218] \\
\hline Jatropha integerrima Jacq. & Euphorbiaceae & Leaf & $\mathrm{CHCl}_{3} / \mathrm{MeOH}$ & DPPH & $13 / 10$ at $50 \mu \mathrm{g} / \mathrm{mL}$ & Egypt & [42] \\
\hline Jatropha multifidal L. & Euphorbiaceae & Leaf & $\mathrm{CHCl}_{3} / \mathrm{MeOH}$ & DPPH & $47 / 17$ at $50 \mu \mathrm{g} / \mathrm{mL}$ & Egypt & [42] \\
\hline Khaya senegalensis A. Juss. & Meliaceae & Leaf & $\mathrm{CHCl}_{3} / \mathrm{MeOH}$ & $\mathrm{DPPH}$ & $13 / 86$ at $50 \mu \mathrm{g} / \mathrm{mL}$ & Egypt & [42] \\
\hline Khaya senegalensis A. Juss. & Meliaceae & Leaf & $\mathrm{EtOH}$ & SORSA & $71 \%$ at $1 \mu \mathrm{g} / \mathrm{mL}$ & Sudan & [45] \\
\hline Kigelia pinnata DC. & Bignoniaceae & Leaf & $\mathrm{CHCl}_{3} / \mathrm{MeOH}$ & DPPH & $3 / 0$ at $50 \mu \mathrm{g} / \mathrm{mL}$ & Egypt & [42] \\
\hline Kochia indica Wight. & Chenopodiaceae & Whole plant & $\mathrm{EtOH} / \mathrm{H}_{2} \mathrm{O}$ & DPPH & $\begin{array}{l}50 / 72 \% \text { at } 100 \mu \mathrm{g} / \\
\mathrm{mL}\end{array}$ & Egypt & [41] \\
\hline Lagerstroemia indica L. & Lythraceae & Leaf & $\mathrm{CHCl}_{3} / \mathrm{MeOH}$ & DPPH & $28 / 89$ at $50 \mu \mathrm{g} / \mathrm{mL}$ & Egypt & [42] \\
\hline Lantana camara L. & Verbenaceae & Leaf & $\mathrm{CHCl}_{3} / \mathrm{MeOH}$ & DPPH & $12 / 32$ at $50 \mu \mathrm{g} / \mathrm{mL}$ & Egypt & [42] \\
\hline Lantana montevidensis Briq. & Verbenaceae & Leaf & $\mathrm{CHCl}_{3} / \mathrm{MeOH}$ & DPPH & $11 / 30$ at $50 \mu \mathrm{g} / \mathrm{mL}$ & Egypt & [42] \\
\hline Laurus nobilis L. & Lauraceae & Leaf & $\mathrm{H}_{2} \mathrm{O}$ & DPPH/ABTS & 18.93/18.61\% & Morocco & [206] \\
\hline Laurus nobilis L. & Lauraceae & Leaf & $\mathrm{CHCl}_{3} / \mathrm{MeOH}$ & DPPH & $49 / 89$ at $50 \mu \mathrm{g} / \mathrm{mL}$ & Egypt & [42] \\
\hline Laurus nobilis L. & Lauraceae & Leaf & Oil & $\begin{array}{l}\text { DPPH, } \\
\text { ABTS/ } H_{2} \mathrm{O}_{2}\end{array}$ & - & Algeria & [217] \\
\hline Lavandula angustifolia Mill. & Lamiaceae & Leaf & $\mathrm{CHCl}_{3} / \mathrm{MeOH}$ & DPPH & $2.6 / 36$ at $50 \mu \mathrm{g} / \mathrm{mL}$ & Egypt & [42] \\
\hline Lepidium sativum & Brassicaceae & Seed & $\mathrm{MeOH}$ & DPPH & $33.61 \mu \mathrm{M}$ & Sudan & [189] \\
\hline Leucophyllum frutescens & Scrophulariaceae & Leaf & $\mathrm{CHCl}_{3} / \mathrm{MeOH}$ & DPPH & $\begin{array}{l}16.4 / 31 \text { at } 50 \mu \mathrm{g} / \\
\mathrm{mL}\end{array}$ & Egypt & [42] \\
\hline Ligustrum ovalifolium Hassk. & Oleaceae & Leaf & $\mathrm{CHCl}_{3} / \mathrm{MeOH}$ & DPPH & $9 / 11$ at $50 \mu \mathrm{g} / \mathrm{mL}$ & Egypt & [42] \\
\hline $\begin{array}{l}\text { Limoniastrum monopetalum } \\
\text { Boiss. }\end{array}$ & Plumaginaceae & Whole plant & $\mathrm{EtOH} / \mathrm{H}_{2} \mathrm{O}$ & DPPH & $\begin{array}{l}85 / 82 \% \text { at } 100 \mu \mathrm{g} / \\
\mathrm{mL}\end{array}$ & Egypt & [41] \\
\hline Lonicera japonica Thunb. & Caprifoliaceae & Leaf & $\mathrm{CHCl}_{3} / \mathrm{MeOH}$ & DPPH & $5 / 16$ at $50 \mu \mathrm{g} / \mathrm{mL}$ & Egypt & [42] \\
\hline Lotas polyphyllus E.D. Clarke & Leguminosae & Whole plant & $\mathrm{EtOH} / \mathrm{H}_{2} \mathrm{O}$ & DPPH & $\begin{array}{l}27 / 27 \% \text { at } 100 \mu \mathrm{g} / \\
\mathrm{mL}\end{array}$ & Egypt & [41] \\
\hline Luffa aegyptiaca Mill. & Curcubitaceae & Leaf & $\begin{array}{l}\text { Cold } \mathrm{H}_{2} \mathrm{O} / \text { hot } \\
\mathrm{H}_{2} \mathrm{O} / \mathrm{MeOH}\end{array}$ & DPPH & $\begin{array}{l}\text { 1.19/17.9/0.75 mg/ } \\
\mathrm{mL}\end{array}$ & Egypt & [202] \\
\hline Majorana hortensis Moench. & Lamiaceae & Leaf & $\mathrm{EtOH}$ & $\mathrm{DPPH} / \mathrm{TBA}$ & $\begin{array}{l}69.73 / 63.6 \text { at } \\
100 \mu \mathrm{g} / \mathrm{mL}\end{array}$ & Egypt & [190] \\
\hline
\end{tabular}


Table 2 Antioxidants activities of Northern Africa African plants (Continued)

\begin{tabular}{|c|c|c|c|c|c|c|c|}
\hline Marrubium vulgare L. & Lamiaceae & Leaf & $\mathrm{H}_{2} \mathrm{O}$ & DPPH & $0.43 \mathrm{mmol} \mathrm{TEAC} / \mathrm{g}$ & Libya & [194] \\
\hline Marrubium vulgare L. & Lamiaceae & Aerial parts & $\mathrm{MeOH}$ & $\mathrm{DPPH}$ & $84.20 \mu \mathrm{g} / \mathrm{mL}$ & Algeria & [193] \\
\hline Matricaria chamomilla L. & Compositae & Leaf & $\mathrm{H}_{2} \mathrm{O}$ & DPPH & $2.15 \mathrm{mmol} \mathrm{TEAC} / \mathrm{g}$ & Libya & [194] \\
\hline Matricaria chmomilla L. & Asteraceae & Flower & $\mathrm{MeOH}$ & $\mathrm{DPPH}$ & $\begin{array}{l}91.69 \% \text { at } 50 \mu \mathrm{g} / \\
\mathrm{mL}\end{array}$ & Sudan & [188] \\
\hline Matricaria recutita $\mathrm{L}$. & Asteraceae & Flower & $\mathrm{H}_{2} \mathrm{O}$ & DPPH/ABTS & $0.67 / 5.97 \%$ & Morocco & [206] \\
\hline Melia azedarach L. & Meliaceae & Leaf & $\mathrm{CHCl}_{3} / \mathrm{MeOH}$ & DPPH & $2 / 32$ at $50 \mu \mathrm{g} / \mathrm{mL}$ & Egypt & [42] \\
\hline Melilotus officinalis Pall. & Fabaceae & Aerial parts & $\mathrm{MeOH}$ & DPPH & $>100 \mu \mathrm{g} / \mathrm{mL}$ & Egypt & [192] \\
\hline Mentha pulegium L. & Lamiaceae & Leaf & $\mathrm{EtOH}$ & DPPH/ABTS & $42.7 / 30.2$ & Algeria & [219] \\
\hline Mentha pulegium L. & Lamiaceae & Leaf & EtOAc & DPPH & $1.7 \mu \mathrm{g} / \mathrm{mL}$ & Algeria & [220] \\
\hline Mentha rotundifolia Sole. & Lamiaceae & Leaf & $\mathrm{EtOH}$ & DPPH/ABTS & $71.3 / 40.4 \mu \mathrm{g} / \mathrm{mL}$ & Algeria & [219] \\
\hline Mentha spicata Crantz. & Lamiaceae & Leaf & $\mathrm{EtOH}$ & DPPH/ABTS & 16. $2 / 10.3 \mu \mathrm{g} / \mathrm{mL}$ & Algeria & [219] \\
\hline Moricandia nitens $\mathrm{L}$. & Cruciferae & Whole plant & $\mathrm{EtOH} / \mathrm{H}_{2} \mathrm{O}$ & $\mathrm{DPPH}$ & $\begin{array}{l}89 / 85 \% \text { at } 100 \mu \mathrm{g} / \\
\mathrm{mL}\end{array}$ & Egypt & [41] \\
\hline Moringa pterygosperma Gaertn. & Moringaceae & Leaf & $\mathrm{CHCl}_{3} / \mathrm{MeOH}$ & DPPH & $15 / 30$ at $50 \mu \mathrm{g} / \mathrm{mL}$ & Egypt & [42] \\
\hline Morus alba $\mathrm{L}$. & Moraceae & Leaf & $\mathrm{CHCl}_{3} / \mathrm{MeOH}$ & $\mathrm{DPPH}$ & $14 / 40$ at $50 \mu \mathrm{g} / \mathrm{mL}$ & Egypt & [42] \\
\hline $\begin{array}{l}\text { Myoporum pictum Banks \& Sol. } \\
\text { Ex G. Forst. }\end{array}$ & Myoporaceae & Leaf & $\mathrm{CHCl}_{3} / \mathrm{MeOH}$ & $\mathrm{DPPH}$ & $\begin{array}{l}42.7 / 26 \text { at } 50 \mu \mathrm{g} / \\
\mathrm{mL}\end{array}$ & Egypt & [42] \\
\hline Myrtus communis Blanco. & Myrtaceae & Leaf & $\mathrm{H}_{2} \mathrm{O}$ & $\mathrm{DPPH}$ & $\begin{array}{l}19.04 \mathrm{mmol} \text { TEAC/ } \\
\mathrm{g}\end{array}$ & Libya & [194] \\
\hline Myrtus Communis Blanco. & Myrtaceae & Leaf & $\mathrm{CHCl}_{3} / \mathrm{MeOH}$ & DPPH & $\begin{array}{l}26.6 / 90 \text { at } 50 \mu \mathrm{g} / \\
\mathrm{mL}\end{array}$ & Egypt & [42] \\
\hline Myrtus communis L. & Myrtaceae & Aerial parts & Oil & $\mathrm{DPPH}$ & $6018 \mu \mathrm{g} / \mathrm{mL}$ & Algeria & [221] \\
\hline Narcissus tazetta L. & Oleaceae & Leaf & $\mathrm{CHCl}_{3} / \mathrm{MeOH}$ & DPPH & $22 / 40$ at $50 \mu \mathrm{g} / \mathrm{mL}$ & Egypt & [42] \\
\hline Nephrlepis bostoniensis L. & Polypodiaceae & Leaf & $\mathrm{CHCl}_{3} / \mathrm{MeOH}$ & DPPH & $16 / 43$ at $50 \mu \mathrm{g} / \mathrm{mL}$ & Egypt & [42] \\
\hline Nerium oleander L. & Apocyanaceae & Leaf & $\mathrm{H}_{2} \mathrm{O}$ & $\mathrm{DPPH}$ & $3.15 \mathrm{mmol}$ TEAC/g & Libya & [194] \\
\hline Nerium oleander L. & Apocynaceae & Leaf & $\mathrm{CHCl}_{3} / \mathrm{MeOH}$ & $\mathrm{DPPH}$ & $19 / 31$ at $50 \mu \mathrm{g} / \mathrm{mL}$ & Egypt & [42] \\
\hline Nerium oleander L. & Apocynaceae & Leaf & $\mathrm{MeOH}$ & DPPH & $64.5 \mu \mathrm{g} / \mathrm{mL}$ & Egypt & [192] \\
\hline Nicotiana glauca L. & Solanaceae & Leaf & $\mathrm{EtOH} / \mathrm{MeOH} / \mathrm{H}_{2} \mathrm{O}$ & DPPH & $54 / 13 / 30 \mu \mathrm{g} / \mathrm{mL}$ & Sudan & [193] \\
\hline Nigella sativa $\mathrm{L}$. & Ranunculaceae & Not stated & $\mathrm{EtOH}$ & SORSA & $<50$ at $1 \mu \mathrm{g} / \mathrm{mL}$ & Sudan & [45] \\
\hline Nigella sativa $\mathrm{L}$. & Ranunculaceae & Seed & $\mathrm{EtOH}$ & $\mathrm{DPPH}$ & $60 \%$ & Sudan & [222] \\
\hline Nigella sativa $\mathrm{L}$. & Ranunculaceae & Seed & $\mathrm{MeOH}$ & DPPH & $>100 \mu \mathrm{g} / \mathrm{mL}$ & Egypt & [192] \\
\hline Nigella sativa L. & Ranunculaceae & Seed & Oil & DPPH & $85 \%$ & Sudan & [200] \\
\hline Ocimum basilicum L. & Lamiaceae & Bark & $\mathrm{EtOH}$ & SORSA & $66 \%$ at $1 \mu \mathrm{g} / \mathrm{mL}$ & Sudan & [45] \\
\hline Ocimum basilicum L. & Lamiaceae & Seed & $\mathrm{EtOH} / \mathrm{H}_{2} \mathrm{O}$ & $\mathrm{DPPH}$ & $\begin{array}{l}72 / 9.8 \% \text { at } 100 \mu \mathrm{g} / \\
\mathrm{mL}\end{array}$ & Egypt & [41] \\
\hline Ocimum basillcum L. & Lamiaceae & Leaf & $\begin{array}{l}\text { Cold } \mathrm{H}_{2} \mathrm{O} / \text { hot } \\
\mathrm{H}_{2} \mathrm{O} / \mathrm{MeOH}\end{array}$ & $\mathrm{DPPH}$ & $\begin{array}{l}0.21 / 53.0 / 0.19 \mathrm{mg} / \\
\mathrm{mL}\end{array}$ & Egypt & [202] \\
\hline $\begin{array}{l}\text { Olea europaea (Wall. Ex G. Don) } \\
\text { Cif. }\end{array}$ & Oleaceae & Whole plant & $\mathrm{EtOH} / \mathrm{H}_{2} \mathrm{O}$ & $\mathrm{DPPH}$ & $\begin{array}{l}50 / 81 \% \text { at } 100 \mu \mathrm{g} / \\
\mathrm{mL}\end{array}$ & Egypt & [41] \\
\hline $\begin{array}{l}\text { Olen europaea (Wall. Ex G. Don) } \\
\text { Cif. }\end{array}$ & Oleaceae & Leaf & $\mathrm{H}_{2} \mathrm{O}$ & $\mathrm{DPPH}$ & $8.08 \mathrm{mmol}$ TEAC/g & Libya & [194] \\
\hline Origanum glandulosum Salzm. & Lamiaceae & Aerial parts & $\mathrm{MeOH}$ & DPPH & $12.80 \mu \mathrm{g} / \mathrm{mL}$ & Algeria & [193] \\
\hline Origanum majorana L. & Lamiaceae & Leaf & $\mathrm{H}_{2} \mathrm{O}$ & $\mathrm{DPPH}$ & $\begin{array}{l}0.859 \mathrm{mmol} \text { TEAC/ } \\
\mathrm{g}\end{array}$ & Libya & [194] \\
\hline Origanum syriacum L. & Lamiaceae & Leaf & $\mathrm{EtOH}$ & DPPH/TBA & $55.7 / 25.39$ & Egypt & [190] \\
\hline Panax quinquefolius L. & Araliaceae & Seed & $\mathrm{EtOH} / \mathrm{H}_{2} \mathrm{O}$ & $\mathrm{DPPH}$ & $\begin{array}{l}11 / 56 \% \text { at } 100 \mu \mathrm{g} / \\
\mathrm{mL}\end{array}$ & Egypt & [41] \\
\hline Parkinsonia aculeata $\mathrm{L}$. & Loganiaceae & Leaf & $\mathrm{CHCl}_{3} / \mathrm{MeOH}$ & $\mathrm{DPPH}$ & $17 / 9$ at $50 \mu \mathrm{g} / \mathrm{mL}$ & Egypt & [42] \\
\hline
\end{tabular}


Table 2 Antioxidants activities of Northern Africa African plants (Continued)

\begin{tabular}{|c|c|c|c|c|c|c|c|}
\hline Peganum harmala L. & Zygophyllaceae & Not stated & $\mathrm{EtOH}$ & SORSA & $<50$ at $1 \mu \mathrm{g} / \mathrm{mL}$ & Sudan & [45] \\
\hline Peganum harmala L. & Zygophyllaceae & Seed & $\mathrm{MeOH}$ & $\mathrm{DPPH}$ & $>100 \mu \mathrm{g} / \mathrm{mL}$ & Egypt & [192] \\
\hline Peganum harmala L. & Zygophyllaceae & Seed & $\mathrm{MeOH}$ & $\mathrm{H}_{2} \mathrm{O}_{2}$ & $3.33 \mathrm{mg} / \mathrm{mL}$ & Algeria & {$[223]$} \\
\hline Peganum harmala L. & Zygophyllaceae & Seed & $\mathrm{MeOH} / \mathrm{H}_{2} \mathrm{O}$ & $\mathrm{DPPH}$ & $0.194 / 1.345 \mathrm{mg} / \mathrm{mL}$ & Algeria & [224] \\
\hline Pelargonium oderatissimum L. & Geraniaceae & Leaf & $\mathrm{CHCl}_{3} / \mathrm{MeOH}$ & DPPH & $9 / 89$ at $50 \mu \mathrm{g} / \mathrm{mL}$ & Egypt & [42] \\
\hline Pelargonium zonale L Her. & Geraniaceae & Leaf & $\mathrm{CHCl}_{3} / \mathrm{MeOH}$ & DPPH & $12 / 32$ at $50 \mu \mathrm{g} / \mathrm{mL}$ & Egypt & [42] \\
\hline Phagnalon rupestre Dc. & Compositae & Leaf & $\mathrm{H}_{2} \mathrm{O}$ & $\mathrm{DPPH}$ & $3.88 \mathrm{mmol}$ TEAC/g & Libya & [194] \\
\hline Phalangium variegate $\mathrm{L}$. & Liliaceae & Leaf & $\mathrm{CHCl}_{3} / \mathrm{MeOH}$ & DPPH & $3 / 17$ at $50 \mu \mathrm{g} / \mathrm{mL}$ & Egypt & [42] \\
\hline Phoenix dactylifera L. & Palmaceae & Whole plant & $\mathrm{EtOH} / \mathrm{H}_{2} \mathrm{O}$ & DPPH & $\begin{array}{l}83 / 77 \% \text { at } 100 \mu \mathrm{g} / \\
\mathrm{mL}\end{array}$ & Egypt & [41] \\
\hline Pinus halipensis Miller. & Pinaceae & Leaf & $\mathrm{MeOH}$ & $\mathrm{DPPH}$ & $115.50 \mu \mathrm{g} / \mathrm{mL}$ & Algeria & [193] \\
\hline Piper nigrum Wall. & Piperaceae & Seed & $\mathrm{MeOH}$ & DPPH & $>100 \mu \mathrm{g} / \mathrm{mL}$ & Egypt & [192] \\
\hline Pistacia atlantica Desf. & Anacardiaceae & Gall & Oil & $\begin{array}{l}\text { DPPH/ABTS/ } \\
\text { FRAP }\end{array}$ & $\begin{array}{l}417.61 / 495.6 / \\
0.115 \mu \mathrm{g} / \mathrm{mL}\end{array}$ & Algeria & [225] \\
\hline Pistacia lentiscus L. & Anacardiaceae & Leaf & $\mathrm{EtOAc}$ & $\mathrm{DPPH} / \mathrm{OH}$ & $6.8 / 8.2 \mu \mathrm{g} / \mathrm{mL}$ & Algeria & [226] \\
\hline Pistacia lentiscus L. & Anacardiaceae & Leaf & $\mathrm{MeOH}$ & $\mathrm{DPPH}$ & $4.30 \mu \mathrm{g} / \mathrm{mL}$ & Algeria & [193] \\
\hline Pithecellobium dulce Benth. & Fabaceae & Leaf & $\mathrm{CHCl}_{3} / \mathrm{MeOH}$ & DPPH & $11 / 23$ at $50 \mu \mathrm{g} / \mathrm{mL}$ & Egypt & {$[42]$} \\
\hline $\begin{array}{l}\text { Pittosporum tobira (Thunb.) W.T. } \\
\text { Alton. }\end{array}$ & Pittosporaceae & Leaf & $\mathrm{CHCl}_{3} / \mathrm{MeOH}$ & DPPH & $11 / 9$ at $50 \mu \mathrm{g} / \mathrm{mL}$ & Egypt & {$[42]$} \\
\hline $\begin{array}{l}\text { Pituranthos tortousus (Coss.) } \\
\text { Maire. }\end{array}$ & Apiaceae & Leaf & $\mathrm{H}_{2} \mathrm{O}$ & DPPH & $0.46 \mathrm{mmol} \mathrm{TEAC} / \mathrm{g}$ & Libya & [194] \\
\hline $\begin{array}{l}\text { Pituranthos tortusous (Coss.) } \\
\text { Maire. }\end{array}$ & Umbelliferae & Whole plant & $\mathrm{EtOH} / \mathrm{H}_{2} \mathrm{O}$ & DPPH & $\begin{array}{l}58 / 81 \% \text { at } 100 \mu \mathrm{g} / \\
\mathrm{mL}\end{array}$ & Egypt & [41] \\
\hline Plantago major Elliot. & Plantaginaceae & Aerial parts & $\mathrm{MeOH}$ & DPPH & $48.00 \mu \mathrm{g} / \mathrm{mL}$ & Algeria & [193] \\
\hline Plumeria alba L. & Apocynaceae & Leaf & $\mathrm{CHCl}_{3} / \mathrm{MeOH}$ & $\mathrm{DPPH}$ & $28 / 15$ at $50 \mu \mathrm{g} / \mathrm{mL}$ & Egypt & {$[42]$} \\
\hline Poinciana regia Bojer. & Caesalpiniaceae & Leaf & $\mathrm{CHCl}_{3} / \mathrm{MeOH}$ & DPPH & $15 / 15$ at $50 \mu \mathrm{g} / \mathrm{mL}$ & Egypt & {$[42]$} \\
\hline Polianthes tuberose L. & Agavaceae & Leaf & $\mathrm{CHCl}_{3} / \mathrm{MeOH}$ & $\mathrm{DPPH}$ & $8 / 12$ at $50 \mu \mathrm{g} / \mathrm{mL}$ & Egypt & {$[42]$} \\
\hline Populus tremula $\mathrm{L}$. & Salicaceae & Leaf & $\mathrm{MeOH}$ & DPPH & $88.70 \mu \mathrm{g} / \mathrm{mL}$ & Algeria & [193] \\
\hline Psidium guajava $\mathrm{L}$. & Myrtaceae & Leaf & $\mathrm{EtOH} / \mathrm{H}_{2} \mathrm{O}$ & DPPH & $\begin{array}{l}97 / 88 \% \text { at } 100 \mu \mathrm{g} / \\
\mathrm{mL}\end{array}$ & Egypt & [41] \\
\hline Punica granatum L. & Punicaceae & Leaf & $\mathrm{CHCl}_{3} / \mathrm{MeOH}$ & $\mathrm{DPPH}$ & $9 / 96$ at $50 \mu \mathrm{g} / \mathrm{mL}$ & Egypt & {$[42]$} \\
\hline Punica granatum L. & Punicaceaea & Fruit & $\mathrm{EtOH} / \mathrm{H}_{2} \mathrm{O}$ & $\mathrm{DPPH}$ & $\begin{array}{l}85 / 75 \% \text { at } 100 \mu \mathrm{g} / \\
\mathrm{mL}\end{array}$ & Egypt & [41] \\
\hline Quercus Coccifera L. & Fagaceae & Leaf & $\mathrm{MeOH}$ & $\mathrm{DPPH}$ & $18.65 \mu \mathrm{g} / \mathrm{mL}$ & Algeria & [198] \\
\hline Quercus robur L. & Fagaceae & Leaf & $\mathrm{H}_{2} \mathrm{O}$ & DPPH & 20.63 mmol TEAC/g & Libya & [194] \\
\hline Raphanus raphanistrum L. & Cruciferae & Leaf & $\mathrm{H}_{2} \mathrm{O}$ & DPPH & $0.47 \mathrm{mmol} \mathrm{TEAC} / \mathrm{g}$ & Libya & [194] \\
\hline $\begin{array}{l}\text { Retama raetam Webb \& } \\
\text { Berthel. }\end{array}$ & Leguminosae & Whole plant & $\mathrm{EtOH} / \mathrm{H}_{2} \mathrm{O}$ & $\mathrm{DPPH}$ & $\begin{array}{l}80 / 78 \% \text { at } 100 \mu \mathrm{g} / \\
\mathrm{mL}\end{array}$ & Egypt & [41] \\
\hline Retama raetem Webb \& Berthel. & Fabaceae & Leaf & $\mathrm{MeOH}$ & DPPH & $40 \mu \mathrm{g} / \mathrm{mL}$ & Libya & $\begin{array}{l}\text { Alghazeer } \\
\text { et al., } 2012\end{array}$ \\
\hline Rhamnus alaternus $\mathrm{L}$. & Rhamnaceae & Leaf & $\mathrm{MeOH}$ & DPPH & $54.16 \mu \mathrm{g} / \mathrm{mL}$ & Algeria & [193] \\
\hline Rhamnus alaternus L. & Rhamnaceae & Leaf & $\mathrm{MeOH}$ & $\mathrm{DPPH}$ & $40.7 \mu \mathrm{g} / \mathrm{mL}$ & Algeria & [198] \\
\hline Rheum palmaum & Polygonaceae & Stem & $\mathrm{MeOH}$ & DPPH & $14.2 \mu \mathrm{g} / \mathrm{mL}$ & Egypt & [192] \\
\hline Ricinus communis $\mathrm{L}$. & Euphorbiaceae & Leaf & $\mathrm{MeOH}$ & DPPH & $90.57 \%$ at $50 \mu \mathrm{g} / \mathrm{mL}$ & Sudan & [188] \\
\hline Ricinus communis $\mathrm{L}$. & Euphorbiaceae & Seed & Oil & $\mathrm{DPPH}$ & $51 \%$ & Sudan & {$[200]$} \\
\hline Rosa banksiae R. Br. & Rosaceae & Leaf & $\mathrm{CHCl}_{3} / \mathrm{MeOH}$ & $\mathrm{DPPH}$ & $25 / 42$ at $50 \mu \mathrm{g} / \mathrm{mL}$ & Egypt & [42] \\
\hline Rosmarinus officinalis $L$. & Lamiaceae & Leaf & $\mathrm{EtOH}$ & $\mathrm{DPPH}$ & + & Algeria & [227] \\
\hline Rosmarinus officinalis $\mathrm{L}$. & Lamiaceae & Leaf & $\mathrm{H}_{2} \mathrm{O}$ & DPPH & $0.51 \mathrm{mmol} \mathrm{TEAC} / \mathrm{g}$ & Libya & [194] \\
\hline
\end{tabular}


Table 2 Antioxidants activities of Northern Africa African plants (Continued)

\begin{tabular}{|c|c|c|c|c|c|c|c|}
\hline Rosmarinus officinalis $\mathrm{L}$. & Lamiaceae & Leaf & $\mathrm{CHCl}_{3} / \mathrm{MeOH}$ & DPPH & $28.6 / 31$ at $50 \mu \mathrm{g} / \mathrm{mL}$ & Egypt & [42] \\
\hline Rosmarinus officinalis $\mathrm{L}$. & Lamiaceae & Leaf & $\mathrm{EtOH}$ & $\mathrm{DPPH} / \mathrm{TBA}$ & $\begin{array}{l}69.73 / 70.6 \text { at } \\
100 \mu \mathrm{g} / \mathrm{mL}\end{array}$ & Egypt & [190] \\
\hline Rosmarinus officinalis $\mathrm{L}$. & Lamiaceae & Whole plant & $\mathrm{EtOH} / \mathrm{H}_{2} \mathrm{O}$ & DPPH & $\begin{array}{l}38 / 65 \% \text { at } 100 \mu \mathrm{g} / \\
\mathrm{mL}\end{array}$ & Egypt & [41] \\
\hline Rosmarinus officinalis L. & Lamiaceae & Aerial parts & $\mathrm{MeOH}$ & DPPH & $19.4 \mu \mathrm{g} / \mathrm{mL}$ & Egypt & [192] \\
\hline Rubus idaeus Thunb. & Rosaceae & Leaf & $\mathrm{EtOAC}$ & DPPH & $4.80 \mu \mathrm{g} / \mathrm{mL}$ & Algeria & [228] \\
\hline Ruscus hyphoglossum L. & Liliaceae & Leaf & $\mathrm{CHCl}_{3} / \mathrm{MeOH}$ & DPPH & $0 / 42$ at $50 \mu \mathrm{g} / \mathrm{mL}$ & Egypt & [42] \\
\hline Russelia juncea Zucc. & Scrophulariaceae & Leaf & $\mathrm{CHCl}_{3} / \mathrm{MeOH}$ & DPPH & $17 / 30$ at $50 \mu \mathrm{g} / \mathrm{mL}$ & Egypt & [42] \\
\hline Ruta graveolens L. & Rutaceae & Leaf & $\mathrm{H}_{2} \mathrm{O}$ & DPPH & 0.60 mmol TEAC/g & Libya & [194] \\
\hline Ruta graveolens $\mathrm{L}$. & Rutaceae & Leaf & $\mathrm{MeOH}$ & DPPH & $61 \mu \mathrm{g} / \mathrm{mL}$ & Egypt & [192] \\
\hline Salix alba Thunb. & Salicaceae & Cortex & $\mathrm{MeOH}$ & DPPH & $15.50 \mu \mathrm{g} / \mathrm{mL}$ & Algeria & [193] \\
\hline Salvia officinalis $\mathrm{L}$. & Lamiaceae & Leaf & $\mathrm{H}_{2} \mathrm{O}$ & DPPH & $0.81 \mathrm{mmol}$ TEAC/g & Libya & [194] \\
\hline Salvia officinalis $L$. & Lamiaceae & Leaf & $\mathrm{CHCl}_{3} / \mathrm{MeOH}$ & DPPH & $45 / 49$ at $50 \mu \mathrm{g} / \mathrm{mL}$ & Egypt & [42] \\
\hline Salvia officinalis $\mathrm{L}$. & Lamiaceae & Leaf & Oil & $\begin{array}{l}\text { DPPH, } \\
\text { ABTS } / \mathrm{H}_{2} \mathrm{O}_{2}\end{array}$ & - & Algeria & {$[217]$} \\
\hline Salvia triloba $\mathrm{L}$. & Lamiaceae & Aerial Parts & $\mathrm{MeOH}$ & DPPH & $20.7 \mu \mathrm{g} / \mathrm{mL}$ & Egypt & [192] \\
\hline Sanseviera guineenses Thunb. & Liliaceae & Leaf & $\mathrm{CHCl}_{3} / \mathrm{MeOH}$ & DPPH & $23.5 / 18$ at $50 \mu \mathrm{g} / \mathrm{mL}$ & Egypt & [42] \\
\hline Santolina chamaecyparissus L. & Asteraceae & Leaf & $\mathrm{H}_{2} \mathrm{O} / \mathrm{MeOH}$ & $\beta-C L A M$ & $\begin{array}{l}64 \% / 61 \% \text { at } 50 \mu \mathrm{g} / \\
\mathrm{mL}\end{array}$ & Algeria & [229] \\
\hline Santolina chamaecyparissus L. & Asteraceae & Leaf & $\mathrm{CHCl}_{3} / \mathrm{MeOH}$ & DPPH & $11 / 46$ at $50 \mu \mathrm{g} / \mathrm{mL}$ & Egypt & [42] \\
\hline Satureja thymbra L. & Lamiaceae & Leaf & Oil & $\mathrm{DPPH}$ & $0.0967 \mathrm{mg} / \mathrm{mL}$ & Libya & [230] \\
\hline Schefflera actinophylla Harms. & Araliaceae & Leaf & $\mathrm{CHCl}_{3} / \mathrm{MeOH}$ & DPPH & $3 / 94$ at $50 \mu \mathrm{g} / \mathrm{mL}$ & Egypt & [42] \\
\hline Schefflera arboricola Hayata. & Araliaceae & Leaf & $\mathrm{CHCl}_{3} / \mathrm{MeOH}$ & DPPH & $2 / 0$ at $50 \mu \mathrm{g} / \mathrm{mL}$ & Egypt & [42] \\
\hline Schinus terebentifolius Raddi. & Anacardiaceae & Leaf & $\mathrm{CHCl}_{3} / \mathrm{MeOH}$ & DPPH & $15 / 12$ at $50 \mu \mathrm{g} / \mathrm{mL}$ & Egypt & [42] \\
\hline Sciadophyllum pulchrima L. & Araliaceae & Leaf & $\mathrm{CHCl}_{3} / \mathrm{MeOH}$ & DPPH & $1.5 / 18$ at $50 \mu \mathrm{g} / \mathrm{mL}$ & Egypt & [42] \\
\hline Sesamum indicum $\mathrm{L}$. & Pedaliaceae & Seed & Oil & $\mathrm{DPPH}$ & $34 \%$ & Sudan & [200] \\
\hline Sesbania aegyptiaca Pers. & Fabaceae & Leaf & $\mathrm{CHCl}_{3} / \mathrm{MeOH}$ & DPPH & $17 / 43$ at $50 \mu \mathrm{g} / \mathrm{mL}$ & Egypt & [42] \\
\hline Solanum lycopersicum L. & Solanaceae & Bark & $\mathrm{EtOH} / \mathrm{H}_{2} \mathrm{O}$ & DPPH & $\begin{array}{l}82 / 82 \% \text { at } 100 \mu \mathrm{g} / \\
\mathrm{mL}\end{array}$ & Egypt & [41] \\
\hline Solanum nigrum L. & Solanaceae & Whole plant & $\mathrm{EtOH} / \mathrm{H}_{2} \mathrm{O}$ & DPPH & $\begin{array}{l}85 / 55 \% \text { at } 100 \mu \mathrm{g} / \\
\mathrm{mL}\end{array}$ & Egypt & [41] \\
\hline Solanum rantonnetii Carriere. & Solanaceae & Leaf & $\mathrm{MeOH}$ & DPPH/ABTS & $162 / 239 \mu \mathrm{g} / \mathrm{mL}$ & Egypt & [201] \\
\hline Solenostemma argel Hayne. & Apocyanaceae & Leaf & $\begin{array}{l}\text { Cold } \mathrm{H}_{2} \mathrm{O} / \text { hot } \\
\mathrm{H}_{2} \mathrm{O} / \mathrm{MeOH}\end{array}$ & DPPH & $\begin{array}{l}0.61 / 33.3 / 0.43 \mathrm{mg} / \\
\mathrm{mL}\end{array}$ & Egypt & [202] \\
\hline Sonchus oleraceus L. & Asteraceae & Leaf & $\mathrm{EtOH}$ & SORSA & 56 at $1 \mu \mathrm{g} / \mathrm{mL}$ & Sudan & [45] \\
\hline Spathodea tilotica P.Beauv. & Bignoniaceae & Leaf & $\mathrm{CHCl}_{3} / \mathrm{MeOH}$ & DPPH & $19 / 85$ at $50 \mu \mathrm{g} / \mathrm{mL}$ & Egypt & [42] \\
\hline Sterculia diversifolia L. & Sterculiaceae & Leaf & $\mathrm{CHCl}_{3} / \mathrm{MeOH}$ & $\mathrm{DPPH}$ & $14 / 88$ at $50 \mu \mathrm{g} / \mathrm{mL}$ & Egypt & [42] \\
\hline Strelitzia reginae Banks. & Streliziaceae & Leaf & $\mathrm{CHCl}_{3} / \mathrm{MeOH}$ & $\mathrm{DPPH}$ & $32 / 45$ at $50 \mu \mathrm{g} / \mathrm{mL}$ & Egypt & [42] \\
\hline Striga hermonthica Delile. & Orobanchaceae & Whole plant & $\mathrm{MeOH}$ & $\begin{array}{l}\text { RSA/lron } \\
\text { chelating }\end{array}$ & $29 / 23 \%$ & Sudan & [208] \\
\hline Sysimbrium officinalis (L.) Scop. & Brassicaceae & Flower & $\mathrm{MeOH}$ & $\mathrm{DPPH}$ & $145.0 \mu \mathrm{g} / \mathrm{mL}$ & Algeria & [193] \\
\hline $\begin{array}{l}\text { Syzgium aromaticum (L.) } \\
\text { Merrill \& Perry. }\end{array}$ & Myrtaceae & Leaf & $\mathrm{H}_{2} \mathrm{O}$ & DPPH & $20.49 \mathrm{mmol}$ TEAC/g & Libya & [194] \\
\hline $\begin{array}{l}\text { Syzygium aromaticum (L.) } \\
\text { Merrill \& Perry. }\end{array}$ & Myrtaceae & Pud & $\mathrm{MeOH}$ & $\mathrm{DPPH}$ & $15.9 \mu \mathrm{g} / \mathrm{mL}$ & Egypt & [192] \\
\hline $\begin{array}{l}\text { Tabernaemontana divaricata G. } \\
\text { Don. }\end{array}$ & Apocynaceae & Leaf & $\mathrm{CHCl}_{3} / \mathrm{MeOH}$ & $\mathrm{DPPH}$ & $40 / 44$ at $50 \mu \mathrm{g} / \mathrm{mL}$ & Egypt & [42] \\
\hline Tecoma capensis Lindl. & Bignoniaceae & Leaf & $\mathrm{CHCl}_{3} / \mathrm{MeOH}$ & DPPH & $0 / 55$ at $50 \mu \mathrm{g} / \mathrm{mL}$ & Egypt & [42] \\
\hline
\end{tabular}


Table 2 Antioxidants activities of Northern Africa African plants (Continued)

\begin{tabular}{|c|c|c|c|c|c|c|c|}
\hline Tecomaria capensis Thunb. & Bignoniaceae & Leaf & $\mathrm{CHCl}_{3} / \mathrm{MeOH}$ & DPPH & $9 / 90$ at $50 \mu \mathrm{g} / \mathrm{mL}$ & Egypt & {$[42]$} \\
\hline Tephrosia apollinea Klotzsch. & Papilionaceae & - & $\mathrm{EtOH}$ & SORSA & $<50$ at $1 \mu \mathrm{g} / \mathrm{mL}$ & Sudan & [45] \\
\hline Tephrosia apollinea Klotzsch. & Leguminosae & Aerial parts & $\begin{array}{l}\mathrm{n}-\mathrm{C}_{6} \mathrm{H}_{12} / \mathrm{EtOH} / \\
\mathrm{MeOH} / \mathrm{H}_{2} \mathrm{O}\end{array}$ & DPPH & $\begin{array}{l}>1000 / 120 / 48 / \\
2835 \mu \mathrm{g} / \mathrm{mL}\end{array}$ & Sudan & {$[45]$} \\
\hline Terminalia arjuna Roxb.ex DC. & Combretaceae & Leaf & $\mathrm{CHCl}_{3} / \mathrm{MeOH}$ & $\mathrm{DPPH}$ & $27 / 42$ at $50 \mu \mathrm{g} / \mathrm{mL}$ & Egypt & {$[42]$} \\
\hline Terminalia arjuna Roxb.ex DC. & Combretaceae & Fruit & $\mathrm{MeOH}$ & $\mathrm{DPPH}$ & $3.1 \mu \mathrm{g} / \mathrm{mL}$ & Egypt & [192] \\
\hline Terminalia chebula Retz. & Combretaceae & Fruit & $\mathrm{MeOH}$ & DPPH & $2.2 \mu \mathrm{g} / \mathrm{mL}$ & Egypt & [192] \\
\hline $\begin{array}{l}\text { Teucrium polium Decne. ex C. } \\
\text { Presl. }\end{array}$ & Lamiaceae & Aerial parts & $\mathrm{MeOH}$ & DPPH & $30.20 \mu \mathrm{g} / \mathrm{mL}$ & Algeria & [193] \\
\hline $\begin{array}{l}\text { Teucrium polium Decne. ex C. } \\
\text { Presl. }\end{array}$ & Lamiaceae & Aerial parts & $\mathrm{MeOH}$ & $\mathrm{DPPH}$ & $96.4 \mu \mathrm{g} / \mathrm{mL}$ & Egypt & [192] \\
\hline $\begin{array}{l}\text { Teucrium polium Decne.ex C. } \\
\text { Presl. }\end{array}$ & Lamiaceae & Leaf & $\mathrm{H}_{2} \mathrm{O}$ & $\mathrm{DPPH}$ & $0.22 \mathrm{mmol} \mathrm{TEAC} / \mathrm{g}$ & Libya & [194] \\
\hline Thapsia garganica L. & Apiaceae & $\begin{array}{l}\text { Root/Leaf/ } \\
\text { Flower }\end{array}$ & $\mathrm{MeOH}$ & DPPH & $\begin{array}{l}9.98 / 10.08 / \\
19.32 \mathrm{mg} / 100 \mathrm{~mL}\end{array}$ & Algeria & $\begin{array}{l}\text { Yasmine et al., } \\
2012\end{array}$ \\
\hline Thapsia garganica L. & Apiaceae & Leaf & $\mathrm{MeOH}$ & DPPH & $50 \mu \mathrm{g} / \mathrm{mL}$ & Libya & $\begin{array}{l}\text { Alghazeer et } \\
\text { al., } 2012\end{array}$ \\
\hline Thapsia garganica L. & Apiaceae & Leaf & $\mathrm{MeOH} / \mathrm{EtOH}$ & $\mathrm{DPPH}$ & $91.92 \% 79.60 \%$ & Algeria. & [231] \\
\hline Thevetia narifolia L. & Apocynaceae & Leaf & $\mathrm{CHCl}_{3} / \mathrm{MeOH}$ & DPPH & $26 / 29$ at $50 \mu \mathrm{g} / \mathrm{mL}$ & Egypt & {$[42]$} \\
\hline Thuja orientalis L. & Cupressaceae & Leaf & $\mathrm{CHCl}_{3} / \mathrm{MeOH}$ & DPPH & $0 / 71$ at $50 \mu \mathrm{g} / \mathrm{mL}$ & Egypt & {$[42]$} \\
\hline Thymelaea hirsute Mill. & Thymelaeaceae & Whole plant & $\mathrm{EtOH} / \mathrm{H}_{2} \mathrm{O}$ & DPPH & $\begin{array}{l}76 / 35 \% \text { at } 100 \mu \mathrm{g} / \\
\mathrm{mL}\end{array}$ & Egypt & [41] \\
\hline $\begin{array}{l}\text { Thymelaea microphylla Coss \& } \\
\text { Durieu. }\end{array}$ & Thymelaceae & Leaf & $\mathrm{EtOH}$ & DPPH & $77.86 \%$ & Algeria & [224] \\
\hline Thymus vulgaris M. Bieb. & Lamiaceae & Leaf & $\mathrm{H}_{2} \mathrm{O}$ & DPPH & $\begin{array}{l}0.949 \mathrm{mmol} \text { TEAC/ } \\
\mathrm{g}\end{array}$ & Libya & [194] \\
\hline Thymus vulgaris M. Bieb. & Lamiaceae & Leaf & $\mathrm{EtOH}$ & $\mathrm{DPPH} / \mathrm{TBA}$ & $\begin{array}{l}96.85 / 70.8 \text { at } \\
100 \mu \mathrm{g} / \mathrm{mL}\end{array}$ & Egypt & [190] \\
\hline Tinospora bakis Miers. & Menispermaceae & Leaf & $\mathrm{EtOH}$ & SORSA & $54 \%$ at $1 \mu \mathrm{g} / \mathrm{mL}$ & Sudan & [45] \\
\hline Tradescantea spp & Commelinaceae & Leaf & $\mathrm{CHCl}_{3} / \mathrm{MeOH}$ & $\mathrm{DPPH}$ & $44 / 0$ at $50 \mu \mathrm{g} / \mathrm{mL}$ & Egypt & {$[42]$} \\
\hline $\begin{array}{l}\text { Tradescantea zebrine (Schinz) } \\
\text { D.R. Hunt. }\end{array}$ & Commelinaceae & Leaf & $\mathrm{CHCl}_{3} / \mathrm{MeOH}$ & DPPH & $1 / 16$ at $50 \mu \mathrm{g} / \mathrm{mL}$ & Egypt & {$[42]$} \\
\hline $\begin{array}{l}\text { Trigonella foenum-graecum } \\
\text { Suter. }\end{array}$ & Fabaceae & Seed & $\mathrm{H}_{2} \mathrm{O}$ & $\mathrm{DPPH} / \mathrm{ABTS}$ & $9.23 / 13.27 \%$ & Morocco & {$[206]$} \\
\hline $\begin{array}{l}\text { Trigonella foenum-graecum } \\
\text { Suter. }\end{array}$ & Fabaceae & Seed & $\mathrm{MeOH}$ & DPPH & $\begin{array}{l}90.94 \% \text { at } 50 \mu \mathrm{g} / \\
\mathrm{mL}\end{array}$ & Sudan & [188] \\
\hline $\begin{array}{l}\text { Trigonella foenum-graecum } \\
\text { Suter. }\end{array}$ & Fabaceae & Seed & $\mathrm{MeOH}$ & DPPH & $37.32 \mu \mathrm{ML}$ & Sudan & [189] \\
\hline Ulmus campestris $\mathrm{L}$. & Ulmaceae & Leaf & $\mathrm{MeOH}$ & DPPH & $61.50 \mu \mathrm{g} / \mathrm{mL}$ & Algeria & [193] \\
\hline Urgininea maritima (L.) Stearn. & Liliaceae & Leaf & $\mathrm{H}_{2} \mathrm{O}$ & DPPH & $0.72 \mathrm{mmol} \mathrm{TEAC} / \mathrm{g}$ & Libya & [194] \\
\hline Urtica urens L. & Urticaceae & Leaf & $\mathrm{H}_{2} \mathrm{O}$ & DPPH & $0.36 \mathrm{mmol} \mathrm{TEAC} / \mathrm{g}$ & Libya & [194] \\
\hline Vernonia amygdalina Delile. & Asteraceae & - & $\mathrm{EtOH}$ & SORSA & $<50$ at $1 \mu \mathrm{g} / \mathrm{mL}$ & Sudan & [45] \\
\hline Vinca rossea (L.) G. Don. & Apocynaceae & Leaf & $\mathrm{CHCl}_{3} / \mathrm{MeOH}$ & DPPH & $9 / 48$ at $50 \mu \mathrm{g} / \mathrm{mL}$ & Egypt & {$[42]$} \\
\hline Vitex trifolia L. & Verbenaceae & Leaf & $\mathrm{CHCl}_{3} / \mathrm{MeOH}$ & $\mathrm{DPPH}$ & $22 / 89$ at $50 \mu \mathrm{g} / \mathrm{mL}$ & Egypt & {$[42]$} \\
\hline Vitis vinifera $\mathrm{L}$. & Vitaceae & Whole plant & $\mathrm{EtOH} / \mathrm{H}_{2} \mathrm{O}$ & DPPH & $\begin{array}{l}90 / 85 \% \text { at } 100 \mu \mathrm{g} / \\
\mathrm{mL}\end{array}$ & Egypt & [41] \\
\hline Xanthium brasilicum Vell. & Asteraceae & - & $\mathrm{EtOH}$ & SORSA & $<50$ at $1 \mu \mathrm{g} / \mathrm{mL}$ & Sudan & [45] \\
\hline Ximenia Americana L. & Olacaceae & - & $\mathrm{EtOH}$ & SORSA & $<50$ at $1 \mu \mathrm{g} / \mathrm{mL}$ & Sudan & {$[45]$} \\
\hline Yucca desmetiana Baker. & Agavaceae & Leaf & $\mathrm{CHCl}_{3} / \mathrm{MeOH}$ & DPPH & $3 / 6$ at $50 \mu \mathrm{g} / \mathrm{mL}$ & Egypt & {$[42]$} \\
\hline Zingiber officinale Roscoe. & Zingiberceae & Leaf & $\mathrm{H}_{2} \mathrm{O}$ & DPPH & $1.08 \mathrm{mmol}$ TEAC/g & Libya & [194] \\
\hline
\end{tabular}


Table 2 Antioxidants activities of Northern Africa African plants (Continued)

\begin{tabular}{|c|c|c|c|c|c|c|c|}
\hline Zingiber officinale Roscoe. & Zingiberaceae & Rhizome & $\mathrm{MeOH}$ & DPPH & $>100 \mu \mathrm{g} / \mathrm{mL}$ & Egypt & [192] \\
\hline Ziziphus spina-christi Georgi. & Rhamnaceae & Leaf & $\mathrm{MeOH}$ & DPPH & $91.13 \%$ at $50 \mu \mathrm{g} / \mathrm{mL}$ & Sudan & [188] \\
\hline Zygophulum simplex L. & Zygophyllaceae & Whole plant & $\mathrm{EtOH} / \mathrm{H}_{2} \mathrm{O}$ & DPPH & $\begin{array}{l}85 / 44 \% \text { at } 100 \mu \mathrm{g} / \\
\mathrm{mL}\end{array}$ & Egypt & [41] \\
\hline Zygophyllum album L. & Zygophyllaceae & Aerial parts & Oil & $\mathrm{DPPH}$ & $615 \mu \mathrm{g} / \mathrm{mL}$ & Algeria & [221] \\
\hline Zygophyllum album L. & Zygophyllaceae & Whole plant & $\mathrm{EtOH} / \mathrm{H}_{2} \mathrm{O}$ & $\mathrm{DPPH}$ & $\begin{array}{l}80 / 64 \% \text { at } 100 \mu \mathrm{g} / \\
\mathrm{mL}\end{array}$ & Egypt & [41] \\
\hline Zygophyllum coccineum L & Zygophyllaceae & Leaf & $\mathrm{n}-\mathrm{C}_{6} \mathrm{H}_{12}$ & DPPH & $10.80 \pm 0.3 \%$ & Egypt & [232] \\
\hline
\end{tabular}

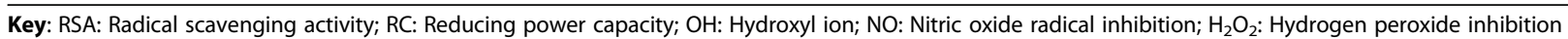
activity; LPO: Lipid peroxidation inhibition activity; $\mathrm{ABTS}^{+}$: 2,2'-azinobis-3-ethylbenzothiozolin-6-sulfonic acid cation decolourization test; ß-CLAMS: ß-Carotenelinoleic acid model system; SORSA: Superoxide anion radical scavenging activity (SORSA);MLP: Microsomal lipid peroxydation; FRAP: Fe ${ }^{2+}$ chelating ability and ferric reducing antioxidant properties; DPPH: 1,1-dipheyl-2-picry-hydrazyl; ORAC: Oxygen radical absorbance capacity; TEAC: Trolox equivalent antioxidant

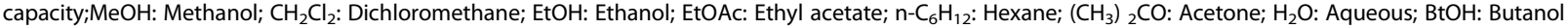

Northern Africa, 30.97\% from Western Africa, 17.98\% from Central Africa, 13.98\% from Southern Africa, and 5.72\% from Eastern Africa (Fig 2). Tables 1, 2, 3, 4, 5 and 6 gives a summary of the plant species that were tested, the family these plants belong to, the parts of the plants that were used to prepare the test samples, the solvent used for the extraction procedure and their potencies in different units depending on the protocol used. The plants that have been extensively studied with regard to these activities belonged to the following families; Fababceae (6.34\%), Asteraceae (6.34\%), Lamiaceae (5.13\%), Moraceae (4.30\%), Euphorbiaceae (2.41\%), Combretaceae (2.19\%), and Malvaceae (1.81\%) (Fig. 3). The structures of the compounds isolated from some of the plants with antioxidant activities are presented in (Fig. 4, Additional file 1). The plant parts that were tested for activities included the leaves, stems and stem bark, roots and root bark, pods, flowers and other aerial parts.

A number of procedures have been developed for assessment of in vitro antioxidant potencies of natural products. These protocols are based on two major chemical reactions including; hydrogen atom and electron transfer reactions. To determine the antioxidant potencies of the extracts and compounds using the hydrogen atom transfer mechanisms, one of the following parameters are measured; oxygen radical absorbance capacity (ORAC), total radical antioxidant power (TRAP) and beta carotene bleaching potential. The second category involves electron transfer reactions that measures the following parameters; ferric reducing antioxidant power (FRAP), diphenyl-2-picryl-hydrazyl radical scavenging assay (DPPH), trolox equivalent antioxidant capacity (TEAC), hydroxyl radical scavenging assay, superoxide anion radical scavenging assay, nitric oxide radical scavenging assay and total phenol assay [28]. Despite the recent popularity in antioxidant research, lack of standardized assays to compare research results from different research groups has been a major challenge [29].
The antioxidant potencies of natural products reviewed in this study were categorized based on the degree of inhibitions of free radicals when tested using one or more of the procedures discussed above. In order to increase the reliability of the antioxidant results more than one protocols were used. However, in accordance with the criteria for evaluation of in vitro antioxidant activities of natural products [23, 30,31], in this report we propose the following cutoff points;

(1)Extracts and compounds are considered to have high or significant capacity $\left(\mathrm{IC}_{50}<10 \mu \mathrm{g} / \mathrm{mL}\right.$ for extract and $\mathrm{IC}_{50}<1 \mu \mathrm{g} / \mathrm{mL}$ for compounds), promising activity $\left(\mathrm{IC}_{50}=10-50 \mu \mathrm{g} / \mathrm{mL}\right.$ for extract and $\mathrm{IC}_{50}=5-10 \mu \mathrm{g} / \mathrm{mL}$ for compounds), moderate activity $\left(\mathrm{IC}_{50}=50-100 \mu \mathrm{g} / \mathrm{mL}\right.$ for extract and $\mathrm{IC}_{50}=5-10 \mu \mathrm{g} / \mathrm{mL}$ for compounds), while sample with $\mathrm{IC}_{50}>100 \mu \mathrm{g} / \mathrm{mL}$ for extract and $>10 \mu \mathrm{g} / \mathrm{mL}$ for compounds were considered to have low antioxidant capacity.

(2) Antioxidants activities of plant extracts are considered to be very high when FRAP was $>20 \mathrm{mM} / \mathrm{L}$, high when FRAP was $10-20 \mathrm{mM} / \mathrm{L}$, good when FRAP was 5-10 mM/L, low when FRAP was $1-5 \mathrm{mM} / \mathrm{L}$ and very low when FRAP was below $1 \mathrm{mM} / \mathrm{L}$.

(3) When dealing with radical scavenging activity at a constant concentrat ion. Plant extracts were considered to exhibit low, medium, high and significant activities when their \% RSA at $50 \mathrm{mg} / \mathrm{mL}$ were observed to be $<25 \%, 25-50 \%, 50-80 \%$ and $>$ $80 \%$, respectively.

(4) When dealing with DPPH radical scavenging activities on the basis of degree of color changes extracts are considered to have high or significant capacity when showed strong intensity of yellow coloration, moderate when showed moderate intensity of yellow colouration, and low capacity when showed moderate intensity of yellow colouration 
Table 3 Antioxidants activities of Southern AfricaAfrican plants

\begin{tabular}{|c|c|c|c|c|c|c|c|}
\hline Plants & Family & $\begin{array}{l}\text { Part } \\
\text { used }\end{array}$ & Solvents & $\begin{array}{l}\text { Assay } \\
\text { Methods }\end{array}$ & Inhibition/EC 50 & $\begin{array}{l}\text { Country } \\
\text { of origine }\end{array}$ & References \\
\hline Acacia galpinii Butt Davy. & Fabaceae & Bark & $\mathrm{EtOH}$ & DPPH & $16.05 \mu \mathrm{g} / \mathrm{mL}$ & $\begin{array}{l}\text { South } \\
\text { Africa }\end{array}$ & {$[46]$} \\
\hline $\begin{array}{l}\text { Acokanthera oppositifolia } \\
\text { Lan. }\end{array}$ & Apocynaceae & Stem & $\mathrm{MeOH}$ & ABTS/DPPH & $\begin{array}{l}99.0 \% \text { at } 0.08 \mathrm{mg} / \mathrm{mL} \\
\text { and } 70 \% \text { at } 1 \mathrm{mg} / \mathrm{mL}\end{array}$ & $\begin{array}{l}\text { South } \\
\text { Africa }\end{array}$ & [233] \\
\hline Adenia gummifera Harms. & Passifloraceae & Root & EtOAc & AChE & $0.0189 \mathrm{mg} / \mathrm{mL}$ & $\begin{array}{l}\text { South } \\
\text { Africa }\end{array}$ & [234] \\
\hline Adenia gummifera Harms. & Passifloraceae & Stem & $\mathrm{MeOH}$ & ABTS/DPPH & $\begin{array}{l}94.2 \text { at } 0.08 \mathrm{mg} / \mathrm{mL} \\
\text { and } 60 \% \text { at } 1 \mathrm{mg} / \mathrm{mL}\end{array}$ & $\begin{array}{l}\text { South } \\
\text { Africa }\end{array}$ & [233] \\
\hline Aloe arborescens Mill. & Xanthorrhoeaceae & Leaf & $\mathrm{EtOH}$ & $\mathrm{DPPH}$ & - & $\begin{array}{l}\text { South } \\
\text { Africa }\end{array}$ & {$[46]$} \\
\hline Aloe barbadensis Mill. & Xanthorrhoeaceae & Leaf & $\mathrm{EtOH}$ & DPPH & - & $\begin{array}{l}\text { South } \\
\text { Africa }\end{array}$ & {$[46]$} \\
\hline Aloe ferox Mill. & Xanthorrhoeaceae & Leaf & $\mathrm{EtOH}$ & $\mathrm{DPPH}$ & - & $\begin{array}{l}\text { South } \\
\text { Africa }\end{array}$ & {$[46]$} \\
\hline Aloe ferox Mill. & Asphodelaceae & Leaf & $\begin{array}{l}\mathrm{EtOH} / \\
\left(\mathrm{CH}_{3}\right)_{2} \mathrm{CO} / \\
\mathrm{MeOH} / \mathrm{H}_{2} \mathrm{O}\end{array}$ & DPPH & $\begin{array}{l}0.086 / 0.288 / 0.288 / \\
0.517 \mathrm{mg} / \mathrm{mL}\end{array}$ & $\begin{array}{l}\text { South } \\
\text { Africa }\end{array}$ & {$[235]$} \\
\hline Bauhinia bowkeri Harv. & Fabaceae & Leaf & $\mathrm{n}-\mathrm{C}_{6} \mathrm{H}_{12} / \mathrm{CH}_{2} \mathrm{Cl}_{2}$ & DPPH. & $11.147 / 5.21 \mu \mathrm{g} / \mathrm{mL}$ & $\begin{array}{l}\text { South } \\
\text { Africa }\end{array}$ & {$[236]$} \\
\hline Bauhinia galpinii N. E. Br. & Fabaceae & Leaf & $\mathrm{n}-\mathrm{C}_{6} \mathrm{H}_{12} / \mathrm{CH}_{2} \mathrm{Cl}_{2}$ & $\mathrm{DPPH}$ & 79.58/9.92 $\mu \mathrm{g} / \mathrm{mL}$ & $\begin{array}{l}\text { South } \\
\text { Africa }\end{array}$ & {$[236]$} \\
\hline Bauhinia petersiana Bolle. & Fabaceae & Leaf & $\mathrm{n}-\mathrm{C}_{6} \mathrm{H}_{12} / \mathrm{CH}_{2} \mathrm{Cl}_{2}$ & $\mathrm{DPPH}$ & $47.45 / 8.18 \mu \mathrm{g} / \mathrm{mL}$ & $\begin{array}{l}\text { South } \\
\text { Africa }\end{array}$ & {$[236]$} \\
\hline Bauhinia variegata Linn. & Fabaceae & Leaf & $\mathrm{n}-\mathrm{C}_{6} \mathrm{H}_{12} / \mathrm{CH}_{2} \mathrm{Cl}_{2}$ & $\mathrm{DPPH}$ & $97.02 / 8.40 \mu \mathrm{g} / \mathrm{mL}$ & $\begin{array}{l}\text { South } \\
\text { Africa }\end{array}$ & {$[236]$} \\
\hline $\begin{array}{l}\text { Heteromorpha trifoliate } \\
\text { (Spreng.) Cham \& Schltdl. }\end{array}$ & Apiaceae & Leaf & $\mathrm{CO}\left(\mathrm{CH}_{3}\right)_{2}$ & DPPH & $4.35 \mathrm{mg} / \mathrm{mL}$ & $\begin{array}{l}\text { South } \\
\text { Africa }\end{array}$ & [237] \\
\hline Indigofera frutescens $\mathrm{L}$. & Papilionaceae & Leaf & $\mathrm{CO}\left(\mathrm{CH}_{3}\right)_{2}$ & $\mathrm{DPPH}$ & $0 \mathrm{mg} / \mathrm{mL}$ & $\begin{array}{l}\text { South } \\
\text { Africa }\end{array}$ & [237] \\
\hline $\begin{array}{l}\text { Zanthoxylum capense } \\
\text { (Thunb) Harv. }\end{array}$ & Rutaceae & Leaf & $\mathrm{CO}\left(\mathrm{CH}_{3}\right)_{2}$ & $\mathrm{DPPH}$ & $4.0 \mathrm{mg} / \mathrm{mL}$ & $\begin{array}{l}\text { South } \\
\text { Africa }\end{array}$ & [237] \\
\hline $\begin{array}{l}\text { Milletia grandis (E.Mey.) } \\
\text { Skeels. }\end{array}$ & Papilionaceae & Leaf & $\mathrm{CO}\left(\mathrm{CH}_{3}\right)_{2}$ & DPPH & $4.6 \mathrm{mg} / \mathrm{mL}$ & $\begin{array}{l}\text { South } \\
\text { Africa }\end{array}$ & [237] \\
\hline Brachylaena discolor DC. & Asteraceae & Leaf & $\mathrm{CO}\left(\mathrm{CH}_{3}\right)_{2}$ & DPPH & $2.6 \mathrm{mg} / \mathrm{mL}$ & $\begin{array}{l}\text { South } \\
\text { Africa }\end{array}$ & [237] \\
\hline $\begin{array}{l}\text { Clerodendrum glabrum E. } \\
\text { Mey. }\end{array}$ & Lamiaceae & Leaf & $\mathrm{CO}\left(\mathrm{CH}_{3}\right)_{2}$ & DPPH & $3.5 \mathrm{mg} / \mathrm{mL}$ & $\begin{array}{l}\text { South } \\
\text { Africa }\end{array}$ & [237] \\
\hline Strychnos mitis S. Moore. & Strychnaceae & Leaf & $\mathrm{CO}\left(\mathrm{CH}_{3}\right)_{2}$ & DPPH & $3.5 \mathrm{mg} / \mathrm{mL}$ & $\begin{array}{l}\text { South } \\
\text { Africa }\end{array}$ & [237] \\
\hline Cyathea dregei Kunze. & Cyatheaceae & Leaf & $\mathrm{CO}\left(\mathrm{CH}_{3}\right)_{2}$ & $\mathrm{DPPH}$ & $3.0 \mathrm{mg} / \mathrm{mL}$ & $\begin{array}{l}\text { South } \\
\text { Africa }\end{array}$ & [237] \\
\hline $\begin{array}{l}\text { Apodytes dimidiate E. Mey. } \\
\text { ex Arn. }\end{array}$ & Icacinaceae & Leaf & $\mathrm{CO}\left(\mathrm{CH}_{3}\right)_{2}$ & $\mathrm{DPPH}$ & $3.5 \mathrm{mg} / \mathrm{mL}$ & $\begin{array}{l}\text { South } \\
\text { Africa }\end{array}$ & [237] \\
\hline Melia azedarach L. & Meliaceae & Leaf & $\mathrm{CO}\left(\mathrm{CH}_{3}\right)_{2}$ & DPPH & $3.3 \mathrm{mg} / \mathrm{mL}$ & $\begin{array}{l}\text { South } \\
\text { Africa }\end{array}$ & [237] \\
\hline $\begin{array}{l}\text { Clausena anisata (Wild.) } \\
\text { Hook.f. ex Benth. }\end{array}$ & Rutaceae & Leaf & $\mathrm{CO}\left(\mathrm{CH}_{3}\right)_{2}$ & DPPH & $2.5 \mathrm{mg} / \mathrm{mL}$ & $\begin{array}{l}\text { South } \\
\text { Africa }\end{array}$ & {$[237]$} \\
\hline Maesa lanceolata Forssk. & Maesaceae & Leaf & $\mathrm{CO}\left(\mathrm{CH}_{3}\right)_{2}$ & $\mathrm{DPPH}$ & $1.4 \mathrm{mg} / \mathrm{mL}$ & $\begin{array}{l}\text { South } \\
\text { Africa }\end{array}$ & [237] \\
\hline $\begin{array}{l}\text { Leucosidea sericea Eckl. \& } \\
\text { Zeyh. }\end{array}$ & Rosaceae & Leaf & $\mathrm{CO}\left(\mathrm{CH}_{3}\right)_{2}$ & $\mathrm{DPPH}$ & $0.0 \mathrm{mg} / \mathrm{mL}$ & $\begin{array}{l}\text { South } \\
\text { Africa }\end{array}$ & [237] \\
\hline Viscum album L. & Viscaceae & Leaf & $\mathrm{MeOH}$ & $\mathrm{Fe}^{+}$ & $10 \mathrm{mg} / \mathrm{mL}$ & Nigeria & [238] \\
\hline Ficus capreifolia Delile. & Moraceae & Leaf & $\mathrm{CO}\left(\mathrm{CH}_{3}\right)_{2}$ & ABTS & 0.34 TEAC & $\begin{array}{l}\text { South } \\
\text { Africa }\end{array}$ & [239] \\
\hline
\end{tabular}


Table 3 Antioxidants activities of Southern AfricaAfrican plants (Continued)

\begin{tabular}{|c|c|c|c|c|c|c|c|}
\hline Ficus cordata Thunb. & Moraceae & Leaf & $\mathrm{CO}\left(\mathrm{CH}_{3}\right)_{2}$ & ABTS & 0.27 TEAC & $\begin{array}{l}\text { South } \\
\text { Africa }\end{array}$ & [239] \\
\hline $\begin{array}{l}\text { Ficus craterostoma Mildbr. } \\
\& \text { Burret. }\end{array}$ & Moraceae & Leaf & $\mathrm{CO}\left(\mathrm{CH}_{3}\right)_{2}$ & ABTS & 0.66 TEAC & $\begin{array}{l}\text { South } \\
\text { Africa }\end{array}$ & [239] \\
\hline Ficus glumosa Delile & Moraceae & Leaf & $\mathrm{CO}\left(\mathrm{CH}_{3}\right)_{2}$ & ABTS & 1.29 TEAC & $\begin{array}{l}\text { South } \\
\text { Africa }\end{array}$ & [239] \\
\hline Ficus lutea Vahl. & Moraceae & Leaf & $\mathrm{CO}\left(\mathrm{CH}_{3}\right)_{2}$ & ABTS & 4.80 TEAC & $\begin{array}{l}\text { South } \\
\text { Africa }\end{array}$ & [239] \\
\hline Ficus natalensis Hochst. & Moraceae & Leaf & $\mathrm{CO}\left(\mathrm{CH}_{3}\right)_{2}$ & ABTS & 0.69 TEAC & $\begin{array}{l}\text { South } \\
\text { Africa }\end{array}$ & [239] \\
\hline Ficus polita Vahl. & Moraceae & Leaf & $\mathrm{CO}\left(\mathrm{CH}_{3}\right)_{2}$ & ABTS & 0.31 TEAC & $\begin{array}{l}\text { South } \\
\text { Africa }\end{array}$ & [239] \\
\hline Ficus religiosa L. & Moraceae & Leaf & $\mathrm{CO}\left(\mathrm{CH}_{3}\right)_{2}$ & ABTS & 0.59 TEAC & $\begin{array}{l}\text { South } \\
\text { Africa }\end{array}$ & [239] \\
\hline Ficus sycomorus L. & Moraceae & Leaf & $\mathrm{CO}\left(\mathrm{CH}_{3}\right)_{2}$ & ABTS & 1.91 TEAC & $\begin{array}{l}\text { South } \\
\text { Africa }\end{array}$ & [239] \\
\hline Ficus thonningii Blume & Moraceae & Leaf & $\mathrm{CO}\left(\mathrm{CH}_{3}\right)_{2}$ & ABTS & 0.77 TEAC & $\begin{array}{l}\text { South } \\
\text { Africa }\end{array}$ & [239] \\
\hline $\begin{array}{l}\text { Peltophorum africanum } \\
\text { Sond. }\end{array}$ & Fabaceae & Leaf & $\mathrm{CO}\left(\mathrm{CH}_{3}\right)_{2}$ & $\mathrm{DPPH}$ & $4.67 \mu \mathrm{g} / \mathrm{mL}$ & $\begin{array}{l}\text { South } \\
\text { Africa }\end{array}$ & [240] \\
\hline $\begin{array}{l}\text { Zanthoxylum capense } \\
\text { (Thunb.) Harv. }\end{array}$ & Rutaceae & Leaf & $\mathrm{CO}\left(\mathrm{CH}_{3}\right)_{2}$ & $\mathrm{DPPH}$ & $138.78 \mu \mathrm{g} / \mathrm{mL}$ & $\begin{array}{l}\text { South } \\
\text { Africa }\end{array}$ & [240] \\
\hline $\begin{array}{l}\text { Clausena anisata (Wild.) } \\
\text { Hook.f. ex Benth. }\end{array}$ & Rutaceae & Leaf & $\mathrm{CO}\left(\mathrm{CH}_{3}\right)_{2}$ & $\mathrm{DPPH}$ & $119.36 \mu \mathrm{g} / \mathrm{mL}$ & $\begin{array}{l}\text { South } \\
\text { Africa }\end{array}$ & [240] \\
\hline $\begin{array}{l}\text { Sutherlandia frutescens (L.) } \\
\text { R. Br. }\end{array}$ & Fabaceae & Leaf & $\mathrm{EtOH}$ & $\mathrm{DPPH}$ & +++ & $\begin{array}{l}\text { South } \\
\text { Africa }\end{array}$ & [241] \\
\hline Senna italic Mill. & Fabaceae & Root & $\mathrm{MeOH}$ & $\mathrm{DPPH}$ & ++ & $\begin{array}{l}\text { South } \\
\text { Africa }\end{array}$ & [242] \\
\hline Combretum vendee & Combretecacea & Leaf & $\mathrm{MeOH}$ & DPPH & + & $\begin{array}{l}\text { South } \\
\text { Africa }\end{array}$ & [243] \\
\hline $\begin{array}{l}\text { Rhoicissus tridentate } \\
\text { Wild \& Drum }\end{array}$ & Vitaceae & Leaf & $\mathrm{CO}\left(\mathrm{CH}_{3}\right)_{2}$ & $\mathrm{DPPH}$ & 2.5 TEAC & $\begin{array}{l}\text { South } \\
\text { Africa }\end{array}$ & [244] \\
\hline $\begin{array}{l}\text { Baphia racemosa } \\
\text { (Hochst) Baker. }\end{array}$ & Fabaceae & Leaf & $\mathrm{CO}\left(\mathrm{CH}_{3}\right)_{2}$ & DPPH/ABTS & $210.69 / 195.10 \mu \mathrm{g} / \mathrm{mL}$ & $\begin{array}{l}\text { South } \\
\text { Africa }\end{array}$ & [245] \\
\hline Crotalaria capensis Jacq. & Fabaceae & Leaf & $\mathrm{CO}\left(\mathrm{CH}_{3}\right)_{2}$ & DPPH/ABTS & $195.26 / 207.09 \mu \mathrm{g} / \mathrm{mL}$ & $\begin{array}{l}\text { South } \\
\text { Africa }\end{array}$ & [245] \\
\hline Erythrina caffra Thunb. & Fabaceae & Leaf & $\mathrm{CO}\left(\mathrm{CH}_{3}\right)_{2}$ & DPPH/ABTS & 268.6/173.28 $\mu \mathrm{g} / \mathrm{mL}$ & $\begin{array}{l}\text { South } \\
\text { Africa }\end{array}$ & [245] \\
\hline $\begin{array}{l}\text { Lonchocarpus nelsii } \\
\text { (Schinz) Heering \& } \\
\text { Grimme. }\end{array}$ & Fabaceae & Leaf & $\mathrm{CO}\left(\mathrm{CH}_{3}\right)_{2}$ & DPPH/ABTS & $247.70 / 134.64 \mu \mathrm{g} / \mathrm{mL}$ & $\begin{array}{l}\text { South } \\
\text { Africa }\end{array}$ & [245] \\
\hline $\begin{array}{l}\text { Virgilia divaricata } \\
\text { Adamson. }\end{array}$ & Fabaceae & Leaf & $\mathrm{CO}\left(\mathrm{CH}_{3}\right)_{2}$ & DPPH/ABTS & $271.58 / 150.57 \mu \mathrm{g} / \mathrm{mL}$ & $\begin{array}{l}\text { South } \\
\text { Africa }\end{array}$ & [245] \\
\hline Indigofera cylindrical L. & Fabaceae & Leaf & $\mathrm{CO}\left(\mathrm{CH}_{3}\right)_{2}$ & DPPH/ABTS & $22.31 / 41.39 \mu \mathrm{g} / \mathrm{mL}$ & $\begin{array}{l}\text { South } \\
\text { Africa }\end{array}$ & [245] \\
\hline Xylia torreana Brenan. & Fabaceae & Leaf & $\mathrm{CO}\left(\mathrm{CH}_{3}\right)_{2}$ & DPPH/ABTS & $16.90 / 14.56 \mu \mathrm{g} / \mathrm{mL}$ & $\begin{array}{l}\text { South } \\
\text { Africa }\end{array}$ & [245] \\
\hline $\begin{array}{l}\text { Podalyria calyptrata } \\
\text { (Retz.) Willd. }\end{array}$ & Fabaceae & Leaf & $\mathrm{CO}\left(\mathrm{CH}_{3}\right)_{2}$ & DPPH/ABTS & $35.21 / 36.66 \mu \mathrm{g} / \mathrm{mL}$ & $\begin{array}{l}\text { South } \\
\text { Africa }\end{array}$ & [245] \\
\hline Dalbergia nitidula Baker. & Fabaceae & Leaf & $\mathrm{CO}\left(\mathrm{CH}_{3}\right)_{2}$ & DPPH/ABTS & $9.31 / 21.30 \mu \mathrm{g} / \mathrm{mL}$ & $\begin{array}{l}\text { South } \\
\text { Africa }\end{array}$ & [245] \\
\hline $\begin{array}{l}\text { Maytenus peduncularis } \\
\text { (Sond) Loes. }\end{array}$ & Celastraceae & Leaf & $\begin{array}{l}\mathrm{CO}\left(\mathrm{CH}_{3}\right)_{2} ; \mathrm{n}- \\
\mathrm{C}_{6} \mathrm{H}_{12}\end{array}$ & $\begin{array}{l}\text { DPPH/ } \\
\text { ABTS/OH }\end{array}$ & 1.88/8.65/23.92 $\mathrm{gg} / \mathrm{mL}$ & $\begin{array}{l}\text { South } \\
\text { Africa }\end{array}$ & [246] \\
\hline $\begin{array}{l}\text { Maytenus procumbens (L.f.) } \\
\text { Loes. }\end{array}$ & Celastraceae & Leaf & $\begin{array}{l}\mathrm{CO}\left(\mathrm{CH}_{3}\right)_{2} ; \mathrm{n}- \\
\mathrm{C}_{6} \mathrm{H}_{12}\end{array}$ & $\begin{array}{l}\text { DPPH/ } \\
\text { ABTS/OH }\end{array}$ & $3.56 / 4.03 / 107.69 \mu \mathrm{g} / \mathrm{mL}$ & $\begin{array}{l}\text { South } \\
\text { Africa }\end{array}$ & [246] \\
\hline
\end{tabular}


Table 3 Antioxidants activities of Southern AfricaAfrican plants (Continued)

\begin{tabular}{|c|c|c|c|c|c|c|c|}
\hline $\begin{array}{l}\text { Maytenus senegalensis } \\
\text { (Lam.) Exell. }\end{array}$ & Celastraceae & Leaf & $\begin{array}{l}\mathrm{CO}\left(\mathrm{CH}_{3}\right)_{2} ; \mathrm{n}- \\
\mathrm{C}_{6} \mathrm{H}_{12}\end{array}$ & $\begin{array}{l}\text { DPPH/ } \\
\mathrm{ABTS} / \mathrm{OH}\end{array}$ & $6.71 / 5.34 / 146.30 \mu \mathrm{g} / \mathrm{mL}$ & $\begin{array}{l}\text { South } \\
\text { Africa }\end{array}$ & [246] \\
\hline Maytenus undata (Thunb) & Celastraceae & Leaf & $\begin{array}{l}\mathrm{CO}\left(\mathrm{CH}_{3}\right)_{2} ; \mathrm{n}- \\
\mathrm{C}_{6} \mathrm{H}_{12}\end{array}$ & $\begin{array}{l}\text { DPPH/ } \\
\mathrm{ABTS} / \mathrm{OH}\end{array}$ & $3.89 / 7.89 / 80.68 \mu \mathrm{g} / \mathrm{mL}$ & $\begin{array}{l}\text { South } \\
\text { Africa }\end{array}$ & [246] \\
\hline Eriosema robustum Baker. & Fabaceae & Twig & $\mathrm{EtOH}$ & $\mathrm{DPPH}$ & $1.84 \mathrm{mg} / \mathrm{mL}$ & $\begin{array}{l}\text { South } \\
\text { Africa }\end{array}$ & [247] \\
\hline Mormodica balsamina L. & Cucurbitaleae & $\begin{array}{l}\text { Aerial } \\
\text { parts }\end{array}$ & $\mathrm{CO}\left(\mathrm{CH}_{3}\right)_{2}$ & $\mathrm{DPPH}$ & $200 \mu \mathrm{g} / \mathrm{mL}$ & $\begin{array}{l}\text { South } \\
\text { Africa }\end{array}$ & [248] \\
\hline Senna italica Mill. & Fabaceae & $\begin{array}{l}\text { Aerial } \\
\text { parts }\end{array}$ & $\mathrm{CO}\left(\mathrm{CH}_{3}\right)_{2}$ & DPPH & $120 \mu \mathrm{g} / \mathrm{mL}$ & $\begin{array}{l}\text { South } \\
\text { Africa }\end{array}$ & [248] \\
\hline Cassia abbreviata Oliv. & Fabaceae & $\begin{array}{l}\text { Stem } \\
\text { bark }\end{array}$ & $\mathrm{CO}\left(\mathrm{CH}_{3}\right)_{2}$ & $\mathrm{DPPH}$ & $<7.8 \mu \mathrm{g} / \mathrm{mL}$ & $\begin{array}{l}\text { South } \\
\text { Africa }\end{array}$ & [248] \\
\hline Waltheria indica $L$. & Malvaceae & $\begin{array}{l}\text { Aerial } \\
\text { parts }\end{array}$ & $\mathrm{CO}\left(\mathrm{CH}_{3}\right)_{2}$ & $\mathrm{DPPH}$ & $80 \mu \mathrm{g} / \mathrm{mL}$ & $\begin{array}{l}\text { South } \\
\text { Africa }\end{array}$ & [248] \\
\hline $\begin{array}{l}\text { Tinospora fragosa (I. Verd.) } \\
\text { I. Verd \& Troupin }\end{array}$ & Menispermaceae & $\begin{array}{l}\text { Aerial } \\
\text { parts }\end{array}$ & $\mathrm{CO}\left(\mathrm{CH}_{3}\right)_{2}$ & $\mathrm{DPPH}$ & $430 \mu \mathrm{g} / \mathrm{mL}$ & $\begin{array}{l}\text { South } \\
\text { Africa }\end{array}$ & [248] \\
\hline $\begin{array}{l}\text { Gymnospora buxifolia (Eckl. } \\
\text { \& Zeyl.) Loes. }\end{array}$ & Celastraceae & $\begin{array}{l}\text { Aerial } \\
\text { parts }\end{array}$ & $\mathrm{CO}\left(\mathrm{CH}_{3}\right)_{2}$ & DPPH & $40 \mu \mathrm{g} / \mathrm{mL}$ & $\begin{array}{l}\text { South } \\
\text { Africa }\end{array}$ & [248] \\
\hline $\begin{array}{l}\text { Combretum apiculatum } \\
\text { Sond. }\end{array}$ & Combretaceae & Leaf & $\mathrm{EtOAc} / \mathrm{BtOH}$ & $\mathrm{DPPH}$ & $3.91 / 2.44 \mu \mathrm{g} / \mathrm{mL}$ & $\begin{array}{l}\text { South } \\
\text { Africa }\end{array}$ & [249] \\
\hline $\begin{array}{l}\text { Aloe sessiliflora Pole- } \\
\text { Evams. }\end{array}$ & Xanthorrhoeaceae & Leaf & $\mathrm{EtOH}$ & $\mathrm{DPPH}$ & - & $\begin{array}{l}\text { South } \\
\text { Africa }\end{array}$ & [46] \\
\hline Amaranthus asper & Amaranthaceae & Leaf & $\begin{array}{l}\left(\mathrm{CH}_{3}\right)_{2} \mathrm{CO} / \\
\mathrm{MeOH} / \mathrm{H}_{2} \mathrm{O}\end{array}$ & DPPH/ABTS & $\begin{array}{l}72.5,53.5 \text { and } \\
46.0 \% / 96.5,61.8 \text { and } \\
79.1 \% \text { at } 0.05 \mathrm{mg} / \mathrm{mL}\end{array}$ & $\begin{array}{l}\text { South } \\
\text { Africa }\end{array}$ & [250] \\
\hline $\begin{array}{l}\text { Amaranthus dubius Mart. } \\
\text { ex Thell. }\end{array}$ & Amaranthaceae & Leaf & $\mathrm{MeOH}$ & DPPH/ABTS & App 50/75\% & $\begin{array}{l}\text { South } \\
\text { Africa }\end{array}$ & [48] \\
\hline Amaranthus spinosus L. & Amaranthaceae & Leaf & $\mathrm{MeOH}$ & DPPH/ABTS & $0.16 \mathrm{mmol} \mathrm{TEAC} / \mathrm{g}$ & $\begin{array}{l}\text { South } \\
\text { Africa }\end{array}$ & [47] \\
\hline Anchusa capensis Thunb. & Boraginacee & Leaf & $\mathrm{EtOH}$ & $\mathrm{DPPH}$ & - & $\begin{array}{l}\text { South } \\
\text { Africa }\end{array}$ & {$[46]$} \\
\hline Annona senegalensis Pers. & Annonaceae & Bark & $\mathrm{EtOH}$ & $\mathrm{DPPH}$ & - & $\begin{array}{l}\text { South } \\
\text { Africa }\end{array}$ & {$[46]$} \\
\hline $\begin{array}{l}\text { Apodytes dimidiate E. } \\
\text { Mey. Exarn }\end{array}$ & Icacinaceae & Leaf & $\left(\mathrm{CH}_{3}\right)_{2} \mathrm{CO}$ & $\mathrm{DPPH}$ & $3.5 \mu \mathrm{g} / \mathrm{mL}$ & $\begin{array}{l}\text { South } \\
\text { Africa }\end{array}$ & [237] \\
\hline Arbutus unedo L. & Ericaceae & Leaf & $\mathrm{EtOH}$ & $\mathrm{DPPH}$ & - & $\begin{array}{l}\text { South } \\
\text { Africa }\end{array}$ & {$[46]$} \\
\hline $\begin{array}{l}\text { Aspalathus linearis } \\
\text { (N.L.Burm.) R. Dahlgr. }\end{array}$ & Leguminosae & Leaf & $\mathrm{EtOH}$ & $\mathrm{DPPH}$ & $3.5 \pm 0.5 \mu \mathrm{g} / \mathrm{mL}$ & $\begin{array}{l}\text { South } \\
\text { Africa }\end{array}$ & {$[46]$} \\
\hline $\begin{array}{l}\text { Barleria albostellata C.B. } \\
\text { Clarke. }\end{array}$ & Acanthaceae & Leaf & $\mathrm{EtOH}$ & $\mathrm{DPPH}$ & - & $\begin{array}{l}\text { South } \\
\text { Africa }\end{array}$ & {$[46]$} \\
\hline Barleria repens Nees. & Acanthaceae & Leaf & $\mathrm{EtOH}$ & $\mathrm{DPPH}$ & - & $\begin{array}{l}\text { South } \\
\text { Africa }\end{array}$ & {$[46]$} \\
\hline Berkheya setifera DC. & Asteraceae & Corn & $\mathrm{MeOH}$ & $\mathrm{DPPH} / \mathrm{H}_{2} \mathrm{O}_{2}$ & $2335 / 55 \mu \mathrm{g} / \mathrm{mL}$ & Lesotho & [251] \\
\hline Bidens Pilosa L. & Asteraceae & Leaf & $\begin{array}{l}\left(\mathrm{CH}_{3}\right)_{2} \mathrm{CO} / \\
\mathrm{MeOH} / \mathrm{H}_{2} \mathrm{O}\end{array}$ & $\mathrm{DPPH}$ & $\begin{array}{l}95.7,94.2,91.7 \% \text {, } \\
\text { at } 1 \mathrm{mg} / \mathrm{mL}\end{array}$ & $\begin{array}{l}\text { South } \\
\text { Africa }\end{array}$ & [252] \\
\hline Bidens pilosa $\mathrm{L}$. & Asteraceae & Leaf & $\mathrm{MeOH}$ & DPPH/ABTS & $\begin{array}{l}12.10 / 0.057 \mathrm{mmol} \\
\text { TEAC/g }\end{array}$ & $\begin{array}{l}\text { South } \\
\text { Africa }\end{array}$ & [47] \\
\hline Brachylaena discolor DC. & Asteraceae & Leaf & $\left(\mathrm{CH}_{3}\right)_{2} \mathrm{CO}$ & $\mathrm{DPPH}$ & $2.6 \mu \mathrm{g} / \mathrm{mL}$ & $\begin{array}{l}\text { South } \\
\text { Africa }\end{array}$ & [237] \\
\hline Broussonetia papyrifera L. & Moraceae & Leaf & $\mathrm{EtOH}$ & $\mathrm{DPPH}$ & - & $\begin{array}{l}\text { South } \\
\text { Africa }\end{array}$ & {$[46]$} \\
\hline Buxus macowanii Oliv. & Buxaceae & Leaf & $\mathrm{EtOH}$ & $\mathrm{DPPH}$ & - & $\begin{array}{l}\text { South } \\
\text { Africa }\end{array}$ & {$[46]$} \\
\hline $\begin{array}{l}\text { Camellia sinensis (L.) } \\
\text { Kuntze }\end{array}$ & Theaceae & Tea & $\mathrm{MeOH}$ & $\mathrm{DPPH} / \mathrm{H}_{2} \mathrm{O}_{2}$ & $1440 / 75 \mu \mathrm{g} / \mathrm{mL}$ & Lesotho & [251] \\
\hline
\end{tabular}


Table 3 Antioxidants activities of Southern AfricaAfrican plants (Continued)

\begin{tabular}{|c|c|c|c|c|c|c|c|}
\hline Carpobrotus edulis L. & Mesembryanthemaceae & Leaf & $\mathrm{H}_{2} \mathrm{O} / \mathrm{EtOH}$ & $\begin{array}{l}\text { DPPH/ } \\
\text { ABTS/NO }\end{array}$ & $\begin{array}{l}0.018 \text { and } 0.016 / 0.020 \\
\text { and } 0.022 / 0.05 \text { and } \\
0.023 \mathrm{mg} / \mathrm{mL} \text {, }\end{array}$ & $\begin{array}{l}\text { South } \\
\text { Africa }\end{array}$ & [253] \\
\hline Carpobrotus edulis L. & Azioaceae & Leaf & $\mathrm{EtOH}$ & DPPH & - & $\begin{array}{l}\text { South } \\
\text { Africa }\end{array}$ & [46] \\
\hline Cassia abbreviate Oliv. & Caesalpinioidaeae & $\begin{array}{l}\text { Bark/ } \\
\text { Leaf/ } \\
\text { Root }\end{array}$ & $\mathrm{MeOH}$ & DPPH. & $86 / 85 / 85 \%$ & Zimbabwe & [51] \\
\hline Celtis Africana Burm. F. & Ulmaceae & $\begin{array}{l}\text { Leaf/ } \\
\text { Stem }\end{array}$ & $\mathrm{MeOH}$ & DPPH & $\begin{array}{l}64.95 / 89.69 \% \text { at } \\
0.1 \mathrm{mg} / \mathrm{mL}\end{array}$ & $\begin{array}{l}\text { South } \\
\text { Africa }\end{array}$ & [254] \\
\hline Ceratonia siliqua L. & Leguminosae & Leaf & $\mathrm{EtOH}$ & DPPH & - & $\begin{array}{l}\text { South } \\
\text { Africa }\end{array}$ & [46] \\
\hline Chenopodium album $\mathrm{L}$. & Amaranthaceae & Leaf & $\begin{array}{l}\left(\mathrm{CH}_{3}\right)_{2} \mathrm{CO} / \\
\mathrm{MeOH} / \mathrm{H}_{2} \mathrm{O}\end{array}$ & DPPH & $\begin{array}{l}62.4,87.2 \text { and } 81.7 \% \\
\text { at } 1 \mathrm{mg} / \mathrm{mL}\end{array}$ & $\begin{array}{l}\text { South } \\
\text { Africa }\end{array}$ & [252] \\
\hline Chenopodium album $\mathrm{L}$. & Chenopodiaceae & Leaf & $\mathrm{MeOH}$ & DPPH/ABTS & App 60/70\% & $\begin{array}{l}\text { South } \\
\text { Africa }\end{array}$ & [48] \\
\hline $\begin{array}{l}\text { Clausena anisaa (Wild.) } \\
\text { Hook. F. ex Benth. }\end{array}$ & Rutaceae & Leaf & $\left(\mathrm{CH}_{3}\right)_{2} \mathrm{CO}$ & $\mathrm{DPPH}$ & $2.5 \mu \mathrm{g} / \mathrm{mL}$ & $\begin{array}{l}\text { South } \\
\text { Africa }\end{array}$ & [237] \\
\hline $\begin{array}{l}\text { Clerodendrum glabrum E. } \\
\text { May. }\end{array}$ & Lamiaceae & Leaf & $\left(\mathrm{CH}_{3}\right)_{2} \mathrm{CO}$ & DPPH & $3.5 \mu \mathrm{g} / \mathrm{mL}$ & $\begin{array}{l}\text { South } \\
\text { Africa }\end{array}$ & [237] \\
\hline $\begin{array}{l}\text { Combretum apiculatum } \\
\text { Sond. }\end{array}$ & Combretaceae & Leaf & $\mathrm{EtOH}$ & DPPH & $1.6 \pm 0.02 \mu \mathrm{g} / \mathrm{mL}$ & $\begin{array}{l}\text { South } \\
\text { Africa }\end{array}$ & [46] \\
\hline $\begin{array}{l}\text { Combretum molle R. Br. ex } \\
\text { G. Don. }\end{array}$ & Combretaceae & Leaf & $\mathrm{EtOH}$ & $\mathrm{DPPH}$ & $9.83 \pm 0.8 \mu \mathrm{g} / \mathrm{mL}$ & $\begin{array}{l}\text { South } \\
\text { Africa }\end{array}$ & {$[46]$} \\
\hline $\begin{array}{l}\text { Corchorus olitarius Engl \& } \\
\text { Diels. }\end{array}$ & Tiliaceae & Leaf & $\mathrm{MeOH}$ & DPPH/ABTS & 17.11/0.04 mmol TEAC/g & $\begin{array}{l}\text { South } \\
\text { Africa }\end{array}$ & [47] \\
\hline Cotyledon orbiculata L. & Crassulaceae & Leaf & $\mathrm{EtOH}$ & DPPH & - & $\begin{array}{l}\text { South } \\
\text { Africa }\end{array}$ & [46] \\
\hline $\begin{array}{l}\text { Crinum bulbispermum } \\
\text { (Burm.f) MilneRedhead \& } \\
\text { Schweick. }\end{array}$ & Amaryllidaceae & Root & EtOAc & AChE & $0.0393 \mathrm{mg} / \mathrm{mL}$ & $\begin{array}{l}\text { South } \\
\text { Africa }\end{array}$ & [234] \\
\hline Cryptocarya woodii Engl. & Lauraceae & Leaf & $\mathrm{EtOH}$ & DPPH & - & $\begin{array}{l}\text { South } \\
\text { Africa }\end{array}$ & [46] \\
\hline Cyathea dregei Kuntze. & Cyatheaceae & Leaf & $\left(\mathrm{CH}_{3}\right)_{2} \mathrm{CO}$ & $\mathrm{DPPH}$ & $3.0 \mu \mathrm{g} / \mathrm{mL}$ & $\begin{array}{l}\text { South } \\
\text { Africa }\end{array}$ & [237] \\
\hline Dahlia imperialis Roezl. & Asteraceae & Leaf & $\mathrm{EtOH}$ & DPPH & - & $\begin{array}{l}\text { South } \\
\text { Africa }\end{array}$ & [46] \\
\hline Datura stramonium Wall. & Solanaceae & Leaf & $\mathrm{EtOH}$ & DPPH & - & $\begin{array}{l}\text { South } \\
\text { Africa }\end{array}$ & [46] \\
\hline $\begin{array}{l}\text { Dichrostachys cinerea } \\
\text { Wight \& Arn. }\end{array}$ & Leguminosae & Leaf & $\mathrm{EtOH}$ & DPPH & - & $\begin{array}{l}\text { South } \\
\text { Africa }\end{array}$ & {$[46]$} \\
\hline $\begin{array}{l}\text { Dichrostachys cinerea } \\
\text { Wight \& Arn. }\end{array}$ & Mimosaceae & $\begin{array}{l}\text { Leaf/ } \\
\text { Root }\end{array}$ & $\mathrm{MeOH}$ & DPPH. & $88 / 27 \%$ & Zimbabwe & [51] \\
\hline Diospyros lycioides Desf. & Ebenaceae & Twig & $\mathrm{EtOH}$ & DPPH & - & $\begin{array}{l}\text { South } \\
\text { Africa }\end{array}$ & {$[46]$} \\
\hline Dodonaea viscose Mart. & Sapindaceae & Leaf & $\mathrm{EtOH}$ & DPPH & - & $\begin{array}{l}\text { South } \\
\text { Africa }\end{array}$ & [46] \\
\hline Elaedendron matabelicum & Celastraceae & Root & $\mathrm{MeOH}$ & DPPH. & $87 \%$ & Zimbabwe & [51] \\
\hline $\begin{array}{l}\text { Elephantorrhiza goetzei } \\
\text { Harns. }\end{array}$ & Leguminosae & Root & $\mathrm{MeOH}$ & DPPH. & $85 \%$ & Zimbabwe & [51] \\
\hline $\begin{array}{l}\text { Erythrophleum lasianthum } \\
\text { Corbishley. }\end{array}$ & Leguminosae & Leaf & $\mathrm{EtOH}$ & $\mathrm{DPPH}$ & - & $\begin{array}{l}\text { South } \\
\text { Africa }\end{array}$ & {$[46]$} \\
\hline Euclea divinorum Hiern. & Ebenaceae & Leaf & $\mathrm{EtOH}$ & DPPH & - & $\begin{array}{l}\text { South } \\
\text { Africa }\end{array}$ & {$[46]$} \\
\hline Euclea natalensis A.Dc & Ebenaceae & Root & $\mathrm{EtOH}$ & DPPH & - & $\begin{array}{l}\text { South } \\
\text { Africa }\end{array}$ & {$[46]$} \\
\hline
\end{tabular}


Table 3 Antioxidants activities of Southern AfricaAfrican plants (Continued)

\begin{tabular}{|c|c|c|c|c|c|c|c|}
\hline Felicia muricata Nees. & Asteraceae & Leaf & $\begin{array}{l}\mathrm{MeOH} /\left(\mathrm{CH}_{3}\right) \\
{ }_{2} \mathrm{CO} / \mathrm{EtOH}\end{array}$ & $\mathrm{DPPH}$ & $70 / 410 / 120 \mu \mathrm{g} / \mathrm{mL}$ & $\begin{array}{l}\text { South } \\
\text { Africa }\end{array}$ & [173] \\
\hline Flacourtia indica Merr. & Flacourticaceae & $\begin{array}{l}\text { Leaf/ } \\
\text { Root }\end{array}$ & $\mathrm{MeOH}$ & DPPH. & $94 / 82 \%$ & Zimbabwe & {$[51]$} \\
\hline \multirow[t]{2}{*}{ Galenia africana $\mathrm{L}$. } & Aizoaceae & Leaf & $\mathrm{EtOH}$ & $\mathrm{DPPH}$ & $90.92 \pm 1.2 \mu \mathrm{g} / \mathrm{mL}$ & $\begin{array}{l}\text { South } \\
\text { Africa }\end{array}$ & {$[46]$} \\
\hline & Asclepiadacae & Leaf & $\mathrm{EtOH}$ & DPPH & - & $\begin{array}{l}\text { South } \\
\text { Africa }\end{array}$ & {$[46]$} \\
\hline $\begin{array}{l}\text { Gomphocarpus fruticosus R. } \\
\text { Br. }\end{array}$ & Greyiaceae & Leaf & $\mathrm{EtOH}$ & $\mathrm{DPPH}$ & - & $\begin{array}{l}\text { South } \\
\text { Africa }\end{array}$ & {$[46]$} \\
\hline Greyia flanaganii Bolus. & Greyiaceae & Leaf & $\mathrm{EtOH}$ & DPPH & $7.9 \pm 0.23 \mu \mathrm{g} / \mathrm{mL}$ & $\begin{array}{l}\text { South } \\
\text { Africa }\end{array}$ & {$[46]$} \\
\hline $\begin{array}{l}\text { Greyia sutherlandii Hook \& } \\
\text { Harv. }\end{array}$ & Celastraceae & $\begin{array}{l}\text { Leaf/ } \\
\text { Root/ } \\
\text { Twig }\end{array}$ & $\mathrm{MeOH}$ & DPPH. & $90 / 96 / 87 \%$ & Zimbabwe & [51] \\
\hline $\begin{array}{l}\text { Gymnosporia senegalensis } \\
\text { Loes. }\end{array}$ & Anacardiaceae & Leaf & $\mathrm{EtOH}$ & $\mathrm{DPPH}$ & $2.6 \pm 0.21 \mu \mathrm{g} / \mathrm{mL}$ & $\begin{array}{l}\text { South } \\
\text { Africa }\end{array}$ & {$[46]$} \\
\hline $\begin{array}{l}\text { Harpephyllum caffrum } \\
\text { Bernh. Ex C. Krauss. }\end{array}$ & Apiaceae & Leaf & $\left(\mathrm{CH}_{3}\right)_{2} \mathrm{CO}$ & DPPH & $4.36 \mu \mathrm{g} / \mathrm{mL}$ & $\begin{array}{l}\text { South } \\
\text { Africa }\end{array}$ & [237] \\
\hline $\begin{array}{l}\text { Heteromorpha trifoliate Eckl } \\
\text { \& Zeyh. }\end{array}$ & Myrtaceae & Leaf & $\mathrm{EtOH}$ & $\mathrm{DPPH}$ & - & $\begin{array}{l}\text { South } \\
\text { Africa }\end{array}$ & {$[46]$} \\
\hline Heteropyxis natalensis & Euphorbiaceae & Leaf & $\mathrm{EtOH}$ & $\mathrm{DPPH}$ & - & $\begin{array}{l}\text { South } \\
\text { Africa }\end{array}$ & {$[46]$} \\
\hline Hyaenanche globosa Lamb. & Hydnoraceae & Leaf & $\mathrm{MeOH}$ & $\begin{array}{l}\text { NO/DPPH/ } \\
\text { ABTS }\end{array}$ & $\begin{array}{l}60 \% / 80 \% / 95 \% \text { at } \\
0.05 \mathrm{mg} / \mathrm{mL}\end{array}$ & $\begin{array}{l}\text { South } \\
\text { Africa }\end{array}$ & [255] \\
\hline Hydnora Africana Thunb. & Hypoxidaceae & Tuber & $\mathrm{MeOH}$ & DPPH. & $86 \%$ & Zimbabwe & {$[51]$} \\
\hline $\begin{array}{l}\text { Hypoxis hemerocallidea } \\
\text { Fisch. }\end{array}$ & Papilionaceae & Leaf & $\left(\mathrm{CH}_{3}\right)_{2} \mathrm{CO}$ & $\mathrm{DPPH}$ & $0 \mu \mathrm{g} / \mathrm{mL}$ & $\begin{array}{l}\text { South } \\
\text { Africa }\end{array}$ & [237] \\
\hline Indigofera frutescens L.F. & Meliaceae & $\begin{array}{l}\text { Bark/ } \\
\text { Root }\end{array}$ & $\mathrm{MeOH}$ & DPPH. & $96 / 87 \%$ & Zimbabwe & [51] \\
\hline Khaya anthotheca C. DC. & Bignoniaceae & $\begin{array}{l}\text { Bark/ } \\
\text { Fruit/ } \\
\text { Root }\end{array}$ & $\mathrm{MeOH}$ & DPPH. & $81 / 85 / 45 \%$ & Zimbabwe & [51] \\
\hline $\begin{array}{l}\text { Kigelia africana (Lam.) } \\
\text { Benth. }\end{array}$ & Ranunculaceae & Root & $\mathrm{EtOH}$ & $\mathrm{DPPH}$ & - & $\begin{array}{l}\text { South } \\
\text { Africa }\end{array}$ & {$[46]$} \\
\hline $\begin{array}{l}\text { Knowltonia vesicatoria } \\
\text { Sims. }\end{array}$ & Anacardiaceae & Root & $\mathrm{MeOH}$ & ABTS/DPPH & $0.0036 / 0.0151 \mathrm{mg} / \mathrm{mL}$ & $\begin{array}{l}\text { South } \\
\text { Africa }\end{array}$ & [234] \\
\hline Lannea schweinfurthii Engl. & Rosaceae & Leaf & $\left(\mathrm{CH}_{3}\right)_{2} \mathrm{CO}$ & DPPH & $0.0 \mu \mathrm{g} / \mathrm{mL}$ & $\begin{array}{l}\text { South } \\
\text { Africa }\end{array}$ & [237] \\
\hline $\begin{array}{l}\text { Leucosidea sericea Eckl. \& } \\
\text { Zeyh. }\end{array}$ & Rosaceae & Leaf & $\mathrm{MeOH}$ & $\mathrm{DPPH} / \mathrm{H}_{2} \mathrm{O}_{2}$ & $850 / 68 \mu \mathrm{g} / \mathrm{mL}$ & Lesotho & [251] \\
\hline $\begin{array}{l}\text { Leucosidea sericea Eckl. \& } \\
\text { Zeyh. }\end{array}$ & Verbenaceae & Leaf & $\mathrm{MeOH}$ & DPPH/ABTS & 14.62/0.015 mmol TEAC/g & $\begin{array}{l}\text { South } \\
\text { Africa }\end{array}$ & [47] \\
\hline Lippia javanica Spreng. & Maesaceae & Leaf & $\left(\mathrm{CH}_{3}\right)_{2} \mathrm{CO}$ & $\mathrm{DPPH}$ & $1.4 \mu \mathrm{g} / \mathrm{mL}$ & $\begin{array}{l}\text { South } \\
\text { Africa }\end{array}$ & [237] \\
\hline Maesa lanceolata G. Don. & Magnoliaceae & Leaf & $\mathrm{EtOH}$ & DPPH & - & $\begin{array}{l}\text { South } \\
\text { Africa }\end{array}$ & {$[46]$} \\
\hline $\begin{array}{l}\text { Magnolia grandiflora ex } \\
\text { Dc. }\end{array}$ & Meliaceae & Leaf & $\left(\mathrm{CH}_{3}\right)_{2} \mathrm{CO}$ & DPPH & $3.3 \mu \mathrm{g} / \mathrm{mL}$ & $\begin{array}{l}\text { South } \\
\text { Africa }\end{array}$ & [237] \\
\hline Melia azedarach Blanco. & Papilionaceae & Leaf & $\left(\mathrm{CH}_{3}\right)_{2} \mathrm{CO}$ & $\mathrm{DPPH}$ & $4.6 \mu \mathrm{g} / \mathrm{mL}$ & $\begin{array}{l}\text { South } \\
\text { Africa }\end{array}$ & [237] \\
\hline Millettia grandis Jkeel. & Myrsinaceae & Stalk & $\mathrm{EtOH}$ & DPPH & - & $\begin{array}{l}\text { South } \\
\text { Africa }\end{array}$ & [46] \\
\hline Myrsine Africana L. & Chrysobalanaceae & Bark & $\mathrm{EtOH}$ & $\mathrm{DPPH}$ & - & $\begin{array}{l}\text { South } \\
\text { Africa }\end{array}$ & [46] \\
\hline
\end{tabular}


Table 3 Antioxidants activities of Southern AfricaAfrican plants (Continued)

\begin{tabular}{|c|c|c|c|c|c|c|c|}
\hline $\begin{array}{l}\text { Parinari curatellifolia } \\
\text { Planch. ex Benth. }\end{array}$ & Geraniaceae & $\begin{array}{l}\text { Leaf/ } \\
\text { Root }\end{array}$ & $\mathrm{MeOH}$ & ABTS/DPPH & $100 \% / 90 \%$ at $0.5 \mathrm{mg} / \mathrm{mL}$ & $\begin{array}{l}\text { South } \\
\text { Africa }\end{array}$ & [256] \\
\hline $\begin{array}{l}\text { Pelargonium reniforme } \\
\text { Spreng. }\end{array}$ & Geraniaceae & $\begin{array}{l}\text { Leaf/ } \\
\text { Root }\end{array}$ & $\mathrm{MeOH}$ & ABTS & $100 \%$ at $0.025 \mathrm{mg} / \mathrm{mL}$ & $\begin{array}{l}\text { South } \\
\text { Africa }\end{array}$ & [256] \\
\hline $\begin{array}{l}\text { Pelargonium reniforme } \\
\text { Spreng. }\end{array}$ & Fabaceae & Leaf & $\mathrm{MeOH}$ & $\mathrm{DPPH}$ & $19.8 \%$ at $2.5 \mathrm{mg} / \mathrm{mL}$ & $\begin{array}{l}\text { South } \\
\text { Africa }\end{array}$ & [257] \\
\hline $\begin{array}{l}\text { Philenoptera violacea Klotz } \\
\text { sch. }\end{array}$ & Piperaceae & Root & $\mathrm{MeOH}$ & ABTS/DPPH & $0.040 / 0.044 \mathrm{mg} / \mathrm{mL}$ & $\begin{array}{l}\text { South } \\
\text { Africa }\end{array}$ & [234] \\
\hline Piper capense L.F. & Polygalaceae & $\begin{array}{l}\text { Leaf/ } \\
\text { Stem }\end{array}$ & $\mathrm{MeOH}$ & $\mathrm{DPPH}$ & $20 \%$ at $2500 \mu \mathrm{g} / \mathrm{mL}$ & Lesotho & [251] \\
\hline Polygala virgate Vell. & Ranunculaceae & Leaf & $\mathrm{EtOH}$ & $\mathrm{DPPH}$ & $24.7 \pm 2.05 \mu \mathrm{g} / \mathrm{mL}$ & $\begin{array}{l}\text { South } \\
\text { Africa }\end{array}$ & {$[46]$} \\
\hline Ranunculus repens Watson. & Anacardiaceae & $\begin{array}{l}\text { Leaf/ } \\
\text { Root }\end{array}$ & $\mathrm{MeOH}$ & DPPH. & $96 / 96 \%$ & Zimbabwe & [51] \\
\hline Rhus chirindensis Baker. & Anacardiacae & Leaf & $\mathrm{EtOH}$ & $\mathrm{DPPH}$ & - & $\begin{array}{l}\text { South } \\
\text { Africa }\end{array}$ & {$[46]$} \\
\hline Rhus lancea L.f. & Euphorbiaceae & Leaf & $\begin{array}{l}\mathrm{MeOH} / \mathrm{n}- \\
\mathrm{C}_{6} \mathrm{H}_{12} / \mathrm{CH}_{2} \mathrm{Cl}_{2} / \\
\left(\mathrm{CH}_{3}\right)_{2} \mathrm{CO}\end{array}$ & ABTS & $\begin{array}{l}\text { 784/629.3/573.6 and } \\
544.6 \mu \mathrm{g} / \mathrm{mL}\end{array}$ & $\begin{array}{l}\text { South } \\
\text { Africa }\end{array}$ & [258] \\
\hline Ricinus communis $\mathrm{L}$. & Polygonaceae & Leaf & $\begin{array}{l}\left(\mathrm{CH}_{3}\right)_{2} \mathrm{CO} / \\
\mathrm{MeOH} / \mathrm{H}_{2} \mathrm{O}\end{array}$ & DPPH & $72.1,97.7,85.3 \%$ & $\begin{array}{l}\text { South } \\
\text { Africa }\end{array}$ & [259] \\
\hline Rumex ecklonianus Meisn. & Amaryllidaceae & Bulb & EtOAc & AChE & $0.0003 \mathrm{mg} / \mathrm{mL}$ & $\begin{array}{l}\text { South } \\
\text { Africa }\end{array}$ & [234] \\
\hline Scadoxus puniceusL. & Fabaceae & $\begin{array}{l}\text { Stem } \\
\text { bark }\end{array}$ & $\mathrm{MeOH}$ & $\begin{array}{l}\mathrm{DPPH} / \\
\mathrm{ABTS} / \mathrm{H}_{2} \mathrm{O}_{2} / \\
\mathrm{LO} / \mathrm{NO}\end{array}$ & $\begin{array}{l}87.5 \%, 89.47 \%, 77.15 \% \\
86.48 \% \text { and } 77.75 \% \text { at } \\
0.5 \mathrm{mg} / \mathrm{mL}\end{array}$ & $\begin{array}{l}\text { South } \\
\text { Africa }\end{array}$ & [260] \\
\hline Schotia latifolia Jacq. & Anacardiaceae & Bark & $\mathrm{EtOH}$ & $\mathrm{DPPH}$ & $2.06 \pm 0.03 \mu \mathrm{g} / \mathrm{mL}$ & $\begin{array}{l}\text { South } \\
\text { Africa }\end{array}$ & {$[46]$} \\
\hline Sclerocarya birrea Hochst. & Anacardiaceae & Bark & $\mathrm{MeOH}$ & DPPH. & $89 \%$ & Zimbabwe & [51] \\
\hline Sclerocarya birrea & Polygalaceae & Root & $\mathrm{MeOH}$ & $\mathrm{DPPH}$. & $93 \%$ & Zimbabwe & [51] \\
\hline $\begin{array}{l}\text { Securidaca } \\
\text { longepedunculata Fresen. }\end{array}$ & Sapotaceae & Bark & $\mathrm{EtOH}$ & DPPH & - & $\begin{array}{l}\text { South } \\
\text { Africa }\end{array}$ & {$[46]$} \\
\hline Sideroxylon inerme L. & Solanaceae & Leaf & $\mathrm{MeOH}$ & DPPH/ABTS & App 35/60\% & $\begin{array}{l}\text { South } \\
\text { Africa }\end{array}$ & [48] \\
\hline Solanum nigrum L. & Asteraceae & Leaf & $\left(\mathrm{CH}_{3}\right)_{2} \mathrm{CO}$ & ABTS/DPPH & $97.8 \% / 85.6$ at $1 \mathrm{mg} / \mathrm{mL}$ & $\begin{array}{l}\text { South } \\
\text { Africa }\end{array}$ & [261] \\
\hline Sonchus asper Hill. & Asteraceae & Leaf & $\left(\mathrm{CH}_{3}\right)_{2} \mathrm{CO}$ & ABTS/DPPH & $99.4 \% / 56.1 \%$ at $1 \mathrm{mg} / \mathrm{mL}$ & $\begin{array}{l}\text { South } \\
\text { Africa }\end{array}$ & [261] \\
\hline Sonchus oleraceus L. & Menispermaceae & $\begin{array}{l}\text { Stem } \\
\text { bark }\end{array}$ & $\mathrm{MeOH}$ & $\mathrm{SOD} / \mathrm{H}_{2} \mathrm{O}_{2}$ & $13.11 / 30.04 \mu \mathrm{g} / \mathrm{mL}$ & $\begin{array}{l}\text { South } \\
\text { Africa }\end{array}$ & [80] \\
\hline $\begin{array}{l}\text { Sphenocentrum jollyanum } \\
\text { Pierre. }\end{array}$ & Loganiaceae & Bark & $\mathrm{H}_{2} \mathrm{O}$ & $\begin{array}{l}\text { DPPH/ } \\
\mathrm{H}_{2} \mathrm{O}_{2} / \text { ABTS/ } \\
\mathrm{NO}\end{array}$ & $\begin{array}{l}0.739 / 0.023 / 0.089 / \\
0.49 \mathrm{mg} / \mathrm{mL}\end{array}$ & $\begin{array}{l}\text { South } \\
\text { Africa }\end{array}$ & [262] \\
\hline Strychnos henningsiib Gilg. & Strychnaceae & Leaf & $\left(\mathrm{CH}_{3}\right)_{2} \mathrm{CO}$ & $\mathrm{DPPH}$ & $3.5 \mu \mathrm{g} / \mathrm{mL}$ & $\begin{array}{l}\text { South } \\
\text { Africa }\end{array}$ & [237] \\
\hline Strychnos mitis S. Moore. & Boraginaceae & Leaf & $\mathrm{EtOH}$ & DPPH & - & $\begin{array}{l}\text { South } \\
\text { Africa }\end{array}$ & {$[46]$} \\
\hline Symphytum officinale & Asteraceae & Leaf & $\mathrm{MeOH}$ & DPPH/ABTS & 13.99/0.012 mmol TEAC/g & $\begin{array}{l}\text { South } \\
\text { Africa }\end{array}$ & [47] \\
\hline Tagetes minuta L. & Cucurbitaceae & Leaf & $\mathrm{MeOH}$ & DPPH/ABTS & 2.93/0.03 mmol TEAC/g & $\begin{array}{l}\text { South } \\
\text { Africa }\end{array}$ & [47] \\
\hline Telfairia occidentalis Hook. F. & Combretaceae & $\begin{array}{l}\text { Leaf/ } \\
\text { Root }\end{array}$ & $\mathrm{MeOH}$ & DPPH. & $89 / 89 \%$ & Zimbabwe & [51] \\
\hline $\begin{array}{l}\text { Terminalia sericea } \\
\text { Carnbess. }\end{array}$ & Combretaceae & Root & $\mathrm{MeOH}$ & ABTS/DPPH & $0.0031 / 0.0147 \mathrm{mg} / \mathrm{mL}$ & $\begin{array}{l}\text { South } \\
\text { Africa }\end{array}$ & [234] \\
\hline
\end{tabular}


Table 3 Antioxidants activities of Southern AfricaAfrican plants (Continued)

\begin{tabular}{|c|c|c|c|c|c|c|c|}
\hline $\begin{array}{l}\text { Terminalia sericea } \\
\text { Carnbess. }\end{array}$ & Fabaceae & $\begin{array}{l}\text { Leaf/ } \\
\text { Stem }\end{array}$ & $\mathrm{MeOH}$ & DPPH & $14 \%$ at $2500 \mu \mathrm{g} / \mathrm{mL}$ & Lesotho & [251] \\
\hline $\begin{array}{l}\text { Trifolium burchellianum } \\
\text { Serr. }\end{array}$ & Alliaceae & Root & EtOAc & $\begin{array}{l}\text { AChE/ } \\
\text { ABTS/DPPH }\end{array}$ & $0.0319 \mathrm{mg} / \mathrm{mL}$ & $\begin{array}{l}\text { South } \\
\text { Africa }\end{array}$ & [234] \\
\hline Tulbaghia violacea Har v. & Alliacea & Rhizome & $\mathrm{MeOH}$ & $\mathrm{DPPH} / \mathrm{H}_{2} \mathrm{O}_{2}$ & $35,19.3 / 17.9 \mu \mathrm{g} / \mathrm{mL}$ & $\begin{array}{l}\text { South } \\
\text { Africa }\end{array}$ & $\begin{array}{l}\text { Olorunnisola } \\
\text { et al., } 2011 \text { b }\end{array}$ \\
\hline Tulbaghia violacea Har v. & Alliaceae & Rhizome & Oil & $\mathrm{DPPH}$ & $83.0 \mu \mathrm{g} / \mathrm{mL}$ & $\begin{array}{l}\text { South } \\
\text { Africa }\end{array}$ & [263] \\
\hline Tulbaghia violacea Har v. & Urticaceae & Leaf & $\mathrm{MeOH}$ & DPPH/ABTS & App 45/75\% & $\begin{array}{l}\text { South } \\
\text { Africa }\end{array}$ & [48] \\
\hline Urtica lobulata E. Mey. & Fabaceae & Leaf & $\mathrm{MeOH}$ & ABTS & $0.95 \mathrm{mmol} \mathrm{TEAC} / \mathrm{g}$ & $\begin{array}{l}\text { South } \\
\text { Africa }\end{array}$ & [47] \\
\hline Vigna unguiculata L. & Cancellaceae & Leaf & $\mathrm{EtOH}$ & $\mathrm{DPPH}$ & $111 \pm 2.5 \mu \mathrm{g} / \mathrm{mL}$ & $\begin{array}{l}\text { South } \\
\text { Africa }\end{array}$ & [46] \\
\hline Warburgia salutaris Chiou. & Canellaceae & $\begin{array}{l}\text { Bark/Leaf/ } \\
\text { Root/ } \\
\text { Twig }\end{array}$ & $\mathrm{MeOH}$ & DPPH. & 73/87/94/89\% & Zimbabwe & [51] \\
\hline Warburgia salutaris Chiou. & Fabaceae & Leaf & $\mathrm{MeOH}$ & $\mathrm{DPPH}$ & $2.5 \mathrm{mg} / \mathrm{mL}$ & $\begin{array}{l}\text { South } \\
\text { Africa }\end{array}$ & {$[257]$} \\
\hline Xanthocercis zambesiaca & Apocynaceae & Root & EtOAc & $\mathrm{DPPH}$ & $0.0005 \mathrm{mg} / \mathrm{mL}$ & $\begin{array}{l}\text { South } \\
\text { Africa }\end{array}$ & [234] \\
\hline $\begin{array}{l}\text { Xysmalobium undulatum } \mathrm{R} \text {. } \\
\mathrm{Br} \text {. }\end{array}$ & Rutaceae & Leaf & $\left(\mathrm{CH}_{3}\right)_{2} \mathrm{CO}$ & DPPH & $4.0 \mu \mathrm{g} / \mathrm{mL}$ & $\begin{array}{l}\text { South } \\
\text { Africa }\end{array}$ & [237] \\
\hline $\begin{array}{l}\text { Zanthoxylum capense Har } \\
\text { v. }\end{array}$ & Rutaceae & Leaf & $\mathrm{EtOH}$ & $\mathrm{DPPH}$ & & $\begin{array}{l}\text { South } \\
\text { Africa }\end{array}$ & [46] \\
\hline $\begin{array}{l}\text { Zanthoxylum capense Har } \\
\text { v. }\end{array}$ & Rutaceae & Root & $\mathrm{MeOH}$ & AChE/ABTS & $0.01 / 0.075 \mathrm{mg} / \mathrm{mL}$ & $\begin{array}{l}\text { South } \\
\text { Africa }\end{array}$ & [234] \\
\hline $\begin{array}{l}\text { Zanthoxylum davyi P.G. } \\
\text { Waterman. }\end{array}$ & Rhamnaceae & Root & $\mathrm{MeOH}$ & ABTS/DPPH & $0.0187 / 0.0291 \mathrm{mg} / \mathrm{mL}$ & $\begin{array}{l}\text { South } \\
\text { Africa }\end{array}$ & {$[234]$} \\
\hline
\end{tabular}

Key: $R S A$ radical scavenging activity, $\mathrm{RC}$ reducing power capacity, $\mathrm{OH}$ hydroxyl ion, $\mathrm{NO}$ nitric oxide radical inhibition, $\mathrm{H}_{2} \mathrm{O}_{2}$ hydrogen peroxide inhibition activity, $\angle P O$ lipid peroxidation inhibition activity, $A B T S^{+}$2,2'-azinobis-3-ethylbenzothiozolin-6-sulfonic acid cation decolourization test, 3 -CLAMS $ß$-carotene-linoleic acid model system, SORSA superoxide anion radical scavenging activity (SORSA), MLP microsomal lipid peroxydation, $F R A P$ fe ${ }^{2+}$ chelating ability and ferric reducing antioxidant properties, DPPH 1,1-dipheyl-2-picry-hydrazyl, ORAC oxygen radical absorbance capacity, TEAC trolox equivalent antioxidant capacity, MeOH methanol, $\mathrm{CH}_{2} \mathrm{Cl}_{2}$ dichloromethane, EtOH ethanol, EtOAc ethyl acetate, $n-\mathrm{C}_{6} \mathrm{H}_{12}$ hexane, $\left(\mathrm{CH}_{3}\right)_{2} \mathrm{CO}$ acetone, $\mathrm{H}_{2} \mathrm{O}$ aqueous, BtOH butanol

(5) When dealing with Trolox equivalents (TEAC), antioxidants activities of plants extracts are considered to be very high when activities was $<0.05$ and $<0.5$ mmol Trolox/g in ABTS and DPPH assay, moderate at $0.05-0.20$ and $0.5-1.0 \mathrm{mmol}$ Trolox/g in ABTS and DPPH assay, low at $0.21-0.5$ and $1.1-5.0 \mathrm{mmol}$ Trolox/g in ABTS and DPPH assay, while extract with trolox equivalents $>0.5$ and $>5 \mathrm{mmol} / \mathrm{g}$ in ABTS and DPPH assay respectively are considered inactive.

(6) When dealing with in vitro hepatoprotective, plant extracts were considered to exhibit significant, medium and low hepatoprotective activities when inhibiting oxidation phenomena of $>80 \%, 50 \%$ and $<50 \%$ at concentration $\leq 200$ $\mu \mathrm{g} / \mathrm{mL}$ respectively

Many antioxidant compounds have been characterized form plants including flavonoids. Flavonoids are phenolic compounds with importants roles in scavenging free radicals and thus play vital roles in preventing oxidative stress associated disorders [4]. The antioxidant effects of flavonoids in biological systems are accredited to its capacity to transport electrons to free radicals, chelate metals, activate antioxidant enzymes, and reduce radicals of alphatocopherol or to inhibit oxidases while phenolic compounds exert it antioxidant activities by inactivating free radicals or preventing decomposition of hydroperoxide into free radicals [32]. In this review the antioxidant potential of flavonoids and other phenolic compounds have been highlighted in Table 7 .

Evaluations of biochemical parameters including aspartate transaminase (AST), alanine transaminase (ALT), alkaline phosphatase (ALP), total proteins, albumins, bilirubins, super oxide dismutase (SOD), catalase, malondialdehyde (MDA), glutathione peroxidase have been widely used in assessing the integrity of the liver [3337]. Therefore, the hepatoprotective capacities of natural products reviewed in this study were assessed based on the levels of ameliorative effect on hapatotoxicants 
Table 4 Antioxidants activities of Central African plants

\begin{tabular}{|c|c|c|c|c|c|c|c|}
\hline Plants & Family & Part used & Solvents & Assay Methods & Inhibition/IC 50 & $\begin{array}{l}\text { Country } \\
\text { of origin }\end{array}$ & References \\
\hline Abrus precatorius $L$ & Papiliomoidae & Leaf & $\mathrm{MeOH}$ & $\mathrm{DPPH}$ & $6.88 \%$ & Cameroon & [53] \\
\hline Acalypha manniana Mull. Arg. & Euphobiaceae & Leaf & $\begin{array}{l}\mathrm{MeOH} / \mathrm{n}- \\
\mathrm{C}_{6} \mathrm{H}_{12}\end{array}$ & DPPH & 4.51 and $4.80 \%$ & Cameroon & {$[264]$} \\
\hline Acalypha racemosa B. Heyne. & Euphorbiaceae & Leaf/Stem & $\mathrm{MeOH}$ & DPPH/NO'HO & $\begin{array}{l}\text { 2.11,1.92,2.12/ } \\
2.28 .1 .49,10.04 \mu \mathrm{g} / \mathrm{mL}\end{array}$ & Cameroon & {$[52]$} \\
\hline $\begin{array}{l}\text { Acanthus montanus T. } \\
\text { Anderson }\end{array}$ & Acanthaceae & Leaf & $\mathrm{MeOH}$ & DPPH & $9.88 \%$ & Cameroon & [53] \\
\hline Adenocarpus mannii Hook. f & Fabaceae & Leaf & $\mathrm{EtOH}$ & $\mathrm{DPPH}$ & $361.30 \mu \mathrm{g} / \mathrm{mL}$ & Cameroon & {$[265]$} \\
\hline Ageratum conizoides $\mathrm{L}$. & Asteraceae & Leaf & $\mathrm{MeOH}$ & DPPH & $9.05 \%$ & Cameroon & [53] \\
\hline Ageratum conyzoides L. & Asteraceae & $\begin{array}{l}\text { Bark/Leaf/ } \\
\text { Rhizome }\end{array}$ & $\mathrm{MeOH} ; \mathrm{CH}_{2} \mathrm{Cl}_{2}$ & $\begin{array}{l}\text { Fe (II)-Ascorbate } \\
\text { induced LP }\end{array}$ & $-9.31 \%$ at $200 \mu \mathrm{g} / \mathrm{mL}$ & Cameroon & [117] \\
\hline $\begin{array}{l}\text { Alchornea cordifolia Pax \& K. } \\
\text { Hoffm. }\end{array}$ & Euphorbiaceae & Leaf & $\mathrm{MeOH}$ & DPPH & $39.70 \%$ & Cameroon & {$[53]$} \\
\hline $\begin{array}{l}\text { Alchornea laxiflora Pax \& K. } \\
\text { Hoffm. }\end{array}$ & Euphorbiaceae & $\begin{array}{l}\text { Bark/Leaf/ } \\
\text { Rhizome }\end{array}$ & $\mathrm{MeOH} ; \mathrm{CH}_{2} \mathrm{Cl}_{2}$ & $\begin{array}{l}\text { Fe (II)-Ascorbate } \\
\text { induced LP }\end{array}$ & $95.90 \%$ at $200 \mu \mathrm{g} / \mathrm{mL}$ & Cameroon & {$[117]$} \\
\hline Allanblackia floribunda $\mathrm{L}$. & Guttiferae & Root Bark & $\mathrm{MeOH}$ & DPPH & $76.3 \mu \mathrm{g} / \mathrm{mL}$ & Cameroon & {$[266]$} \\
\hline Amaranthus spinosa $\mathrm{L}$. & Amaranthaceae & Leaf & $\mathrm{MeOH}$ & DPPH & $3.78 \%$ & Cameroon & [53] \\
\hline Annona muricata L. & Annonaceae & Leaf & $\mathrm{MeOH}$ & $\mathrm{DPPH}$ & $9.88 \%$ & Cameroon & [53] \\
\hline Annona senegalensis Pers. & Anonaceae & $\begin{array}{l}\text { Bark/Leaf/ } \\
\text { Rhizome }\end{array}$ & $\mathrm{MeOH} ; \mathrm{CH}_{2} \mathrm{Cl}_{2}$ & $\begin{array}{l}\text { Fe (II)-Ascorbate } \\
\text { induced LP }\end{array}$ & $16.17 \%$ at $200 \mu \mathrm{g} / \mathrm{mL}$ & Cameroon & {$[117]$} \\
\hline Anthocleista schweinfurthii Gilg. & Gentianaceae & Leaf & $\mathrm{MeOH}$ & DPPH & $1.20 \mu \mathrm{g} / \mathrm{mL}$ & Congo & {$[267]$} \\
\hline Anthocleista schweinfurthii Gilg. & Loganiaceae & $\begin{array}{l}\text { Bark/Leaf/ } \\
\text { Rhizome }\end{array}$ & $\mathrm{MeOH} ; \mathrm{CH}_{2} \mathrm{Cl}_{2}$ & $\begin{array}{l}\text { Fe (II)-Ascorbate } \\
\text { induced LP }\end{array}$ & $-0.05 \%$ at $200 \mu \mathrm{g} / \mathrm{mL}$ & Cameroon & {$[117]$} \\
\hline Aspilia africana Pers. & Asteraceae & $\begin{array}{l}\text { Bark/Leaf/ } \\
\text { Rhizome }\end{array}$ & $\mathrm{MeOH} ; \mathrm{CH}_{2} \mathrm{Cl}_{2}$ & $\begin{array}{l}\text { Fe (II)-Ascorbate } \\
\text { induced LP }\end{array}$ & $52.91 \%$ at $200 \mu \mathrm{g} / \mathrm{mL}$ & Cameroon & {$[117]$} \\
\hline Asystasia gangetica A. Juss. & Acanthaceae & Leaf & $\mathrm{MeOH}$ & DPPH & $3.08 \%$ & Cameroon & [53] \\
\hline Azadirachta indica A. Juss. & Meliaceae & Bark/Leaf & $\mathrm{MeOH}$ & $\mathrm{DPPH}$ & $59.80 / 2.88 \%$ & Cameroon & [53] \\
\hline Barteria fistulosa Mast. & Passifloraceae & Leaf & $\mathrm{EtOH}$ & DPPH & $100.16 \mu \mathrm{g} / \mathrm{mL}$ & Cameroon & {$[265]$} \\
\hline Bersama engleriana Gunke. & Melianthaceae & Leaf & $\mathrm{MeOH}$ & $\mathrm{DPPH}$ & $93.71 \%$ at $1000 \mu \mathrm{g} / \mathrm{mL}$ & Cameroon & {$[268]$} \\
\hline Bidens pilosa L. & Asteraceae & Leaf & $\mathrm{MeOH}$ & $\mathrm{DPPH}$ & $7.57 \%$ & Cameroon & [53] \\
\hline Bidens pilosa $\mathrm{L}$. & Asteraceae & $\begin{array}{l}\text { Bark/leaf/ } \\
\text { Rhizome }\end{array}$ & $\mathrm{MeOH} ; \mathrm{CH}_{2} \mathrm{Cl}_{2}$ & $\begin{array}{l}\text { Fe (II)-Ascorbate } \\
\text { induced LP }\end{array}$ & $50.92 \%$ at $200 \mu \mathrm{g} / \mathrm{mL}$ & Cameroon & [117] \\
\hline Bracica dera $\mathrm{L}$. & Bracicaceae & Leaf & $\mathrm{MeOH}$ & DPPH & $5.11 \%$ & Cameroon & [53] \\
\hline Carica papaya L. & Caricaceae & Leaf & $\mathrm{MeOH}$ & DPPH & $7.72 \%$ & Cameroon & [53] \\
\hline Carica papaya L. & Caricaceae & $\begin{array}{l}\text { Bark/leaf/ } \\
\text { Rhizome }\end{array}$ & $\mathrm{MeOH} ; \mathrm{CH}_{2} \mathrm{Cl}_{2}$ & $\begin{array}{l}\text { Fe (II)-Ascorbate } \\
\text { induced LP }\end{array}$ & $-2.68 \%$ at $200 \mu \mathrm{g} / \mathrm{mL}$ & Cameroon & {$[117]$} \\
\hline Cassia alata $\mathrm{L}$. & Legceasalpoidee & Leaf & $\mathrm{MeOH}$ & $\mathrm{DPPH}$ & $1.95 \%$ & Cameroon & [53] \\
\hline Ceiba pentandra L. & Bombacea & Bark & $\mathrm{MeOH}$ & DPPH & $28.72 \%$ & Cameroon & {$[53]$} \\
\hline Centella asiatica Urb. & Apiaceae & $\begin{array}{l}\text { Whole } \\
\text { plant }\end{array}$ & $\mathrm{MeOH}$ & $\mathrm{DPPH} / \mathrm{NO}$ & - & Cameroon & [269] \\
\hline Centella asiatica Urb. & Apiaceae & $\begin{array}{l}\text { Whole } \\
\text { plant }\end{array}$ & $\mathrm{MeOH}$ & DPPH/NOSA & - & Cameroon & [269] \\
\hline $\begin{array}{l}\text { Chrysanthellum americanum } \\
\text { Vatke. }\end{array}$ & Asteraceae & $\begin{array}{l}\text { Bark/leaf/ } \\
\text { Rhizome }\end{array}$ & $\mathrm{MeOH} ; \mathrm{CH}_{2} \mathrm{Cl}_{2}$ & $\begin{array}{l}\text { Fe (II)-Ascorbate } \\
\text { induced LP }\end{array}$ & $17.20 \%$ at $200 \mu \mathrm{g} / \mathrm{mL}$ & Cameroon & {$[117]$} \\
\hline Cissus populnea Guill \& Perr. & Vitaceae & Root & $\mathrm{MeOH}$ & DPPH/NO & $15.72 / 409 \mu \mathrm{g} / \mathrm{mL}$ & Cameroon & [269] \\
\hline Cissus populnea Guill \& Perr. & Vitaceae & Root & $\mathrm{MeOH}$ & DPPH/NOSA & $15.72 / 409.00 \mu \mathrm{g} / \mathrm{mL}$ & Cameroon & [269] \\
\hline Cissus quadrangularis $\mathrm{L}$. & Vitaceae & Leaf & $\mathrm{MeOH}$ & DPPH & $2.60 \%$ & Cameroon & [53] \\
\hline $\begin{array}{l}\text { Citrus aurantifolia (Christm.) } \\
\text { Swingle. }\end{array}$ & Rutaceae & $\begin{array}{l}\text { Bark/Leaf/ } \\
\text { Rhizome }\end{array}$ & $\mathrm{MeOH} ; \mathrm{CH}_{2} \mathrm{Cl}_{2}$ & $\begin{array}{l}\text { Fe (II)-Ascorbate } \\
\text { induced LP }\end{array}$ & $54.59 \%$ at $200 \mu \mathrm{g} / \mathrm{mL}$ & Cameroon & [117] \\
\hline
\end{tabular}


Table 4 Antioxidants activities of Central African plants (Continued)

\begin{tabular}{|c|c|c|c|c|c|c|c|}
\hline Citrus sinensis Pers. & Rutaceae & $\begin{array}{l}\text { Bark/Leaf/ } \\
\text { Rhizome }\end{array}$ & $\mathrm{MeOH} ; \mathrm{CH}_{2} \mathrm{Cl}_{2}$ & $\begin{array}{l}\text { Fe (II)-Ascorbate } \\
\text { induced LP }\end{array}$ & $100.00 \%$ at $200 \mu \mathrm{g} / \mathrm{mL}$ & Cameroon & [117] \\
\hline Cleome ciliatea & Cleomaceae & Leaf & $\mathrm{MeOH}$ & $\mathrm{DPPH}$ & $1.95 \%$ & Cameroon & [53] \\
\hline $\begin{array}{l}\text { Clerodendrum formicarum } \\
\text { Gurke. }\end{array}$ & Lamiacea & Leaf & $\mathrm{MeOH}$ & $\mathrm{DPPH}$ & $>200 \mu \mathrm{g} / \mathrm{mL}$ & Cameroon & [140] \\
\hline Coffea arabica L. & Rubiaceae & $\begin{array}{l}\text { Bark/Leaf/ } \\
\text { Rhizome }\end{array}$ & $\mathrm{MeOH} ; \mathrm{CH}_{2} \mathrm{Cl}_{2}$ & $\begin{array}{l}\text { Fe (II)-Ascorbate } \\
\text { induced LP }\end{array}$ & $10.05 \%$ at $200 \mu \mathrm{g} / \mathrm{mL}$ & Cameroon & [117] \\
\hline Coffea robusta L. Linden & Rubiaceae & $\begin{array}{l}\text { Bark/Leaf/ } \\
\text { Rhizome }\end{array}$ & $\mathrm{MeOH} ; \mathrm{CH}_{2} \mathrm{Cl}_{2}$ & $\begin{array}{l}\text { Fe (II)-Ascorbate } \\
\text { induced LP }\end{array}$ & $41.23 \%$ at $200 \mu \mathrm{g} / \mathrm{mL}$ & Cameroon & [117] \\
\hline Coleus coprosijblius & Lamiaceae & Leaf & $\mathrm{MeOH}$ & $\mathrm{DPPH}$ & $39.58 \%$ & Cameroon & [53] \\
\hline Cordyline fruticosa (L.) A. Chev. & Agavaceae & Leaf & $\mathrm{MeOH}$ & DPPH & $181.30 \mu \mathrm{g} / \mathrm{mL}$ & Cameroon & {$[270]$} \\
\hline Costus afer $\mathrm{L}$. & Costaceae & $\begin{array}{l}\text { Bark/Leaf/ } \\
\text { Rhizome }\end{array}$ & $\mathrm{MeOH} ; \mathrm{CH}_{2} \mathrm{Cl}_{2}$ & $\begin{array}{l}\text { Fe (II)-Ascorbate } \\
\text { induced LP }\end{array}$ & $68.16 \%$ at $200 \mu \mathrm{g} / \mathrm{mL}$ & Cameroon & [117] \\
\hline Costus afer $\mathrm{L}$. & Costaceae & Leaf & $\mathrm{MeOH}$ & $\mathrm{DPPH}$ & $3.04 \%$ & Cameroon & [53] \\
\hline Crinum sp. & Amarillidaceae & Leaf & $\mathrm{MeOH}$ & DPPH & $4.69 \%$ & Cameroon & [53] \\
\hline $\begin{array}{l}\text { Crotalaria lachnophora Hochst. } \\
\text { ex. R. }\end{array}$ & Fabaceae & $\begin{array}{l}\text { Bark/Leaf/ } \\
\text { Rhizome }\end{array}$ & $\mathrm{MeOH} ; \mathrm{CH}_{2} \mathrm{Cl}_{2}$ & $\begin{array}{l}\text { Fe (II)-Ascorbate } \\
\text { induced LP }\end{array}$ & $97.41 \%$ at $200 \mu \mathrm{g} / \mathrm{mL}$ & Cameroon & [117] \\
\hline Curcuma longa $\mathrm{L}$. & Zingiberaceae & $\begin{array}{l}\text { Bark/Leaf/ } \\
\text { Rhizome }\end{array}$ & $\mathrm{MeOH} ; \mathrm{CH}_{2} \mathrm{Cl}_{2}$ & $\begin{array}{l}\text { Fe (II)-Ascorbate } \\
\text { induced LP }\end{array}$ & $90.36 \%$ at $200 \mu \mathrm{g} / \mathrm{mL}$ & Cameroon & [117] \\
\hline Cylicodiscusgabunensis Harms. & Mimosaceae & Bark & $\mathrm{MeOH}$ & DPPH & $28.00 \%$ & Cameroon & [53] \\
\hline Cymbopogon citrates Stapf. & Poaceae & Leaf & $\mathrm{BtOH}$ & $\begin{array}{l}\text { DPPH/FRAP/RP/ } \\
\mathrm{H}_{2} \mathrm{O}_{2} / \mathrm{NO}\end{array}$ & - & Angola & [271] \\
\hline Cymbopogon citrates Stapf. & Poaceae & Leaf & $\mathrm{MeOH}$ & DPPH & $6.05 \%$ & Cameroon & [53] \\
\hline Cymbopogon citrates Stapf. & Poaceae & $\begin{array}{l}\text { Bark/Leaf/ } \\
\text { Rhizome }\end{array}$ & $\mathrm{MeOH} ; \mathrm{CH}_{2} \mathrm{Cl}_{2}$ & $\begin{array}{l}\text { Fe (II)-Ascorbate } \\
\text { induced LP }\end{array}$ & $-9.66 \%$ at $200 \mu \mathrm{g} / \mathrm{mL}$ & Cameroon & [117] \\
\hline $\begin{array}{l}\text { Dacryodes edulis (G.Don) H.J. } \\
\text { Lam. }\end{array}$ & Burseraceae & Leaf & $\mathrm{MeOH}$ & $\mathrm{DPPH}$ & $93.01 \%$ & Cameroon & {$[53]$} \\
\hline $\begin{array}{l}\text { Dacryodes edulis (G.Don) H.J. } \\
\text { Lam. }\end{array}$ & Burseraceae & $\begin{array}{l}\text { Bark/Leaf/ } \\
\text { Rhizome }\end{array}$ & $\mathrm{MeOH} ; \mathrm{CH}_{2} \mathrm{Cl}_{2}$ & $\begin{array}{l}\text { Fe (II)-Ascorbate } \\
\text { induced LP }\end{array}$ & $-8.20 \%$ at $200 \mu \mathrm{g} / \mathrm{mL}$ & Cameroon & [117] \\
\hline $\begin{array}{l}\text { Dichrocephala integrifolia (L.F) } \\
\text { Knntze. }\end{array}$ & Asteraceae & $\begin{array}{l}\text { Bark/Leaf/ } \\
\text { Rhizome }\end{array}$ & $\mathrm{MeOH} ; \mathrm{CH}_{2} \mathrm{Cl}_{2}$ & $\begin{array}{l}\text { Fe (II)-Ascorbate } \\
\text { induced LP }\end{array}$ & $25.43 \%$ at $200 \mu \mathrm{g} / \mathrm{mL}$ & Cameroon & [117] \\
\hline Dichrostachys glomerata Chi. & Mimosaceae & Seed & $\mathrm{EtOAc} / \mathrm{MeOH}$ & $\mathrm{DPPH}$ & High & Cameroon & {$[272]$} \\
\hline Dissotis perkinsiae Gilg. & Melastomaceae & Leaf & $\mathrm{EtOH}$ & DPPH & $130.66 \mu \mathrm{g} / \mathrm{mL}$ & Cameroon & [265] \\
\hline Dorstenia barteri Bureau. & Moraceae & Leaf/Twig & $\mathrm{EtOAc/MeOH}$ & $\mathrm{DPPH}$ & $60.46 / 48.12 \mu \mathrm{g} / \mathrm{mL}$ & Cameroon & [31] \\
\hline Dracaena deisteliana Engl. & Dracaenaceae & Leaf & $\mathrm{MeOH}$ & $\mathrm{DPPH}$ & $6.66 \%$ & Cameroon & {$[53]$} \\
\hline Draceana deisteliana Engl. & Agavaceae & $\begin{array}{l}\text { Bark/Leaf/ } \\
\text { Rhizome }\end{array}$ & $\mathrm{MeOH} ; \mathrm{CH}_{2} \mathrm{Cl}_{2}$ & $\begin{array}{l}\text { Fe (II)-Ascorbate } \\
\text { induced LP }\end{array}$ & $-0.46 \%$ at $200 \mu \mathrm{g} / \mathrm{mL}$ & Cameroon & {$[117]$} \\
\hline Ekebergia senegalensis Fuss. & Meliaceae & Back & $\mathrm{MeOH}$ & $\mathrm{DPPH}$ & $15.83 \mu \mathrm{g} / \mathrm{mL}$ & Cameroon & [269] \\
\hline Ekebergia senegalensis Fuss. & Meliaceae & Bark & $\mathrm{MeOH}$ & DPPH/NOSA & $15.83 / 299 \mu \mathrm{g} / \mathrm{mL}$ & Cameroon & [269] \\
\hline Eleusine indica Gaertn. & Poaceae & Leaf & $\mathrm{MeOH}$ & DPPH & $1.36 \%$ & Cameroon & {$[53]$} \\
\hline Emilia coccinia Cass. & Asteraceae & $\begin{array}{l}\text { Bark/Leaf/ } \\
\text { Rhizome }\end{array}$ & $\mathrm{MeOH} ; \mathrm{CH}_{2} \mathrm{Cl}_{2}$ & $\begin{array}{l}\text { Fe (II)-Ascorbate } \\
\text { induced LP }\end{array}$ & $-1.51 \%$ at $200 \mu \mathrm{g} / \mathrm{mL}$ & Cameroon & [117] \\
\hline Emilia cocinea Cass. & Asteraceae & Leaf & $\mathrm{MeOH}$ & $\mathrm{DPPH}$ & $2.99 \%$ & Cameroon & [53] \\
\hline Enantia chlorantha Oliv. & Anonaceae & $\begin{array}{l}\text { Bark/Leaf/ } \\
\text { Rhizome }\end{array}$ & $\mathrm{MeOH} ; \mathrm{CH}_{2} \mathrm{Cl}_{2}$ & $\begin{array}{l}\text { Fe (II)-Ascorbate } \\
\text { induced LP }\end{array}$ & $53.97 \%$ at $200 \mu \mathrm{g} / \mathrm{mL}$ & Cameroon & {$[117]$} \\
\hline Entada africana Guill \& perr. & Mimosaceae & $\begin{array}{l}\text { Bark/Leaf/ } \\
\text { Rhizome }\end{array}$ & $\mathrm{MeOH} ; \mathrm{CH}_{2} \mathrm{Cl}_{2}$ & $\begin{array}{l}\text { Fe (II)-Ascorbate } \\
\text { induced LP }\end{array}$ & $82.73 \%$ at $200 \mu \mathrm{g} / \mathrm{mL}$ & Cameroon & [117] \\
\hline Entandophragma angolense L. & Meliaceae & Bark & $\mathrm{MeOH}$ & $\mathrm{DPPH}$ & 7.60 & Cameroon & [53] \\
\hline $\begin{array}{l}\text { Eremomastas speciosa (Hochst.) } \\
\text { Cufod. }\end{array}$ & Acanthaceae & $\begin{array}{l}\text { Bark/Leaf/ } \\
\text { Rhizome }\end{array}$ & $\mathrm{MeOH} ; \mathrm{CH}_{2} \mathrm{Cl}_{2}$ & $\begin{array}{l}\text { Fe (II)-Ascorbate } \\
\text { induced LP }\end{array}$ & $46.16 \%$ at $200 \mu \mathrm{g} / \mathrm{mL}$ & Cameroon & {$[117]$} \\
\hline Eremomastas speciosa (Hochst.) & Acanthaceae & Leaf & $\mathrm{MeOH}$ & $\mathrm{DPPH} / \mathrm{NO}$ & $454 / 278 \mu \mathrm{g} / \mathrm{mL}$ & Cameroon & [269] \\
\hline
\end{tabular}


Table 4 Antioxidants activities of Central African plants (Continued)

\begin{tabular}{|c|c|c|c|c|c|c|c|}
\hline $\begin{array}{l}\text { Eremomastas speciosa (Hochst.) } \\
\text { Cufod. }\end{array}$ & Acanthaceae & Leaf & $\mathrm{MeOH}$ & $\mathrm{DPPH}$ & $454 \mu \mathrm{g} / \mathrm{mL}$ & Cameroon & [269] \\
\hline $\begin{array}{l}\text { Eremomastas speciosa (Hochst.) } \\
\text { Cufod. }\end{array}$ & Acanthaceae & Leaf & $\mathrm{MeOH}$ & DPPH & $5.43 \%$ & Cameroon & [53] \\
\hline $\begin{array}{l}\text { Eriobotrya japonica (Thunb) } \\
\text { Lindl }\end{array}$ & Rosaceae & Stem bark & $\mathrm{MeOH}$ & DPPH & $16.55 \mu \mathrm{g} / \mathrm{mL}$ & Cameroon & {$[270]$} \\
\hline Erythrina Senegalensis L. & Fabaceae & Stem bark & $\mathrm{EtOH}$ & $\begin{array}{l}\text { B-CLAMS/FRAP/ } \\
\text { MLP }\end{array}$ & $\begin{array}{l}\text { 12.35/, 10.24/1.47 } \mu \mathrm{g} / \\
\mathrm{mL}\end{array}$ & Cameroon & [273] \\
\hline Erythrina Senegalensis L. & Fabaceae & Stem bark & $\mathrm{MeOH}$ & $\mathrm{DPPH}$ & $46.9 \mu \mathrm{g} / \mathrm{mL}$ & Cameroon & {$[274]$} \\
\hline Erythrina senegalensis L. & Fabaceae & $\begin{array}{l}\text { Bark/Leaf/ } \\
\text { Rhizome }\end{array}$ & $\mathrm{MeOH} ; \mathrm{CH}_{2} \mathrm{Cl}_{2}$ & $\begin{array}{l}\text { Fe (II)-Ascorbate } \\
\text { induced LP }\end{array}$ & $94.25 \%$ at $200 \mu \mathrm{g} / \mathrm{mL}$ & Cameroon & [117] \\
\hline Erythrina vogelii Hook. f. & Fabaceae & Leaf & $\mathrm{MeOH}$ & DPPH & $>200 \mu \mathrm{g} / \mathrm{mL}$ & Cameroon & [140] \\
\hline Eucalyptus oblique L Her. & Myrtaceae & $\begin{array}{l}\text { Bark/Leaf/ } \\
\text { Rhizome }\end{array}$ & $\mathrm{MeOH} ; \mathrm{CH}_{2} \mathrm{Cl}_{2}$ & $\begin{array}{l}\text { Fe (II)-Ascorbate } \\
\text { induced LP }\end{array}$ & $76.19 \%$ at $200 \mu \mathrm{g} / \mathrm{mL}$ & Cameroon & [117] \\
\hline Faraga macrophylla & Rutaceae & Bark & $\mathrm{MeOH}$ & $\mathrm{DPPH}$ & $2.29 \%$ & Cameroon & [53] \\
\hline Ficus asperifolia Miq. & Moraceae & Stem bark & $\mathrm{MeOH}$ & $\mathrm{DPPH}$ & Least activity & Cameroon & {$[272]$} \\
\hline Ficus exasperata Vahl. & Moraceae & $\begin{array}{l}\text { Bark/Leaf/ } \\
\text { Rhizome }\end{array}$ & $\mathrm{MeOH} ; \mathrm{CH}_{2} \mathrm{Cl}_{2}$ & $\begin{array}{l}\text { Fe (II)-Ascorbate } \\
\text { induced LP }\end{array}$ & $-6.98 \%$ at $200 \mu \mathrm{g} / \mathrm{mL}$ & Cameroon & [117] \\
\hline Ficus sur Forssk. & Moraceae & Leaf & $\mathrm{MeOH}$ & DPPH & $4.91 \%$ & Cameroon & [53] \\
\hline Garcinia lucida Vesque. & Clusiaceae & Fruit/Bark & $\mathrm{MeOH}$ & $\mathrm{DPPH}, \mathrm{NO}, \mathrm{HO}$ & $\begin{array}{l}\text { 1.83,3.12,1.99/ } \\
2.35,3.59,2.01 \mu \mathrm{g} / \mathrm{mL}\end{array}$ & Cameroon & {$[52]$} \\
\hline Gardenia aqualla J.Ellis & Rubiaceae & Leaf & $\mathrm{MeOH}$ & $\mathrm{DPPH} / \mathrm{NO}$ & $105.9 / 253 \mu \mathrm{g} / \mathrm{mL}$ & Cameroon & [269] \\
\hline Gardenia aqualla J.Ellis & Rubiaceae & Leaf & $\mathrm{MeOH}$ & DPPH/NOSA & $105.90 / 278.00 \mu \mathrm{g} / \mathrm{mL}$ & Cameroon & [269] \\
\hline Gladiolus dalenii L. & Iridaceae & $\begin{array}{l}\text { Bark/Leaf/ } \\
\text { Rhizome }\end{array}$ & $\mathrm{MeOH} ; \mathrm{CH}_{2} \mathrm{Cl}_{2}$ & $\begin{array}{l}\text { Fe (II)-Ascorbate } \\
\text { induced LP }\end{array}$ & $-8.23 \%$ at $200 \mu \mathrm{g} / \mathrm{mL}$ & Cameroon & [117] \\
\hline Gosypium barbadense L. & Malvaceae & $\begin{array}{l}\text { Bark/Leaf/ } \\
\text { Rhizome }\end{array}$ & $\mathrm{MeOH} ; \mathrm{CH}_{2} \mathrm{Cl}_{2}$ & $\begin{array}{l}\text { Fe (II)-Ascorbate } \\
\text { induced LP }\end{array}$ & $56.98 \%$ at $200 \mu \mathrm{g} / \mathrm{mL}$ & Cameroon & [117] \\
\hline $\begin{array}{l}\text { Harungana madagascariensis } \\
\text { Lam. }\end{array}$ & Hypercaceae & Leaf & $\mathrm{MeOH}$ & $\mathrm{DPPH}$ & $90.15 \%$ & Cameroon & [53] \\
\hline $\begin{array}{l}\text { Harungana madagascariensis } \\
\text { Lam. }\end{array}$ & Hypericaceae & $\begin{array}{l}\text { Bark/Leaf/ } \\
\text { Rhizome }\end{array}$ & $\mathrm{MeOH} ; \mathrm{CH}_{2} \mathrm{Cl}_{2}$ & $\begin{array}{l}\text { Fe (II)-Ascorbate } \\
\text { induced LP }\end{array}$ & $81.75 \%$ at $200 \mu \mathrm{g} / \mathrm{mL}$ & Cameroon & [117] \\
\hline Hibiscus asper Hook. f. & Malvaceae & Aerial parts & $\mathrm{n}-\mathrm{C}_{6} \mathrm{H}_{12}$ & $\mathrm{DPPH}$ & Least activity & Cameroon & {$[272]$} \\
\hline Hymenocardia lyrata Miq. & Phllantaceae & Root/bark & $\mathrm{MeOH}$ & $\mathrm{DPPH} / \mathrm{NO} / \mathrm{HO}$ & $\begin{array}{l}1.96,3.82,2.43 / \\
1.74,2.46,3.30 \mu \mathrm{g} / \mathrm{mL}\end{array}$ & Cameroon & {$[52]$} \\
\hline Ipomea batatas Blackie. & Convolvulaceae & $\begin{array}{l}\text { Bark/Leaf/ } \\
\text { Rhizome }\end{array}$ & $\mathrm{MeOH} ; \mathrm{CH}_{2} \mathrm{Cl}_{2}$ & $\begin{array}{l}\text { Fe (II)-Ascorbate } \\
\text { induced LP }\end{array}$ & $14.30 \%$ at $200 \mu \mathrm{g} / \mathrm{mL}$ & Cameroon & [117] \\
\hline Irvingia wombolu Hook. f. & Irvingiaceae & Pulp & $\mathrm{H}_{2} \mathrm{O}$ & $\begin{array}{l}\text { DPPH/FRAP/ABTS. } \\
\mathrm{OH}\end{array}$ & $\begin{array}{l}37.86 / 15.55 / 55.53 \% 31.63 \\
\text { at } 1 \mathrm{mg} / \mathrm{mL}\end{array}$ & Cameroon & {$[275]$} \\
\hline $\begin{array}{l}\text { Kalonchoe crenata (Andrews) } \\
\text { Haw. }\end{array}$ & Crasulaceae & $\begin{array}{l}\text { Bark/Leaf/ } \\
\text { Rhizome }\end{array}$ & $\mathrm{MeOH} ; \mathrm{CH}_{2} \mathrm{Cl}_{2}$ & $\begin{array}{l}\text { Fe (II)-Ascorbate } \\
\text { induced LP }\end{array}$ & $73.70 \%$ at $200 \mu \mathrm{g} / \mathrm{mL}$ & Cameroon & [117] \\
\hline Khaya grandifoliola C. DC. & Meliaceae & $\begin{array}{l}\text { Bark/Leaf/ } \\
\text { Rhizome }\end{array}$ & $\mathrm{MeOH} ; \mathrm{CH}_{2} \mathrm{Cl}_{2}$ & $\begin{array}{l}\text { Fe (II)-Ascorbate } \\
\text { induced LP }\end{array}$ & $78.91 \%$ at $200 \mu \mathrm{g} / \mathrm{mL}$ & Cameroon & [117] \\
\hline $\begin{array}{l}\text { Lannea kerstingii Engl. \& K. } \\
\text { Krause. }\end{array}$ & Anacardiaceae & Back & $\mathrm{MeOH}$ & $\mathrm{DPPH} / \mathrm{NO}$ & $34.40 / 306 \mu \mathrm{g} / \mathrm{mL}$ & Cameroon & [269] \\
\hline $\begin{array}{l}\text { Lannea kerstingii Engl. \& K. } \\
\text { Krause. }\end{array}$ & Anacardiaceae & Bark & $\mathrm{MeOH}$ & DPPH/NOSA & $34.40 / 253.00 \mu \mathrm{g} / \mathrm{mL}$ & Cameroon & [269] \\
\hline Lantana camara L. & Verbenaceae & Leaf & $\mathrm{MeOH}$ & $\mathrm{DPPH}$ & $23.47 \%$ & Cameroon & [53] \\
\hline Lippia adoensis L. & Lamiaceae & Leaf & $\mathrm{MeOH}$ & DPPH & $10.41 \%$ & Cameroon & {$[53]$} \\
\hline Lygopodium macrophyllum L. & Pteridophyte & Leaf & $\mathrm{MeOH}$ & $\mathrm{DPPH}$ & $14.72 \%$ & Cameroon & {$[53]$} \\
\hline Mangifera indica L. & Anacardiaceae & $\begin{array}{l}\text { Bark/Leaf/ } \\
\text { Rhizome }\end{array}$ & $\mathrm{MeOH} ; \mathrm{CH}_{2} \mathrm{Cl}_{2}$ & $\begin{array}{l}\text { Fe (II)-Ascorbate } \\
\text { induced LP }\end{array}$ & $75.35 \%$ at $200 \mu \mathrm{g} / \mathrm{mL}$ & Cameroon & [117] \\
\hline Manihot esculenta Crantz. & Euphorbiaceae & $\begin{array}{l}\text { Bark/Leaf/ } \\
\text { Rhizome }\end{array}$ & $\mathrm{MeOH} ; \mathrm{CH}_{2} \mathrm{Cl}_{2}$ & $\begin{array}{l}\text { Fe (II)-Ascorbate } \\
\text { induced LP }\end{array}$ & $-4.80 \%$ at $200 \mu \mathrm{g} / \mathrm{mL}$ & Cameroon & [117] \\
\hline
\end{tabular}


Table 4 Antioxidants activities of Central African plants (Continued)

\begin{tabular}{|c|c|c|c|c|c|c|c|}
\hline Melinis minutiflora P. Beauv. & Poaceae & $\begin{array}{l}\text { Bark/Leaf/ } \\
\text { Rhizome }\end{array}$ & $\mathrm{MeOH} ; \mathrm{CH}_{2} \mathrm{Cl}_{2}$ & $\begin{array}{l}\text { Fe (II)-Ascorbate } \\
\text { induced LP }\end{array}$ & $58.47 \%$ at $200 \mu \mathrm{g} / \mathrm{mL}$ & Cameroon & [117] \\
\hline Mimosa pudica L. & Mimosaceae & Leaf & $\mathrm{MeOH}$ & $\mathrm{DPPH}$ & $19.37 \%$ & Cameroon & [53] \\
\hline Musa sapientum L. & Musaceae & $\begin{array}{l}\text { Bark/Leaf/ } \\
\text { Rhizome }\end{array}$ & $\mathrm{MeOH} ; \mathrm{CH}_{2} \mathrm{Cl}_{2}$ & $\begin{array}{l}\text { Fe (II)-Ascorbate } \\
\text { induced LP }\end{array}$ & $-9.33 \%$ at $200 \mu \mathrm{g} / \mathrm{mL}$ & Cameroon & [117] \\
\hline Nauclea latifolia Sm. & Rubiaceae & $\begin{array}{l}\text { Bark/Leaf/ } \\
\text { Rhizome }\end{array}$ & $\mathrm{MeOH} ; \mathrm{CH}_{2} \mathrm{Cl}_{2}$ & $\begin{array}{l}\text { Fe (II)-Ascorbate } \\
\text { induced LP }\end{array}$ & $43.02 \%$ at $200 \mu \mathrm{g} / \mathrm{mL}$ & Cameroon & {$[117]$} \\
\hline Occimum gratissimum L. & Labieae & $\begin{array}{l}\text { Bark/Leaf/ } \\
\text { Rhizome }\end{array}$ & $\mathrm{MeOH} ; \mathrm{CH}_{2} \mathrm{Cl}_{2}$ & $\begin{array}{l}\text { Fe (II)-Ascorbate } \\
\text { induced LP }\end{array}$ & $68.01 \%$ at $200 \mu \mathrm{g} / \mathrm{mL}$ & Cameroon & [117] \\
\hline Ocimum basilicum L. & Lamiaceae & Leaf & $\mathrm{MeOH}$ & $\mathrm{DPPH}$ & $39.98 \%$ & Cameroon & [53] \\
\hline Olax subscorpioideae Oliv. & Olacaceae & $\begin{array}{l}\text { Bark/Leaf/ } \\
\text { Rhizome }\end{array}$ & $\mathrm{MeOH} ; \mathrm{CH}_{2} \mathrm{Cl}_{2}$ & $\begin{array}{l}\text { Fe (II)-Ascorbate } \\
\text { induced LP }\end{array}$ & $44.71 \%$ at $200 \mu \mathrm{g} / \mathrm{mL}$ & Cameroon & {$[117]$} \\
\hline Paullinia pinnata L. & Sapindaceae & Leaf & $\mathrm{n}-\mathrm{C}_{6} \mathrm{H}_{12}$ & $\mathrm{DPPH}$ & Least activity & Cameroon & {$[272]$} \\
\hline Pentadesma butyracea Sabine. & Clusiaceae & Fruits & $\mathrm{MeOH}$ & $\mathrm{DPPH}$ & High & Cameroon & {$[272]$} \\
\hline Persea americana Mlill. & Lauraceae & Leaf & $\mathrm{MeOH}$ & DPPH & $69.91 \%$ & Cameroon & [53] \\
\hline Persea americana Mlill. & Lauraceae & $\begin{array}{l}\text { Bark/Leaf/ } \\
\text { Rhizome }\end{array}$ & $\mathrm{MeOH} ; \mathrm{CH}_{2} \mathrm{Cl}_{2}$ & $\begin{array}{l}\text { Fe (II)-Ascorbate } \\
\text { induced LP }\end{array}$ & $24.31 \%$ at $200 \mu \mathrm{g} / \mathrm{mL}$ & Cameroon & [117] \\
\hline Persea americana Mlill. & Lauraceae & $\begin{array}{l}\text { Bark/Leaf/ } \\
\text { Rhizome }\end{array}$ & $\mathrm{MeOH} ; \mathrm{CH}_{2} \mathrm{Cl}_{2}$ & $\begin{array}{l}\text { Fe (II)-Ascorbate } \\
\text { induced LP }\end{array}$ & $44.85 \%$ at $200 \mu \mathrm{g} / \mathrm{mL}$ & Cameroon & {$[117]$} \\
\hline Piliostigma thonningii Mlill. & Cesalpilaceae & $\begin{array}{l}\text { Bark/Leaf/ } \\
\text { Rhizome }\end{array}$ & $\mathrm{MeOH} ; \mathrm{CH}_{2} \mathrm{Cl}_{2}$ & $\begin{array}{l}\text { Fe (II)-Ascorbate } \\
\text { induced LP }\end{array}$ & $74.26 \%$ at $200 \mu \mathrm{g} / \mathrm{mL}$ & Cameroon & {$[117]$} \\
\hline Polyscias fulva Harns (Hieram). & Araliaceae & $\begin{array}{l}\text { Bark/Leaf/ } \\
\text { Rhizome }\end{array}$ & $\mathrm{MeOH} ; \mathrm{CH}_{2} \mathrm{Cl}_{2}$ & $\begin{array}{l}\text { Fe (II)-Ascorbate } \\
\text { induced LP }\end{array}$ & $-0.01 \%$ at $200 \mu \mathrm{g} / \mathrm{mL}$ & Cameroon & [117] \\
\hline Protea elliotii C.H. Wright. & Proteaceae & Back & $\mathrm{MeOH}$ & $\mathrm{DPPH} / \mathrm{NO}$ & $14.20 / 205 \mu \mathrm{g} / \mathrm{mL}$ & Cameroon & [269] \\
\hline Protea elliotii C.H. Wright. & Proteaceae & Bark & $\mathrm{MeOH}$ & DPPH/NOSA & $14.20 / 306.00 \mu \mathrm{g} / \mathrm{mL}$ & Cameroon & {$[269]$} \\
\hline Prunus Africana (Hook. f.) & Rosaceae & Bark & $\mathrm{MeOH}$ & DPPH & $22.10 \%$ & Cameroon & [53] \\
\hline Psidium guajava $\mathrm{L}$. & Myrsinacee & Leaf & $\mathrm{MeOH}$ & DPPH & $39.84 \%$ & Cameroon & {$[53]$} \\
\hline Psidium guayava $\mathrm{L}$. & Myrtaceae & $\begin{array}{l}\text { Bark/Leaf/ } \\
\text { Rhizome }\end{array}$ & $\mathrm{MeOH} ; \mathrm{CH}_{2} \mathrm{Cl}_{2}$ & $\begin{array}{l}\text { Fe (II)-Ascorbate } \\
\text { induced LP }\end{array}$ & $50.47 \%$ at $200 \mu \mathrm{g} / \mathrm{mL}$ & Cameroon & [117] \\
\hline $\begin{array}{l}\text { Psorospermum febrifugum } \\
\text { Spach. }\end{array}$ & Guttiferae & Stem bark & $\mathrm{MeOH}$ & DPPH & Least activity & Cameroon & {$[272]$} \\
\hline Pycnocycla ledernanii Wolff. & Apiaceae & Leaf & $\mathrm{MeOH}$ & DPPH & $8.57 \%$ & Cameroon & {$[53]$} \\
\hline Rumex abyssinicus Jacq. & Polygonaceae & Bulb & $\mathrm{MeOH}$ & $\mathrm{DPPH}$ & High activity & Cameroon & {$[272]$} \\
\hline Rumex bequaertii De wild. & Polygonaceae & Bulb & $\mathrm{MeOH}$ & $\mathrm{DPPH}$ & High activity & Cameroon & {$[272]$} \\
\hline Senna alata $\mathrm{L}$. & Fabaceae & $\begin{array}{l}\text { Bark/Leaf/ } \\
\text { Rhizome }\end{array}$ & $\mathrm{MeOH} ; \mathrm{CH}_{2} \mathrm{Cl}_{2}$ & $\begin{array}{l}\text { Fe (II)-Ascorbate } \\
\text { induced LP }\end{array}$ & $88.50 \%$ at $200 \mu \mathrm{g} / \mathrm{mL}$ & Cameroon & {$[117]$} \\
\hline Senna siamea Lam. & Fabaceae & Leaf & $\mathrm{MeOH}$ & DPPH & $236 \mu \mathrm{g} / \mathrm{mL}$ & Cameroon & [269] \\
\hline Senna siamea Lam. & Fabaceae & Leaf & $\mathrm{MeOH}$ & $\mathrm{DPPH}$ & $236 \mu \mathrm{g} / \mathrm{mL}$ & Cameroon & [269] \\
\hline Solanum acaleastrum & Solanaceae & $\begin{array}{l}\text { Bark/Leaf/ } \\
\text { Rhizome }\end{array}$ & $\mathrm{MeOH} ; \mathrm{CH}_{2} \mathrm{Cl}_{2}$ & $\begin{array}{l}\text { Fe (II)-Ascorbate } \\
\text { induced LP }\end{array}$ & $28.57 \%$ at $200 \mu \mathrm{g} / \mathrm{mL}$ & Cameroon & [117] \\
\hline Sonchus oleraceus L. & Asteraceae & $\begin{array}{l}\text { Bark/Leaf/ } \\
\text { Rhizome }\end{array}$ & $\mathrm{MeOH} ; \mathrm{CH}_{2} \mathrm{Cl}_{2}$ & $\begin{array}{l}\text { Fe (II)-Ascorbate } \\
\text { induced LP }\end{array}$ & $31.02 \%$ at $200 \mu \mathrm{g} / \mathrm{mL}$ & Cameroon & [117] \\
\hline $\begin{array}{l}\text { Spilanthes filicaulis (Schum. \& } \\
\text { Thonn.) C.D. Adam. }\end{array}$ & Asteraceae & $\begin{array}{l}\text { Bark/Leaf/ } \\
\text { Rhizome }\end{array}$ & $\mathrm{MeOH} ; \mathrm{CH}_{2} \mathrm{Cl}_{2}$ & $\begin{array}{l}\text { Fe (II)-Ascorbate } \\
\text { induced LP }\end{array}$ & $58.93 \%$ at $200 \mu \mathrm{g} / \mathrm{mL}$ & Cameroon & {$[117]$} \\
\hline Syzyguim guineense Wall. & Myrtaceae & Leaf & $\mathrm{MeOH} ; \mathrm{H}_{2} \mathrm{O}$ & DPPH/ABTS/OH & $\begin{array}{l}5.52 \mathrm{~g} / \mathrm{mL} / 16.25 \mathrm{mg} / \\
\mathrm{mL} / 126.35 \mathrm{~g} / \mathrm{mL}\end{array}$ & Cameroon & {$[276]$} \\
\hline Tectona grandis L.F. & Lamiaceae & Leaf & $\mathrm{MeOH}$ & $\mathrm{DPPH}$ & Least activity & Cameroon & {$[272]$} \\
\hline Terminalia glaucescens Planch. & Combretaceae & $\begin{array}{l}\text { Bark/Leaf/ } \\
\text { Rhizome }\end{array}$ & $\mathrm{MeOH} ; \mathrm{CH}_{2} \mathrm{Cl}_{2}$ & $\begin{array}{l}\text { Fe (II)-Ascorbate } \\
\text { induced LP }\end{array}$ & $47.68 \%$ at $200 \mu \mathrm{g} / \mathrm{mL}$ & Cameroon & [117] \\
\hline Terminalia macroptera Mart. & Combretaceae & Root & $\mathrm{MeOH}$ & DPPH/NO & $19.90 / 290 \mu \mathrm{g} / \mathrm{mL}$ & Cameroon & [269] \\
\hline
\end{tabular}


Table 4 Antioxidants activities of Central African plants (Continued)

\begin{tabular}{|c|c|c|c|c|c|c|c|}
\hline Terminalia macroptera Mart. & Combretaceae & Root & $\mathrm{MeOH}$ & DPPH/NOSA & $19.90 / 205.00 \mu \mathrm{g} / \mathrm{mL}$ & Cameroon & [269] \\
\hline Trema orientalis Blume. & Ulmaceae & $\begin{array}{l}\text { Bark/Leaf/ } \\
\text { Rhizome }\end{array}$ & $\mathrm{MeOH} ; \mathrm{CH}_{2} \mathrm{Cl}_{2}$ & $\begin{array}{l}\text { Fe (II)-Ascorbate } \\
\text { induced LP }\end{array}$ & $-5.23 \%$ at $200 \mu \mathrm{g} / \mathrm{mL}$ & Cameroon & [117] \\
\hline Urena lobata L. & Malvaceae & Leaf & $\mathrm{MeOH}$ & DPPH & $9.70 \%$ & Cameroon & {$[53]$} \\
\hline Vernonia amygdalina Delile. & Asteraceae & $\begin{array}{l}\text { Bark/Leaf/ } \\
\text { Rhizome }\end{array}$ & $\mathrm{MeOH} ; \mathrm{CH}_{2} \mathrm{Cl}_{2}$ & $\begin{array}{l}\text { Fe (II)-Ascorbate } \\
\text { induced LP }\end{array}$ & $33.49 \%$ at $200 \mu \mathrm{g} / \mathrm{mL}$ & Cameroon & [117] \\
\hline Vismia laurentii De Wild. & Guttiferae & Stem bark & $\mathrm{EtOAc} / \mathrm{MeOH}$ & $\mathrm{DPPH}$ & High & Cameroon & {$[272]$} \\
\hline Vitellaria paradoxa C.F.Gaertn. & Sapotaceae & Back & $\mathrm{MeOH}$ & DPPH/NO & $22.14 / 108 \mu \mathrm{g} / \mathrm{mL}$ & Cameroon & [269] \\
\hline Voacanga africana Stapf. & Apocynaceae & $\begin{array}{l}\text { Bark/Leaf/ } \\
\text { Rhizom }\end{array}$ & $\mathrm{MeOH} ; \mathrm{CH}_{2} \mathrm{Cl}_{2}$ & $\begin{array}{l}\text { Fe(II)-Ascorbate } \\
\text { induced LP }\end{array}$ & $100.00 \%$ at $200 \mu \mathrm{g} / \mathrm{mL}$ & Cameroon & [117] \\
\hline Voacanga africana Stapf. & Apocynaceae & Bark & $\mathrm{MeOH}$ & DPPH & $3.73 \%$ & Cameroon & {$[53]$} \\
\hline $\begin{array}{l}\text { Xanthosoma sagittifolium (L.) } \\
\text { schott. }\end{array}$ & Araceae & $\begin{array}{l}\text { Bark/Leaf/ } \\
\text { Rhizome }\end{array}$ & $\mathrm{MeOH} ; \mathrm{CH}_{2} \mathrm{Cl}_{2}$ & $\begin{array}{l}\text { Fe(II)-Ascorbate } \\
\text { induced LP }\end{array}$ & $48.01 \%$ at $200 \mu \mathrm{g} / \mathrm{mL}$ & Cameroon & {$[117]$} \\
\hline Zea mays $L$. & Poaceae & Leaf & $\mathrm{MeOH}$ & $\mathrm{DPPH}$ & $12.06 \%$ & Cameroon & [53] \\
\hline
\end{tabular}

Key: $R S A$ radical scavenging activity, $R C$ reducing power capacity, $\mathrm{OH}$ hydroxyl ion, $\mathrm{NO}$ nitric oxide radical inhibition, $\mathrm{H}_{2} \mathrm{O}_{2}$ hydrogen peroxide inhibition activity, LPO lipid peroxidation inhibition activity, $A B T S^{+}$2,2'-azinobis-3-ethylbenzothiozolin-6-sulfonic acid cation decolourization test, ß-CLAMS ß-carotene-linoleic acid model system, SORSA superoxide anion radical scavenging activity (SORSA), MLP microsomal lipid peroxydation, $F R A P$ fe ${ }^{2+}$ chelating ability and ferric reducing antioxidant properties, DPPH 1,1-dipheyl-2-picry-hydrazyl, ORAC oxygen radical absorbance capacity, TEAC trolox equivalent antioxidant capacity, MeOH methanol, $\mathrm{CH}_{2} \mathrm{Cl}_{2}$ dichloromethane, EtOH ethanol, EtOAc ethyl acetate, $n-\mathrm{C}_{6} \mathrm{H}_{12}$ hexane, $\left(\mathrm{CH}_{3}\right)_{2} \mathrm{CO}$ acetone, $\mathrm{H}_{2} \mathrm{O}$ aqueous, $\mathrm{BtOH}$ butanol

induced alterations in level of these biochemical parameters (Table 8).

\section{Antioxidant activities of extracts of plants from Western Africa}

A total of 341 plants species representing 77 families from Western Africa plants were documented to have antioxidant activities (Table 1). Plant extracts from twenty five plants showed significant antioxidant capacity $\left(\mathrm{IC}_{50}<10 \mu \mathrm{g} / \mathrm{mL}\right)$. Fourty eight extracts revealed promising antioxidant activities with $\mathrm{IC}_{50}$ values ranging from 10 to $50 \mu \mathrm{g} / \mathrm{mL}$; while 59 extracts showed moderate antioxidant activities with $\mathrm{IC}_{50}$ values ranging from 50 to $100 \mu \mathrm{g} / \mathrm{mL}$.

Oke and Hamburger [38] and Omale [39] presented the antioxidants activities of some medicinal plant on the basis of degree of color changes in which methanol cortex, folium and radix extract of Cnestis ferruginea, funtumia elastica, Gongronema latifolia, Sphenocentrum jollyanum, Voacanga africana and Landolfia owariensis showed strong intensity of yellow coloration in DPPH radical scavenging assay and were considered to have very high antioxidants activities, while Leea gunensis, Hedranthera barteri, Icacina trichantha, Crinum purpurascenc and Byrsocarpus coccineus revealed moderate intensity of yellow colouration. Determination of antioxidant potential on the basis of FRAP, revealed that 9 plant extracts had minimal FRAP $(<1 \mathrm{mM} / \mathrm{L}), 37$ including Althaeae radix, Foeniculi fructus, Cetrariae lichen and Phaseoli pericarpum had low FRAP (1-5 mM/L), 15 had good FRAP $(5-10 \mathrm{mM} / \mathrm{L})$ while 8 had high FRAP (10-20 mM/L) with the leaf extract of Mellisa officinalis having significant FRAP of $2.52 \mathrm{mM} / \mathrm{L}$ [30]. The extract of the leaves of Mellisa officinalis could be considered as the most suitable candidate for development into antioxidant phytomedicine. The constituent compounds should also be evaluated for their antioxidant potential. Phytochemical investigation of plants from Western Africa exhibiting antioxidant and related activities led to isolation of lophirones B (50) and lophirones C (51) (Table 6 and Fig. 3), from chloroform stem bark of Lophira alata. These two compounds show significant antioxidants activities in DPPH assay (84.4\%, and $90.0 \%$ respectively at $1 \mu \mathrm{g} / \mathrm{mL}$ ) and in vivo antioxidants activity [40]. This study shows that treatments of normal rats with 5,10 , and $20 \mathrm{mg} / \mathrm{kg}$ body of lophirones B (50) and lophirones $\mathrm{C}$ (51) once daily for 2 days increases the activities of ROS detoxifying enzymes (SOD, CAT, GPx, and GR) in the liver of rats when compared to the control.

\section{Antioxidant activities of extracts of plants from Northern Africa}

A total of 345 plants species representing 72 families from Northern Africa plants were documented to have antioxidant activities (Table 2). The antioxidant activities of most plant extracts originating from Northern Africa were determined using the free radical scavenging assays carried out at constant concentration of $50 \mathrm{mg} / \mathrm{mL}$, in order to evaluate the \% radical scavenging activities (RSA). Using this criteria, plant extracts were reported to exhibit low, medium, high and significant activities when their \% RSA were observed to be $<25 \%$, 25-50\%, $50-80 \%$ and $>80 \%$, respectively. Based on this criteria 39 
Table 5 Antioxidants activities of Eastern African plants

\begin{tabular}{|c|c|c|c|c|c|c|c|}
\hline Plants & Family & Part used & Solvents & $\begin{array}{l}\text { Assay } \\
\text { Methods }\end{array}$ & Inhibition/EC 50 & Country & References \\
\hline $\begin{array}{l}\text { Aframomum corrorima } \\
\text { (A. Braun) P.C.M. Jansen. }\end{array}$ & Zingeberaceae & Seed & Oil & $\mathrm{DPPH}$ & $34.9 \mu \mathrm{L} / \mathrm{mL}$ & Ethiopia & {$[277]$} \\
\hline $\begin{array}{l}\text { Afrocantharellus splendens (Buyck) } \\
\text { Tibuhwa. }\end{array}$ & Cantherellaceae & Mushroom & $\mathrm{EtOH}$ & DPPH & $<0.4 \mathrm{mg} / \mathrm{mL}$ & Tanzania & {$[278]$} \\
\hline Afrocantharellus symoensii & Cantherellaceae & Mushroom & $\mathrm{EtOH}$ & DPPH & $<0.2 \mathrm{mg} / \mathrm{mL}$ & Tanzania & {$[278]$} \\
\hline Aloe harlana Reynolds. & Xanthorrhoeaceae & Latex & $\mathrm{EtOH}$ & DPPH & $14.21 \mu \mathrm{g} / \mathrm{mL}$ & Ethiopia & [279] \\
\hline Aloe otallensis Baker. & Asteraceae & Latex & $\mathrm{EtOH}$ & DPPH & $26.9 \mathrm{mg} / \mathrm{mL}$ & Ethiopia & Paulos et al., 2012 \\
\hline Amaranthus dubius Mart. & Amaranthaceae & Leaf & $\mathrm{EtOH}$ & ORAC & $928 \mu \mathrm{MTE} / \mu \mathrm{g}$ & Kenya & {$[56]$} \\
\hline $\begin{array}{l}\text { Apium leptophylum (Pers.) } \\
\text { Sprague ex Britton \& P.Wils }\end{array}$ & Apiaceae & Leaf & Oil & DPPH & $4.3 \mu \mathrm{l} / \mathrm{ml}$ & Ethiopia & {$[280]$} \\
\hline $\begin{array}{l}\text { Artemisia abyssinica Sch. } \\
\text { Bip, ex A. Rich. }\end{array}$ & Compositae & Aerial parts & Oil & DPPH & $28.9 \mu \mathrm{L} / \mathrm{mL}$ & Ethiopia & {$[281]$} \\
\hline Artemisia afra Jacq. ex Wild. & Compositae & Aerial parts & Oil & DPPH & $1.1 \mu \mathrm{L} / \mathrm{mL}$ & Ethiopia & {$[281]$} \\
\hline Azadirachta indica A.Juss. & Meliaceae & Leaf & $\mathrm{EtOH}$ & ORAC & $1761 \mu \mathrm{MTE} / \mu \mathrm{g}$ & Kenya & {$[56]$} \\
\hline Bersama abyssinica Fresen. & melianthaceae & Leaf & $\mathrm{EtOH}$ & DPPH & $7.5 \mu \mathrm{g} / \mathrm{ml}$ & Ethiopia & {$[58]$} \\
\hline Brassica oleracea L. & Brassicaceae & Leaf & $\mathrm{EtOH}$ & ORAC & $1184 \mu \mathrm{MTE} / \mu \mathrm{g}$ & Kenya & {$[56]$} \\
\hline $\begin{array}{l}\text { Cantharellus cascadensis } \\
\text { Dunham, O Dell \& R. Molina. }\end{array}$ & Cantharaceae & Mushroom & $\mathrm{EtOH}$ & DPPH & $<0.2 \mathrm{mg} / \mathrm{mL}$ & Tanzania & {$[278]$} \\
\hline $\begin{array}{l}\text { Cantharellus cyanoxanthus R. } \\
\text { Heim ex Heinem. }\end{array}$ & Cantharaceae & Mushroom & $\mathrm{EtOH}$ & DPPH & $<0.4 \mathrm{mg} / \mathrm{mL}$ & Tanzania & {$[278]$} \\
\hline Cantharellus pseudocibarius Henn. & Cantharaceae & Mushroom & $\mathrm{EtOH}$ & DPPH & $0.14 \mathrm{mg} / \mathrm{mL}$ & Tanzania & {$[278]$} \\
\hline $\begin{array}{l}\text { Cantharellus rufopunctatus } \\
\text { (Beeli) Heinem. }\end{array}$ & Cantharaceae & Mushroom & $\mathrm{EtOH}$ & DPPH & $0.4 \mathrm{mg} / \mathrm{mL}$ & Tanzania & {$[278]$} \\
\hline $\begin{array}{l}\text { Cantharellus tomentosus } \\
\text { Eyssart. \& Buyck. }\end{array}$ & Cantharaceae & Mushroom & $\mathrm{EtOH}$ & DPPH & $<0.4 \mathrm{mg} / \mathrm{mL}$ & Tanzania & {$[278]$} \\
\hline Cheilanthes farinose Sw. & Pteridaceae & Aerial parts & $\mathrm{EtOH}$ & $\mathrm{DPPH}$ & $52.5 \mu \mathrm{g} / \mathrm{ml}$ & Ethiopia & {$[58]$} \\
\hline $\begin{array}{l}\text { Cineraria abyssinica Sch. } \\
\text { Bip. Ex A. Rich. }\end{array}$ & Asteraceae & Leaf & $\mathrm{EtOH} / \mathrm{H}_{2} \mathrm{O}$ & DPPH & $5.78 / 6.27 \mu \mathrm{g} / \mathrm{ml}$ & Ethiopia & {$[57]$} \\
\hline Cucurbita maxima Duschesne. & Cucurbitaceae & Leaf & $\mathrm{EtOH}$ & ORAC & $447 \mu \mathrm{MTE} / \mu \mathrm{g}$ & Kenya & {$[56]$} \\
\hline Delonix elata $\mathrm{L}$. & Fabaceae & Flower & $\mathrm{CO}\left(\mathrm{CH}_{3}\right)_{2} / \mathrm{MeOH} / \mathrm{H}_{2} \mathrm{O}$ & DPPH & $\begin{array}{l}91.3 / 86 / 89.3 \% \\
\text { at } 100 \mu \mathrm{L}\end{array}$ & Ethopia & [282] \\
\hline Eriobotrya japonica (Thunbs) Lindl. & Rosaceae & Fruit & $\mathrm{EtOH}$ & ORAC & $411 \mu \mathrm{MTE} / \mu \mathrm{g}$ & Kenya & {$[56]$} \\
\hline Euclea racemosa $\mathrm{L}$. & Ebenaceae & Leaf & $\left(\mathrm{CH}_{3}\right)_{2} \mathrm{CO}$ & DPPH & $11.3 \mu \mathrm{g} / \mathrm{ml}$ & Ethiopia & {$[58]$} \\
\hline $\begin{array}{l}\text { Hydnora abyssinica } \\
\text { A.Braun ex Schweinf. }\end{array}$ & Hydnoraceae & Leaf & $\mathrm{CH}_{2} \mathrm{Cl}_{2}: \mathrm{MeOH}$ & DPPH & $26.7 \mu \mathrm{g} / \mathrm{mL}$ & Kenya & [283] \\
\hline Juniperus procera Hochst. ex Endl. & Cupressaceae & Aerial parts & Oil & DPPH & $14.9 \mu \mathrm{L} / \mathrm{mL}$ & Ethiopia & {$[281]$} \\
\hline Leucas glabrata (vahl)Sm. & Lamiaceae & Aerial parts & Oil & DPPH & $10.4 \%$ at $100 \mathrm{ppm}$ & Tanzania & {$[284]$} \\
\hline Lippia adoensis Hochst. ex Walp. & Verbenaceae & Leaf & Oil & DPPH & $2.2 \mu \mathrm{l} / \mathrm{ml}$ & Ethiopia & {$[285]$} \\
\hline Lippia adoensis Hochst. ex Walp. & Verbenaceae & Aerial parts & Oil & DPPH & $6.13 \mu \mathrm{L} / \mathrm{mL}$ & Ethiopia & {$[277]$} \\
\hline Mangifera indica $\mathrm{L}$. & Anacardiaceae & Leaf & $\mathrm{EtOH}$ & ORAC & $5940 \mu \mathrm{MTE} / \mu \mathrm{g}$ & Kenya & {$[56]$} \\
\hline Mentha aquatica $\mathrm{L}$. & Lamiaceae & Leaf & Oil & DPPH & $11.2 \mu \mathrm{l} / \mathrm{ml}$ & Ethiopia & {$[286]$} \\
\hline Ocimum americanum L. & Lamiaceae & Leaf & $\mathrm{EtOH}$ & ORAC & $3190 \mu \mathrm{MTE} / \mu \mathrm{g}$ & Kenya & {$[56]$} \\
\hline Ocimum americanum L. & Lamiaceae & Leaf & $\mathrm{CH}_{2} \mathrm{Cl}_{2}$ & DPPH & $50.47 \%$ & Kenya & [287] \\
\hline Ocimum americanum L. & Lamiaceae & Aerial parts & Oil & DPPH & $16 \mu \mathrm{g} / \mathrm{mL}$ & Ethiopia & {$[288]$} \\
\hline Ocimum basilicum L. & Lamiaceae & Aerial parts & Oil & $\mathrm{DPPH}$ & $0.04 \mu \mathrm{L} / \mathrm{mL}$ & Ethiopia & {$[277]$} \\
\hline Ocimum basillicum L. & Lamiaceae & Aerial parts & Oil & DPPH & $60 \mu \mathrm{g} / \mathrm{mL}$ & Ethiopia & {$[288]$} \\
\hline Ocimum gratissimum L. & Lamiaceae & Leaf & $\mathrm{EtOH}$ & ORAC & $1594 \mu \mathrm{MTE} / \mu \mathrm{g}$ & Kenya & {$[56]$} \\
\hline Plectranthus parviflorus Willd. & Lamiaceae & Aerial parts & Oil & DPPH & $3.8 \%$ at $100 \mathrm{ppm}$ & Tanzania & [284] \\
\hline
\end{tabular}


Table 5 Antioxidants activities of Eastern African plants (Continued)

\begin{tabular}{|c|c|c|c|c|c|c|c|}
\hline Psidium guajava $\mathrm{L}$. & Myrtaceae & Leaf & $\mathrm{EtOH}$ & ORAC & 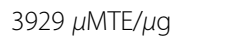 & Kenya & {$[56]$} \\
\hline Rubus apetalus Thunb. & Rosaceae & Leaf & $\mathrm{EtOH}$ & $\mathrm{DPPH}$ & $12.3 \mu \mathrm{g} / \mathrm{mL}$ & Ethiopia & [289] \\
\hline Rubus niveus Thunb. & Rosaceae & Leaf & $\mathrm{EtOH}$ & $\mathrm{DPPH}$ & $19 \mu \mathrm{g} / \mathrm{mL}$ & Ethiopia & [289] \\
\hline Rubus steudneri Schweinf. & Rosaceae & Leaf & $\mathrm{EtOH}$ & DPPH & $6.5 \mu \mathrm{g} / \mathrm{mL}$ & Ethiopia & [289] \\
\hline Salvia nilotica Jacq. & Lamiaceae & Leaf & Oil & $\mathrm{DPPH}$ & $7.52 \mu \mathrm{g} / \mathrm{mL}$ & Ethiopia & [290] \\
\hline Salvia nilotica Jacq. & Lamiaceae & Aerial parts & Oil & $\mathrm{DPPH}$ & $76.2 \%$ at $100 \mathrm{ppm}$ & Tanzania & [284] \\
\hline Salvia schimperi Jansen, P.C.M. & Lamiaceae & Leaf & Oil & DPPH & $6.79 \mu \mathrm{g} / \mathrm{mL}$ & Ethiopia & [290] \\
\hline Satureja punctata (Beth.) Briq. & Lamiaceae & Aerial parts & $\mathrm{H}_{2} \mathrm{O}$ & DPPH & $9.7 \mu \mathrm{g} / \mathrm{mL}$ & Ethiopia & [291] \\
\hline Senna singueana (Delile) & Fabaceae & Leaf & $\mathrm{EtOH}$ & $\mathrm{DPPH}$ & $6.16 \mu \mathrm{g} / \mathrm{mL}$ & Ethiopia & [292] \\
\hline Solanum scabrum Mill. & Solanaceae & Leaf & $\mathrm{EtOH}$ & ORAC & $2675 \mu \mathrm{MTE} / \mu \mathrm{g}$ & Kenya & [56] \\
\hline $\begin{array}{l}\text { Stephania abyssinica Quart. } \\
\text { Dill \& A. Rich. }\end{array}$ & Menispermaceae & Root & $\mathrm{EtOH}$ & $\mathrm{DPPH}$ & $220 \mu \mathrm{g} / \mathrm{mL}$ & Ethiopia & [293] \\
\hline Vernonia smithiana Less. & Asteraceae & Aerial parts & Oil & DPPH & $6.6 \%$ at $100 \mathrm{ppm}$ & Tanzania & [284] \\
\hline Vigna unguiculata (L.) Walp. & Fabaceae & Leaf & $\mathrm{EtOH}$ & ORAC & $1233 \mu \mathrm{MTE} / \mu \mathrm{g}$ & Kenya & [56] \\
\hline Vitex payos (Lour.) Merr. & Verbenaceae & Fruit & $\mathrm{EtOH}$ & ORAC & $179 \mu \mathrm{MTE} / \mu \mathrm{g}$ & Kenya & {$[56]$} \\
\hline Zanthoxylum chalybeum Engl. & Rutaceae & Leaf & $\mathrm{EtOH}$ & ORAC & $2414 \mu \mathrm{MTE} / \mu \mathrm{g}$ & Kenya & [56] \\
\hline Zingiber officinale Roscoe. & Zingiberaceae & Rhizome & Oil & DPPH & $9.66 \mu \mathrm{L} / \mathrm{mL}$ & Ethiopia & [277] \\
\hline
\end{tabular}

Key: $R S A$ radical scavenging activity, $R C$ reducing power capacity, $\mathrm{OH}$ hydroxyl ion, $\mathrm{NO}$ nitric oxide radical inhibition, $\mathrm{H}_{2} \mathrm{O}_{2}$ hydrogen peroxide inhibition activity, LPO lipid peroxidation inhibition activity, $A B T S^{+}$2,2'-azinobis-3-ethylbenzothiozolin-6-sulfonic acid cation decolourization test, ß-CLAMS ß-carotene-linoleic acid model system, SORSA superoxide anion radical scavenging activity (SORSA), MLP microsomal lipid peroxydation, $F R A P$ fe ${ }^{2+}$ chelating ability and ferric reducing antioxidant properties, DPPH 1,1-dipheyl-2-picry-hydrazyl, ORAC oxygen radical absorbance capacity, TEAC trolox equivalent antioxidant capacity, MeOH methanol, $\mathrm{CH}_{2} \mathrm{Cl}_{2}$ dichloromethane, $\mathrm{EtOH}$ ethanol, EtOAc ethyl acetate, $n-\mathrm{C}_{6} \mathrm{H}_{12}$ hexane, $\left(\mathrm{CH}_{3}\right)_{2} \mathrm{CO}$ acetone, $\mathrm{H}_{2} \mathrm{O}$ aqueous, BtOH butanol

plant extracts including; Punica granatum, Bombax malabaricum, Schefflera actinophylla, Phalangium variegate, Eucalyptus rostrata, Didonia viscose, Myrtus Communis, Tecoma capensis, Vitex trifolia, Gazania splendens, Lagerstroemia indica, Acalypha marginata, Laurus nobilis, Pelargonium oderatissimum, Khaya senegalensis and Spathodea tilotica had extremely high antioxidant power (>80\% inhibition). At $5 \mathrm{mg} / \mathrm{mL}$ plant extracts of the following plants; Chrysanthemum frutesence, Aspidistra lurida, Thuja orientalis and Ruscus hyphoglossum exhibited very low antioxidant properties of $<1 \%$ RSA. In separate studies the antioxidant activities were determined at relatively higher concentration $(100 \mathrm{mg} / \mathrm{mL})$, where Capsicum annuum, Camellia sinensis, Atriplex sp., and Asphodelus microcarpus showed high \% RSA [41].

Geographical locations usually influence the accumulation of secondary metabolites in most plants. Variations of these substances may be observed on different parts of the plants used in the study. Solvent systems used for extraction process may also substantially affect the composition of the extracts and hence their bioactivities [4].

The percentage (\%) RSA using DPPH of the methanol and chloroform extracts of 124 Egyptian plants was evaluated at $50 \mathrm{mg} / \mathrm{mL}$. The chloroform extracts of these plants were less active demonstrating \% inhibition ranging from 0.5 to $49 \%$; while the methanol extracts elaborating more polar compounds showed \% inhibition ranging from 3 to $96 \%$ [42].
The variations in scavenging activities of the methanol and chloroform extracts are most probably attributed to the differences in polarities of the phytochemicals [43], and also the classes of compounds extracted by the two solvents. Phytochemical investigation of some plants from Northern Africa exhibiting antioxidant and related activities led to isolation of approximately 56 compounds (Table 6 and Fig. 3). The most potent compounds included; nifedipine (47), trilinolein (42), usnic acid monoacetate (41), 5-bromosalicylaldehyde (39), naphtho $[2,1-b]$ furan-2(1 h)- one,decahydro- $3 \alpha, 6,6,9 \alpha-$ tetramethy (38) and 2,3 dihydroxypropyl elaidate (47) (obtained from the leaf extract of Solanum nigrum) with $\%$ RSA of $78.4 \%, 68.5 \%, 74 \%, 72.5 \%, 74 \%$ and $76 \%$ at $100 \mu \mathrm{g} / \mathrm{mL}$ respectively [44], and catechin (120) obtained from the ethyl acetate leaf extract of Hydnora abyssinica with \% RSA of $68.5 \%$ at $1 \mathrm{mM}$ [45]. The presence of these important compounds and the significant antioxidants power they demonstrated is an indication that these compounds, if properly screened could yield drugs of pharmaceutical significant.

\section{Antioxidant activities of extracts of plants from Southern Africa}

A total of 178 extracts from 145 plants belonging to 43 families were identified from Southern Africa (Table 3). However, the ethanol extract of the bark of Sclerocarya birrea and the leaf extract of Harpephyllum caffrum, 
Table 6 Isolated Compounds from African medicinal plants with antioxidants potential

\begin{tabular}{|c|c|c|c|c|c|c|c|c|}
\hline Compounds & Plant species & $\begin{array}{l}\text { Part } \\
\text { used }\end{array}$ & Family & $\begin{array}{l}\text { Solvent } \\
\text { Used }\end{array}$ & Assay Method & Activity $/ \mathrm{CC}_{50}$ & $\begin{array}{l}\text { Country of } \\
\text { origin }\end{array}$ & Reference \\
\hline Stigmasterol (1) & Dorstenia barteri L. & $\begin{array}{l}\text { Whole } \\
\text { plant }\end{array}$ & Moraceae & $\begin{array}{l}\text { EtOAc; } \\
\mathrm{MeOH}\end{array}$ & $\mathrm{DPPH}$ & $62.18 \mu \mathrm{g} / \mathrm{mL}$ & Cameroon & [31] \\
\hline Isobavachalcone (2) & Dorstenia barteri L. & $\begin{array}{l}\text { Whole } \\
\text { plant }\end{array}$ & Moraceae & $\begin{array}{l}\mathrm{EtOAc} ; \\
\mathrm{MeOH}\end{array}$ & DPPH & $84.33 \mu \mathrm{g} / \mathrm{mL}$ & Cameroon & [31] \\
\hline 6-Prenylapigenin (3) & $\begin{array}{l}\text { Dorstenia kameruniana } \\
\text { Engl. }\end{array}$ & Leaf & Moraceae & $\begin{array}{l}\text { EtOAc; } \\
\mathrm{MeOH}\end{array}$ & DPPH & $86.43 \mu \mathrm{g} / \mathrm{mL}$ & Cameroon & [31] \\
\hline Dorsmanin F (4) & Dorstenia mannii Hook.f. & Leaf & Moraceae & $\begin{array}{l}\mathrm{EtOAc} ; \\
\mathrm{MeOH}\end{array}$ & DPPH & $53.89 \mu \mathrm{g} / \mathrm{mL}$ & Cameroon & [31] \\
\hline Quercitrin (5) & $\begin{array}{l}\text { Mallotus oppositifolium } \\
\text { (Geiseler) Mull. Arg. }\end{array}$ & Leaf & Moraceae & $\begin{array}{l}\mathrm{EtOAC;} \\
\mathrm{MeOH}\end{array}$ & DPPH & $28.16 \mu \mathrm{g} / \mathrm{mL}$ & Cameroon & [31] \\
\hline 6,8-Diprenyleridictyol (6) & Dorstenia mannii Hook.f. & Leaf & Moraceae & $\begin{array}{l}\mathrm{EtOAc} ; \\
\mathrm{MeOH}\end{array}$ & DPPH & $32.12 \mu \mathrm{g} / \mathrm{mL}$ & Cameroon & [31] \\
\hline Bartericin A (7) & Dorstenia barteri L. & $\begin{array}{l}\text { Whole } \\
\text { plant }\end{array}$ & Moraceae & $\begin{array}{l}\mathrm{EtOAc} ; \\
\mathrm{MeOH}\end{array}$ & DPPH & $47.85 \mu \mathrm{g} / \mathrm{mL}$ & Cameroon & [31] \\
\hline Isoquercetrin (8) & $\begin{array}{l}\text { Bersama abyssinica } \\
\text { Fresen. }\end{array}$ & Leaf & Melianthaceae & $\mathrm{MeOH}$ & DPPH & $23.7 \mu \mathrm{M}$ & Ethiopia & [58] \\
\hline Hyperoside (9) & $\begin{array}{l}\text { Bersama abyssinica } \\
\text { Fresen. }\end{array}$ & Leaf & Melianthaceae & $\mathrm{MeOH}$ & DPPH & $22.6 \mu \mathrm{M}$ & Ethiopia & [58] \\
\hline Quercetin-3-O -Arabinopyranoside (10) & $\begin{array}{l}\text { Bersama abyssinica } \\
\text { Fresen. }\end{array}$ & Leaf & Melianthaceae & $\mathrm{MeOH}$ & DPPH & $20.7 \mu \mathrm{M}$ & Ethiopia & [58] \\
\hline Kaempferol-3-O-Arabinopyranoside (11) & $\begin{array}{l}\text { Bersama abyssinica } \\
\text { Fresen. }\end{array}$ & Leaf & Melianthaceae & $\mathrm{MeOH}$ & DPPH & $>50 \mu \mathrm{M}$ & Ethiopia & [58] \\
\hline Mangiferin (12) & $\begin{array}{l}\text { Bersama abyssinica } \\
\text { Fresen. }\end{array}$ & Leaf & Melianthaceae & $\mathrm{MeOH}$ & DPPH & $15.9 \mu \mathrm{M}$ & Ethiopia & [58] \\
\hline Rutin (13) & Cheilanthes farinose Sw. & $\begin{array}{l}\text { Aerial } \\
\text { parts }\end{array}$ & Pteridaceae & $\mathrm{MeOH}$ & DPPH & $9.5 \mu \mathrm{M}$ & Ethiopia & [58] \\
\hline Rutin (13) & $\begin{array}{l}\text { Cineraria abyssinica Sch. } \\
\text { Bip. Ex A. }\end{array}$ & Leaf & Asteraceae & $\mathrm{MeOH}$ & DPPH & $3.53 \mu \mathrm{g} / \mathrm{ml}$ & Ethiopia & [57] \\
\hline Quercetin-3-O-Diglucosylrhamnoside (14) & Cheilanthes farinose Sw. & $\begin{array}{l}\text { Aerial } \\
\text { parts }\end{array}$ & Pteridaceae & $\mathrm{MeOH}$ & $\mathrm{DPPH}$ & $15.1 \mu \mathrm{M}$ & Ethiopia & [58] \\
\hline Kaempferol-3-O-Diglucosylrhamnoside (15) & Cheilanthes farinose Sw. & $\begin{array}{l}\text { Aerial } \\
\text { parts }\end{array}$ & Pteridaceae & $\mathrm{MeOH}$ & DPPH & $>58.1 \mu \mathrm{M}$ & Ethiopia & [58] \\
\hline Kaempferol-3-O-Glucorhamnoside (16) & Cheilanthes farinose Sw. & $\begin{array}{l}\text { Aerial } \\
\text { parts }\end{array}$ & Pteridaceae & $\mathrm{MeOH}$ & DPPH & $>78.0 \mu \mathrm{M}$ & Ethiopia & [58] \\
\hline Caffeic Acid (17) & Cheilanthes farinose Sw. & $\begin{array}{l}\text { Aerial } \\
\text { parts }\end{array}$ & Pteridaceae & $\mathrm{MeOH}$ & DPPH & $23.3 \mu \mathrm{M}$ & Ethiopia & [58] \\
\hline Chlorogenic acid (18) & Cheilanthes farinose Sw. & $\begin{array}{l}\text { Aerial } \\
\text { parts }\end{array}$ & Pteridaceae & $\mathrm{MeOH}$ & DPPH & $22.6 \mu \mathrm{M}$ & Ethiopia & {$[58]$} \\
\hline Quercetrin (19) & Euclea racemosa $\mathrm{L}$. & Leaf & Ebenaceae & $\left(\mathrm{CH}_{3}\right)_{2} \mathrm{CO}$ & $\mathrm{DPPH}$ & $26.8 \mu \mathrm{M}$ & Ethiopia & [58] \\
\hline
\end{tabular}


Table 6 Isolated Compounds from African medicinal plants with antioxidants potential (Continued)

\begin{tabular}{|c|c|c|c|c|c|c|c|c|}
\hline Myricitrin (20) & Euclea racemosa $\mathrm{L}$. & Leaf & Ebenaceae & $\left(\mathrm{CH}_{3}\right)_{2} \mathrm{CO}$ & DPPH & $14.2 \mu \mathrm{M}$ & Ethiopia & [58] \\
\hline Myricetin-3-O-Arabinopyranoside (21) & Euclea racemosa $\mathrm{L}$. & Leaf & Ebenaceae & $\left(\mathrm{CH}_{3}\right)_{2} \mathrm{CO}$ & DPPH & $15.8 \mu \mathrm{M}$ & Ethiopia & [58] \\
\hline Quercetin (22) & Euclea racemosa $\mathrm{L}$. & Leaf & Ebenaceae & $\left(\mathrm{CH}_{3}\right)_{2} \mathrm{CO}$ & DPPH & $18.2 \mu \mathrm{M}$ & Ethiopia & [58] \\
\hline Aloin (23) & Aloe harlana Reynolds. & Latex & Asphodelaceae & $\mathrm{MeOH}$ & DPPH & $0.026 \mathrm{mM}$ & Ethiopia & [279] \\
\hline 7-O-Methylaloeresin (24) & Aloe harlana Reynolds. & Latex & Asphodelaceae & $\mathrm{MeOH}$ & DPPH & $0.026 \mathrm{mM}$ & Ethiopia & [279] \\
\hline a-Amyrin (25) & $\begin{array}{l}\text { Echinops galalensis } \\
\text { Schweinf. }\end{array}$ & $\begin{array}{l}\text { Aerial } \\
\text { parts }\end{array}$ & Asteraceae & EtOH & $\begin{array}{l}\mathrm{CCl}_{4} \text { induce cell } \\
\text { damage on Huh7 }\end{array}$ & $\begin{array}{l}\text { Decreas AST, ALT, MDA level and } \\
\text { increase SOD activities }\end{array}$ & Egypt. & [102] \\
\hline$\beta$-Sitosterol (26) & $\begin{array}{l}\text { Echinops galalensis } \\
\text { Schweinf. }\end{array}$ & $\begin{array}{l}\text { Aerial } \\
\text { parts }\end{array}$ & Asteraceae & $\mathrm{EtOH}$ & $\begin{array}{l}\mathrm{CCl}_{4-\text { induce cell }} \\
\text { damage on Huh7 }\end{array}$ & $\begin{array}{l}\text { Decreas AST, ALT, MDA level and } \\
\text { increase SOD activities }\end{array}$ & Egypt. & [102] \\
\hline$\beta$-Sitosterol (26) & Tinospora bakis DC. & Leaf & Menispermaceae & $\mathrm{EtOH}$ & SORSA & $33 \%$ at $1 \mathrm{mM}$ & Sudan & [45] \\
\hline$\beta$-Sitosterol (26) & Piper umbellatum $\mathrm{L}$. & Branch & Piperaceae & & DPPH & Less Potent & Cameroon & [294] \\
\hline Erythrodiol (27) & $\begin{array}{l}\text { Echinops galalensis } \\
\text { Schweinf. }\end{array}$ & $\begin{array}{l}\text { Aerial } \\
\text { parts }\end{array}$ & Asteraceae & $\mathrm{MeOH}$ & $\begin{array}{l}\mathrm{CCl}_{4 \text { _induce cell }} \\
\text { damage on Huh7 }\end{array}$ & $\begin{array}{l}\text { Decreas AST, ALT, MDA level and } \\
\text { increase SOD activities }\end{array}$ & Egypt. & [102] \\
\hline Lup-20(29)-ene- 1,3-diol (28) & $\begin{array}{l}\text { Echinops galalensis } \\
\text { Schweinf. }\end{array}$ & $\begin{array}{l}\text { Aerial } \\
\text { parts }\end{array}$ & Asteraceae & $\mathrm{MeOH}$ & $\begin{array}{l}\mathrm{CCl}_{4 \_} \text {induce cell } \\
\text { damage on Huh7 }\end{array}$ & $\begin{array}{l}\text { Decreas AST, ALT, MDA level and } \\
\text { increase SOD activities }\end{array}$ & Egypt. & [102] \\
\hline 1,5-Dicaffeoylquinic acid (29) & $\begin{array}{l}\text { Echinops galalensis } \\
\text { Schweinf. }\end{array}$ & $\begin{array}{l}\text { Aerial } \\
\text { parts }\end{array}$ & Asteraceae & $\mathrm{MeOH}$ & $\begin{array}{l}\mathrm{CCl}_{4-\text { induce cell }} \\
\text { damage on Huh7 }\end{array}$ & $\begin{array}{l}\text { Decreas AST, ALT, MDA level and } \\
\text { increase SOD activities }\end{array}$ & Egypt. & [102] \\
\hline 3,5-Dicaffeoylquinic acid (30) & $\begin{array}{l}\text { Echinops galalensis } \\
\text { Schweinf. }\end{array}$ & $\begin{array}{l}\text { Aerial } \\
\text { parts }\end{array}$ & Asteraceae & $\mathrm{MeOH}$ & $\begin{array}{l}\mathrm{CCl}_{4} \text { induce cell } \\
\text { damage on Huh7 }\end{array}$ & $\begin{array}{l}\text { Decreas AST, ALT, MDA level and } \\
\text { increase SOD activities }\end{array}$ & Egypt. & [102] \\
\hline 3,4-Dicaffeoylquinic acid (31) & $\begin{array}{l}\text { Echinops galalensis } \\
\text { Schweinf. }\end{array}$ & $\begin{array}{l}\text { Aerial } \\
\text { parts }\end{array}$ & Asteraceae & $\mathrm{MeOH}$ & $\begin{array}{l}\mathrm{CCl}_{4-\text { induce cell }} \\
\text { damage on Huh7 }\end{array}$ & $\begin{array}{l}\text { Decreas AST, ALT, MDA level and } \\
\text { increase SOD activities }\end{array}$ & Egypt. & [102] \\
\hline 4,5- Dicaffeoylquinic acid (32) & $\begin{array}{l}\text { Echinops galalensis } \\
\text { Schweinf. }\end{array}$ & $\begin{array}{l}\text { Aerial } \\
\text { parts }\end{array}$ & Asteraceae & $\mathrm{MeOH}$ & $\begin{array}{l}\mathrm{CCl}_{4 \_ \text {induce cell }} \\
\text { damage on Huh7 }\end{array}$ & $\begin{array}{l}\text { Decreas AST, ALT, MDA level and } \\
\text { increase SOD activities }\end{array}$ & Egypt. & [102] \\
\hline Apigenin-7-O- $\beta$-D-glucoside (33) & $\begin{array}{l}\text { Echinops galalensis } \\
\text { Schweinf. }\end{array}$ & $\begin{array}{l}\text { Aerial } \\
\text { parts }\end{array}$ & Asteraceae & $\mathrm{MeOH}$ & $\begin{array}{l}\mathrm{CCl}_{4} \text { induce cell } \\
\text { damage on Huh7 }\end{array}$ & $\begin{array}{l}\text { Decreas AST,ALT, MDA level and } \\
\text { increase SOD activities }\end{array}$ & Egypt. & [102] \\
\hline 2, 3-Dihydro-2'-hydroxyosajin (34) & Erythrina senegalensis $\mathrm{L}$. & $\begin{array}{l}\text { Stem } \\
\text { bark }\end{array}$ & Fabaceae & $\mathrm{EtOH}$ & $\begin{array}{l}\text { DPPH/ } \beta-C L A M S / \\
\text { FRAP }\end{array}$ & 41.28/19.17/15.99 $\mu \mathrm{g} / \mathrm{mL}$ & Cameroon & [295] \\
\hline Osajin (35) & Erythrina senegalensis $\mathrm{L}$. & $\begin{array}{l}\text { Stem } \\
\text { bark }\end{array}$ & Fabaceae & $\mathrm{EtOH}$ & $\begin{array}{l}\text { DPPH/ } \beta \text {-CLAMS/ } \\
\text { FRAP }\end{array}$ & $61.18 / 49.15 / 44.04 \mu \mathrm{g} / \mathrm{mL}$ & Cameroo & [295] \\
\hline 6, 8-Diprenylgenistein (36) & Erythrina senegalensis $\mathrm{L}$. & $\begin{array}{l}\text { Stem } \\
\text { bark }\end{array}$ & Fabaceae & $\mathrm{EtOH}$ & $\begin{array}{l}\text { DPPH/ } \beta-C L A M S / \\
\text { FRAP }\end{array}$ & $53.00 / 24.95 / 19.17 \mu \mathrm{g} / \mathrm{mL}$ & $\begin{array}{l}\text { Cameroon } \\
\mathrm{n}\end{array}$ & [295] \\
\hline 2,3-Dihydroxypropyl elaidate (37) & Solanum nigrum L. & Leaf & Solanaceae & $\mathrm{EtOH}$ & DPPH & $80.5 \%$ at $100 \mu \mathrm{g} / \mathrm{mL}$ & Egypt & [44] \\
\hline $\begin{array}{l}\text { Naphtho [2,1-B]furan-2(1H)-one, decahydro- } \\
\text { 3a,6,6,9a-tetramethyl (38) }\end{array}$ & Solanum nigrum L. & Leaf & Solanaceae & $\mathrm{EtOH}$ & DPPH & $65.6 \%$ at $100 \mu \mathrm{g} / \mathrm{mL}$ & Egypt & [44] \\
\hline 5-Bromosalicylaldehyde (39) & Solanum nigrum L. & Leaf & Solanaceae & $\mathrm{EtOH}$ & DPPH & $50.5 \%$ at $100 \mu \mathrm{g} / \mathrm{mL}$ & Egypt & [44] \\
\hline 12-Sulfanyldodecanoic acid (40) & Solanum nigrum L. & Leaf & Solanaceae & $\mathrm{EtOH}$ & DPPH & $65.3 \%$ at $100 \mu \mathrm{g} / \mathrm{mL}$ & Egypt & [44] \\
\hline Usnic acid monoacetate (41) & Solanum nigrum L. & Leaf & Solanaceae & $\mathrm{EtOH}$ & DPPH & $60 \%$ at $100 \mu \mathrm{g} / \mathrm{mL}$ & Egypt & [44] \\
\hline Trilinolein (42) & Solanum nigrum L. & Leaf & Solanaceae & $\mathrm{EtOH}$ & DPPH & $40.8 \%$ at $100 \mu \mathrm{g} / \mathrm{mL}$ & Egypt & [44] \\
\hline
\end{tabular}


Table 6 Isolated Compounds from African medicinal plants with antioxidants potential (Continued)

\begin{tabular}{|c|c|c|c|c|c|c|c|c|}
\hline Niclofen (43) & Solanum nigrum L. & Leaf & Solanaceae & $\mathrm{EtOH}$ & $\mathrm{DPPH}$ & $45.6 \%$ at $100 \mu \mathrm{g} / \mathrm{mL}$ & Egypt & [44] \\
\hline $\begin{array}{l}\text { 8-Azabicyclo [3.2.1] octane-2-carboxylic acid, } \\
\text { 3-hydroxy-8-methyl,(2-endo, 3-exo) (44) }\end{array}$ & Solanum nigrum L. & Leaf & Solanaceae & $\mathrm{EtOH}$ & DPPH & $30.2 \%$ at $100 \mu \mathrm{g} / \mathrm{mL}$ & Egypt & [44] \\
\hline 5,6-Dichloro-2-methyl-1H-benzimidazole (45) & Cassia italic Mill. & Leaf & Fabaceae & $\mathrm{EtOH}$ & $\mathrm{DPPH}$ & $48.7 \%$ at $100 \mu \mathrm{g} / \mathrm{mL}$ & Egypt & [44] \\
\hline trans-2-Methyl-4-N-Pentylthiane, (46) & Cassia italic Mill. & Leaf & Fabaceae & $\mathrm{EtOH}$ & DPPH & $34.8 \%$ at $100 \mu \mathrm{g} / \mathrm{mL}$ & Egypt & [44] \\
\hline Nifedipine (47) & Cassia italic Mill. & Leaf & Fabaceae & $\mathrm{EtOH}$ & DPPH & $78.4 \%$ at $100 \mu \mathrm{g} / \mathrm{mL}$ & Egypt & [44] \\
\hline $\begin{array}{l}\text { Propionic acid (3,6,7,8-tetrahydro-3,7-methano- } \\
\text { 2,4,6-trimethyl-2H-Oxocin-7-yl) methyl ester } \\
\text { (48) }\end{array}$ & Cassia italic Mill. & Leaf & Fabaceae & $\mathrm{EtOH}$ & $\mathrm{DPPH}$ & $68.4 \%$ at $100 \mu \mathrm{g} / \mathrm{mL}$ & Egypt & [44] \\
\hline Octadecyl bromoacetate (49) & Cassia italic Mill. & Leaf & Fabaceae & $\mathrm{EtOH}$ & DPPH & $56.7 \%$ at $100 \mu \mathrm{g} / \mathrm{mL}$ & Egypt & [44] \\
\hline Lophirones B (50) & $\begin{array}{l}\text { Lophira alata Bank ex } \\
\text { Gaertn. }\end{array}$ & $\begin{array}{l}\text { Stem } \\
\text { bark }\end{array}$ & Ochnaceae & $\mathrm{CHCl}_{3}$ & $\mathrm{DPPH}$ & $\begin{array}{l}84.4 \% \text { at } 1 \mathrm{mg} / \mathrm{mL} . \mathrm{Increase} \text { activities of } \\
\text { SOD, CAT, GPx, and GR in the liver of } \\
\text { rats }\end{array}$ & Nigeria & $\begin{array}{l}{[40] \text { and }} \\
2014 b\end{array}$ \\
\hline Lophirones C (51) & $\begin{array}{l}\text { Lophira alata Bank ex } \\
\text { Gaertn. }\end{array}$ & $\begin{array}{l}\text { Stem } \\
\text { bark }\end{array}$ & Ochnaceae & $\mathrm{CHCl}_{3}$ & DPPH & $\begin{array}{l}90.0 \% \text { at } 1 \mathrm{mg} / \mathrm{mL} \text {. Increase activities of } \\
\text { SOD, CAT, GPx, and GR in the liver of } \\
\text { rats }\end{array}$ & Nigeria & $\begin{array}{l}{[40] \text { and }} \\
2014 b\end{array}$ \\
\hline 3-Friedelanone (52) & $\begin{array}{l}\text { Irvingia gabonensis } \\
\text { (AubryLecomte ex O } \\
\text { Rorke) Baill. }\end{array}$ & $\begin{array}{l}\text { Stem } \\
\text { bark }\end{array}$ & Irvingiaceae & $\mathrm{MeOH}$ & $\beta$-CLAMS/FRAP & 49.05/38.28 $\mu \mathrm{g} / \mathrm{mL}$ & Cameroon & {$[296]$} \\
\hline Betulinic acid (53) & $\begin{array}{l}\text { Irvingia gabonensis } \\
\text { (AubryLecomte ex O } \\
\text { Rorke) Baill. }\end{array}$ & $\begin{array}{l}\text { Stem } \\
\text { bark }\end{array}$ & Irvingiaceae & $\mathrm{MeOH}$ & $\beta$-CLAMS/FRAP & $31.95 / 27.52 \mu \mathrm{g} / \mathrm{mL}$ & Cameroon & {$[296]$} \\
\hline Oleanolic acid (54) & $\begin{array}{l}\text { Irvingia gabonensis } \\
\text { (AubryLecomte ex O } \\
\text { Rorke) Baill. }\end{array}$ & $\begin{array}{l}\text { Stem } \\
\text { bark }\end{array}$ & Irvingiaceae & $\mathrm{MeOH}$ & $\begin{array}{l}\text { DPPH/B-CLAMS/ } \\
\text { FRAP }\end{array}$ & $8.55 / 6.53 / 11.76 \mu \mathrm{g} / \mathrm{mL}$ & Cameroon & {$[296]$} \\
\hline 3, 3',4'-Tri-O-methyl ellagic acid (55) & $\begin{array}{l}\text { Irvingia gabonensis } \\
\text { (AubryLecomte ex O } \\
\text { Rorke) Baill. }\end{array}$ & $\begin{array}{l}\text { Stem } \\
\text { bark }\end{array}$ & Irvingiaceae & $\mathrm{MeOH}$ & $\begin{array}{l}\text { DPPH/B-CLAMS/ } \\
\text { FRAP }\end{array}$ & $14.20 / 15.18 / 12.47 \mu \mathrm{g} / \mathrm{mL}$ & Cameroon & {$[296]$} \\
\hline Methyl gallate (56) & $\begin{array}{l}\text { Irvingia gabonensis } \\
\text { (AubryLecomte ex O } \\
\text { Rorke) Baill. }\end{array}$ & $\begin{array}{l}\text { Stem } \\
\text { bark }\end{array}$ & Irvingiaceae & $\mathrm{MeOH}$ & $\begin{array}{l}\text { DPPH/B-CLAMS/ } \\
\text { FRAP }\end{array}$ & 14.78/8.88/6.35 $\mu \mathrm{g} / \mathrm{mL}$ & Cameroon & {$[296]$} \\
\hline Hardwiickic acid (57) & $\begin{array}{l}\text { Irvingia gabonensis } \\
\text { (AubryLecomte ex O } \\
\text { Rorke) Baill. }\end{array}$ & $\begin{array}{l}\text { Stem } \\
\text { bark }\end{array}$ & Irvingiaceae & $\mathrm{MeOH}$ & $\begin{array}{l}\text { DPPH/B-CLAMS/ } \\
\text { FRAP }\end{array}$ & - & Cameroon & {$[296]$} \\
\hline 3- $\beta$-Acetoxyursolic acid (58) & $\begin{array}{l}\text { Irvingia gabonensis } \\
\text { (AubryLecomte ex O } \\
\text { Rorke) Baill. }\end{array}$ & $\begin{array}{l}\text { Stem } \\
\text { bark }\end{array}$ & Irvingiaceae & $\mathrm{MeOH}$ & $\begin{array}{l}\text { DPPH/B-CLAMS/ } \\
\text { FRAP }\end{array}$ & 8.84/7.66/12.47 $\mu \mathrm{g} / \mathrm{mL}$ & Cameroon & {$[296]$} \\
\hline Plumbagin (59) & $\begin{array}{l}\text { Diospyros bipindensis } \\
\text { Gurke. }\end{array}$ & $\begin{array}{l}\text { Stem } \\
\text { bark }\end{array}$ & Ebenaceae & $\mathrm{CH}_{2} \mathrm{Cl}_{2}$ & DPPH/ABTS & $3.5 / 2.7 \%$ at $40 \mu \mathrm{g} / \mathrm{mL}$ & Cameroon & [297] \\
\hline Canaliculatin (60) & $\begin{array}{l}\text { Diospyros bipindensis } \\
\text { Gurke }\end{array}$ & $\begin{array}{l}\text { Stem } \\
\text { bark }\end{array}$ & Ebenaceae & $\mathrm{CH}_{2} \mathrm{Cl}_{2}$ & DPPH/ABTS & $4.7 / 4.3 \%$ at $40 \mu \mathrm{g} / \mathrm{mL}$ & Cameroon & {$[297]$} \\
\hline Ismailin (61) & $\begin{array}{l}\text { Diospyros bipindensis } \\
\text { Gurke }\end{array}$ & $\begin{array}{l}\text { Stem } \\
\text { bark }\end{array}$ & Ebenaceae & $\mathrm{CH}_{2} \mathrm{Cl}_{2}$ & DPPH/ABTS & 4.7/4.0\% at $40 \mu \mathrm{g} / \mathrm{mL}$ & Cameroon & {$[297]$} \\
\hline
\end{tabular}


Table 6 Isolated Compounds from African medicinal plants with antioxidants potential (Continued)

\begin{tabular}{|c|c|c|c|c|c|c|c|c|}
\hline Betulinic acid (62) & $\begin{array}{l}\text { Diospyros bipindensis } \\
\text { Gurke }\end{array}$ & $\begin{array}{l}\text { Stem } \\
\text { bark }\end{array}$ & Ebenaceae & $\mathrm{CH}_{2} \mathrm{Cl}_{2}$ & DPPH/ABTS & $6.4 / 6.5$ at $40 \mu \mathrm{g} / \mathrm{mL}$ & Cameroon & [297] \\
\hline 4-Hydroxy-5-methylcoumarin (63) & $\begin{array}{l}\text { Diospyros bipindensis } \\
\text { Gurke }\end{array}$ & $\begin{array}{l}\text { Stem } \\
\text { bark }\end{array}$ & Ebenaceae & $\mathrm{CH}_{2} \mathrm{Cl}_{2}$ & DPPH/ABTS & $14.9 / 15.0 \%$ at $\mu \mathrm{g} / \mathrm{mL}$ & Cameroon & [297] \\
\hline Betulinic acid (62) & $\begin{array}{l}\text { Ficus gnaphalocarpa } \\
\text { (Miq.) Steud. ex A. Rich. }\end{array}$ & $\begin{array}{l}\text { Stem } \\
\text { bark }\end{array}$ & Moraceae & $\mathrm{MeOH}$ & $\begin{array}{l}\mathrm{CCl}_{4} \text { induced } \\
\text { hepatoma cells } \\
\text { damage }\end{array}$ & $\begin{array}{l}\text { Prevented liver cell death and LDH } \\
\text { leakage }\end{array}$ & Cameroon & {$[55]$} \\
\hline 3-Methoxyquercetin (64) & $\begin{array}{l}\text { Ficus gnaphalocarpa } \\
\text { (Miq.) Steud. ex A. Rich. }\end{array}$ & $\begin{array}{l}\text { Stem } \\
\text { bark }\end{array}$ & Moraceae & $\mathrm{MeOH}$ & $\begin{array}{l}\mathrm{CCl}_{4} \text { induced } \\
\text { hepatoma cells } \\
\text { damage }\end{array}$ & $\begin{array}{l}\text { Prevented liver cell death and LDH } \\
\text { leakage }\end{array}$ & Cameroon & {$[55]$} \\
\hline Catechin (65) & $\begin{array}{l}\text { Ficus gnaphalocarpa } \\
\text { (Miq.) Steud. ex A. Rich. }\end{array}$ & $\begin{array}{l}\text { Stem } \\
\text { bark }\end{array}$ & Moraceae & $\mathrm{MeOH}$ & $\begin{array}{l}\mathrm{CCl}_{4-} \text { induced } \\
\text { hepatoma cells } \\
\text { damage }\end{array}$ & $\begin{array}{l}\text { Prevented liver cell death and LDH } \\
\text { leakage }\end{array}$ & Cameroon & {$[55]$} \\
\hline Epicatechin (66) & $\begin{array}{l}\text { Ficus gnaphalocarpa } \\
\text { (Miq.) Steud. ex A. Rich. }\end{array}$ & $\begin{array}{l}\text { Stem } \\
\text { bark }\end{array}$ & Moraceae & $\mathrm{MeOH}$ & $\begin{array}{l}\mathrm{CCl}_{4} \text { induced } \\
\text { hepatoma cells } \\
\text { damage }\end{array}$ & $\begin{array}{l}\text { Prevented liver cell death and LDH } \\
\text { leakage }\end{array}$ & Cameroon & {$[55]$} \\
\hline Quercetin (67) & $\begin{array}{l}\text { Ficus gnaphalocarpa } \\
\text { (Miq.) Steud. ex A. Rich. }\end{array}$ & $\begin{array}{l}\text { Stem } \\
\text { bark }\end{array}$ & Moraceae & $\mathrm{MeOH}$ & $\begin{array}{l}\mathrm{CCl}_{4} \text { induced } \\
\text { hepatoma cells } \\
\text { damage }\end{array}$ & $\begin{array}{l}\text { Prevented liver cell death and LDH } \\
\text { leakage }\end{array}$ & Cameroon & {$[55]$} \\
\hline Quercitrin (68) & $\begin{array}{l}\text { Ficus gnaphalocarpa } \\
\text { (Miq.) Steud. ex A. Rich. }\end{array}$ & $\begin{array}{l}\text { Stem } \\
\text { bark }\end{array}$ & Moraceae & $\mathrm{MeOH}$ & $\begin{array}{l}\mathrm{CCl}_{4-\text { induced }} \\
\text { hepatoma cells } \\
\text { damage }\end{array}$ & $\begin{array}{l}\text { Prevented liver cell death and LDH } \\
\text { leakage }\end{array}$ & Cameroon & {$[55]$} \\
\hline 1,7-Dihydroxyxanthone (69) & $\begin{array}{l}\text { Allanblackia floribunda } \\
\text { Oliv. }\end{array}$ & $\begin{array}{l}\text { Root } \\
\text { bark }\end{array}$ & Guttiferae & $\mathrm{MeOH}$ & DPPH & $488.53 \mu \mathrm{g} / \mathrm{mL}$ & Cameroon & {$[266]$} \\
\hline Morelloflavone (70) & $\begin{array}{l}\text { Allanblackia floribunda } \\
\text { Oliv. }\end{array}$ & $\begin{array}{l}\text { Root } \\
\text { bark }\end{array}$ & Guttiferae & $\mathrm{MeOH}$ & DPPH & $62.8 \mu \mathrm{g} / \mathrm{mL}$ & Cameroon & {$[266]$} \\
\hline 7'-O-Glucoside morelloflavone (71) & $\begin{array}{l}\text { Allanblackia floribunda } \\
\text { Oliv. }\end{array}$ & $\begin{array}{l}\text { Root } \\
\text { bark }\end{array}$ & Guttiferae & $\mathrm{MeOH}$ & DPPH & $49.08 \mu \mathrm{g} / \mathrm{mL}$ & Cameroon & {$[266]$} \\
\hline Piperumbellactams A (72) & Piper umbellatum L. & $\begin{array}{l}\text { Whole } \\
\text { plant }\end{array}$ & Piperaceae & - & $\mathrm{DPPH}$ & Less Potent & Cameroon & [294] \\
\hline Piperumbellactams B (73) & Piper umbellatum L. & $\begin{array}{l}\text { Whole } \\
\text { plant }\end{array}$ & Piperaceae & - & $\mathrm{DPPH}$ & Potent activity & Cameroon & [294] \\
\hline Piperumbellactams C (74) & Piper umbellatum L. & $\begin{array}{l}\text { Whole } \\
\text { plant }\end{array}$ & Piperaceae & - & DPPH & Potent activity & Cameroon & [294] \\
\hline Piperumbellactams D (75) & Piper umbellatum L. & $\begin{array}{l}\text { Whole } \\
\text { plant }\end{array}$ & Piperaceae & - & $\mathrm{DPPH}$ & Less Potent & Cameroon & [294] \\
\hline Apigenin -8-C- $\beta$-D-glucopyranoside (76) & $\begin{array}{l}\text { Croton zambesicus Mull. } \\
\text { Arg. }\end{array}$ & Fruit & Euphorbiaceace & $\mathrm{MeOH}$ & DPPH & $<80.5 \%$ at $1 \mathrm{mM}$ & Sudan & [298] \\
\hline ent-Kaurane $-3 \beta, 16 \beta, 17$-triol (77) & $\begin{array}{l}\text { Croton zambesicus Mull. } \\
\text { Arg. }\end{array}$ & Fruit & Euphorbiaceace & $\mathrm{MeOH}$ & DPPH & $<80.5 \%$ at $1 \mathrm{mM}$ & Sudan & [298] \\
\hline $\begin{array}{l}\text { Lupeol (20(29) lupene-3-ol, } 3 \beta \text {-form)- } \\
\text { derivative (78) }\end{array}$ & $\begin{array}{l}\text { Croton zambesicus Mull. } \\
\text { Arg. }\end{array}$ & Fruit & Euphorbiaceace & $\mathrm{MeOH}$ & $\mathrm{DPPH}$ & $<80.5 \%$ at $1 \mathrm{mM}$ & Sudan & [298] \\
\hline
\end{tabular}


Table 6 Isolated Compounds from African medicinal plants with antioxidants potential (Continued)

\begin{tabular}{|c|c|c|c|c|c|c|c|c|}
\hline Lupenone lup -20(29) -ene-3 $\beta$-one(79) & $\begin{array}{l}\text { Diospyros mespiliform } \\
\text { Hochst. ex A. DC. }\end{array}$ & Fruit & Euphorbiaceace & $\mathrm{MeOH}$ & DPPH & $<80.5 \%$ at $1 \mathrm{mM}$ & Sudan & [298] \\
\hline Betulin lup- 20(29)-ene-3 $\beta, 28$-diol (80) & $\begin{array}{l}\text { Croton zambesicus Mull. } \\
\text { Arg. }\end{array}$ & Fruit & Euphorbiaceace & $\mathrm{MeOH}$ & DPPH & $<80.5 \%$ at $1 \mathrm{mM}$ & Sudan & [298] \\
\hline $\begin{array}{l}\text { Betulinic acid } 3 \beta \text { - hydroxylup-20(29)-en-28-oic } \\
\text { acid-derivative (81) }\end{array}$ & $\begin{array}{l}\text { Croton zambesicus Mull. } \\
\text { Arg. }\end{array}$ & Fruit & Euphorbiaceace & $\mathrm{MeOH}$ & DPPH & $<80.5 \%$ at $1 \mathrm{mM}$ & Sudan & [298] \\
\hline $\begin{array}{l}\text { Betulinic acid 33-hydroxylup-20(29)-en-28-oic } \\
\text { acid (82) }\end{array}$ & $\begin{array}{l}\text { Croton zambesicus Mull. } \\
\text { Arg. }\end{array}$ & Fruit & Euphorbiaceace & $\mathrm{MeOH}$ & DPPH & $<80.5 \%$ at $1 \mathrm{mM}$ & Sudan & [298] \\
\hline Lupeol (20(29) lupene-3-ol, $3 \beta$-form) (83) & $\begin{array}{l}\text { Croton zambesicus Mull. } \\
\text { Arg. }\end{array}$ & Fruit & Euphorbiaceace & $\mathrm{MeOH}$ & $\mathrm{DPPH}$ & $<80.5 \%$ at $1 \mathrm{mM}$ & Sudan & [298] \\
\hline Moracin T (84) & Morus mesozygia Stapf. & Bark & Moraceae & $\mathrm{MeOH}$ & $\mathrm{DPPH}$ & $4.12 \mu \mathrm{g} / \mathrm{mL}$ & Cameroon & {$[54]$} \\
\hline Moracin U (85) & Morus mesozygia Stapf. & Bark & Moraceae & $\mathrm{MeOH}$ & $\mathrm{DPPH}$ & $5.06 \mu \mathrm{g} / \mathrm{mL}$ & Cameroon & [54] \\
\hline Moracin S (86) & Morus mesozygia Stapf. & Bark & Moraceae & $\mathrm{MeOH}$ & $\mathrm{DPPH}$ & $6.08 \mu \mathrm{g} / \mathrm{mL}$ & Cameroon & {$[54]$} \\
\hline Moracin R (87) & Morus mesozygia Stapf. & Bark & Moraceae & $\mathrm{MeOH}$ & DPPH & $7.17 \mu \mathrm{g} / \mathrm{mL}$ & Cameroon & [54] \\
\hline 5,7,3'-Trihydroxy-3,8,4',5'-trimethoxyflavone (88) & Microglossa pyrifolia DC. & Leaf & Asteraceae & EtOAc & DPPH & $8.79 \mathrm{mg} / \mathrm{mL}$ & Kenya & [299] \\
\hline $\begin{array}{l}5,7,4^{\prime} \text {-Trihydroxy-3,8,3',5'-tetramethoxyflavone } \\
\text { (89) }\end{array}$ & Microglossa pyrifolia DC. & Leaf & Asteraceae & EtOAc & DPPH & $6.45 \mathrm{mg} / \mathrm{mL}$ & Kenya & [299] \\
\hline 8-Acetoxyisochiliolide lactone (90) & Microglossa pyrifolia DC. & Leaf & Asteraceae & EtOAc & $\mathrm{DPPH}$ & $6.45 \mathrm{mg} / \mathrm{mL}$ & Kenya & [299] \\
\hline Harunmadagascarins A (91) & $\begin{array}{l}\text { Harungana } \\
\text { Madagascariensis Lam. }\end{array}$ & $\begin{array}{l}\text { Stem } \\
\text { back }\end{array}$ & Hypericaceae & $\begin{array}{l}\text { Not } \\
\text { specified }\end{array}$ & DPPH & $60.97 \mu \mathrm{M}$ & Cameroon & [300] \\
\hline Harunmadagascarins B (92) & $\begin{array}{l}\text { Harungana } \\
\text { Madagascariensis Lam. }\end{array}$ & $\begin{array}{l}\text { Stem } \\
\text { back }\end{array}$ & Hypericaceae & $\begin{array}{l}\text { Not } \\
\text { specified }\end{array}$ & DPPH & $60.97 \mu \mathrm{M}$ & Cameroon & [300] \\
\hline Harunganol B (93) & $\begin{array}{l}\text { Harungana } \\
\text { Madagascariensis Lam. }\end{array}$ & $\begin{array}{l}\text { Stem } \\
\text { back }\end{array}$ & Hypericaceae & $\begin{array}{l}\text { Not } \\
\text { specified }\end{array}$ & DPPH & $64.76 \mu \mathrm{M}$ & Cameroon & [300] \\
\hline Harungin anthrone (94) & $\begin{array}{l}\text { Harungana } \\
\text { Madagascariensis Lam. }\end{array}$ & $\begin{array}{l}\text { Stem } \\
\text { back }\end{array}$ & Hypericaceae & $\begin{array}{l}\text { Not } \\
\text { specified }\end{array}$ & DPPH & $155.39 \mu \mathrm{M}$ & Cameroon & [300] \\
\hline Emodin (95) & $\begin{array}{l}\text { Psorospermum } \\
\text { febrifugum Spach. }\end{array}$ & $\begin{array}{l}\text { Stem } \\
\text { bark }\end{array}$ & Clusiaceae & $\begin{array}{l}\mathrm{EtOAc} ; \\
\mathrm{MeOH}\end{array}$ & $\mathrm{DPPH}$ & $>70$ GEAC; $\mu \mathrm{g} / \mathrm{mL}$ & Cameroon & [272] \\
\hline 3-Geranyloxyemodin (96) & $\begin{array}{l}\text { Psorospermum } \\
\text { febrifugum Spach. }\end{array}$ & $\begin{array}{l}\text { Stem } \\
\text { bark }\end{array}$ & Clusiaceae & $\begin{array}{l}\mathrm{EtOAc} ; \\
\mathrm{MeOH}\end{array}$ & $\mathrm{DPPH}$ & $<50 \mathrm{GEAC} ; \mu \mathrm{g} / \mathrm{mL}$ & Cameroon & {$[272]$} \\
\hline 2-Geranylemodin (97) & $\begin{array}{l}\text { Psorospermum } \\
\text { febrifugum Spach. }\end{array}$ & $\begin{array}{l}\text { Stem } \\
\text { bark }\end{array}$ & Clusiaceae & $\begin{array}{l}\mathrm{EtOAc} ; \\
\mathrm{MeOH}\end{array}$ & DPPH & $<40 \mathrm{GEAC} ; \mu \mathrm{g} / \mathrm{mL}$ & Cameroon & {$[272]$} \\
\hline Afzeliixanthones A (98) & Garcinia afzelii Engl. & $\begin{array}{l}\text { Stem } \\
\text { bark }\end{array}$ & Clusiaceae & $\begin{array}{l}\mathrm{EtOAc} ; \\
\mathrm{MeOH}\end{array}$ & DPPH & $17.7 \mu \mathrm{g} / \mathrm{mL}$ & Cameroon & [301] \\
\hline Afzeliixanthones B (99) & Garcinia afzelii Engl. & $\begin{array}{l}\text { Stem } \\
\text { bark }\end{array}$ & Clusiaceae & $\begin{array}{l}\mathrm{EtOAC} ; \\
\mathrm{MeOH}\end{array}$ & DPPH & $14.0 \mu \mathrm{g} / \mathrm{mL}$ & Cameroon & [301] \\
\hline Bangangxanthone A (100) & Garcinia polyantha Oliv. & Leaf & Guttiferae & $\mathrm{CHCl}_{3}$ & DPPH & $87.0 \mu \mathrm{M}$ & Cameroon & [302] \\
\hline Bangangxanthone B (101) & Garcinia polyantha Oliv. & Leaf & Guttiferae & $\mathrm{CHCl}_{3}$ & DPPH & $>87.0 \mu \mathrm{M}$ & Cameroon & [302] \\
\hline 2-Hydroxy-1,7-dimethoxyxanthone (102) & Garcinia polyantha Oliv. & Leaf & Guttiferae & $\mathrm{CHCl}_{3}$ & $\mathrm{DPPH}$ & $>87.0 \mu \mathrm{M}$ & Cameroon & [302] \\
\hline
\end{tabular}


Table 6 Isolated Compounds from African medicinal plants with antioxidants potential (Continued)

\begin{tabular}{|c|c|c|c|c|c|c|c|c|}
\hline 1,5-Dihydroxyxanthone (103) & Garcinia polyantha Oliv. & Leaf & Guttiferae & $\mathrm{CHCl}_{3}$ & DPPH & $>87.0 \mu \mathrm{M}$ & Cameroon & [302] \\
\hline Rheediinoside A (104) & Entada rheedii Spreng. & Seed & Mimosaceae & - & ABTS/DPPH & Low activity & Cameroon & [303] \\
\hline Rheediinoside B (105) & Entada rheedii Spreng. & Seed & Mimosaceae & - & ABTS/DPPH & Moderat e activity & Cameroon & [303] \\
\hline Piperumbellactams D (106) & Piper umbellatum L. & $\begin{array}{l}\text { Whole } \\
\text { plant }\end{array}$ & Piperaceae & - & DPPH & Less Potent & Cameroon & [294] \\
\hline N-Hydroxyaristolam II (107) & Piper umbellatum L. & $\begin{array}{l}\text { Whole } \\
\text { plant }\end{array}$ & Piperaceae & - & DPPH & Potent activity & Cameroon & [294] \\
\hline 4-Nerolidylcatechol (108) & Piper umbellatum L. & $\begin{array}{l}\text { Whole } \\
\text { plant }\end{array}$ & Piperaceae & - & DPPH & Less Potent & Cameroon & [294] \\
\hline N-Transferuloyltyramine (109) & Piper umbellatum L. & $\begin{array}{l}\text { Whole } \\
\text { plant }\end{array}$ & Piperaceae & - & DPPH & Less Potent & Cameroon & [294] \\
\hline $\begin{array}{l}\text { E-3-(3,4-Dihydroxyphenyl)-N-2-[4- } \\
\text { Hydroxyphenylethyl]-2-Propenamide (110) }\end{array}$ & Piper umbellatum L. & $\begin{array}{l}\text { Whole } \\
\text { plant }\end{array}$ & Piperaceae & - & DPPH & Less Potent & Cameroon & [294] \\
\hline$\beta$-Amyrin (111) & Piper umbellatum L. & $\begin{array}{l}\text { Whole } \\
\text { plant }\end{array}$ & Piperaceae & - & DPPH & Less Potent & Cameroon & [294] \\
\hline Friedelin (112) & Piper umbellatum L. & $\begin{array}{l}\text { Whole } \\
\text { plant }\end{array}$ & Piperaceae & - & DPPH & Less Potent & Cameroon & [294] \\
\hline Apigenin 8-C-Neohesperidoside (113) & Piper umbellatum L. & $\begin{array}{l}\text { Whole } \\
\text { plant }\end{array}$ & Piperaceae & - & DPPH & Less Potent & Cameroon & [294] \\
\hline Acacetin 6-C- B-D-glucopyranoside (114) & Piper umbellatum $\mathrm{L}$. & Branch & Piperaceae & - & DPPH & Less Potent & Cameroon & [294] \\
\hline Alpinumisoflavone (115) & $\begin{array}{l}\text { Ficus chlamydocarpa } \\
\text { Mildbr. \& Burret. }\end{array}$ & $\begin{array}{l}\text { Stem } \\
\text { bark }\end{array}$ & Moraceae & $\mathrm{MeOH}$ & $\begin{array}{l}\text { DPPH/B-CLAMS/ } \\
\text { FRAP }\end{array}$ & 6/8.9/8.0 $\mu \mathrm{g} / \mathrm{mL}$ & Cameroon & [99] \\
\hline Genistein (4,5,7- trihydroxyisoflavone) (116) & $\begin{array}{l}\text { Ficus chlamydocarpa } \\
\text { Mildbr. \& Burret. }\end{array}$ & $\begin{array}{l}\text { Stem } \\
\text { bark }\end{array}$ & Moraceae & $\mathrm{MeOH}$ & DPPH & $5.7 \mu \mathrm{g} / \mathrm{mL}$ & Cameroon & [99] \\
\hline Luteolin (3',4',5,7- tetrahydroxy Flavone) (117) & $\begin{array}{l}\text { Ficus chlamydocarpa } \\
\text { Mildbr. \& Burret. }\end{array}$ & $\begin{array}{l}\text { Stem } \\
\text { bark }\end{array}$ & Moraceae & $\mathrm{MeOH}$ & $\begin{array}{l}\text { DPPH/ } \beta-C L A M S / \\
\text { FRAP }\end{array}$ & 5.0/6.9/5.1 $\mu \mathrm{g} / \mathrm{mL}$ & Cameroon & [99] \\
\hline $\begin{array}{l}\text { 3,11,12,14,19-Pentahydroxy-5,8,11,13- } \\
\text { abietatraen-7-pyran[4,6]-16-dione (118) }\end{array}$ & $\begin{array}{l}\text { Plectranthus punuctatus } \\
\mathrm{L} \text {. }\end{array}$ & Leaf & Lamiaceae & $\mathrm{MeOH}$ & DPPH & $9.65 \mu \mathrm{g} / \mathrm{mL}$ & Ethiopia & [304] \\
\hline $\begin{array}{l}\text { Tetradecanoic acid, 2-hydroxyhexadecyl ester } \\
\text { (119) }\end{array}$ & $\begin{array}{l}\text { Hydnora abyssinica A. } \\
\text { Braun ex Schweinf. }\end{array}$ & Leaf & Hydnoraceae & $\mathrm{EtOH}$ & SORSA & $37 \%$ at $1 \mathrm{mM}$ & Sudan & [45] \\
\hline Catechin (120) & $\begin{array}{l}\text { Hydnora abyssinica A. } \\
\text { Braun ex Schweinf. }\end{array}$ & Leaf & Hydnoraceae & $\mathrm{EtOH}$ & SORSA & $68.5 \%$ at $1 \mathrm{mM}$ & Sudan & [45] \\
\hline Tyrosol (121) & $\begin{array}{l}\text { Hydnora abyssinica A. } \\
\text { Braun ex Schweinf. }\end{array}$ & Leaf & Hydnoraceae & $\mathrm{EtOH}$ & SORSA & $26 \%$ at $1 \mathrm{mM}$ & Sudan & [45] \\
\hline Benzoic acid, 3, 4-dihydroxy-, ethyl ester (122) & $\begin{array}{l}\text { Hydnora abyssinica A. } \\
\text { Braun ex Schweinf. }\end{array}$ & Leaf & Hydnoraceae & $\mathrm{EtOH}$ & SORSA & $59 \%$ at $1 \mathrm{mM}$ & Sudan & [45] \\
\hline Columbin (123) & $\begin{array}{l}\text { Tinospora bakis } \\
\text { (A.Rich.)Miers. }\end{array}$ & Leaf & Menispermaceae & $\mathrm{EtOH}$ & SORSA & $20 \%$ at $1 \mathrm{mM}$ & Sudan & [45] \\
\hline Przewalskinone B (124) & $\begin{array}{l}\text { Tinospora bakis } \\
\text { (A.Rich.)Miers. }\end{array}$ & Leaf & Menispermaceae & $\mathrm{EtOH}$ & SORSA & $29 \%$ at $1 \mathrm{mM}$ & Sudan & [45] \\
\hline
\end{tabular}


Table 6 Isolated Compounds from African medicinal plants with antioxidants potential (Continued)

\begin{tabular}{|c|c|c|c|c|c|c|c|c|}
\hline 1-Tetracontanol (125) & $\begin{array}{l}\text { Tinospora baki (A.Rich.) } \\
\text { Miers. }\end{array}$ & Leaf & Menispermaceae & $\mathrm{EtOH}$ & SORSA & $26 \%$ at $1 \mathrm{mM}$ & Sudan & [45] \\
\hline $\begin{array}{l}\text { Di-P,octyl phenoxy } 1,5 \text { naphthalene } \\
\text { dicarboxylase ester (126) }\end{array}$ & Cassia italic Mill. & Leaf & Fabaceae & $\mathrm{EtOH}$ & $\mathrm{DPPH}$ & $30.2 \%$ at $100 \mu \mathrm{g} / \mathrm{mL}$ & Egypt. & [44] \\
\hline $\begin{array}{l}\text { Propionic acid (3,6,7,8-tetrahydro-3,7-methano- } \\
\text { 2,4,6-trimethyl-2 h-oxocin-7-yl) methyl ester } \\
\text { (127) }\end{array}$ & Cassia italic Mill. & Leaf & Fabaceae & $\mathrm{EtOH}$ & DPPH & $68.4 \%$ at $100 \mu \mathrm{g} / \mathrm{mL}$ & Egypt. & [44] \\
\hline Octadecyl bromoacetate (128) & Cassia italic Mill. & Leaf & Fabaceae & $\mathrm{EtOH}$ & $\mathrm{DPPH}$ & $56.7 \%$ at $100 \mu \mathrm{g} / \mathrm{mL}$ & Egypt. & [44] \\
\hline 11-O-Phydroxybenzoylnorbergenin (129) & $\begin{array}{l}\text { Diospyros sanza-minika } \\
\text { A. Chev. }\end{array}$ & $\begin{array}{l}\text { Stem } \\
\text { bark }\end{array}$ & Ebenaceae & - & DPPH & - & Cameroon & [305] \\
\hline 4-O-(30-Methylgalloyl) Norbergenin (130) & $\begin{array}{l}\text { Diospyros sanza-minika } \\
\text { A. Chev. }\end{array}$ & $\begin{array}{l}\text { Stem } \\
\text { bark }\end{array}$ & Ebenaceae & - & $\mathrm{DPPH}$ & - & Cameroon & {$[305]$} \\
\hline 4-O-SyringoyInorbergenin; Norbergenin (131) & $\begin{array}{l}\text { Diospyros sanza-minika } \\
\text { A. Chev. }\end{array}$ & $\begin{array}{l}\text { Stem } \\
\text { bark }\end{array}$ & Ebenaceae & - & $\mathrm{DPPH}$ & - & Cameroon & {$[305]$} \\
\hline 4-O-Galloylnorbergenin (132) & $\begin{array}{l}\text { Diospyros sanza-minika } \\
\text { A. Chev }\end{array}$ & $\begin{array}{l}\text { Stem } \\
\text { bark }\end{array}$ & Ebenaceae & - & DPPH & & Cameroon & {$[305]$} \\
\hline Quercitol (133) & $\begin{array}{l}\text { Diospyros sanza-minika } \\
\text { A. Chev }\end{array}$ & $\begin{array}{l}\text { Stem } \\
\text { bark }\end{array}$ & Ebenaceae & - & $\mathrm{DPPH}$ & & Cameroon & {$[305]$} \\
\hline
\end{tabular}

Key: $R S A$ radical scavenging activity, $R C$ reducing power capacity, $\mathrm{OH}$ hydroxyl ion, $\mathrm{NO}$ nitric oxide radical inhibition, $\mathrm{H}_{2} \mathrm{O}_{2}$ hydrogen peroxide inhibition activity, $L P O$ lipid peroxidation inhibition activity, $A B T S^{+} 2,2^{\prime}-$ azinobis-3-ethylbenzothiozolin-6-sulfonic acid cation decolourization test, $B$-CLAMS B-carotene-linoleic acid model system, MLP microsomal lipid peroxydation, FRAP fe ${ }^{2+}$ chelating ability and ferric reducing antioxidant properties, DPPH 1,1-dipheyl-2-picry-hydrazyl, ORAC oxygen radical absorbance capacity, TEAC trolox equivalent antioxidant capacity, $\mathrm{MeOH}$ methanol, $\mathrm{CH}_{2} \mathrm{Cl}_{2}$ dichloromethane, EtOH ethanol, EtOAc ethyl acetate, $n$ $\mathrm{C}_{6} \mathrm{H}_{12}$, hexane, $\left(\mathrm{CH}_{3}\right)_{2} \mathrm{CO}$ acetone, $\mathrm{H}_{2} \mathrm{O}$ aqueous, $\mathrm{BtOH}$ butanol 


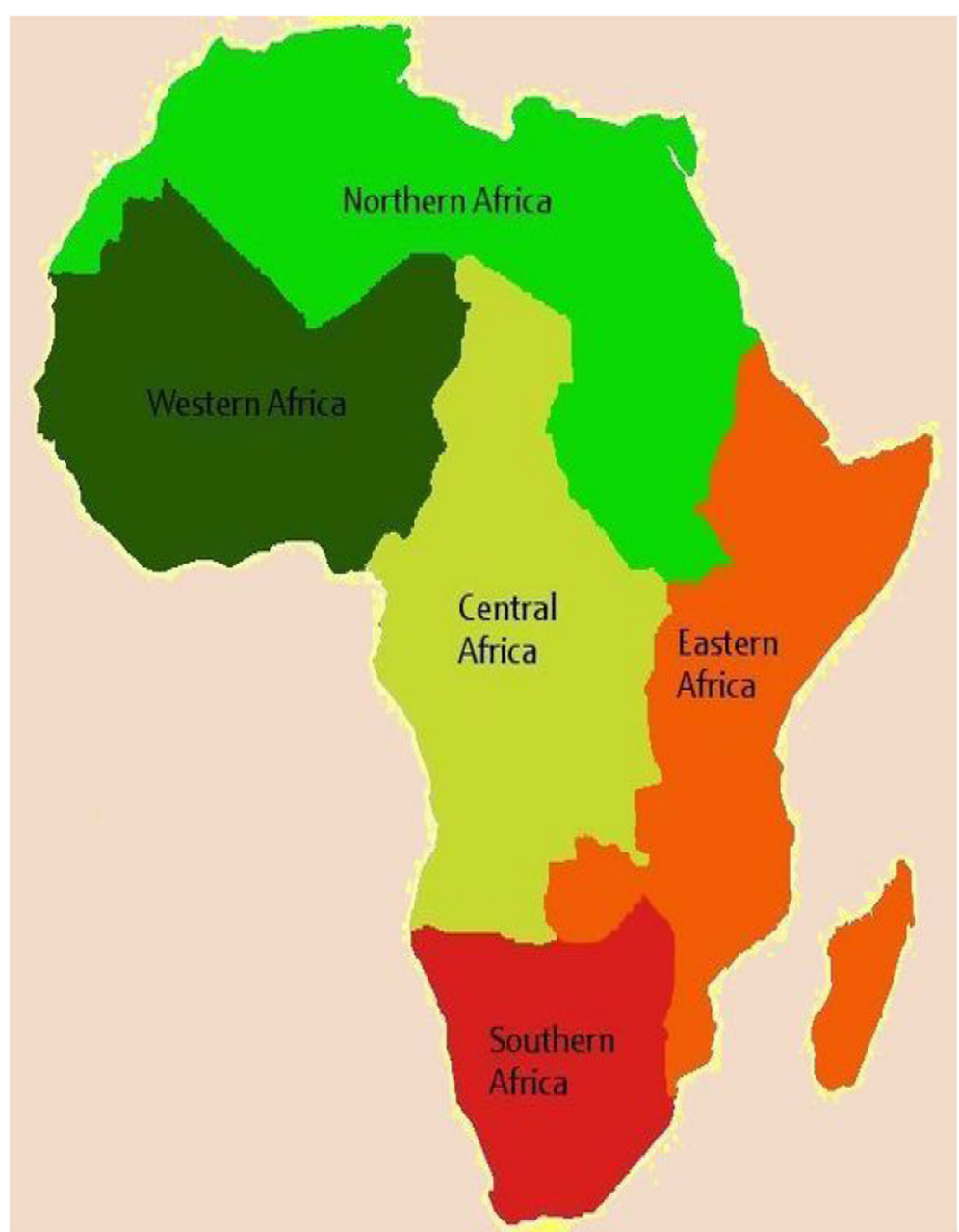

Fig. 1 Map of Africa showing the different subregions

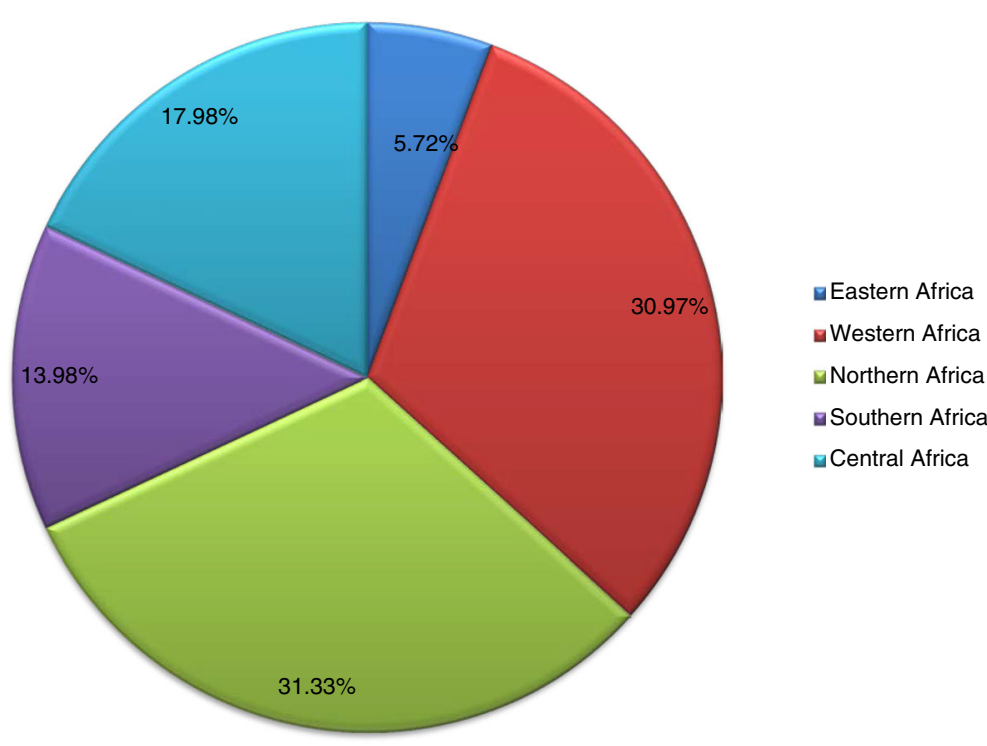

Fig. 2 Regional distribution of of investigated African plants with antioxidant potentials 


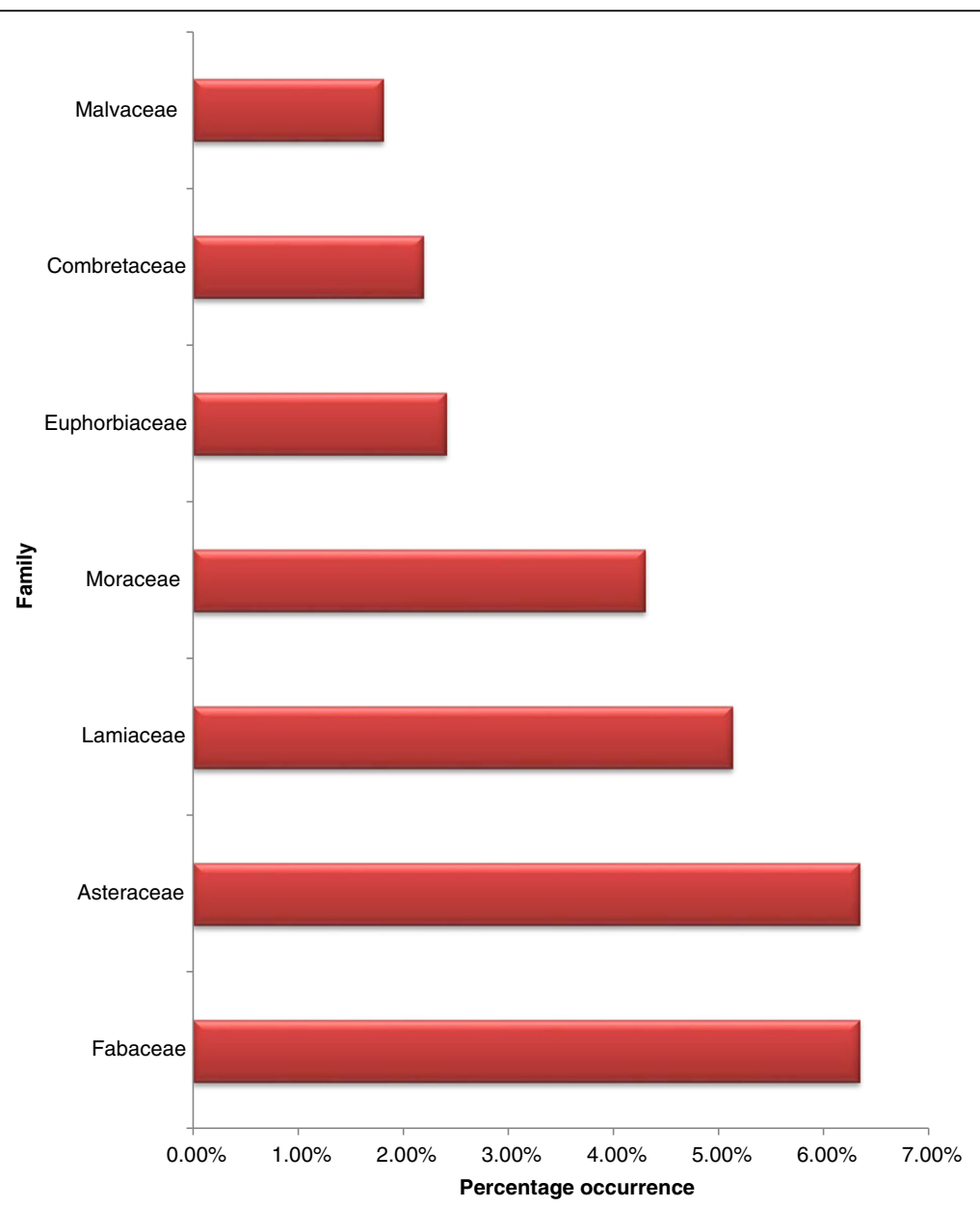

Fig. 3 Percentage occurrence of the most investigated African plants families for antioxidants activities

Aspalathus lineari and Combretum apiculatum demonstrated the most significant DPPH scavenging activities with $\mathrm{IC}_{50}$ values of $2.06 \pm 0.03,2.6 \pm 0.21,3.5 \pm 0.5$ and 1.6 $\pm 0.02 \mu \mathrm{g} / \mathrm{mL}$, respectively while leaf extract of Galenia africana revealed weak antioxidants activity with an $\mathrm{IC}_{50}$ value of $90.92 \pm 1.2 \mu \mathrm{g} / \mathrm{mL}$ [46]. The antioxidant capacity of plant extracts were found to vary with the antioxidant assays used, for instance, Katerere et al. [47] reported Trolox equivalents (TEAC) per $100 \mathrm{~g}$ of plant material of Vigna unguiculata, Lippia javanica, Tagetes minuta, Bidens pilosa, Telfairia occidentalis and Corchorus olitarius which ranged from 0.76 to $5.77 \mathrm{mmol}$ Trolox/100 g in ABTS assay and 16.29-1711.22 mmol Trolox/100 $\mathrm{g}$ for the DPPH assay. Similarly, Thozama [48] reported the percentage (\%) inhibition of Chenopodium album, Solanum nigrum, Urtica lobulata and Amaranthus dubius ranging from 35 to $50 \%$ in DPPH assay and from 60 to $75 \%$ in ABTS assay. The difference in the antioxidant potencies among the assays was expected as each method has a unique mechanism of action under different reaction conditions [49]. For instance, $\mathrm{ABTS}^{+}$is soluble in both aqueous and organic solvents and thus can be used to determine the antioxidant capacities of both lipophilic and hydrophilic substance $[49,50]$. Viol [51] studied the antioxidants activity of 27 Zimbabwe medicinal plants extracts. Eight of these extracts exhibited antioxidant activities using DPPH with the leaves and root extracts of Rhus chirindensis and the bark of Khaya anthotheca exhibiting significant RSA of $96.9 \%$ and $96.1 \%$, respectively. However, the roots of Dichrostachys cinerea revealed modest activities with RSA of $27.4 \%$ [51].

Antioxidant activities of extracts of plants from Central Africa A total of 198 extracts from 166 plants belonging to 38 families originating from Central Africa, predominantly from Cameroon, have been investigated for their antioxidant potential (Table 4). The extracts that exhibited the highest antioxidant activities included; methanol extracts of the leaves and stem of Acalypha racemosa with $\mathrm{IC}_{50}$ values of 2.11 and $2.28 \mu \mathrm{g} / \mathrm{mL}$, respectively; of the fruits and bark of Garcinia lucida with $\mathrm{IC}_{50} 1.83$ and $2.35 \mu \mathrm{g} / \mathrm{mL}$, respectively and of 
<smiles>CC(C)=CCC(C)C1CCC2C1CCC1C3CCC(O)CC3=CCC12</smiles><smiles>CC(C)=CC(C)c1c(O)cc2oc(-c3ccc(O)cc3)cc(=O)c2c1O</smiles><smiles>CC(C)CCc1c(O)c2c(c3c1OC(C(C)(C)O)C3)OC(c1ccc(O)c(O)c1)CC2=O</smiles><smiles>CC1(CO)C(O)C(O)C2OC(Cc3c(-c4cc(O)c(O)c(O)c4)oc4cc(O)cc(O)c4c3=O)C1O2</smiles><smiles>CC(C)=CCc1c(O)c(C(I)CC(C)C)c(O)c2c1OC(c1ccc(O)c(O)c1)CC2=O</smiles><smiles>C=C(C)C(O)Cc1cc(C(=O)/C=C/c2ccc(O)c(CC=C(C)C)c2)c(O)cc1O</smiles><smiles></smiles><smiles></smiles><smiles>O=c1c(OC(O)CO)c(-c2ccc(O)c(O)c2)oc2cc(O)cc(O)c12</smiles>

10

Fig. 4 Structure of chemical compounds isolated from African plants with potential antioxidants and hepatoprotectives properties (Additional file 1)

the roots and bark of Hymenocardia lyrata with $\mathrm{IC}_{50}$ values of 1.96 and $1.74 \mu \mathrm{g} / \mathrm{mL}$, respectively [52]. Agbor et al. [53] investigated different extracts of 42 medicinal plants for their antioxidant activities. The methanol extract of the leaves of Harungana madagascariensis, bark of Azadirachta indica, leaves of Psidium guqjava and leaf of Alchornea were considered to have the highest activities using three different assay systems for antioxidant analysis. Detailed phytochemical studies of ethnomedicinal plants from Central Africa having antioxidant activities led to isolation of approximately 62 compounds (Table 6, Fig. 3). The most active compound included; moracin $\mathrm{T}, \mathrm{U}, \mathrm{S}$ and $\mathrm{R}$ (84-87) isolated from the bark of Morus mesozygia. These compounds revealed significant $\mathrm{DPPH}$ scavenging potential exhibiting $\mathrm{IC}_{50}$ values of 4.12, 5.06, 6.08 and $7.17 \mu \mathrm{g} / \mathrm{mL}$, respectively [54]. Additionally, Donfack et al. [55], studied the in vitro hepatoprotective activity of six (6) compounds from methanol stem bark of Ficus gnaphalocarpa; betulinic acid (53), catechin (65), quercetin (67), quercitrin (68), epicatechin (66) and 3-methoxyquercetin (64). In this study, simultaneous treatment of hepatoma cells with these compounds exhibited antioxidants and hepatoprotective effects as judged by their ability to prevent liver cell death and $\mathrm{LDH}$ leakage during $\mathrm{CCl}_{4}$ intoxication. The hepatoprotection, showed by the aptitude of these molecules to preserve cellular viability and to inhibit the leakage of LDH in extracellular medium was particularly pronounced with compounds $(64,67-68)$. 
Table 7 Total phenol, total flavonoids and folic acid content of some African medicinal plants with Antioxidant potential

\begin{tabular}{|c|c|c|c|c|c|c|c|c|}
\hline Plants & Family & $\begin{array}{l}\text { Part } \\
\text { studied }\end{array}$ & $\begin{array}{l}\text { Solvents } \\
\text { used }\end{array}$ & $\begin{array}{l}\text { Total Phenol } \\
\text { contents }\end{array}$ & $\begin{array}{l}\text { Folic acid } \\
\text { contents }\end{array}$ & $\begin{array}{l}\text { Total } \\
\text { flavonoids } \\
\text { contents }\end{array}$ & $\begin{array}{l}\text { Country } \\
\text { of origine }\end{array}$ & Reference \\
\hline Adansonia digitata $\mathrm{L}$. & Bombacaceae & Fruit & - & $<14.08 \mathrm{~g} / 100 \mathrm{~g}$ & - & - & Zimbabwe & {$[306]$} \\
\hline Adasonia digitata $\mathrm{L}$. & Bombacaceae & Leaf & $\mathrm{MeOH}$ & $170.9 \mathrm{mg} / \mathrm{g}$ & - & $25.38 \mathrm{mg} / \mathrm{g}$ & Nigeria & {$[175]$} \\
\hline Ajuga iva (L.) Schreb. & Lamiaceae & Aerial parts & $\mathrm{MeOH}$ & $3.96 \mathrm{mg} / \mathrm{g}$ & & $0.87 \mathrm{mg} / \mathrm{g}$ & Algeria & [193] \\
\hline Albizia amara (Roxb,) Boiv. & Fabaceae & Leaf Stem & $\mathrm{EtOH}$ & $0.077 \mathrm{mg} / 100 \mathrm{~g}$ & & & Zimbabwe & [307] \\
\hline Allium sativum $\mathrm{L}$. & Alliaceae & & & $12.42 \mathrm{mg} / \mathrm{g}$ & & $0.0021 \mathrm{~g} / \mathrm{g}$ & Nigeria & [308] \\
\hline Aloe barbadensis (L.). Burm. f. & Aloaceae & Leaf & & $0.232 \mathrm{~g} / 100 \mathrm{~g}$ & & $\begin{array}{l}3.246 \mathrm{~g} / / \\
100 \mathrm{~g}\end{array}$ & Nigeria & [309] \\
\hline Amaranthus dubius Mart. ex Thell. & Amaranthaceae & Leaf & $\mathrm{MeOH}$ & $18.03 \mathrm{mg} / \mathrm{g}$ & - & $11.08 \mathrm{mg} / \mathrm{g}$ & $\begin{array}{l}\text { South } \\
\text { Africa }\end{array}$ & [48] \\
\hline Amaranthus hybridus $\mathrm{L}$. & Amaranthaceae & Leaf & $\mathrm{MeOH}$ & $39.32 \mathrm{mg} / \mathrm{g}$ & & & Nigeria & {$[150]$} \\
\hline Amaranthus viridis $\mathrm{L}$. & Amaranthaceae & Leaf & $\mathrm{MeOH}$ & $49.3 \mathrm{mg} / \mathrm{g}$ & & & Nigeria & {$[150]$} \\
\hline Anacyclus clavatus (Desf.) Pers. & & Aerial parts & $\mathrm{MeOH}$ & $71.09 \mathrm{mg} / \mathrm{g}$ & & $3.60 \mathrm{mg} / \mathrm{g}$ & Algeria & [193] \\
\hline $\begin{array}{l}\text { Anogeissus leiocarpus (DC.) } \\
\text { Guill \& Perr. }\end{array}$ & Combretaceae & Leaf & $\mathrm{MeOH}$ & $223.1 \mathrm{mg} / \mathrm{g}$ & - & $223.1 \mathrm{mg} / \mathrm{g}$ & Mali & {$[310]$} \\
\hline Bauhinia rufescens Lam. & Caesalpiniaceae & Leaf & $\mathrm{MeOH}$ & $68.40 \mathrm{mg} / \mathrm{g}$ & & - & Nigeria & {$[154]$} \\
\hline Beilschmiedia mannii Nees. & Lauraceae & Seed & & $206.4 \mathrm{~g} / 100 \mathrm{~g}$ & & & Ivory coast & {$[165]$} \\
\hline Blighia sapida K.D. Koenig. & Sapindaceae & Mushroom & $\mathrm{MeOH}$ & $91.8 \mathrm{mg} / \mathrm{g}$ & & $72.8 \mathrm{mg} / \mathrm{g}$ & Nigeria & {$[311]$} \\
\hline Calycotome spinosa L. & Fabaceae & Leaf & $\mathrm{MeOH}$ & $143.55 \mathrm{mg} / \mathrm{g}$ & & $4.87 \mathrm{mg} / \mathrm{g}$ & Algeria & [193] \\
\hline Cantharellus Cibarius Fr. & Cantharellaceae & Mushroom & - & - & $\begin{array}{l}5.07 \pm \\
0.39\end{array}$ & & Nigeria & {$[160]$} \\
\hline Cassia abbreviate Oliv. & C aesalpinioidaeae & $\begin{array}{l}\text { Bark/leaf/ } \\
\text { root }\end{array}$ & $\mathrm{MeOH}$ & $\begin{array}{l}0.41 / 0.24 / \\
0.398 \mathrm{mg} / \mathrm{mg}\end{array}$ & - & - & Zimbabwe & {$[51]$} \\
\hline Celosia argentea $\mathrm{L}$. & Amaranthaceae & Leaf & $\mathrm{MeOH}$ & $212.16 \mathrm{mg} / \mathrm{g}$ & - & $47.88 \mathrm{mg} / \mathrm{g}$ & Nigeria & {$[175]$} \\
\hline Centaurea calcitrapa L. & Asteraceae & Aerial parts & $\mathrm{MeOH}$ & $57.50 \mathrm{mg} / \mathrm{g}$ & - & $3.28 \mathrm{mg} / \mathrm{g}$ & Algeria & [193] \\
\hline Ceratotheca sesamoides Endl. & Pedaliaceae & Leaf & $\mathrm{MeOH}$ & $186.2 \mathrm{~g} / 100 \mathrm{~g}$ & & & Ivory coast & {$[165]$} \\
\hline Chenopodium album $\mathrm{L}$. & Amaranthaceae & Leaf & $\mathrm{MeOH}$ & $9.34 \mathrm{mg} / \mathrm{g}$ & - & $9.14 \mathrm{mg} / \mathrm{g}$ & $\begin{array}{l}\text { South } \\
\text { Africa }\end{array}$ & {$[48]$} \\
\hline Cissus populnea Guill \& Perr. & Vitidaceae & Root back & & $76.4 \mathrm{mg} / \mathrm{g}$ & - & $27.6 \mathrm{mg} / \mathrm{g}$ & Mali & {$[310]$} \\
\hline Cleome gynandra L. & Capparidaceae & Leaf & $\mathrm{CH}_{2} \mathrm{Cl}_{2}$ & $188.2 \mathrm{~g} / 100 \mathrm{~g}$ & & - & Ivory coast & {$[165]$} \\
\hline Clitocybe odora (Fr.) P. Kumm. & Tricholometaceae & Mushroom & $\begin{array}{l}\text { Not } \\
\text { stated }\end{array}$ & - & $\begin{array}{l}4.79 \mathrm{~g} / \\
100 \mathrm{~g}\end{array}$ & - & Nigeria & {$[160]$} \\
\hline Cnestis ferruginea DC. & Connaraceae & Leaf & $\mathrm{H}_{2} \mathrm{O}$ & $125.58 \mathrm{mg} / \mathrm{g}$ & - & $27.95 \mathrm{mg} / \mathrm{g}$ & Ivory coast & {$[166]$} \\
\hline Corchorus olitorius L. & Malvaceae & Leaf & $\mathrm{MeOH}$ & $330.07 \mathrm{mg} / \mathrm{g}$ & - & $\begin{array}{l}157.38 \mathrm{mg} / \\
\mathrm{g}\end{array}$ & Nigeria & {$[175]$} \\
\hline $\begin{array}{l}\text { Crinum bulbispermum (Burm.f) } \\
\text { Milne-Redhead \& Schweick. }\end{array}$ & Amaryllidaceae & Root & EtOAc & $202.38 \mathrm{mg} / \mathrm{g}$ & - & $9.18 \mathrm{mg} / \mathrm{g}$ & $\begin{array}{l}\text { South } \\
\text { Africa }\end{array}$ & [234] \\
\hline Cupressus sempervirens L. & Cupressaceae & Leaf & $\mathrm{MeOH}$ & $143.5 \mathrm{mg} / \mathrm{g}$ & - & $3.09 \mathrm{mg} / \mathrm{g}$ & Algeria & [193] \\
\hline Dialium dinklagei Harms. & Caesalpiniaceae & Leaf & $\mathrm{H}_{2} \mathrm{O}$ & $185.59 \mathrm{mg} / \mathrm{g}$ & - & $6.78 \mathrm{mg} / \mathrm{g}$ & Ivory coast & {$[166]$} \\
\hline Dichrostachys cinerea Wight et Arn. & Mimosaceae & Leaf/Root & $\mathrm{MeOH}$ & $0.28 / 0.10 \mathrm{mg} / \mathrm{mg}$ & - & - & Zimbabwe & [51] \\
\hline Diospyros monbuttensis $\mathrm{L}$. & Ebenaceae & Leaf & $\mathrm{H}_{2} \mathrm{O}$ & $136.54 \mathrm{mg} / \mathrm{g}$ & - & $62.18 \mathrm{mg} / \mathrm{g}$ & Ivory coast & {$[166]$} \\
\hline Elaedendron malanorpum F. Muell. & Celastraceae & Root & $\mathrm{MeOH}$ & $0.357 \mathrm{mg} / \mathrm{mg}$ & - & - & Zimbabwe & {$[51]$} \\
\hline Elephantorrhiza goetzei & Leguminosae & Root & $\mathrm{MeOH}$ & $0.339 \mathrm{mg} / \mathrm{mg}$ & - & - & Zimbabwe & {$[51]$} \\
\hline Elionurus muticus (Spreng.) Kuntze. & Poaceae & $\begin{array}{l}\text { Whole } \\
\text { Plant }\end{array}$ & & $0.076 \mathrm{mg} / 100 \mathrm{~g}$ & - & - & Zimbabwe & {$[307]$} \\
\hline Ethulia conyzoides Lf. & Asteraceae & Leaf & $\mathrm{MeOH}$ & $425 \mathrm{mg} / 100 \mathrm{~g}$ & - & - & Nigeria & {$[172]$} \\
\hline Fadogia ancylantha Hiern. & Rubiaceae & Leaf & $\mathrm{MeOH}$ & $<14.08 \mathrm{~g} / 100 \mathrm{~g}$ & - & - & Zimbabwe & [306] \\
\hline
\end{tabular}


Table 7 Total phenol, total flavonoids and folic acid content of some African medicinal plants with Antioxidant potential (Continued)

\begin{tabular}{|c|c|c|c|c|c|c|c|c|}
\hline Ficus carica L. & Moraceae & Leaf & $\mathrm{MeOH}$ & $23.70 \mathrm{mg} / \mathrm{g}$ & & $3.75 \mathrm{mg} / \mathrm{g}$ & Algeria & [193] \\
\hline Ficus asperifolia L. & Moraceae & Leaf & $\mathrm{H}_{2} \mathrm{O}$ & $69.20 \mathrm{mg} / \mathrm{g}$ & - & $39.90 \mathrm{mg} / \mathrm{g}$ & Nigeria & [174] \\
\hline Ficus dicranostyla E.J. \& Ake Assi, L. & Moraceae & Leaf & $\mathrm{CH}_{2} \mathrm{Cl}_{2}$ & $178.5 \mathrm{~g} / 100 \mathrm{~g}$ & - & - & Ivory coast & [165] \\
\hline Ficus sycamore L. & Moraceae & Leaf & & $14.08 \mathrm{~g} / 100 \mathrm{~g}$ & - & - & Zimbabwe & [306] \\
\hline Flacourtia indica (Burm.f.) Merr. & Flacourticaceae & Leaf/Root & $\mathrm{MeOH}$ & $0.431 / 0.21 \mathrm{mg} / \mathrm{mg}$ & - & - & Zimbabwe & [51] \\
\hline Globularia alypum L. & Plantaginaceae & Leaf & $\mathrm{MeOH}$ & $25.38 \mathrm{mg} / \mathrm{g}$ & - & $3.76 \mathrm{mg} / \mathrm{g}$ & Algeria & [193] \\
\hline Gnetum africanum L. & Gnetaceae & Leaf & $\mathrm{MeOH}$ & $227.47 \mathrm{mg} / \mathrm{g}$ & - & $91.75 \mathrm{mg} / \mathrm{g}$ & Nigeria & [175] \\
\hline Gongronema latifolium (Endl.) & Apocyanaceae & Leaf & $\mathrm{MeOH}$ & $186.60 \mathrm{mg} / \mathrm{g}$ & - & $51.87 \mathrm{mg} / \mathrm{g}$ & Nigeria & [175] \\
\hline Gymnosporia senegalensis Lam. & Celastraceae & $\begin{array}{l}\text { Leaf/Root/ } \\
\text { Twig }\end{array}$ & $\mathrm{MeOH}$ & $\begin{array}{l}0.34 / 0.22 / 0.268 \mathrm{mg} / \\
\mathrm{mg}\end{array}$ & - & - & Zimbabwe & [51] \\
\hline Helychrisum stoechas Mill. & Asteraceae & Aerial parts & $\mathrm{MeOH}$ & $15.43 \mathrm{mg} / \mathrm{g}$ & - & $4.36 \mathrm{mg} / \mathrm{g}$ & Algeria & [193] \\
\hline Hericium erinaceus (Bull.) Persoon. & Hericiaceae & Mushroom & $\mathrm{MeOH}$ & - & $\begin{array}{l}5.51 \mathrm{~g} / \\
100 \mathrm{~g}\end{array}$ & & Nigeria & [160] \\
\hline Herniaria glabra L. & Caryophyllacea & Aerial parts & $\mathrm{MeOH}$ & $34.48 \mathrm{mg} / \mathrm{g}$ & & $4.90 \mathrm{mg} / \mathrm{g}$ & Algeria & [193] \\
\hline Heteropyxis natalensis L. & Heteropyxidaceae & Leaf Stem & $\mathrm{EtOH}$ & $0.096 \mathrm{mg} / 100 \mathrm{~g}$ & - & - & Zimbabwe & {$[307]$} \\
\hline Hibiscus sabdariffa L. & Malvaceae & Leaf & $\mathrm{MeOH}$ & $104.8 \mathrm{mg} / \mathrm{g}$ & - & - & Nigeria & {$[177]$} \\
\hline Hibiscus sabdariffa L. & Malvaceae & Leaf & $\mathrm{MeOH}$ & $388.46 \mathrm{mg} / \mathrm{g}$ & - & $87.00 \mathrm{mg} / \mathrm{g}$ & Nigeria & [175] \\
\hline Hoslundia opposita Engl. & Lamiaceae & Leaf Stem & $\mathrm{EtOH}$ & $0.054 \mathrm{mg} / 100 \mathrm{~g}$ & - & - & Zimbabwe & [307] \\
\hline $\begin{array}{l}\text { Hypoxis hemerocallidea } \\
\text { Fisch. Mey. \& Ave-Lall. }\end{array}$ & Hypoxidaceae & Tuber & $\mathrm{MeOH}$ & $0.476 \mathrm{mg} / \mathrm{mg}$ & - & - & Zimbabwe & [51] \\
\hline $\begin{array}{l}\text { Justicia galeopsis T. } \\
\text { Anderson ex C.B. Clarke }\end{array}$ & Acanthaceae & Leaf & $\mathrm{CH}_{2} \mathrm{Cl}_{2}$ & $189.8 \mathrm{~g} / 100 \mathrm{~g}$ & - & - & Ivory coast & [165] \\
\hline Khaya anthotheca (Welw.) C. DC. & Meliaceae & Bark/Root & $\mathrm{MeOH}$ & $0.596 / 0.336 \mathrm{mg} / \mathrm{mg}$ & - & - & Zimbabwe & [51] \\
\hline Kigelia africana DC. & Bignoniaceae & $\begin{array}{l}\text { Bark/Fruit/ } \\
\text { Root }\end{array}$ & $\mathrm{MeOH}$ & $\begin{array}{l}0.224 / 0.327 / \\
0.184 \mathrm{mg} / \mathrm{mg}\end{array}$ & - & - & Zimb & [51] \\
\hline Laccaria amethysta (Huds.) Cooke & Hydnangiaceae & Mushroom & $\begin{array}{l}\text { Not } \\
\text { stated }\end{array}$ & - & $\begin{array}{l}5.30 \mathrm{~g} / \\
100 \mathrm{~g}\end{array}$ & - & Nigeria & [160] \\
\hline Laccaria laccata (Scop.) Cooke & Hydnangiaceae & Mushroom & $\begin{array}{l}\text { Not } \\
\text { stated }\end{array}$ & - & $\begin{array}{l}4.87 \mathrm{~g} / \\
100 \mathrm{~g}\end{array}$ & - & Nigeria & [160] \\
\hline $\begin{array}{l}\text { Lactarius deliciousus (L.ex Fr) S.F. } \\
\text { Gray. }\end{array}$ & Russulaceae & Mushroom & $\begin{array}{l}\text { Not } \\
\text { stated }\end{array}$ & - & $\begin{array}{l}4.93 \mathrm{~g} / \\
100 \mathrm{~g}\end{array}$ & - & Nigeria & [160] \\
\hline Lactuca taraxicofolia (Wild.) Schum. & Asteraceae & Leaf & $\mathrm{MeOH}$ & $28.38 \mathrm{mg} / \mathrm{g}$ & - & - & Nigeria & [150] \\
\hline Lannea schweinfurthii Engl. & Anacardiaceae & Root & $\mathrm{MeOH}$ & $10127 \mathrm{mg} / \mathrm{g}$ & - & $13.58 \mathrm{mg} / \mathrm{g}$ & $\begin{array}{l}\text { South } \\
\text { Africa }\end{array}$ & [234] \\
\hline Laportea aestuans (L.) Chew & Urticaceae & Leaf & $\begin{array}{l}\text { Not } \\
\text { stated }\end{array}$ & $199.3 \mathrm{mg} / 100 \mathrm{~g}$ & $\begin{array}{l}52.0 \mathrm{mg} / \\
100 \mathrm{~g}\end{array}$ & $\begin{array}{l}90.7 \mathrm{mg} / \\
100 \mathrm{~g}\end{array}$ & Nigeria & [179] \\
\hline $\begin{array}{l}\text { Lepista nuda (Bull.)H.E. } \\
\text { Bigelow \& A.H. Sm. }\end{array}$ & Tricholomataceae & Mushroom & $\begin{array}{l}\text { Not } \\
\text { stated }\end{array}$ & - & $\begin{array}{l}5.02 \mathrm{~g} / \\
100 \mathrm{~g}\end{array}$ & - & Nigeria & [160] \\
\hline Lepista saeva (Fr.) Cooke. & Tricholomataceae & Mushroom & $\begin{array}{l}\text { Not } \\
\text { stated }\end{array}$ & - & $\begin{array}{l}5.17 \mathrm{~g} / \\
100 \mathrm{~g}\end{array}$ & - & Nigeria & [160] \\
\hline Lippia javanica L. & Verbenaceae & Leaf & $\begin{array}{l}\text { Not } \\
\text { stated }\end{array}$ & $<14.08 \mathrm{~g} / 100 \mathrm{~g}$ & - & - & Zimbabwe & [306] \\
\hline Lippia javanica L. & Verbenaceae & Leaf Stem & $\begin{array}{l}\text { Not } \\
\text { stated }\end{array}$ & $0.064 \mathrm{mg} / 100 \mathrm{~g}$ & - & - & Zimbabwe & {$[307]$} \\
\hline $\begin{array}{l}\text { Macrolepiot ataprocera (Scop.) } \\
\text { Singer. }\end{array}$ & Lepiotaceae & Mushroom & $\begin{array}{l}\text { Not } \\
\text { stated }\end{array}$ & - & $\begin{array}{l}4.72 \mathrm{~g} / \\
100 \mathrm{~g}\end{array}$ & - & Nigeria & [160] \\
\hline Marrubium vulgare $\mathrm{L}$. & Lamiaceae & Aerial parts & $\mathrm{MeOH}$ & $47.58 \mathrm{mg} / \mathrm{g}$ & & $2.01 \mathrm{mg} / \mathrm{g}$ & Algeria & [193] \\
\hline Mitragyna inermis Korth. & Rubiaceae & Trunk bark & & 19.5 mg/g & - & $11.1 \mathrm{mg} / \mathrm{g}$ & Mali & [310] \\
\hline Moringa oleifera Lam & Moringaceae & Leaf & $\mathrm{MeOH}$ & $366.66 \mathrm{mg} / \mathrm{g}$ & & 34.16 mg/g & Nigeria & [175] \\
\hline Myrianthus arboreus P. Beauv. & Cecropiaceae & Leaf & $\begin{array}{l}\text { Not } \\
\text { stated }\end{array}$ & $263.9 \mathrm{~g} / 100 \mathrm{~g}$ & - & - & Ivory coast & [165] \\
\hline
\end{tabular}


Table 7 Total phenol, total flavonoids and folic acid content of some African medicinal plants with Antioxidant potential (Continued)

\begin{tabular}{|c|c|c|c|c|c|c|c|c|}
\hline Myrothamnus flabellifolius Welw. & Myrothamnaceae & Leaf & $\mathrm{CH}_{2} \mathrm{Cl}_{2}$ & $<14.08 \mathrm{~g} / 100 \mathrm{~g}$ & - & - & Zimbabwe & {$[306]$} \\
\hline $\begin{array}{l}\text { Newbouldia laevis (P.Beauv.Seem. } \\
\text { ex Bureau. }\end{array}$ & Bignoniaceae & Leaf & $\mathrm{H}_{2} \mathrm{O}$ & $91.49 \mathrm{mg} / \mathrm{g}$ & - & $22.42 \mathrm{mg} / \mathrm{g}$ & Ivory coast & {$[166]$} \\
\hline $\begin{array}{l}\text { Ocimum urticifolia (N.E.Br) A.J. } \\
\text { Paton. }\end{array}$ & Lamiaceae & Leaf Stem & & $0.024 \mathrm{mg} / 100 \mathrm{~g}$ & - & - & Zimbabwe & {$[307]$} \\
\hline Origanum glandulosum Desf. & & $\begin{array}{l}\text { Aerial } \\
\text { parts }\end{array}$ & $\mathrm{MeOH}$ & $96.36 \mathrm{mg} / \mathrm{g}$ & - & $7.56 \mathrm{mg} / \mathrm{g}$ & Algeria & [193] \\
\hline Pinus halipensis & Pinaceae & Leaf & $\mathrm{MeOH}$ & $108.66 \mathrm{mg} / \mathrm{g}$ & - & $2.80 \mathrm{mg} / \mathrm{g}$ & Algeria & [193] \\
\hline Piper capense L.f. var. Capense. & Piperaceae & Root & $\mathrm{MeOH}$ & $237.60 \mathrm{mg} / \mathrm{g}$ & - & $18.14 \mathrm{mg} / \mathrm{g}$ & $\begin{array}{l}\text { South } \\
\text { Africa }\end{array}$ & [234] \\
\hline Piper guineense Sw. & Piperaceae & Leaf & $\mathrm{MeOH}$ & $319.17 \mathrm{mg} / \mathrm{g}$ & - & $85.41 \mathrm{mg} / \mathrm{g}$ & Nigeria & [175] \\
\hline Pistacia lentiscus L. & & Leaf & $\mathrm{MeOH}$ & $205.22 \mathrm{mg} / \mathrm{g}$ & - & $8.21 \mathrm{mg} / \mathrm{g}$ & Algeria & [193] \\
\hline Plantago major $\mathrm{L}$. & Plantaginaceae & Aerial parts & $\mathrm{MeOH}$ & $106.70 \mathrm{mg} / \mathrm{g}$ & - & $1.54 \mathrm{mg} / \mathrm{g}$ & Algeria & [193] \\
\hline $\begin{array}{l}\text { Pleurotus ostreatus (Jacq. ex Fr.) } \\
\text { P.Kumm. }\end{array}$ & Pleurotaceae & Mushroom & $\begin{array}{l}\text { Not } \\
\text { stated }\end{array}$ & - & $\begin{array}{l}4.75 \mathrm{~g} / \\
100 \mathrm{~g}\end{array}$ & & Nigeria & [160] \\
\hline Populus trimula $\mathrm{L}$. & Salicaceae & Leaf & $\mathrm{MeOH}$ & $116.60 \mathrm{mg} / \mathrm{g}$ & - & $3.98 \mathrm{mg} / \mathrm{g}$ & Algeria & [193] \\
\hline Psalliota campestris $\mathrm{L}$. & Agaricaceae & Mushroom & & $6.012 \mathrm{mg} / \mathrm{g}$ & - & $0.031 \mathrm{~g} / \mathrm{g}$ & Nigeria & [308] \\
\hline Psorospermum febrifugum Spach & Hypericaceae & Leaf & $\mathrm{MeOH}$ & $29.18 \mathrm{mg} / 100 \mathrm{~g}$ & - & & Ivory coast & [165] \\
\hline Pterocarpus midbraedii Jaca. & Fabaceae & Leaf & $\mathrm{MeOH}$ & $499.78 \mathrm{mg} / \mathrm{g}$ & - & $\begin{array}{l}127.88 \mathrm{mg} / \\
\mathrm{g}\end{array}$ & Nigeria & [175] \\
\hline Rhamnus alaternus L. & Rhamnaceae & Leaf & $\mathrm{MeOH}$ & 107.95 & - & $26.84 \mathrm{mg} / \mathrm{g}$ & Algeria & [193] \\
\hline Rhus chirindensis Baker $\mathrm{f}$. & Anacardiaceae & Leaf/Root & $\mathrm{MeOH}$ & $\begin{array}{l}0.323 / 0.258 \\
\mathrm{mg} / \mathrm{mg}\end{array}$ & - & & Zimbabwe & {$[51]$} \\
\hline Rhynchosia buettneri & Fabaceae & Leaf & $\mathrm{MeOH}$ & $224.5 \mathrm{~g} / 100 \mathrm{~g}$ & - & & Ivory coast & {$[165]$} \\
\hline Salix alba L. & & Cortex & $\mathrm{MeOH}$ & $259.65 \mathrm{mg} / \mathrm{g}$ & - & $1.13 \mathrm{mg} / \mathrm{g}$ & Algeria & [193] \\
\hline Sclerocarya birrea (A.Rich.) Hochst. & Celastraceae & Bark & $\mathrm{MeOH}$ & $0.439 \mathrm{mg} / \mathrm{mg}$ & - & & Zimbabwe & {$[51]$} \\
\hline Securidaca longepedunculata Engl. & Polygalaceae & Root & $\mathrm{MeOH}$ & $0.406 \mathrm{mg} / \mathrm{mg}$ & - & - & Zimbabwe & {$[51]$} \\
\hline Sesamum radiatum Sendtn. & pedaliaceae & Leaf & $\mathrm{MeOH}$ & $273.32 \mathrm{mg} / \mathrm{g}$ & - & $48.50 \mathrm{mg} / \mathrm{g}$ & Nigeria & [175] \\
\hline Sesamum radiatum Sendtn. & Pedaluiaceae & Leaf & $\mathrm{MeOH}$ & $273.32 \mathrm{mg} / \mathrm{g}$ & - & $48.50 \mathrm{mg} / \mathrm{g}$ & Nigeria & [175] \\
\hline Solanium aethiopium L. & Solanaceae & Leaf & $\mathrm{MeOH}$ & $40.60 \mathrm{mg} / \mathrm{g}$ & - & - & Nigeria & [150] \\
\hline Solanum macrocarpum L. & Solanaceae & Leaf & $\mathrm{MeOH}$ & $183.1 \mathrm{~g} / 100 \mathrm{~g}$ & - & - & Ivory coast & {$[165]$} \\
\hline Solanum melongena $\mathrm{L}$. & Solanaceae & Leaf & $\mathrm{MeOH}$ & $178.74 \mathrm{mg} / \mathrm{g}$ & - & $85.33 \mathrm{mg} / \mathrm{g}$ & Nigeria & [175] \\
\hline Solanum nigrum L. & Solanaceae & Leaf & $\mathrm{MeOH}$ & $30.00 \mathrm{mg} / \mathrm{g}$ & - & $13.30 \mathrm{mg} / \mathrm{g}$ & $\begin{array}{l}\text { South } \\
\text { Africa }\end{array}$ & [48] \\
\hline Sysimbrium officinalis (L.) Scop. & BrassicaceaE & Flower & $\mathrm{MeOH}$ & $48.87 \mathrm{mg} / \mathrm{g}$ & - & $4.86 \mathrm{mg} / \mathrm{g}$ & Algeria & [193] \\
\hline Telfaria occidentalis Hook. $f$ & Cucurbitaceae & Leaf & $\mathrm{MeOH}$ & $49.32 \mathrm{mg} / \mathrm{g}$ & - & - & Nigeria & $\begin{array}{l}\text { Adetutu } \\
\text { et al., } 2015\end{array}$ \\
\hline Terminalia macroptera Guill. \& Perr. & Combretaceae & Trunk bark & & $48.5 \mathrm{mg} / \mathrm{g}$ & - & $14.2 \mathrm{mg} / \mathrm{g}$ & Mali & {$[310]$} \\
\hline Terminalia sericea Burch. ex DC. & Combretaceae & Root & $\mathrm{MeOH}$ & $36.73 \mathrm{mg} / \mathrm{g}$ & - & $73.05 \mathrm{mg} / \mathrm{g}$ & $\begin{array}{l}\text { South } \\
\text { Africa }\end{array}$ & [234] \\
\hline Terminalia sericea Burch. ex DC. & Combretaceae & leaf/Root & $\mathrm{MeOH}$ & $0.208 / 0.228 \mathrm{mg} / \mathrm{mg}$ & - & - & Zimbabwe & {$[51]$} \\
\hline Teucrium polium L. & Lamiaceae & Aerial parts & $\mathrm{MeOH}$ & $134.00 \mathrm{mg} / \mathrm{g}$ & - & $3.44 \mathrm{mg} / \mathrm{g}$ & Algeria & [193] \\
\hline Trema orientalis (L.) Blume. & Cannabaceae & Leaf & $\mathrm{H}_{2} \mathrm{O}$ & $240.73 \mathrm{mg} / \mathrm{g}$ & - & $59.59 \mathrm{mg} / \mathrm{g}$ & Ivory coast & {$[166]$} \\
\hline Trichaptum biforme & Polyporaceae & Mushroom & - & $4.41 \mathrm{mg} / \mathrm{g}$ & - & $0.0174 \mathrm{~g} / \mathrm{g}$ & Nigeria & [308] \\
\hline Tricholoma nudum (L.) P. Kumm. & Tricholometaceae & Mushroom & - & $64.122 \mathrm{mg} / \mathrm{g}$ & - & $0.0164 \mathrm{~g} / \mathrm{g}$ & Nigeria & [308] \\
\hline Ulmus campestris Mill. & Urticaceae & Leaf & $\mathrm{MeOH}$ & $24.21 \mathrm{mg} / \mathrm{g}$ & - & $3.60 \mathrm{mg} / \mathrm{g}$ & Algeria & [193] \\
\hline Urtica lobulata E. Mey. Ex Bl. & Urticaceae & Leaf & $\mathrm{MeOH}$ & $20.25 \mathrm{mg} / \mathrm{g}$ & - & $11.01 \mathrm{mg} / \mathrm{g}$ & $\begin{array}{l}\text { South } \\
\text { Africa }\end{array}$ & [48] \\
\hline Vepris heterophylla (Engl.) Letouzey. & Rutaceae & Leaf & & $51.5 \mathrm{mg} / \mathrm{g}$ & - & $9.3 \mathrm{mg} / \mathrm{g}$ & Mali & [310] \\
\hline
\end{tabular}


Table 7 Total phenol, total flavonoids and folic acid content of some African medicinal plants with Antioxidant potential (Continued)

\begin{tabular}{|c|c|c|c|c|c|c|c|c|}
\hline Vitellaria paradoxa C.F. Gaetn. & Sapotacee & Mushroom & $\mathrm{MeOH}$ & $55.6 \mathrm{mg} / \mathrm{g}$ & - & $64.8 \mathrm{mg} / \mathrm{g}$ & Nigeria & [311] \\
\hline Vitex doniana $\mathrm{L}$. & Verbernaceae & Mushroom & $\mathrm{MeOH}$ & $96.4 \mathrm{mg} / \mathrm{g}$ & - & $\begin{array}{l}20.8 \pm \\
0.05 \mathrm{mg} / \mathrm{g}\end{array}$ & Nigeria & [311] \\
\hline Warburgia salutaris (Bertol.f) Chiov. & Canellaceae & Leaf/Stem & $\mathrm{EtOH}$ & $0.065 \mathrm{mg} / 100 \mathrm{~g}$ & - & - & Zimbabwe & [307] \\
\hline Warburgia salutaris (Bertol.f) Chiov. & Canellaceae & $\begin{array}{l}\text { Bark/Leaf/ } \\
\text { Root/Twig }\end{array}$ & $\mathrm{MeOH}$ & $\begin{array}{l}0.208 / 0.228 / 0.296 / \\
0.278 \mathrm{mg} / \mathrm{mg}\end{array}$ & - & - & Zimbabwe & [51] \\
\hline $\begin{array}{l}\text { Zanthoxylum davyi } \\
\text { (I. Verd.) Waterm. }\end{array}$ & Rutaceae & Root & $\mathrm{MeOH}$ & $97.26 \mathrm{mg} / \mathrm{g}$ & - & $8.66 \mathrm{mg} / \mathrm{g}$ & $\begin{array}{l}\text { South } \\
\text { Africa }\end{array}$ & [234] \\
\hline Zingiber officianale Roscoe. & Zingiberaceae & Leaf & $\mathrm{MeOH}$ & $64.42 \mathrm{mg} / \mathrm{g}$ & - & $0.045 \mathrm{~g} / \mathrm{g}$ & Nigeria & [308] \\
\hline Ziziphus mucronata Wild. & Rhamnaceae & Root & $\mathrm{MeOH}$ & $73.86 \mathrm{mg} / \mathrm{g}$ & - & $17.76 \mathrm{mg} / \mathrm{g}$ & $\begin{array}{l}\text { South } \\
\text { Africa }\end{array}$ & [234] \\
\hline Zizyphus mucronata Wild. & Rhamnaceae & Leaf & - & $52.2 \mathrm{mg} / \mathrm{g}$ & - & $14.4 \mathrm{mg} / \mathrm{g}$ & Mali & [310] \\
\hline
\end{tabular}

Key: $\mathrm{MeOH}$ methanol, $\mathrm{CH}_{2} \mathrm{Cl}_{2}$ dichloromethane, EtOH ethanol, EtOAc ethyl acetate, $n-\mathrm{C}_{6} \mathrm{H}_{12}$ hexane, $\left(\mathrm{CH}_{3}\right)_{2} \mathrm{CO}$ acetone, $\mathrm{H}_{2} \mathrm{O}$ aqueous, BtOH butanol

\section{Antioxidant activities of extracts of plants from Eastern Africa}

A total of 63 extracts from 51 plants belonging to 23 families were identified to exhibit antioxidant activities (Table 5). Tufts et al. [56] evaluated the ethanol extract of 13 medicinal plants for antioxidant activities using the oxygen radical absorbance capacity (ORAC) assay. Out of these extracts Mangifera indica, Psidium guajava and Ocimum americanum showed the highest antioxidant activities of 5940, 3929 and $3190 \mu \mathrm{MTE} / \mu \mathrm{g}$ respectively. These extracts also exhibited significant anti-inflammatory effect. The significant antioxidant and anti-inflammatory effect of these plants may confer hepatoprotective virtue to the plants. Detailed phytochemical studies of ethnomedicinal plants from Eastern Africa having antioxidant activities led to isolation of approximately 19 compounds (Table 6, Fig. 3). The most potents of these compounds included; rutin (13) with $\mathrm{IC}_{50}$ of $3.53 \mu \mathrm{g} / \mathrm{ml}$ using DPPH free radicals [57], myricitrin- based glycosides including; myricitrin (20) $\left(\mathrm{IC}_{50}=14.2 \mu \mathrm{M}\right)$, myricetin-3-O-arabinopyranoside (21) $\left(\mathrm{IC}_{50}=15.8 \mu \mathrm{M}\right)$, and quercetin-based glycosides including; quercetin-3-Odiglucosylrhamnoside (14) $\left(\mathrm{IC}_{50}=20.7 \mu \mathrm{M}\right)$ and quercetrin (19) $\left(\mathrm{IC}_{50}=26.8 \mu \mathrm{M}\right)$ [58]. The radical scavenging activities of the quercetin-based glycosides appears to be much higher than those of the kaempferol-based glycosides. This can be attributed to the presence ortho-dihydroxyl groups in the B ring of the former, which is not exemplified in the latter. Similarly, myricitrin-based glycosides which contain ortho-trihydroxy groups in the B ring were shown to be more potent scavengers than their corresponding quercetin-based glycosides. Thus, structureactivity considerations for the present series of flavonoids indicate the importance of multiple $\mathrm{OH}$ substitutions for antiradical action towards DPPH with ortho-trihydroxyl group in the $\mathrm{B}$ ring elevating the radical scavenging efficiency above that of the ortho-dihydroxyl group.
Hepatoprotective activities of extracts of plants from Africa The liver is a vital organ which regulates many important metabolic functions and is responsible for maintaining homeostasis of the body [59]. The aetiology of liver diseases is diverse and a variety of plants has been reported to show hepatoprotective activity and so may be useful in the treatment of these diseases [25]. The mechanism of hepatic injury invariably involves peroxidation of hepatocyte membrane fatty acids causing destruction of the cells and their intracellular organelles. Oxidative stress plays a pivotal role in the initiation and progression of hepatic damage following insult to a variety of hepatotoxins [60]. These toxicants damage the hepatocyte primarily by producing reactive oxygen species which form covalent bond with the lipid moiety of the hepatic cell membranes. The drugs/chemicals and plants with antioxidant properties have been shown to protect against toxin induced hepatotoxicity through inhibition of the generation of free radicals. A list of plants reported to have significant hepatoprotective activity is shown in Table 8 in alphabetical order of their family, together with their scientific names, origin, plant part used, kind of extract used, type of assay and inducer of liver damage. Most of these planta are discussed in greater details below.

\section{Moringa oleifera}

Moringa oleifera Lam. (Moringaceae) locally known as "ben oil or drumstick tree" is a small, graceful, deciduous tree with sparse foliage [61]. The plant grows abundantly in many tropical and subtropical countries. Moringa is an ancient magic plant with a plethora of medicinal and nutritional value. The leaves, flowers, root, gums, fruit, and seed of $M$. oleifera have been extensively used in traditional medicine for the treatment of liver disease, lipid disorders, arthritis, and other inflammatory disorders [62]. The ethanolic extract of the leaves of $M$. oleifera was found to exhibit hepatoprotective effect against alcohol induced 
Table 8 Hepatoprotective activity of some African medicinal plants

\begin{tabular}{|c|c|c|c|c|c|c|c|c|}
\hline Plants & Family & $\begin{array}{l}\text { Part } \\
\text { used }\end{array}$ & Solvents & Toxicant & $\begin{array}{l}\text { Dose of } \\
\text { extract } \\
(\mathrm{mg} / \mathrm{kg})\end{array}$ & $\begin{array}{l}\text { Ameliorative effect demonstrated } \\
\text { by the extract on toxin induced } \\
\text { alterations in biomarkers of liver } \\
\text { integrity }\end{array}$ & $\begin{array}{l}\text { Country } \\
\text { of origine }\end{array}$ & References \\
\hline $\begin{array}{l}\text { Acalypha } \\
\text { racemosa H.M. }\end{array}$ & Euphorbiaceae & Leaf & $\mathrm{H}_{2} \mathrm{O}$ & $\mathrm{CCL}_{4}$ & 60 & $\begin{array}{l}\text { Decrease serum AST, ALT, and } \\
\text { total bilirubin and increase serum } \\
\text { TP and ALB concentrations }\end{array}$ & Nigeria & {$[312]$} \\
\hline $\begin{array}{l}\text { Acalypha } \\
\text { wilkesiana L. }\end{array}$ & Euphorbiaceae & Leaf & $\mathrm{H}_{2} \mathrm{O}$ & PCM & $\begin{array}{l}100 / \\
200 / \\
300\end{array}$ & $\begin{array}{l}\text { Decrease serum AST, ALT and } \\
\text { ALP activities and prevent } \\
\text { histopathological alterations in } \\
\text { liver }\end{array}$ & Nigeria & {$[313]$} \\
\hline $\begin{array}{l}\text { Aframomum } \\
\text { melegueta K. } \\
\text { Schum. }\end{array}$ & Zingiberaceae & Fruit & $\mathrm{H}_{2} \mathrm{O}$ & $\mathrm{EtOH}$ & 100 & $\begin{array}{l}\text { Decrease serum AST, ALT and TG. } \\
\text { Increase serum SOD GSH and } \\
\text { prevent histopathological } \\
\text { alterations in liver }\end{array}$ & Nigeria & {$[314]$} \\
\hline Ajuga iva (L.) & Lamiacea & $\begin{array}{l}\text { Aerial } \\
\text { parts }\end{array}$ & Oil & $\mathrm{CCL}_{4}$ & 50 & Decreas serum ALP,AST, ALT & Libya & {$[315]$} \\
\hline $\begin{array}{l}\text { Alchornea } \\
\text { cordifolia Mull. } \\
\text { Arg. }\end{array}$ & Euphorbiaceae & Leaf & $\mathrm{MeOH}$ & $\mathrm{CCL}_{4}$ & 300 & $\begin{array}{l}\text { Decrease serum AST, ALT, ALP } \\
\text { and TB }\end{array}$ & Nigeria & [147] \\
\hline $\begin{array}{l}\text { Allanblackia } \\
\text { gabonensis } \\
\text { (Pellegr.) Bamps. }\end{array}$ & Guttiferae & $\begin{array}{l}\text { Stem } \\
\text { bark }\end{array}$ & $\mathrm{H}_{2} \mathrm{O}$ & PCM & $\begin{array}{l}100 / \\
200\end{array}$ & $\begin{array}{l}\text { Decrease serum ALT, AST, } \\
\text { bilirubin and MDA, increase SOD, } \\
\text { CAT and GSH }\end{array}$ & Cameroon & [111] \\
\hline $\begin{array}{l}\text { Anacardium } \\
\text { occidentale L. }\end{array}$ & Anacardiaceae & Leaf & $\mathrm{MeOH}$ & $\mathrm{CCL}_{4}$ & $\begin{array}{l}500 / \\
1000\end{array}$ & $\begin{array}{l}\text { Decrease serum AST, ALT and } \\
\text { ALP }\end{array}$ & Nigeria & [316] \\
\hline $\begin{array}{l}\text { Andrographis } \\
\text { paniculata Bum.F. }\end{array}$ & Acanthaceae & Leaf & $\mathrm{H}_{2} \mathrm{O}$ & $\mathrm{CCL}_{4}$ & $\begin{array}{l}100- \\
300\end{array}$ & $\begin{array}{l}\text { Decrease serum AST, ALT, ALP, } \\
\text { TB,DBL,CHL, TG, LDL, VLDL and } \\
\text { MDA }\end{array}$ & Nigeria & {$[317]$} \\
\hline $\begin{array}{l}\text { Annona muricata } \\
\mathrm{L} \text {. }\end{array}$ & Annonaceae & Leaf & $\mathrm{EtOH}$ & PCM & 400 & $\begin{array}{l}\text { Decrease serum AST, ALT, ALP, TP } \\
\text { and TB levels. Prevented toxins- } \\
\text { induced liver necrosis }\end{array}$ & Nigeria & [318] \\
\hline $\begin{array}{l}\text { Azadirachta } \\
\text { indica A, Juss. }\end{array}$ & Meliaceae & Leaf & $\mathrm{EtOH}$ & PCM & 300 & $\begin{array}{l}\text { Decrease serum AST, ALT, ALP, } \\
\text { GGT, CHOL and TG. Prevented } \\
\text { toxins induced alterations in } \\
\text { haematological parameters }\end{array}$ & Nigeria & [319] \\
\hline $\begin{array}{l}\text { Balanites } \\
\text { aegyptiaca (L.) } \\
\text { Delile. }\end{array}$ & Balantitiaceae & $\begin{array}{l}\text { Stem } \\
\text { bark }\end{array}$ & $\mathrm{H}_{2} \mathrm{O}$ & PCM & 100 & $\begin{array}{l}\text { Decrease serum AST, ALT and } \\
\text { ALP activities }\end{array}$ & Nigeria & [320] \\
\hline $\begin{array}{l}\text { Camellia sinensis } \\
\text { (L.) Kuntze }\end{array}$ & Theaceae & Leaf & $\mathrm{H}_{2} \mathrm{O}$ & Tamoxifen & 45 & $\begin{array}{l}\text { Decrease serum AST, ALT and } \\
\text { TBARS }\end{array}$ & egypt & [321] \\
\hline Carica papaya L. & Caricaceae & Leaf & $\mathrm{H}_{2} \mathrm{O}$ & $\mathrm{PCM}$ and $\mathrm{CCl}_{4}$ & $\begin{array}{l}100 / \\
300\end{array}$ & $\begin{array}{l}\text { Decrease serum AST, ALT, ALP, } \\
\text { BIL and MDA. Increase GSH, CAT } \\
\text { and SOD }\end{array}$ & Nigeria & [322] \\
\hline Cassia italic Mill. & cesalpiniaceae & Leaf & $\mathrm{EtOH}$ & $\mathrm{CCL}_{4}$ & 200 & $\begin{array}{l}\text { Decrease serum and liver AST, } \\
\text { ALT, ALP and GGT. }\end{array}$ & Nigeria & [323] \\
\hline $\begin{array}{l}\text { Cassia } \\
\text { Occidentalis L. }\end{array}$ & Caesalpinoidae & Leaf & $\mathrm{H}_{2} \mathrm{O}$ & PCM & $\begin{array}{l}250 / \\
500\end{array}$ & $\begin{array}{l}\text { Prevented vascular congestion, } \\
\text { periportal infiltrates of chronic } \\
\text { inflammatory cells and periportal } \\
\text { oedema. }\end{array}$ & Nigeria & {$[324]$} \\
\hline $\begin{array}{l}\text { Cassia } \\
\text { sieberiana DC. }\end{array}$ & Fabaceae & Leaf & $\mathrm{MeOH}$ & $\mathrm{CCL}_{4}$ & $\begin{array}{l}100 / \\
200 / \\
400\end{array}$ & $\begin{array}{l}\text { Decrease serum AST, ALT, ALP } \\
\text { MDA. Increase serum CAT }\end{array}$ & Nigeria & [163] \\
\hline $\begin{array}{l}\text { Cassia singueana } \\
\text { Burkill. H.M. }\end{array}$ & Fabaceae & Root & $\mathrm{MeOH}$ & $\mathrm{CCL}_{4}$ & 50 & $\begin{array}{l}\text { Decrease serum AST, ALT BIL, } \\
\text { MDA and LDL Increase serum } \\
\text { HDL,SOD, CAT, }\end{array}$ & Nigeria & {$[325]$} \\
\hline $\begin{array}{l}\text { Chrysophyllum } \\
\text { Albidum G. Don. }\end{array}$ & Sapotaceae & Leaf & $\mathrm{EtOH}$ & $\mathrm{CCL}_{4}$ & $\begin{array}{l}500 / \\
1000 / \\
1500\end{array}$ & $\begin{array}{l}\text { Decrease serum AST, ALT, ALP } \\
\text { and TB. Prevented toxins-induced } \\
\text { centrilobular fat ty degeneration } \\
\text { and necrosis in liver }\end{array}$ & Nigeria & [326] \\
\hline
\end{tabular}


Table 8 Hepatoprotective activity of some African medicinal plants (Continued)

\begin{tabular}{|c|c|c|c|c|c|c|c|c|}
\hline $\begin{array}{l}\text { Cochlospermum } \\
\text { tinctorium A. } \\
\text { Rich. }\end{array}$ & Cochlospermaceae & Leaf & $\mathrm{MeOH}$ & $\mathrm{CCL}_{4}$ & 200 & $\begin{array}{l}\text { Decrease serum ALT, AST, bilirubin } \\
\text { and MDA and prevent } \\
\text { histopathological alterations in liver }\end{array}$ & Nigeria & [72] \\
\hline $\begin{array}{l}\text { Cochlospermum } \\
\text { Tinctorium A. } \\
\text { Rich. }\end{array}$ & Cochlospermaceae & Leaf & $\mathrm{MeOH}$ & $\mathrm{CCL}_{4}$ & 200 & $\begin{array}{l}\text { Decrease serum AST, ALT, CHOL, } \\
\text { MDA and BIL levels. }\end{array}$ & Nigeria & [72] \\
\hline Costus afer $\mathrm{L}$. & Zingiberaceae & Stem & $\mathrm{MeOH}$ & ALC & $60 / 120$ & Decrease serum AST, ALP & Nigeria & [327] \\
\hline $\begin{array}{l}\text { Echinops } \\
\text { galalensis } \\
\text { Schweinf. }\end{array}$ & Asteraceae & $\begin{array}{l}\text { Aerial } \\
\text { parts }\end{array}$ & $\mathrm{MeOH}$ & $\mathrm{CCL}_{4}$ & $\begin{array}{l}100 \mu \mathrm{g} / \\
\mathrm{mL}\end{array}$ & $\begin{array}{l}\text { Decreas AST, ALT, MDA level and } \\
\text { increase SOD activities }\end{array}$ & Egypt & [102] \\
\hline $\begin{array}{l}\text { Erythrina } \\
\text { senegalensis L. }\end{array}$ & Fabaceae & $\begin{array}{l}\text { Stem } \\
\text { bark }\end{array}$ & $\mathrm{EtOH}$ & $\mathrm{CCL}_{4}$ & 100 & $\begin{array}{l}\text { Decrease serum ALT, AST and } \\
\text { lipid peroxidationin liver } \\
\text { homogenate }\end{array}$ & Cameroon & [116] \\
\hline $\begin{array}{l}\text { Ficus } \\
\text { chlamydocarpa } \\
\text { Mildbr. \& Burret }\end{array}$ & Moraceae & $\begin{array}{l}\text { Stem } \\
\text { bark }\end{array}$ & $\mathrm{MeOH}$ & $\mathrm{CCL}_{4}$ & $50-200$ & $\begin{array}{l}\text { Increase hepatic GSH, decrease } \\
\text { liver MDA decrease AST, ALT and } \\
\text { LDH }\end{array}$ & Cameroon & [99] \\
\hline $\begin{array}{l}\text { Ficus exasperate } \\
\text { Vahl. }\end{array}$ & Moraceae & Leaf & $\mathrm{EtOH}$ & PCM & $\begin{array}{l}125 / \\
150 / \\
500\end{array}$ & $\begin{array}{l}\text { Decrease serum AST,ALT,ALP and } \\
\text { TB }\end{array}$ & Nigeria & [115] \\
\hline $\begin{array}{l}\text { Ficus exasperata } \\
\text { Vahl. }\end{array}$ & Moraceae & Leaf & $\mathrm{EtOH}$ & PCM & $\begin{array}{l}125- \\
500\end{array}$ & $\begin{array}{l}\text { Increase liver ALT, AST but } \\
\text { decrease liver ALP and bilirubin } \\
\text { level }\end{array}$ & Nigeria & [115] \\
\hline $\begin{array}{l}\text { Gongronema } \\
\text { latifolium }\end{array}$ & Asclepiadaceae, & Leaf & $\mathrm{H}_{2} \mathrm{O}$ & $\mathrm{CCL}_{4}$ & 500 & $\begin{array}{l}\text { Decrease serum AST, ALT, ALP } \\
\text { TB,CRT, urea, CHOL andTG }\end{array}$ & Nigeria & [328] \\
\hline $\begin{array}{l}\text { Harungana } \\
\text { madagascariensis } \\
\text { Lam. ex Poiret. }\end{array}$ & Hypericaceae & Root & $\mathrm{H}_{2} \mathrm{O}$ & PCM & $\begin{array}{l}100- \\
500\end{array}$ & $\begin{array}{l}\text { Decrease serum ALT, AST, ALP } \\
\text { and FBG but increase serum } \\
\text { levels of TP and ALB }\end{array}$ & Nigeria & [329] \\
\hline $\begin{array}{l}\text { Hibiscus } \\
\text { cannabinus L. }\end{array}$ & Malvaceae & Leaf & $\mathrm{H}_{2} \mathrm{O}$ & $\mathrm{PCM} / \mathrm{cm}^{3}$ & 1600 & $\begin{array}{l}\text { Decrease serum AST, ALT, BIL and } \\
\text { MDA. Prevented toxin induced } \\
\text { severe inflamm at ion and liver } \\
\text { necrosis }\end{array}$ & Nigeria & [330] \\
\hline $\begin{array}{l}\text { Hibiscus } \\
\text { sabdariffa L. }\end{array}$ & Malvaceae & Flower & $\mathrm{EtOH}$ & $\mathrm{CCL}_{4}$ & $\begin{array}{l}200 / \\
300\end{array}$ & $\begin{array}{l}\text { Decrease serum ALT, AST, ALP,TC, } \\
\text { LDL-C, TG and liver MDA level. } \\
\text { 1ncrease in HDL-C, vitamins A, C, } \\
\text { and } \beta \text {-carotene level }\end{array}$ & Nigeria & [331] \\
\hline $\begin{array}{l}\text { Hibiscus } \\
\text { sabdariffa L. }\end{array}$ & Malvaceae & Leaf & $\mathrm{MeOH}$ & $\mathrm{CCL}_{4}$ & $\begin{array}{l}500 / \\
1000\end{array}$ & $\begin{array}{l}\text { Decrease serum ALT, AST, ALP, } \\
\text { LDH and TBARS but increase } \\
\text { serum GSH, SOD and CAT }\end{array}$ & Nigeria & [177] \\
\hline $\begin{array}{l}\text { Hibiscus } \\
\text { Sabdariffa L. }\end{array}$ & Malvacea & Leaf & $\mathrm{MeOH}$ & $\mathrm{CCL}_{4}$ & $\begin{array}{l}600 / \\
1000\end{array}$ & $\begin{array}{l}\text { Increase serum SOD, CAT, GSH } \\
\text { and decrease serum ALP }\end{array}$ & Nigeria & [332] \\
\hline $\begin{array}{l}\text { Irvingia } \\
\text { gabonensis }\end{array}$ & Irvingiaceae & Leaf & $\mathrm{EtOH}$ & Sodium arsenite & $\begin{array}{l}250 / \\
500\end{array}$ & $\begin{array}{l}\text { Decrease serum ALT, AST and } \\
\gamma G T \text { and prevent } \\
\text { histopathological alterations in } \\
\text { liver }\end{array}$ & Nigeria & [100] \\
\hline $\begin{array}{l}\text { Khaya } \\
\text { grandifoliola } \\
\text { C.DC. }\end{array}$ & Meliaceae & $\begin{array}{l}\text { Stem } \\
\text { bark }\end{array}$ & $\begin{array}{l}\mathrm{EtOAC/} \\
\mathrm{MeOH}\end{array}$ & $\mathrm{CCL}_{4}$ & $25 / 100$ & $\begin{array}{l}\text { Decreas serum ALP,AST, ALT and } \\
\text { TP; Increase liver TBARS, SOD,GSH } \\
\text { and GR) in liver. }\end{array}$ & Cameroon & {$[83]$} \\
\hline $\begin{array}{l}\text { Khaya } \\
\text { senegalensis } \\
\text { (Desr.) A Juss. }\end{array}$ & Meliaceae & $\begin{array}{l}\text { Stem } \\
\text { bark }\end{array}$ & $\mathrm{H}_{2} \mathrm{O}$ & PCM & 100 & $\begin{array}{l}\text { Decrease serum AST, ALT and } \\
\text { ALP activities }\end{array}$ & Nigeria & [320] \\
\hline $\begin{array}{l}\text { Lawsonia inermis } \\
\mathrm{L} \text {. }\end{array}$ & Lythraceae & Leaf & $\mathrm{H}_{2} \mathrm{O}$ & $\mathrm{CCL}_{4}$ & $\begin{array}{l}100 / \\
150\end{array}$ & Decrease serum AST and ALT & Nigeria & [107] \\
\hline $\begin{array}{l}\text { Lawsonia inermis } \\
\text { L. }\end{array}$ & Lythraceae & Leaf & $\mathrm{MeOH}$ & $\mathrm{CCl}_{4}$ & $\begin{array}{l}100 / \\
200\end{array}$ & $\begin{array}{l}\text { Decrease serum AST, ALT, ALP. TP } \\
\text { and BIL. Prevented toxin induced } \\
\text { necrosis of hepatic architecture } \\
\text { with vacuolization and } \\
\text { congestion of sinusoids }\end{array}$ & Sudan & [106] \\
\hline $\begin{array}{l}\text { Mangifera Indica } \\
L \text {. }\end{array}$ & Anacardiaceae & $\begin{array}{l}\text { Stem } \\
\text { bark }\end{array}$ & $\begin{array}{l}\mathrm{H}_{2} \mathrm{O} / \\
\mathrm{EtOH}\end{array}$ & PCM & 200 & $\begin{array}{l}\text { Decrease serum AST, ALT, ALP } \\
\text { and MDA increase TP, GSH, CAT } \\
\text { and SOD }\end{array}$ & Nigeria & [333] \\
\hline
\end{tabular}


Table 8 Hepatoprotective activity of some African medicinal plants (Continued)

\begin{tabular}{|c|c|c|c|c|c|c|c|c|}
\hline $\begin{array}{l}\text { Marrubium } \\
\text { vulgare L. }\end{array}$ & Lamiacea & $\begin{array}{l}\text { Aerial } \\
\text { parts }\end{array}$ & Oil & $\mathrm{CCL}_{4}$ & 50 & Decreas serum ALP,AST, ALT & Libya & [315] \\
\hline $\begin{array}{l}\text { Moringa oleifera } \\
\mathrm{L} \text {. }\end{array}$ & Moringaceae & Leaf & $\mathrm{EtOH}$ & Alcohol & 300 & $\begin{array}{l}\text { Decrease serum AST, ALT, ALP, } \\
\text { GGT andprevented } \\
\text { histopathological changes in liver. }\end{array}$ & Nigeria & [63] \\
\hline $\begin{array}{l}\text { Nauclea latifolia } \\
\mathrm{L} \text {. }\end{array}$ & Rubiaceae & Leaf & $\mathrm{EtOH}$ & PCM & 400 & $\begin{array}{l}\text { Decrease serum AST, ALT, } \\
\text { increase serum TP, ALB, CAT,GPX } \\
\text { andSOD concentrations }\end{array}$ & Nigeria & [334] \\
\hline $\begin{array}{l}\text { Newbouldia } \\
\text { Laevies (P. Beauv) } \\
\text { Seem. Ex Burea }\end{array}$ & Bignoniaceae & Leaf & $\mathrm{EtOH}$ & $\mathrm{CCL}_{4}$ & $\begin{array}{l}100 / \\
300\end{array}$ & $\begin{array}{l}\text { Decrease serum AST, } \\
\text { ALT,ALP,TB,TP andCHL }\end{array}$ & Nigeria & [335] \\
\hline $\begin{array}{l}\text { Ocimum } \\
\text { americanum L. }\end{array}$ & Lamiaceae & Leaf & $\mathrm{H}_{2} \mathrm{O}$ & PCM & $\begin{array}{l}200 / \\
400\end{array}$ & $\begin{array}{l}\text { Decrease serum ALP, AST, ALT. } \\
\text { TBIL and preserve liver } \\
\text { architecture }\end{array}$ & Nigeria & [94] \\
\hline $\begin{array}{l}\text { Ocimum } \\
\text { gratissimum L. }\end{array}$ & Lamiaceae & Leaf & $\mathrm{H}_{2} \mathrm{O}$ & $\mathrm{CCL}_{4}$ & 500 & $\begin{array}{l}\text { Decrease serum AST, ALT, ALP } \\
\text { TB,CRT, urea, CHOL andTG }\end{array}$ & Nigeria & [328] \\
\hline $\begin{array}{l}\text { Prosopis africana } \\
\text { (Guill. \& Perr.) } \\
\text { Taub. }\end{array}$ & Mimosaceae & $\begin{array}{l}\text { Stem } \\
\text { bark }\end{array}$ & $\mathrm{H}_{2} \mathrm{O}$ & PCM & 100 & $\begin{array}{l}\text { Decrease serum AST, ALT and } \\
\text { ALP activities }\end{array}$ & Nigeria & [320] \\
\hline $\begin{array}{l}\text { Rosmarinus } \\
\text { officinalis L. }\end{array}$ & Lamiacea & $\begin{array}{l}\text { Aerial } \\
\text { parts }\end{array}$ & Oil & $\mathrm{CCL}_{4}$ & 50 & Decreas serum ALP,AST, ALT & Libya & [315] \\
\hline $\begin{array}{l}\text { Senna alata (L.) } \\
\text { Roxb. }\end{array}$ & Fabaceae & Leaf & $\mathrm{MeOH}$ & $\mathrm{CCL}_{4}$ & 400 & $\begin{array}{l}\text { Decrease serum ALT, AST, ALP, } \\
\text { total and direct bilirubin and liver } \\
\text { TBARS, increase serum total } \\
\text { protein and albumin and prevent } \\
\text { histopathological alterations in } \\
\text { liver }\end{array}$ & Nigeria & {$[68]$} \\
\hline $\begin{array}{l}\text { Spathodea } \\
\text { campanulata P. } \\
\text { Beauv. }\end{array}$ & Bignoniaceae & $\begin{array}{l}\text { Stem } \\
\text { bark }\end{array}$ & $\mathrm{H}_{2} \mathrm{O}$ & $\mathrm{CCL}_{4}$ & $\begin{array}{l}100 / \\
300 / \\
625\end{array}$ & $\begin{array}{l}\text { Decrease serum AST, ALT and } \\
\text { GGT and prevent } \\
\text { histopathological alterations in } \\
\text { liver }\end{array}$ & Ghana & {$[86]$} \\
\hline $\begin{array}{l}\text { Sphenocentrum } \\
\text { jollyanum L. }\end{array}$ & Menispermaceae & $\begin{array}{l}\text { Stem } \\
\text { bark }\end{array}$ & $\mathrm{MeOH}$ & $\mathrm{CCL}_{4}$ & $\begin{array}{l}50 / 100 / \\
200\end{array}$ & $\begin{array}{l}\text { Decrease serum AST,ALT, ALP, TB } \\
\text { and LP and Increase liver TP, } \\
\text { SOD, CAT, GPx GST }\end{array}$ & S. Africa & {$[96]$} \\
\hline $\begin{array}{l}\text { Swietenia } \\
\text { Mahogani (L.) } \\
\text { Jacq. }\end{array}$ & Maliaceae & Leaf & $\mathrm{H}_{2} \mathrm{O}$ & Alcohol & $\begin{array}{l}250 / \\
500\end{array}$ & $\begin{array}{l}\text { Decrease serum AST, ALT, ALP BIL } \\
\text { and CRT }\end{array}$ & Nigeria & [336] \\
\hline $\begin{array}{l}\text { Telfairia } \\
\text { occidentalis Hook. } \\
\text { F. }\end{array}$ & Cucurbitaceae & Leaf & $\mathrm{EtOH}$ & $\mathrm{CCL}_{4}$ & 500 & $\begin{array}{l}\text { Increase livee AST, ALT, ALP and } \\
\text { prevented toxin-induced central } \\
\text { vein congestion with eroded } \\
\text { endothelium and haemolised } \\
\text { blood vessels, pkynotic nucleic } \\
\text { and fats infiltration }\end{array}$ & Nigeria & [337] \\
\hline $\begin{array}{l}\text { Thymus capitatus } \\
\text { L. }\end{array}$ & Lamiacea & $\begin{array}{l}\text { Aerial } \\
\text { parts }\end{array}$ & Oil & $\mathrm{CCL}_{4}$ & 50 & Decreas serum ALP,AST, ALT & Libya & [315] \\
\hline $\begin{array}{l}\text { Tulbaghia } \\
\text { violacea Harv. }\end{array}$ & Alliaceae & Rhizome & - & $\begin{array}{l}\text { Atherosclerogenic } \\
\text { (ath) }\end{array}$ & $\begin{array}{l}250 / \\
500\end{array}$ & $\begin{array}{l}\text { Decrease Serum TG, TC, LDL-C, } \\
\text { VLDL-C, TBARS, fibrinogen, LDH, } \\
\text { AST,ALT, ALP, BIL,CRET and } \\
\text { prevent histopathological } \\
\text { alterations in liver }\end{array}$ & $\begin{array}{l}\text { South } \\
\text { Africa }\end{array}$ & [263] \\
\hline $\begin{array}{l}\text { Uvaria afzelii P. } \\
\text { Beauv. }\end{array}$ & Annonaceae & Root & $\mathrm{MeOH}$ & $\mathrm{CCL}_{4}$ & $\begin{array}{l}125 / \\
250 / \\
500\end{array}$ & $\begin{array}{l}\text { Decreases serum ALT, AST, ALP, } \\
\text { total and un-conjugated bilirubin }\end{array}$ & Nigeria & {$[76]$} \\
\hline $\begin{array}{l}\text { Vernonia } \\
\text { ambigua L. }\end{array}$ & Asteraceae & Leaf & $\mathrm{EtOH}$ & $\mathrm{CCL}_{4}$ & $\begin{array}{l}250 / \\
500\end{array}$ & $\begin{array}{l}\text { Decrease serum ALT, AST and } \\
\text { ALP, TB, CHOL, TGA increase TP } \\
\text { and ALB }\end{array}$ & Nigeria & {$[90]$} \\
\hline $\begin{array}{l}\text { Vernonia } \\
\text { amygdalina } \\
\text { Delile. }\end{array}$ & Asteraceae & Leaf & $\mathrm{EtOH}$ & PCM & 300 & $\begin{array}{l}\text { Decrease serum AST, ALT, ALP, } \\
\text { GGT, CHOL and TG. Prevented } \\
\text { toxins induced alterations in } \\
\text { haematological parameters }\end{array}$ & Nigeria & [319] \\
\hline
\end{tabular}


Table 8 Hepatoprotective activity of some African medicinal plants (Continued)

\begin{tabular}{|c|c|c|c|c|c|c|c|c|}
\hline $\begin{array}{l}\text { Vernonia } \\
\text { amygdalina } \\
\text { Delile. }\end{array}$ & Asteraceae & Leaf & $\mathrm{MeOH}$ & & $20 / 60$ & $\begin{array}{l}\text { Increase liver and kidney AST and } \\
\text { ALT, }\end{array}$ & Nigeria & [338] \\
\hline $\begin{array}{l}\text { Vitellaria } \\
\text { paradoxa C.F. } \\
\text { Gaertn. }\end{array}$ & Sapotaceae & $\begin{array}{l}\text { Stem } \\
\text { bark }\end{array}$ & $\mathrm{H}_{2} \mathrm{O}$ & PCM & 100 & $\begin{array}{l}\text { Decrease serum AST, ALT and } \\
\text { ALP activities }\end{array}$ & Nigeria & [320] \\
\hline $\begin{array}{l}\text { Xylopia aethiopica } \\
\text { Delile. }\end{array}$ & Annonaceae & $\begin{array}{l}\text { Stem } \\
\text { bark }\end{array}$ & $\mathrm{H}_{2} \mathrm{O}$ & $\mathrm{CCL}_{4}$ & $\begin{array}{l}250 / \\
500\end{array}$ & $\begin{array}{l}\text { Decrease serum AST, ALT, ALP } \\
\text { and BIL }\end{array}$ & Nigeria & [339] \\
\hline $\begin{array}{l}\text { Satureja punctata } \\
\text { (Benth.) Briq. }\end{array}$ & Lamiaceae & $\begin{array}{l}\text { Aerial } \\
\text { parts }\end{array}$ & $\mathrm{H}_{2} \mathrm{O}$ & Fe-NTA & $\begin{array}{l}250 / \\
500\end{array}$ & Decrease serum AST, ALT, ALP & Ethiopia & [291] \\
\hline $\begin{array}{l}\text { Solanecio } \\
\text { angulatus (Vahl) } \\
\text { C. Jeffrey }\end{array}$ & Asteraceae & Leaf & $\mathrm{H}_{2} \mathrm{O}$ & Fe-NTA & $\begin{array}{l}250 / \\
500\end{array}$ & Decrease serum AST and ALT, & Ethiopia & [291] \\
\hline $\begin{array}{l}\text { Cineraria } \\
\text { abyssinica Sch. } \\
\text { Bip.ex A. }\end{array}$ & Asteraceae & Leaf & $\begin{array}{l}\mathrm{MeOH} / \\
\mathrm{H}_{2} \mathrm{O}\end{array}$ & $\mathrm{CCL}_{4}$ & 200 & $\begin{array}{l}\text { Decrease serum AST, ALT, ALP. } \\
\text { Prevented toxins induced liver } \\
\text { necrosis and inflammation }\end{array}$ & Ethiopia & [340] \\
\hline
\end{tabular}

Key: $A L T$ alanine aminotransferase, $A S T$ aspartate amino transferase, $A L P$ alkaline phosphatase, $T P$ total bilirubin, $D B$ direct bilirubin, $L D L$ low density lipoprotein, $V L D L$ very low density lipoprotein, $M D A$ malondialdehyde, $C A T$ catalase, GPx glutathione peroxidase, SOD superoxide dismutase, $C R T$ creatinine, $C H O L$ cholesterol, TG triglyceride, $\mathrm{CCL}_{4}$ carbon tetrachloride, Fe-NTA ferric nitrilotriacetate, $\mathrm{PCM}$ paracetamol, $\mathrm{MeOH}$ methanol, $\mathrm{CH}_{2} \mathrm{Cl}_{2}$ dichloromethane, EtOH ethanol, EtOAC ethyl acetate, $n-\mathrm{C}_{6} \mathrm{H}_{12}$ Hexane; $\left(\mathrm{CH}_{3}\right)_{2} \mathrm{CO}$ acetone, $\mathrm{H}_{2} \mathrm{O}$ aqueous, btoh:butanol

hepatotoxicity in rats [63]. This research proved that animal pretreatment with ethanolic extract of $M$. oleifera (300 mg/kg of weight) significantly attenuated hepatotoxin induced biochemical (serum AST, ALT, ALP, and GGT) and histopathological changes in the liver. Additionally, $M$. oleifera leaves also showed significant anti-inflammatory [64], and antioxidant potencies [63], [65], which may be contributing to its hepatoprotective activity. A number of phytochemicals with antioxidant activities have been characterized from Moringa oleifera including; quercetin (22), rutin (13), kaempferol and caffeoyqumic acids.

\section{Senna alata}

Senna alata (L.) Roxb) (Fabaceae) is commonly known as candle bush, with reference to the shape of its inflorescences, or ringworm tree for it traditional use. It is an annual, erect, tropical herb of $0.15 \mathrm{~m}$ high [66]. The leaves are well known for their medicinal used for various diseases of the liver [67]. The hepatoprotective effect of the plant has been shown in Wistar albino rat intoxicated with $\mathrm{CCl}_{4}$. This study reported that methanol extract and fractions (ethanol and butanol) of S. alata leaves administered orally at $400 \mathrm{mg} / \mathrm{kg}$ decreased hepatic enzyme levels (serum ALT, AST, ALP,) total and direct bilirubin, liver TBARS induced by $\mathrm{CCl}_{4}$ damage. Administration of the methanol extract of this plant showed maintenance of the hepatocytes membrane's structural integrity [68]. The extract also showed strong antioxidant and anti-inflammatory [69], activities which may contribute to its hepatoprotective property.

\section{Cochlospermum tinctorium}

Cochlospermum tinctorium (Cochlospermaceae) is a bushy savannah plant, commonly found in fallow farms across northern Nigeria. It is a shrub that grows up to $10 \mathrm{~m}$ high [70]. Decoctions of the whole roots of C. tinctorium have been reported to be used as remedy for gonorrhoea, jaundice, gastrointestinal diseases, helminthes, bilharzias infest ations, as well as for the management of epilepsy [71]. The hepatoprotective effect of methanol extracts of C. tinctorium leaf has been studied against $\mathrm{CCl}_{4}$ induced liver injury [72]. The extract attenuated $\mathrm{CCl}_{4}$ induced rise in liver enzymes including AST and ALT, bilirubin, MDA level and prevented histopathological alterations in the liver [72]. The hepatoprotective activities of the extract have been linked to both enzymic and non-enzymic antioxidants that could bring about free radical suppressing activity.

\section{Uvaria afzelii}

Uvaria afzelii Sc Elliot (Annonaceae) is widely distributed and grown in the South and eastern part of Nigeria, where it is known by various local names such as "gbogbonishe" (Yoruba), "Umimi ofia" (Igbo) and "Osu-umimi" (Ukwani) [73]. Locally it is used in the treatment of cough, vaginal tumour, gonorrhea, jaundice, infections of the liver, kidney and bladder $[74,75]$. The hepatoprotective activity of this plant was evaluatedin the experimental acute hepatic damage induced by $\mathrm{CCl}_{4}$ in rat [76]. In this study, it was reported that the methanolic extracts of the root of Uvaria afzelii, at doses of $125 \mathrm{mg} / \mathrm{kg}, 250 \mathrm{mg} / \mathrm{kg}$ and $500 \mathrm{mg} / \mathrm{kg}$, significantly reduced the serum hepatic enzymes, total and un-conjugated bilirubin. Phytochemical studies of this plant has shown the presence of syncarpic acid, dimethoxym atteucinol, emorydone, 2-hydroxydemethoxym at-teucinol, uvafzelic acid, syncarpurea, afzeliindanone, flavonoids, triterpenoids and phenols [76-78]. Some of these compounds have also been credited for their antiparasitic and antioxidant activities [79]. 


\section{Sphenocntrum jollyanum}

Sphenocntrum jollyanum Pierre (Menispermaceae) is locally known as Aduro kokoo (red medicine) and Okramankote (dog's penis) in Ghana. It is a small erect sparsely branched rub which grows up to $1.5 \mathrm{~m}$ in height. Different part of $S$. jollyanum has been used extensively for the treatment of various ailments in Western Africa Sub-region. The methanolic extract of $S$. jollyanum stem bark showed significant hepatoprotective activity against $\mathrm{CCl}_{4}$ induced liver injury [80]. In addition, this extract possesses significant antioxidant activities with $\mathrm{IC}_{50}$ values of 13.11 and $30.04 \mu \mathrm{g} / \mathrm{mL}$ in superoxide and hydrogen radical scavenging activity, respectively [80] and antiinflammatory [81], activities which may be contributing to its hepatoprotective effects.

\section{Khaya grandifoliola}

Khaya grandifoliola (Meliaceae) is commonly used in traditional medicine by the Bamun (a tribe of Western Cameroon) for curing liver related diseases [82]. The hepatoprotective effect of $K$. grandifoliola has been studied against PCM [83], and $\mathrm{CCl}_{4}$ induced hepatotoxicity [84] in rats. The methanol; methylchloride extract of the stem bark of this plant at 25 and $100 \mathrm{mg} / \mathrm{kg}$ dose dependently attenuated hepatotoxin induced alterations in biochemical parameters (serum ALP, AST, ALT and TP and liver TBARS, SOD, GSH and GR) and prevented toxin induced alteration in liver histopathology. The extract also showed antioxidant and anti-inflammatory activities [84] which may be contributing to its hepatoprotective activity.

\section{Spathodea campanulata}

Spathodea campanulata, (Bignoniaceae), it's a widely used traditional African medicinal plant for skin diseases and stomach aches [85]. The extract of the stem bark of Spathodea campanulata produced significant hepatoprotection [86]. In this study it was reported that the methanolic extracts of the stem bark of $S$. campanulata, at doses of 100, 300, and $625 \mathrm{mg} / \mathrm{kg}$ significantly attenuated $\mathrm{CCl}_{4}$ induced rise in biochemical (serum AST, ALT and GGT) and histopathological changes in the liver [86]. Phytochemical studies on S. campanulata showed the presence of flavonoids, tannins, spathoside, $n$-alkanes, linear aliphatic alcohols, beta-sitosterol-3-O-beta-D-glucopyranoside, oleanolic acid, pomolic acid, $p$-hydroxybenzoic acid, phenylethanol esters, reducing sugars. The in vitro testing which gave positive results for reducing power and total phenolic content [86-88], also support the activity of the plant extract with reference to its hepatoprotection.

\section{Vernonia ambigua}

Vernonia ambigua (Asteraceae) is an annual shrub growing up to $6 \mathrm{~m}$ high. It is widely distributed in areas like Angola, Sudan, Tanzania, Uganda and tropical
Western Africa. In Nigeria it is used for gastrointestinal disorders, as a general tonic and appetite stimulant, for skin diseases and as a medication for fever, dysentery, malaria, diabetics and constipation [89]. The hepatoprotective activity of leaf extract of $V$. ambigua has been investigated using $\mathrm{CCl}_{4}$ induced hepatotoxicity in albino rats. The extract significantly attenuated $\mathrm{CCl}_{4}$ induced biochemical (ALT, AST and ALP, TB, CHOL, TGA, TP and ALB [90]. Plants of the genus Vernonia are known to produce characteristic compounds such as sesquiterpene lactones, with several reported biological activities, such as fungistatic [91], and cytotoxic activities [92]. The hepatoprotective properties of plants from genus Vernonia may be attributed to presence of mainly; flavonoids, steroids and polysaccharides [93], that has been characterized previously from this genus.

\section{Ocimum americanum}

Ocimum americanum (Lamiaceae) commonly known as "African basil" It is a wild herb with a distinct mint flavor, hairy leaves and scented flowers that is native to tropical Africa. The aqueous extract of $O$. americanum (200 and $400 \mathrm{mg} / \mathrm{kg}$ ) significantly attenuated PCM induced biochemical (serum ALP, AST, ALT and TBIL level) and histopathological alterations in the liver [94]. The hepatoprotective activity of Ocimum americanum may be attributed to its antioxidant activities [95].

\section{Tulbaghia violacea}

Tulbaghia violacea (Alliaceae) is a fast-growing, bulbous plant that reaches a height of $0.5 \mathrm{~m}$. In the Eastern Cape of South Africa rhizomes of Tulbaghia violacea has been used for the treatment of jaundice, gall bladder stones, liver diseases and heart disease [96]. The rhizomes extract of $T$. violacea dose dependently attenuated atherosclerogenic induced alteration in markers of endothelial dysfunction, lipid profile, liver enzymes and histological changes [97]. The antioxidant and cytotoxicity activities of $T$. violacea as well as its phytochemical components such flavonoids and saponins [98] may be responsible for its hepatoprotective properties.

\section{Irvingia gabonensis}

Irvingia gabonensis (Irvingiaceae) locally known as "bush mango or African mango" since the trees bear fruits that look like small mango (Matos et al., 2010). In Senegal, the decoction of the stem bark is used in the treatment of gonorrhoea, hepatic and gastrointestinal disorders [99]. The thanol extract of the leaves of this plant has been investigated for its hepatoprotective activity in sodium arsenite (SA) induced hepatotoxicity and clastogenicity in male Wistar rats [100]. The extract at 250 or $500 \mathrm{mg} / \mathrm{kg}$ dose dependently attenuated sodium arsenite 
induced rise in liver enzymes including AST, ALT and and gamma glutamyltransferase $(\gamma \mathrm{GT})$ and prevented histopathological alterations in the liver [100]. Phytochemical studies on the ethanol extract of Irvingia gabonensis showed the presence of of tannins, saponins, alkaloids, terpenoids, flavonoids and phenols [100]. Tannins have been reported to have anti-inflammatory and antiulcer property in rodents and they also exhibit strong antioxidant properties [101].

\section{Echinops galalensis}

The methanol extract of the flowering aerial parts of Echinops galalensis (Asteraceae), its fractions and the isolated compounds (25-33) have been reported for their hepatoprotective effects agaisnt $\mathrm{CCl}_{4}$ induced cell damage in an in vitro assay on human hepatoma cell line (Huh7). The extract and isolated compounds (25-33) at $100 \mu \mathrm{g} / \mathrm{mL}$ prior to $\mathrm{CCl}_{4}$ challenge protected against cell injury by decreasing the level of AST, ALT, MDA and increasing the activities of SOD [102]. The protective effects of E. galalensis methanolic extract, its fractions as well as the isolated compounds is at least partly due to their antioxidant activities as evidenced by the reduction in MDA level and the increase in SOD activity.

\section{Lawsonia inermis}

Lawsonia inermis (lythraceae) is a shrub or small tree cultivated in many regions as an ornamental and commercial dye crop [103]. It is mostly found in the tropic, sub-tropic, and semi-arid zones of Africa (tropical Savannah and tropical arid zones), South Asia and North Australia [104]. As a medicinal plant, the leaves, seed and bark of $L$. inermis have been used in folk remedy as astringent, hypotensive, sedative, and against a headache, jaundice, spleen enlargement, leprosy and other liver disease [105]. Its hepatoprotective activity was shown in a toxicity model by $\mathrm{CCI}_{4}$ in rats. These research proved that animal pretreatment with a methanolic extract of Lawsonia inermis (100 and $200 \mathrm{mg} / \mathrm{kg}$ of weight) attenuated the increase in AST serum activity, alanine aminotransferase (ALT), alkaline phosphatase (ALP), total bilirubin (TB), and histological changes observed in the damage induced by $\mathrm{CCl}_{4}[106,107]$. Previous reports have shown that $L$. inermis is rich in phenolic compounds such as phenolic acids, flavonoids, tannins, lignin, and others that possess antioxidant, anticarcinogenic, and antimutagenic effects as well as antiproliferative potentials [108], which may be responsible for its hepatoprotective activities.

\section{Ficus chlamydocarpa}

Ficus chlamydocarpa (Moraceae) is traditionally used in Cameroon for the management of different diseases including; filarial, diarrheal infections and tuberculosis
[109]. Another ethnopharmacological survey has revealed that a decoction of the stem bark is used in West Cameroon folk medicine for the treatments of abdominal problems, arthritis, inflammatory conditions and jaundice, which are commonly considered symptomatic of liver-related diseases.

Its hepatoprotective effect was evaluated through the induction of acute hepatic damage in rats using $\mathrm{CCl}_{4}$ [99]. In this, study the pre-treatment with $50-200 \mathrm{mg} /$ $\mathrm{kg}$ of methanolic extract of $F$. chlamydocarpa stem bark prevented serum increase of hepatic enzyme markers and lactate dehydrogenase (LDH), enhanced hepatic reduced glutathione (GSH) level and decreased of hepatic malondialdehyde (MDA) during $\mathrm{CCl}_{4}$ intoxication. Previous phytochemical studies on stem bark of F. chlamydocarpa revealed the presence of the following flavonoids; alpinumisoflavone (115), genistein $(4 ', 5,7-$ trihydroxyisoflavone 116) and luteolin $\left(3^{\prime}, 4{ }^{\prime}, 5,7-\right.$ tetrahydroxy flavones 117) with significant DPPH radical scavenging activities with $\mathrm{IC}_{50}(\mu \mathrm{g} / \mathrm{mL}$ of $6,5.7,5.0$ respecively [99].

\section{Allanblackia gabonensis}

Allanblackia gabonensis (Guttiferae) is commonly grown in tropical Africa including; Cameroon, Democratic Republic of Congo, etc. between around 500 and $1750 \mathrm{~m}$ above sea level [110]. The plant is used in traditional medicine to treat some inflammatory diseases. The aqueous suspension of the stem bark of $A$. gabonensis showed significant hepatho-nephroprotective activity against acetaminophen-induced liver and kidney disorders in rats. In this, study the pre-treatment with 100 and $200 \mathrm{mg} / \mathrm{kg}$ significantly reduced the serum level of MDA, increase in enzymatic antioxidant activities (SOD and CAT) and non enzymatic antioxidant (GSH) levels [111]. The stem bark of this plant has been known to elaborate the following compounds xanthones, benzophenone, flavonoide, and phytosterol [112]. In addition, A. gabonensis possess significant analgesic and antiinflammatory activities [113] which may be contributing to its hepatoprotective activities.

\section{Ficus exasperata}

Ficus exasperata vahl (Moraceae) is a terrestrial plant that grows $20 \mathrm{~m}$ high and inhabits the evergreen and secondary rainforest of West Africa. The plant is commonly known as sand paper tree, it is also known locally as "anwerinwa" [114]. The ethanol extracts of the leaves of $F$. exasperata showed significant hepatoprotective activitie in acetaminophen-induced hepatotoxic rats [115]. The extract at $125-500 \mathrm{mg} / \mathrm{kg}$ significantly ameliorated toxin induced alterations in the liver ALT, AST, ALP and bilirubin levels. The histological evaluation showed a partial 
prevention of inflammation, necrosis and vacuolization induced by $\mathrm{CCl}_{4}[115]$.

\section{Erythrina senegalensis}

Erythrina senegalensis DC (Fabaceae), locally known by the Bamun people in Cameroon as 'Megham njû' is a thorny shrub or small tree, with a corky stem bark and bright red flowers, found in Sudanese savannah regions. Hepatoprotective effect of the ethanolic extract of Erythrina senegalensis stem bark was studied in vivo against

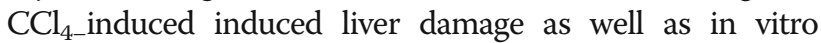
against rat liver slices intoxicated $\mathrm{CCl}_{4}$. E. senegalensis extract at $100 \mathrm{mg} / \mathrm{kg}$ significantly attenuated hepatotoxin induced biochemical serum ALT, AST and lipid peroxidation in liver homogenate. Polyphenols including flavonoids have been characterized from this plants which could be implicated for its hepatoprotective potential [116].

Njayou et al. [117], evaluated the hepatoprotective effect of fifty four Cameroonian plants extracts against Fe (II)-Ascorbate induced microsomal lipid peroxidationin rat liver. Only 15 plants extract inhibiting oxidation phenomena with percentage inhibition of $>50$ at $200 \mu \mathrm{g} / \mathrm{mL}$ were considered as possessing a high lipid oxidation inhibitory potential. In this respect, Mangifera indica, Enantia chlorantha, Voacanga africana, Aspilia africana, Senna alata, Piliostigma thonningii, Piliostigma thonningii, Kalonchoe crenata, Alchornea laxiflora, Crotalaria lachnophora, Erythrina senegalensis, Khaya grandifoliola, Entada africana, Melinis minutiflora and Curcuma longa were found to be active. Among these active plant species, some of them, namely E. chlorantha [118], E. africana [119] and C. longa [120], have been reported to be active against experimentally induced hepatitis. $M$. indica on its part has been shown to be very effective against lipid and protein oxidation in vitro and injury associated to hepatic ischemia reperfusion [121, 122]. The inhibitory effect against the free radical-mediated degradation of microsomal lipid peroxidation by plant extracts mentioned above may also be attributed to flavonoids and polyphenols as many of these phytoconstituents are known to be antioxidants [123]. The presence of flavonoids and polyphenols has been reported in all the above cited plant extracts [124, 125].

Aja et al., [2], documented the antioxidant activities of the ethanol leaf extracts of $C$. citratus and $H$. spicigera against Plasmodium berghei induced oxidative stress by significantly $(P<0.05)$ increasing the superoxide dismutase, reduced glutathione, catalase and peroxidase activities and decreasing the lipid peroxidation when compared with the controls. This study indicates the effectiveness of the use of Cymbopogon citratus and Hyptis spicigera in the management of oxidative stress caused by malaria [2].
Mulata et al. [126], evaluated the effect of hydroethanolic seed extract of Calpurnia aurea against highly active antiretroviral therapy (HAART) induced free radical reactions in the liver and liver cell damage in rats. The authors reported that the extract $(300 \mathrm{mg} / \mathrm{kg})$ reduced the HAART induced liver toxicity by decreasing the free radical reactions, ALP, ALT, AST release and increasing antioxidant profiles in treated rats.

A polyherbal formulation comprising of Gongronema latifolia, Ocimum gratissimum and Vernonia amygdalina demonstrated significant hepatoprotective activities by attenuating the increase in serum hepatic enzyme levels after $\mathrm{CCl}_{4}$ treatment compared to the toxin control group and increasing the levels of serum CAT, GPx, GSH, GST, SOD, total protein and significantly $(p<0.05)$ decreasing lipid peroxidation compared to the toxin control group [127].

"Ata-Ofa" a polyherbal formulation consisting of twenty one (21) plant products, including, Ginger officinalle, Tamarindus indica, Khaya senegalensis, Moringa oleifera, Nauclea latifolia, Camellia sinensis, Anacardium occidentale, Aframomum melegueta, Phyllantus amarus, Morinda lucida and Mangifera indica was reported (at $5 \mathrm{mg} / \mathrm{kg}$ ) for in vivo antioxidant, hepatoprotective and curative effects by its ability to ameliorate $\mathrm{CCl}_{4}$ induced alterations in biochemical parameters and antioxidants enzymes in intoxicated rat [128].

\section{Antioxidants and hepatoprotective activities of insect/ mollusk and their secreations}

Omalu et al. [129], evaluated the free radical scavenging activity of Nigeria Leech (Aliolimnatis michaelseni) saliva extract. Their results revealed that the extract excert significant DPPH free radical scavenging activity with $\mathrm{IC}_{50}$ value of $8.169 \mu \mathrm{g} / \mathrm{mL}$ initially and $8.67 \mu \mathrm{g} / \mathrm{mL}$ after starvation for 1 month. Omalu et al., [130], also documented the antioxidants potency of maggots of the blowfly ( $\mathrm{Luci}$ lia robineau) excretion/saliva extract with $\mathrm{DPPH}$ free radical scavenging activity of $\left(\mathrm{IC}_{50}\right.$ of $\left.152.66 \mu \mathrm{g} / \mathrm{mL}\right)$ compared with $108.99 \mu \mathrm{g} / \mathrm{mL}$ of L-ascorbic.

Giant African Snail (Achachatina maginata) haemolymph has been reported for in vitro antioxidant activity with an $\mathrm{IC}_{50}$ value of $579.66 \pm 2.69 \mu \mathrm{g} / \mathrm{mL}$ in $\mathrm{DPPH}$ radical scavenging assay and $310.75 \pm 3.12 \mu \mathrm{g} / \mathrm{mL}$ in lipid peroxidation inhibitory assay. The haemolymph also excert ameliorative effects on $\mathrm{CCL}_{4-}$ induced elevations of the levels of AST, ALT, ALP, TBARS and it reversal effect on reduced concentration of catalase induced by $\mathrm{CCL}_{4}$ intoxication. The total phenolics and flavonoids contents were reported to be $9.30 \pm 0.11 \mathrm{mg} / \mathrm{g}$ GAE and $15.20 \pm 0.59 \mathrm{mg} / \mathrm{g}$ catechin equivalent respectively [5]

Shittu et al. [131], reported the ameliorative effects of the methanol extracts of Musca domestica $(400 \mathrm{mg} / \mathrm{kg}$ ) against T. brucei induced alteration in antioxidants 
enzymes (SOD and CAT). Antioxidant screening of the extract against $\mathrm{DPPH}$ was positive, with $\mathrm{IC}_{50}$ and antioxidant activities index (AAI) of $174.38 \mathrm{mg} / \mathrm{mL}$ and 0.29 respectively. Since oxidative stress has been implicated in the etiology of African trypanosomiasis, these two findings suggest that the methanol extract of Musca domestica probably excert it anti-trypanosoma effect by free radical scavenging and thus could serve as a candidate for the development of new drugs for the treatment of trypanosomiasis. The methanol extracts of Nigeria bee propolis $(600 \mathrm{mg} / \mathrm{kg})$ has been reported for hepatocurative effect by ameliorating $\mathrm{CCL}_{4-}$ induced alterations in the serum and liver AST, ALT and ALP activities when administered orally to rats for 10 days [132].

Tanzania honey bee has been reported for DPPH radical scacvenging activity with $\mathrm{IC}_{50} 4.19,12.93$ and $18.03 \mathrm{mg} / \mathrm{mL}$ in stingless bee honeys, raw bees honey and processed bees honey respectively. Similarly, iron chelating activities were reported with $\mathrm{IC}_{50}$ value of $0.04,0.057$ and $0.158 \mathrm{mg} / \mathrm{mL}$ for stingless bee's honey, raw bee's honey and processed bee's honey respectively [133]. Previous phytochemical investigation of the Nigerian sweet and bitter honey revealed total flavonoids contents of $20.81 \mu \mathrm{g} / \mathrm{mL}$ and $18.92 \mu \mathrm{g} / \mathrm{mL}$ respectively [134].

Nyanzi et al., [135], reported the antioxidant activities of methanol extract from freeze-dried cells of probiotic Lactobacillus strains. At the extract concentration of $20 \mathrm{mg} / \mathrm{mL}$ the authors reported that $L b$. acidophilus, Lb. rhamnosus and Lb. casei strains had DPPH scavenging activities of $77.9-86.1 \%, 45.7-86.4 \%$ and $36.9-45.8 \%$ respectively. This finding is an indication that Probiotic extracts can potentially be used as bio-preservatives and in reduction of oxidative stress.

\section{Conclusion and future prospects}

Meta-analysis of available scientific literature on antioxidants and hepatoprotective activity of African natural products to a great extent validate folkloric claims about the usefulness of these botanicals to treat liver diseases and other oxidative stress induced disorder. This review has documented the list of African natural products with potential antioxidants and hepatoprotectives effect. Many of these natural products displayed good antioxidants and hepatoprotective activities. This explains the effort of Africa research institutes in drug discovery from natural products. However, the variations in method of analsis, presentations of results, doses, durat ion as well as the geographical difference of the plants reviewed in this study has made it difficult to accurately point out plant/compounds with the best reported antioxidants and hepatoprotective activities. But our close analysis of the reports seem to suggest that Combretum apiculatum, Telfaria occidentalis, Acalypha racemosa, Garcinia lucida, Xeoderris sthulmannii,
Clausena anisata, Harpephyllum caffrum, Ceratotheca sesamoides, Camellia sinensis, Cyathea dregei, Harpephyllum caffrum, Aspalathus linearis were the most active ROS-detoxifying plant extracts from African flora. The best ROS-detoxifying phytochemicals were moracin $\mathrm{T}, \mathrm{U}$, $\mathrm{S}$ and $\mathrm{R}$ (84-87), oleanolic acid (54), 5,7, '-trihydroxy-3,8,3',5'-tetramethoxyflavone (89), 5,7,3'-trihydroxy-3,8, $4^{\prime}, 5^{\prime}$-trimethoxyflavone (88), luteolin $\left(3^{\prime}, 4^{\prime}\right.$, 5,7-tetrahydroxy flavone) (117) and genistein (4',5,7trihydroxyisoflavone) (116). It is hoped that pertinent scientist and stakeholders will look further into some of these plants and compounds for detailed authentification and subsequent commercialization. Although, most of studies reviewed are preliminary in nature, detailed isolation, characterization, mechanisms of actions of these of isolated compounds, safety studies, quality control as well as clinical trials on some of these herbs and their isolated compounds is far from satisfactory.

\section{Additional file}

Additional file 1: Structure of chemical compounds isolated from African plants with potential antioxidants properties. (DOCX $121 \mathrm{~kb}$ )

\section{Authors' contributions}

This work was carried out in collaboration between all authors. Author BL \& OKS did the literature search. Author BL, OKS, FIO, EBB \& MH carry out the data analysis and preparation of the manuscript. All authors read and approved the final manuscript.

\section{Competing interests}

The authors declare that they have no competing interests.

\section{Author details}

'Department of Biochemistry, Tropical Disease Research Unit, Federal University of Technology, P.M.B. 65 Minna, Nigeria. ${ }^{2}$ National School of Tropical Medicine, Baylor College of Medicine, 1102 Bate Avenue, Houston, TX 77030, USA. ${ }^{3}$ Faculty of Medicine and Biomedical Science, University of Yaounde 1, Yaounde, Cameroon.

Received: 31 August 2016 Accepted: 25 October 2016

Published online: 09 November 2016

\section{References}

1. Okoli JTN, Agbo MO, Ukekwe IF. Antioxidant and Hepatoprotective Activity of Fruit Extracts of Tetrapleura tetraptera (Schum \& Thonn) Taubert. Jordan Journal of Biological Sciences. 2014;7(4):251-4

2. Aja PM, Odeh CO, Uraku AJ, Offor CE. Evaluation of antioxidant activities of ethanol leaf extracts of Cymbopogon citratus and Hyptis spicigera in mice exposed to Plasmodium berghei. Int J Curr Microbiol App Sci. 2015;4:382-93.

3. Bjelakovic G, Nikolova D, Gluud LL, Simonetti RG, Gluud C. Mortality in randomized trials of antioxidant supplements for primary and secondary prevention: systematic review and Meta-analysis. J Am Med Assoc. 2007;297: 842-57.

4. Lawal B, Ossai PC, Shittu OK, Abubakar AN. Evaluation of phytochemicals, proxim at e, minerals and anti-nutritional compositions of yam peel, maize chaff and bean coat. Int J Appl Biol Res. 2014;6:21-37.

5. Lawal B, Shittu OK, Ossai PC, Abubakar AN, Ibrahim AM. Antioxidant activities of giant African snail (Achachatina maginata) haemolymph against $\mathrm{CCl}_{4-}$ induced hepatotoxicity in albino rats. Brit J pharm Res. 2015:6:141-54.

6. Souri $\mathrm{E}$, Amin G, Farsam H, Barazandeh TM. Screening of antioxidant activity and phenolic content of 24 medicinal plant extracts. Daru. 2008;16:83-7. 
7. Anderson JW, Smith BM, Wasnock CS. Cardiovascular and renal benefits of dry bean and soyabean intake. Amer J Clin Nutr. 1999;70:464-74.

8. Ndhlala A, Ncube B, Van Staden J. Antioxidants versus reactive oxygen species - A tug of war for human benefits? In: Laher I, editor. Systems Biology of Free Radicals and Antioxidants. Berlin Heidelberg: Springer; 2014. p. 3987-4002.

9. Lampe JW. Spicing up a vegetarian diet: chemopreventive effects of phytochemicals. Amer J Clin Nutr. 2003;78:579S-83S.

10. Patience OO, Festus BCO, Philip FU, Nneka RN, ljeoma EA, Nkemakonam CO. Phytochemical analysis, Hepatoprotective and antioxidant activity of Alchornea cordifolia Methanol leaf extract on carbon tetrachloride-induced hepatic damage in rats. Asian Pac J Trop Med. 2012;5:289-93.

11. Ibrahim M, Khaja MN, Aara A. Hepatoprotective activity of Sapindus mukorossi and Rheum emodi extracts: in vitro and in vivo studies. World J Gastroenterol. 2008;14:2566-71.

12. Lawal B, Shittu OK, Oibiokpa IF, Mohammed H, Umar SI, Haruna GM. Antimicrobial evaluation, acute and sub-acute toxicity studies of Allium sativum. J Acute Dis. 2016. doi:10.1016/j.joad.2016.05.002.

13. Rajkapoor BY, Venugopal J, Anbu N, Harikrishman MG, Ravichandran V. Protective effect of phyllanthus polyphllus on acetaminphen induced hepatotoxicity in rats. Pak JPharm Sci. 2008;21:90-3.

14. Jyothi KSN, Hemalatha P, Avanthi A, Challa S. A comparative analysis on the alpha amylase inhibitory potential of six ornamented medicinal plants. J Nat Prod Plant Res. 2013;3:1-6.

15. Ostapowicz G, Fontana RJ, Schiodt FV, Larson A, Davern TJ, Han SH, et al. Results of a prospective study of acute liver failure at 17 tertiary care centers in the united st at es. Annals Internal Med. 2002;137:947-54.

16. Kodavanti RR, Joshi UM, Young YA, Meydrech EF, Mehendale HM. Protection of hepatotoxic and lethal effects of $\mathrm{CCl}_{4}$. Toxicological Pathology. 1989;17:494-505.

17. Arhoghro EM, Ekpo KE, Anosike EO, Ibeh GO. Effect of aqueous extract of bitter leaf (Vernonia Amygdalina Del) on carbon tetrachloride $\left(\mathrm{CCl}_{4}\right)$ induced liver damage in albino wistar rats. Eur I Scientific Res. 2009;26:122-30.

18. Pramyothin P, Ngamtin C, Poungshompoo S, Chaichantipyuth C. Hepatoprotective activity of Phyllanthus amarus Schum. et. Thonn. extract in ethanol tre at ed rats: in vitro and in vivo studies. J Ethnopharmacol. 2007:114:169-73.

19. Bashir L, Shittu OK, Sani S, Busari MB, Adeniyi KA. African natural products with potential antitrypanosoma properties: A review. Int J Biochem Res Rev. 2015;7:45-79.

20. Manach C, Morand C, Demigne C, Texier O, Regerat F, Remesy C. Bioavailability of rutin and quercetin in rats. FEBS Lett. 1997;409:12-6.

21. Nafiu MO, Salawu MO, Kazeem MI. Antioxidant activity of African medicinal plants. In: Kuete V, editor. Medicinal Plant Research in Africa. Oxford: Elsevier; 2013. p. 787-803.

22. Atawodi SE. Antioxidant potential of African medicinal plants. Afri 」 Biotechnol. 2005;4:128-33.

23. Kuete V, Efferth T. Cameroonian medicinal plants: pharmacology and derived natural products. Front Pharmacol. 2010;1:1-19.

24. Hamzah, R.U., Jigam, A.A., Makun H.A., Egwim, E.C. (2013a). Antioxidant Properties of Selected African Vegetables, Fruits and Mushrooms: A Review. Intech. http://dx.doi.org/10.5772/52771

25. Adewusi EA, Afolayan AJ. A review of natural products with hepatoprotective activity. J Med Plant Res. 2010:4:1318-34.

26. Adebayo JO, Krettli AU. Potential antimalarials from Nigerian plants: A review. J Ethnopharmacol. 2011:133:289-302.

27. Lawal B, Shittu OK, Kabiru AY, Jigam AA, Umar MB, Berinyuy EB, et al. Potential antimalarials from African natural products: A review. J Intercult Ethnopharmacol. 2015;4:318-43. doi:10.5455/jice.20150928102856.

28. Chanda S, Dave R. In vitro models for antioxidant activity Evaluation and some medicinal plants possessing antioxidant properties: An overview. Afri J Microbiol Res. 2009;3:981-96.

29. Ndhlala A, Moyo M, Van Staden J. Natural antioxidants: Fascinating or mythical biomolecules? Molecules. 2010;15:6905-30.

30. Katalinic V, Milos M, Kulisic T, Jukic M. Screening of 70 medicinal plant extracts for antioxidant capacity and total phenols. Food Chem. 2006;94:550-7.

31. Omisore NOA, Adewunmi CO, Iwalewa EO, Ngadjui BT, Adenowo TK, Abegaz BM, et al. Antitrichomonal and antioxidant activities of Dorstenia barteri and Dorstenia convexa. Braz J Med Biol Res. 2005;38:1087-94.

32. Ramde-Tiendrebeogo A, Tibiri A, Hilou A, Lompo M, Millogo-Kone H, Nacoulma OG, et al. Antioxidative and antibacterial activities of phenolic compounds from Ficus sue Forssk. Inter J Biol Chem Sci. 2012;6(1):328-36.
33. Bashir L, Shittu OK, Busari MB, Sani S, Aisha MI. Safety Evaluation of Giant African land Snails (Archachatina marginata) haemolymph on hematological and biochemical parameters of albino rats. J Adv med Pharm Sci. 2015;3:122-30.

34. Lawal B, Shittu OK, Abubakar AN, Umar MB, Ibrahim AM, Haruna GM. Biochemical evaluation in Wister rats (Rattus novergicus) following chronic exposure of methanol leaf extract of Telfairia occcidentalis. J Pharm Biomed Sci. 2015;5:740-4.

35. Shittu OK, Lawal B, Abubakar NA, Berinyuy BE, Busari MB, Ibrahim AO. Toxicological Implications of Methanol Extract from Nigerian Bee Propolis on Some Selected Rat Tissues. J Pharm Biomed Sci. 2015;05:524-31.

36. Shittu OK, Lawal B, Blessing Uchenna AB, Haruna GM, Abubakar AN, Berinyuy EB. Alteration in Biochemical Indices Following Chronic Administration of Methanolic Extract of Nigeria Bee Propolis in Wister Rats. Asian Pac J Trop Dis. 2015;5:654-7.

37. Yusuf OK, Bewaji CO, Ekanem JT. Biochemical Evaluation of Fermented Wheat Germ Extract on Trypanosoma brucei -infected rats. Afr J Biomed Res. 2010;13:219-24.

38. Oke JM, Hamburger MO. Screening of some Nigerian medicinal plants for antioxidant activity using 2, 2, Diphenyl-picryl-hydrazyl radical. Afri J Biom Res. 2002;5:77-9.

39. Omale J. Cytotoxicity and Antioxidant Screening Of Some Selected Nigerian Medicinal Plants. Asian J Pharm Clin Res. 2009;2:48-53.

40. Ajiboye TO, Yakubu MT, Oladiji AT. Cytotoxic, Antimutagenic, and antioxidant activities of methanolic extract and chalcone dimers (Lophirones B and C) derived from Lophira alata (Van Tiegh. Ex Keay) stem bark. J Evid Based Complementary Altern Med. 2014;19:2.

41. Aboul-Enein AM, El-Ela FA, Shalaby EA, El-Shemy HA. Traditional medicinal plants research in Egypt: Studies of antioxidant and anticancer activities. J Med Plant Res. 2012;5:689-703.

42. Moussa AM, Emam AM, Diab YM, Mahmoud ME, Mahmoud AS. Evaluation of antioxidant potential of 124 Egyptian plants with emphasis on the action of Punica gran at um leaf extract on rats. Int Food Res J. 2011;18:535-42.

43. Sudjaroen Y, Haubner R, Wurtele G, Hull WE, Erben G, Spiegelhalder B, et al. Isolation and structure elucidation of phenolics antioxidants from Tamarind (Tamarindus indica L) seeds and pericarp. Food Chem Toxicol. 2005;43(11): 1673-82.

44. Aboul-Enein AM, El-Ela FA, Shalaby E, El-Shemy H. Potent Anticancer and Antioxidant Activities of Active Ingredients Separated from Solanum nigrum and Cassia italica Extracts. J Arid Land Stud. 2014;24:145-52.

45. Koko WS, Osman E, Galal M. Antioxidant and antiglyCAT ion potential of some Sudanese medicinal plants and their Isolated compounds. Boletín Latinoamericano y del Caribe de Plantas Medicinales y Aromáticas. 2009;8:402-11.

46. Sharma R, Lall N. Antibacterial, antioxidant activities and cytotoxicity of plants against Propionibacterium acnes. South Afri J Sci. 2014;110:8.

47. Katerere DR, Graziani G, Thembo KM, Nyazema NZ, Ritieni A. Antioxidant activity of some African medicinal and dietary leafy African vegetables. Afr J Biotechnol. 2012;11:4103-8.

48. Thozama, K.M. Phytochemical and Antioxidant Composition of Selected Local Wild Plants in South Africa: Considerat ion of Alternative Nutrients for Health Promotion. 2015 5th International Conference on Biomedical Engineering and Technology IACSIT Press, Singapore; 2015. V81. 17. DOI: 10. 7763/IPCBEE

49. Arnao MB. Some Methodological Problems in the Determination of antioxidant activity using chromogen radicals: A Practical Case. Trends Food Sci Tech. 2000;11:419-21.

50. Thaipong K, Boonprakob U, Crosby K, Cisneros-Zevallos L, Byrne D. Comparison of ABTS, DPPH, FRAP, and ORAC assays for estimating antioxidant activity from guava fruit extracts. J Food Compos Anal. 2006;19:669-75.

51. Viol DI. Screening of traditional medicinal plants from Zimbabwe for phytochemistry, antioxidant, antimicrobial, antiviral and toxicological activities. Harare: Master Thesis submitted to School of Pharmacy College of Health Sciences University of Zimbabwe; 2009.

52. Sylvie DD, Anatole PC, Cabral BP, Veronique BP. Comparison of in vitro antioxidant properties of extracts from three plants used for medical purpose in Cameroon: Acalypha racemosa, Garcinia lucida and Hymenocardia lyrata. Asian Pac J Trop Biomed. 2014;4:625-S32.

53. Agbor GA, Kuate A, Oben JE. Medicinal plants can be good source of antioxidant: Case study in Cameroon. Pak J Biol Sci. 2007;10:537-44.

54. Kapche GDWF, Fozing CD, Donfack JH, Fotso FW, Amadou D, Tchana AN, et al. Moracin Q-U, new antioxidant prenylated arylbenzofuran derivatives from Morus mesosygia. Phytochemistry. 2009;70:216-21. 
55. Donfack JH, Amadou D, Ngueguim TF, Kapche DWFG, Tchana NA, Buonocore D, et al. In vitro hepatoprotective and antioxidant activities of crude extract and isolated compounds from Ficus gnaphalocarpa. Inflammopharmacol. 2011;19:35-43. doi:10.1007/s10787-010-0070-4.

56. Tufts H. R, Harris CS, Bukania Z. N, Johns T. Antioxidant and AntiInflammatory Activities of Kenyan Leafy Green Vegetables, Wild Fruits, and Medicinal Plants with Potential Relevance for Kwashiorkor. Evid Based Complementary Altern Med. 2015, http://dx.doi.org/10.1155/2015/807158.

57. Sintayehu B, Asres K, Raghavendra Y. Radical scavenging activities of the leaf extracts and a flavonoid glycoside Isolated from Cineraria abyssinica Sch. Bip Exa Rich J Appl Pharm Sci. 2012;02:44-9.

58. Asres K, Gibbons S, Bucar F. Radical Scavenging Compounds from Ethiopian Medicinal Plants. Ethiop Pharm J. 2006;24:23-30.

59. Enas AKM. Hepatoprotective effect of aqueous leaves extract of Psidium guajava and Zizyphusspina-christi against paracetamol induced hepatotoxicity in rats. J Appl Sci Res. 2012;8:2800-6.

60. Al-Asmari AK, Al-Elaiwi AM, Athar MT, Tariq M, Al Eid A, Al-Asmary SM. A Review of hepatoprotective plants used in Saudi traditional medicine. Evid Based Compl Altern Med. 2014;2014:1-22. http://dx.doi.org/10.1155/2014/ 890842.

61. Fuglie, L. J. The Moringa Tree: a local solution to malnutrition? Church World Service in Senegal. 2005. pp75

62. Biswas SK, Chowdhury A, Das J, Roy A, ZHosen SM. Pharmacological potentials of Moringa oleifera Lam.: A review. Inter J Pharm Sci Res. 2012;3:305-10.

63. Saalu LC, Ogunlade B, Ajayi GO, Oyewopo AO, Akunna GG, Ogunmodede OS The hep at o-protective potentials of Moringa oleifera leaf extract on alcoholinduced hepato-toxicity in wistar rat. Am J Biotechnol Mol Sci. 2012;2:6-14.

64. Kurma SR, Mishra SH. Antiinflammatory and Hepatoprotective activities of fruits of Moringa. Ind J Nat Prod. 1998;14:3-10.

65. Kumar NA, Pari L. Antioxidant action of Moringa oleifera Lam. (drumstick) against antitubercular drugs induced lipid peroxidationin rats. J Med Food. 2003;6:255-9.

66. Yakubu MT, Musa IF. Liver and kidney functional indices of pregnant rats following the administration of the crude alkaloids from Senna alata (linn. roxb) leaves. Irani J Toxicol. 2012;6:615-25.

67. Adedayo O, Anderson WA, Moo-Young M, Snieckus V, Patil PA, Kolawole DO. Kinetics of antibacterial activity and physicochemical damage caused by the extracts of Senna alata flowers. Pharma Biol. 2002:40:461-5.

68. Patrick-Iwuanyanwu KC, Iwuanyanwu P, Matthew O, Makhmoor T. Hepatoprotective effect of crude methanolic extract and fractions of Ring worm plant Senna alata (L. Roxb) leaves from Nigeria against carbon tetrachloride -induced hepatic damage in rats. Europ J Exp Biol. 2011;1:128-38.

69. Hennebelle T, Weniger B, Joseph H, Sahpaz S, Bailleul F. Senna alata. Fitoterapia. 2009;80:385-93.

70. Traore M, Guiguemde A, Yago I, Nikiema JB, Tinto H, Dakuyo ZP, et al. Investigation of antiplasmodial compounds from two plants, Cochlospermum tinctorium A, Rich and Gardenia sokotensis. Afr J Tradit Comp Alt Med. 2006;:34-41.

71. Mann A, Gbate M, Umar AN. Phytomedicine. In: Evans JEA, editor. Medicinal and Economic plants of Nupe Land. Nigeria: Bida; 2003. p. 64.

72. Akinloye OA, Ayankojo AG, Olaniyi MO. Hepatoprotective Activity of Cochlospermum tinctorium against carbon tetrachloride induced hepatotoxicity in rats. Rom J Biochem. 2012;49:3-12.

73. Odugbemi T. Medicnal plants as antimicrobials. In: Outlines and pictures of Medicinal plants from Nigeria. Lagos: University of Logos press; 2006. p. 53-64.

74. Gill LS. Ethnomedical Uses of Plants in Nigeria. Benin City: University of Benin Press; 1989. p. 134

75. Kayode J, Ige OE, Adejogo TA, Igbakin AA. Conservation and biodiversity erosion in Ondo State, Nigeria (3): Survey of plant barks used in native pharmaceutical extraction in Akoko region. Ethnobotanical leaflet. 2011;13:655-67.

76. Ofeimun JO, Eze Gl, Okirika OM, Uanseoje SO. Evaluation of the Hepatoprotective effect of the methanol extract of the root of Uvaria afzelii (Annonaceae). J Appl Pharma Sci. 2013;3:125-9.

77. Hufford CD, Oguntimein B, Martin M, Clardy J. Syncarpurea; a novel metabolite from U. afzelii. Tetrahedron Lett. 1984;25(4):371-4.

78. Okpekon T, Millot M, Champy P, Gleye C, Yolou S, Bories C, et al. A Novel I-indanone isolated from Uvaria afzelii roots. Nat Prod Res. 2009;23(10):909-15.

79. Mehta RS, Shankar MB, Geetha M, Saliyu AK. Hepatoprotective activity of rianthema portulacastrum. Indian Drugs. 1999;36:241-4.
80. Olorunnisola OS, Bradley G, Afolayan AJ. Ethnobotanical inform at ion on plants used for the management of cardiovascular diseases in Nkonkobe municipality of South Africa. J Med Plants Res. 2011;5:4256-60.

81. Moody JO, Robert VA, Connolly JD, Houghton PJ. Antiinflammatory activities of the methanol extracts and an isolated furanoditerpene constituent of Sphenocentrum jollyanum Pierre (Menispermaceae). J Ethnopharm. 2006;104:87-91.

82. Moundipa PF, Njayou FN, Yantitoum S, Sonke B, Tchouanguep FM. Medical plants used in the Bamoun region of the western province of Cameroon against jaundice and other liver disorders. Cam J Biol Biochem Sci. 2002;12:39-46.

83. Njayou FN, Ngoungoure FP, Tchana A, Moundipa PF. Protective Effect of Khaya grandifoliola C. DC. stem bark extract on carbon tetrachloride- induced hepatotoxicity in rats. Inter J Indige Med Plants. 2013;29:11-6

84. Njayou FN, Aboudi ECE, Tandjang MK, Tchana AK, Ngadjui BT, Moundipa PF. Hepatoprotective and antioxidant activities of stem bark extract of Khaya grandifoliola (Welw) CDC and Entada africana Guill. et Perr. J Nat Prod. 2013; 6:73-80.

85. Green EC. The WHO forum on traditional medicine in health systems, Harare, Zimbabwe, February 14-18, 2000. J Altern Complement Med. 2000;6: $379-82$.

86. Dadzeasah PEA. Safety Evaluation and Hepatoprotective Activity of the Aqueous Stem Bark Extract of Spathodea Campanul at a. Kumasi: A Thesis Submitted Kwame Nkrumah University of Science and Technology; 2012.

87. Gormann R, Schreiber L, Kolodziej H. Cuticular wax profiles of leaves of some traditionally used African Bignoniaceae. Z Naturforsch C. 2004;59:631-5.

88. Mbosso EJ, Ngouela S, Nguedia JC, Penlap V, Rohmer M, Tsamo E. Spathoside, a cerebroside and other antibacterial constituents of the stem bark of Spathodea campanulata. Nat Prod Res. 2008;22:296-304.

89. Amole O, Izegbu C, Onakoya A, Dada O. Toxicity studies of the aqueous extract of Vernonia amygdalina. Biomed Res. 2006;17:39-40.

90. Orji OU, Ibiam UA, Aja PM, Uraku AJ, Inya-Agha OR, Ugwu Okechukwu PC. Hepatoprotective activity of ethanol extract of Vernonia ambigua against carbon tetrachloride induced hepatotoxicity in albino rats. IOSR J Dental Med Sci. 2015;14:22-9.

91. Mandlekar S, Kong AN. Mechanisms of famoxiten Apoptoses. Apoptosis. 2001;6:469-77.

92. Ekpo A, Eseyin A, Ikpeme O, Edoho J. Studies on some biochemical effects of Vernonia amygdalina in rats. J Biochem. 2007;2:193-7.

93. Leonard S, Karen L, Bruce B, Thomas K, Jay H. Complementary and Alternative medicine in chronic liver disease. Hepatology. 2002;34:595-603.

94. Aluko BT, Oloyede Ol, Afolayan AJ. Hepatoprotective activity of Ocimum americanum $L$ Leaves against paracetamol - induced liver damage in rats. Amer J Life Sci. 2013;1:37-42.

95. Oboh G. Antioxidative potential of Ocimum gratissimum and Ocimum canum leaf polyphenols and protective effects on some pro-oxidants induced lipid peroxidationin rat brain: An in vitro study. American J Food Technol. 2008:3:325-34.

96. Olorunnisola OS, Akintola AO, Afolayan AJ. Hepatoprotective and antioxidant effect of Sphenocentrum jollyanum (Menispermaceae) stem bark extract against CCl4- induced oxidative stress in rats. Afri J Pharm Pharmacol. 2011;5:1241-6.

97. Olorunnisola OS, Bradley G, Afolayan AJ. Protective Effect of Tulbaghia violacea Harv. on Aortic P at hology, Tissue Antioxidant Enzymes and Liver Damage in Diet-Induced at herosclerotic Rats. Int J Mol Sci. 2012;13:12747-60.

98. Olorunnisola OS, Bradley G, Afolayan AF. Antioxidant properties and cytotoxicity Evaluation of methanolic extract of dried and fresh rhizomes of Tulbaghia violacea. Afr J Pharm Pharmacol. 2011;5:2490-7.

99. Donfack JH, Simob CFF, Ngamenic B, Tchanaa AN, Kerrd PG, Finzie PV, et al. Antihepatotoxic and antioxidant activities of methanol extract and isolated compounds from Ficus chlamydocarpa. Nat prod Comm. 2010;5:1607-12.

100. Gbadegesin MA, Adegoke AM, Ewere EG, Odunola OA. Hepatoprotective and anticlastogenic effects of ethanol extract of Irvingia gabonensis (IG) leaves in sodium arsenite-induced toxicity in male Wistar rats. Niger J Physiol Sci. 2014;2:029-36.

101. Souza SMC, Aquino LCM, Bandeira MAM, Nobre MEP, Viana GSB. Antiinflammatory and antiulcer properties of tannins from Myracrodruon urundeuva Allemão (Anacardiaceae) in Rodents. Phytother Res. 2007;21:220-5.

102. Abdallah HM, Ezzat SM, El Dine RS, Abdel-Sattar E, Abdel-Naim AB. Protective effect of Echinops galalensis against $\mathrm{CCl}_{4}$ - induced injury on the human hepatoma cell line (Huh7). Phytochem Lett. 2013;6:73-8. 
103. Muthumani P, Meera R, Sundaraganapathy DP, Mohamed Sheik AS, Cholarja K. Biological Evaluation of dried fruits of Lawsonia inermis. J Pharm Biomed Sci. 2010;1:1-5.

104. Donkor SC, Quainoo AK, Gustav M. Propagation of Henna (Lawsonia inermis) cuttings using nathelene acetic acid, indole-3- butyric acid and wood ash. JPBAS. 2013;1:115-23.

105. Abdulmoneim SM. Evaluation of Lawsonia inermis Linn. (Sudanese Henna) leaf extracts as an antimicrobial agent. Res J Biol Sci. 2007;2:419-23.

106. Mohamed MA, Taj Eldin IM, Mohammed AH, Hassan HM. Effects of Lawsonia inermis L. (Henna) leaves' methanolic extract on carbon tetrachloride-induced hepatotoxicity in rats. J Intercult Ethnopharmacol. 2016;5:22-6.

107. Sanni S, Thilza IB, Ahmed MT, Sanni FS, Talle M, Okwor GO. The effect of aqueous leaves extract of henna (Lawsonia inermis) in carbon tetrachloride induced hep at o-toxicity in swiss albino mice. Academia arena. 2010;2:87-9.

108. Uma D, Aida W. Optimiz at ion of extraction parameters of total phenolic compounds from Henna (Lawsonia inermis) leaves. Sains Malays. 2010;39:119-28.

109. Kuete V, Ngameni B, Fotso-Simo CC, Kengap TR, Tchaleu NB, Meyer JJM, et al. Antimicrobial activity of the crude extracts and compounds from Ficus chlamydocarpa and Ficus cordata (Moraceae). J Ethnopharmacol. 2008;120:17-24.

110. Bamps P. Guttiferae. (Clusiaceae). In: Boutique R, editor. Flore du Congo belge et du Ruanda-Burundi, Spermaphytes, Jardin Botanique National de Belgique, Brussels, Belgium. 1970. p. p 40.

111. Vouffo EY, Donfack FM, Temdie RJ, Ngueguim FT, Donfack JH, Dzeufiet DS, et al. Hepatho-nephroprotective and antioxidant effect of stem bark of Allanblackia gabonensis aqueous extract against acetaminophen-induced liver and kidney disorders in rats. Journal of Experimental and Integrative Medicine 2012. 2012;2(4):337-44.

112. Azebaze AG, Ouahouo BM, Vardamides JC, Valentin A, Kuete V, Acebey L, et al. Antimicrobial and antileishmanial xanthones from the stem bark of Allanblackia gabonensis (Guttiferae). Nat Product Res. 2008;22:333-41.

113. Ymele VE, Dongmo AB, Dimo T. Analgesic and anti-inflammatory effect of the aqueous extract of the stem bark of Allanblackia gabonensis (guttiferae). Inflammopharmacology. 2011. doi:10.1007/s10787-011-0096-2.

114. Ijeh II, Ukweni Al. Acute effect of administrationof ethanol extracts of Ficus exasperate vahl on kidney function in albino wistar rats. J Med Plant Res. 2007;1:027-9.

115. Odutuga AA, Dairo JO, Ukpanukpong RU, Eze FN. Hepatoprotective activity of ethanol extracts of Ficus exasperat a leaves on acetaminophen-induced hep at otoxic rats. Merit Res J Biochem Bioinform. 2014;2:028-33.

116. Njayou NI, Moundipa PF, Donfack JH, Chuisseu PD, Tchana AN, Ngadjui BT, et al. Hepato-protective, antioxidant activities and acute toxicity of a stem bark extract of Erythrina senegalensis DC. Int J Biol Chem Sci. 2010;3:738-47.

117. Njayou FN, Moundipa PF, Tchana AN, Ngadjui BT, Tchouanguep FM. Inhibition of microsomal lipid peroxidationand protein oxidation by extracts from plants used in Bamun folk medicine (Cameroon) Against Hep at itis. Afr J Trad Compl Altern Med. 2008;5:278-89.

118. Virtanen P, Lassila V, Soderstrom KO. Protoberberine alkaloids from Enantia chlorantha therapy of allyl-alcohol and D-galactosamine traumatized rats. Pathobiology. 1993;61(1):51-6.

119. Sanogo R, Germano MP, D’Angelo V, Gugliemo M, De Pascuale R. Antihep at otoxic properties of Entada africana (Mimosaceae). Phytother Res. 1998;12 157-9.

120. Ruby AJ, Kuttan G, Dinesh BK, Rajasekharan KN, Kuttan R. Anti-tumor and antioxidant activity of natural curcuminoids. Cancer Lett. 1995;94:79-83.

121. Martinez GM, Giuliani A, Leon-F OS, Davison GP, Nunez-Selles AJ. Effect of Mangifera indica L. extract (QF808) on protein and hepatic microsome peroxidation. Phytother Res. 2001;15:581-5.

122. Sanchez GM, Re L, Giuliani A, Nunez-Selles AJ, Davison GP, Leon FOS. Protective effects of Mangifera indica L. extract, Mangiferin, and selected antioxidants against TPA- induced biomolecule oxidation and peritoneal macrophage activ at ion in mice. Pharmacol Res. 2000;42:5665-73.

123. Middleton MJR, Chithan K, Theoharis CT. The effects of plant flavonoids on mammalian cells: Implications for inflammation, heart disease and cancer. Pharmacol Rev. 2000;52:673-751.

124. Noguchi N, Komuro E, Niki E, Willson RL. Action of curcumin as an antioxidant against lipid peroxidation. Yukagaku. 1994;43:1045-51.

125. Wandji J, Fomum TZ, Tillequin F, Seguin E, Koch M. Two isoflavones from Erythrina senegalensis. Phytochemistry. 1994;35:245-8.

126. Mulata HN, Daniel S, Melaku U, Ergete W, Gnanasekaran N. Protective Effects of Calpurnia aurea Seed Extract on HAART Hepatotoxicity. Eur J Med Plants. 2015;9:1-12
127. Iroanya O, Okpuzor J, Adebesin O. Hepatoprotective and antioxidant properties of a triherbal formulation against carbon tetrachloride induced hepatotoxicity. IOSR J Pharm. 2012;2:130-6.

128. Atawodi SE. In vivo antioxidant, organ protective, ameliorative and cholesterol lowering potential of ethanolic and methanolic extracts of "AtaOfa" polyherbal tea (A-Polyherbal). Int J Res Pharm Sci. 2011;2:473-82.

129. Omalu ICJ, Egwim EC, Mgbemena CC, Eke SS, Ubanwa D, Busari MB, et al. Free Radical Scavenging Activity of the Nigerian Leech (Aliolimn at is michaelseni) Saliva Extract. Bri J Pharm Res. 2015:8:1-6.

130. Omalu ICJ, Egwim EC, Abdulraman K, Ibrahim S, Hassan C, Eke SS. Free Radical Scavenging Activity and Protein Concentration and Profile of the Blowfly Maggot (Lucilia robineau) Excretion/Saliva Extract. Bri J Pharm Res. 2016;9:1-6.

131. Shittu OK, Lawal B, Oluyomi Ol. Effects of Methanol Extract of Musca domestica Larvae on Antioxidants Enzymes in T. Brucei Infected Rats. Nig J Biochem Mol Biol. 2014;29(2):1-10.

132. Shittu OK, Lawal B, Haruna GM, Berinyuy EB, Yusuf AA, Ibrahim AM. HepatoCurative Effects of Methanol extract from Nigeria Bee Propolis in Carbon Tetrachloride $\left(\mathrm{CCL}_{4}\right)$ Intoxicated Rat. Euro J Biotechnol Biosci. 2015;3:12-6.

133. Muruke MH. Assessment of antioxidant properties of honeys from Tanzania. J Biol Agric Health. 2014;4:22-32.

134. Adeniyi KA, Olayemi IK, Shittu KO, Busari MB, Mohammed SS, Bashir L, et al. Comparative phytochemical and antinutritional constituents of Nigeria sweet and bitter honey varieties. World J Pharm Res. 2016;5: 255-67.

135. Nyanzi R, Shuping DSS, Jooste PJ, Eloff JN. Antibacterial and Antioxidant Activity of Extracts from Selected Probiotic Bacteria. J Food Res. 2015;4(5):122-32.

136. Olutayo O, Doyinsola I, Simon O, Abayomi O, Thomas S. Phytochemical and antioxidant properties of some Nigerian medicinal plants. Am J Sci Ind Res. 2011:4:328-32.

137. Okoh SO, Asekun OT, Familoni OB, Afolayan AJ. Composition and Antioxidant Activities of leaf and root volatile Oils of Morinda lucida. Nat prod Comm. 2011;6(10):1537-41.

138. Amoussa AO, Sanni A, Lagnika L. Antioxidant activity and total phenolic, flavonoid and flavonol contents of the bark extracts of Acacia ataxacantha. J Pharmacog Phytochem. 2015;4:172-8.

139. Sawadogo WR, Maciuk A, Banzouzi JT, Champy P, Figadere B, Guissou IP, et al. Mutagenic effect, antioxidant and anticancer activities of six medicinal plants from Burkina Faso. Nat Prod Res. 2011. doi:10.1080/14786419.2010. 534737.

140. Tauseef S, Ali MS, Ahmed A, Ali MI, Ahmed Z, Sherwani SK, et al. In vitro Antioxidant activity analysis of five medicinally important plants. J Pharmacog Phytochem. 2013;2:183-8.

141. Lagnika L, Anago E, Sanni A. Screening for antibacterial, antioxidant activity and toxicity of some medicinal plants used in Benin folkloric medicine. Journal of Medicinal Plants Research Vol. 2011;5(5):773-7.

142. Kabine O, Mamadou BS, Fatoumata B, Namagan K, Luopou HN, Mamadou BA. Anti-oxidative activity of fruit extracts of some medicinal plants used against chronic diseases (diabetes, hypertension) in Kankan, Guinea. J Plant Sci. 2015;3:1-5.

143. Oloyede GK, Onocha PA, Soyinka J, Oguntokun OW, Thonda E. Phytochemical screening, antimicrobial and antioxidant activities of four Nigerian medicinal plants. Annals Biol Res. 2010;1:114-20.

144. Lamien-Meda A, Lamien CE, Compaore MMY, Meda RNT, Kiendrebeogo M, et al. Polyphenol content and antioxidant activity of fourteen wild edible fruits from Burkina Faso. Molecules. 2008;13:581-94.

145. Kazeem Ml, Akanji MA, Hafizur RM, Choudhary MI. AntiglyCAT ion, antioxidant and toxicological potential of polyphenol extracts of alligator pepper, ginger and nutmeg from Nigeria. Asian Pac J Trop Biomed. 2012;2:727-32.

146. Aliyu AB, Musa AM, Ibrahim MA, Ibrahim H, Oyewale AO. Preliminary Phytochemical Screening and antioxidant activity of leave extract of Albizia Chevalieri Harms (Leguminoseae-Mimosoideae). Bayero J Pure Appl Sci. 2009:2:149-53.

147. Osadebe PO, Festus BC, Philip FU, Nneka RN, ljeoma EA, Nkemakonam CO. Phytochemical analysis, Hepatoprotective and antioxidant activity of Alchornea cordifolia Methanol leaf extract on carbon tetrachloride-induced hepatic damage in rats. Asian Pac J Trop Med. 2012;5:289-93.

148. Otunola GA, Afolayan AJ. Evaluation of the polyphenolic contents and some antioxidant properties of aqueous extracts of Garlic, Ginger, Cayenne Pepper and their mixture. J Appl Bota Food Qual. 2013;86:66-70. 
149. Chinaka ON, Julius OO, Motunrayo GA. In vitro antioxidant potentials of some herbal plants from Southern Nigeria. J Med Sci. 2013;13(1):56-61.

150. Adetutu A, Sinbad OO, Bukoye OE. Phytochemical composition, antioxidant properties and antibacterial activities of five West-African green leafy vegetables. Senra Acad Pub Brit Col. 2013;7:2357-62.

151. Atawodi SE, Onaolapo GS. Comparat ive in vitro antioxidant potential of different parts of Ipomoea asarifolia, Roemer and Schultes, Guiera senegalensis. J F Gmel and Anisopus mannii N E Brown Braz J Pharma Sci. 2010;46:246-50

152. Salau AK, Yakubu MT, Oladiji AT. In vitro and In vivo Antioxidant Activity of Aqueous Extracts of Anogeissus / eiocarpus (DC) Guill and Perr and Terminalia avicennioides Guill and Perr Root Barks. Cam J Biol Bioche Sci. 2015;23:9-16.

153. Karou SD, Tchacondo T, Ouattara L, Anani O, Savadogo A, Agbonon A, et al. Antimicrobial, antiplasmodial, haemolytic and antioxidant activities of crude extracts from three selected Togolese medicinal plants. Asian Pac J Trop Med. 2011:4:808-13.

154. Aliyu AB, Ibrahim MA, Musa AM, Ibrahim H, Abdulkadir IE, Oyewale AO. Evaluation of antioxidant activity of leave extract of Bauhinia rufescens Lam. (Caesalpiniaceae). J Med Plants Res. 2009;3:563-7.

155. Sawadogo WR, Meda A, Lamien CE, Kiendrebeogo M, Guissou IP, Nacoulma OD. Phenolic Content and Antioxidant Activity of Six Acanthaceae from Burkina Faso. J Biol Sci. 2006;6:249-52.

156. Aladesanmi AJ, Iwalewa EO, Adebayo AC, Akinkunmi EO, Taiwo BJ, Olorunmola FO, Lamikanra A. Antimicrobial and Antioxidant activities of some Nigerian Medicinal Plants. Afri J Trad CAM. 2007;4(2):173-84.

157. Anago E, Lagnika L, Gbenou J, Loko F, Moudachirou M, Sanni A. Antibacterial Activity and Phytochemical Study of Six Medicinal Plants used in Benin. Pak J Biol Sci. 2011. doi:10.3923/pjbs.2011.

158. Emeka EJl, Fang-Fang L, Rong- Rong C, Yan L, Conrad AO, Ing-Jun Z. Anticancer and Free radical scavenging activity of some Nigerian food plants in vitro. Int J Cancer Res. 2015;11:41-51.

159. Falodun A, Irabor EEl. Phytochemical, Proximate, Antioxidant And Free Radical Scavenging Evaluations Of Calliandria Surinamensis. Acta Poloniae Pharma Drug Res. 2008;65:571-5.

160. Egwim EC, Elem RC, Egwuche RU. Proximate composition, phytochemical screening and antioxidant activity of ten selected wild edible Nigerian mushrooms. Am J Food Nutr. 2011;1(2):89-94.

161. Aina DA, Jonathan SG, Olawuyi OJ, Ojelabi DO, Durowoju BM. Antioxidant, antimicrobial and phytochemical properties of alcoholic extracts of Cantharellus cibarius - a Nigerian mushroom. N Y Sci J. 2012;5:114-20.

162. Ayoola GA, Coker HAB, Adesegun SA, Adepoju-Bello AA, Obaweya K, Ezennia EC, et al. Phytochemical screening and antioxidant activities of some selected medicinal plants used for malaria therapy in Southwestern Nigeria. Trop J Pharm Res. 2008;7:1019-24.

163. Madubuike GK, Onoja SO, Ezeja MI. Antioxidant and Hepatoprotective Activity of Methanolic Extract of Cassia sieberiana Leaves in Carbon Tetrachloride-induced Hepatotoxicity in Rats. J Adv Med Pharmaceut Sci. 2015;2(1):1-9.

164. Lagnika L, Amoussa O, Oketokoun SA, Adjovi Y, Sanni A. In vitro antifungal and antioxidant activities of two Benin medicinal plants. J Med Plants Res. 2014;8:513-9.

165. Konan Y, Witabouna KM, Bassirou B, Kagoyire K. Antioxidant activity and total phenolic content of nine plants from Côte d'Ivoire (West Africa). J Appl Pharm Sci. 2014;4:036-41.

166. Karim T, Béourou S, Touré AO, Ouattara K, Meité S, Ako A, et al. Antioxidant activities and estimation of the phenols and flavonoids content in the extracts of medicinal plants used to treat malaria in Ivory Coast. Int J Curr Microbiol App Sci. 2015;4:862-74.

167. Oghenerobo VI, Falodun A. Antioxidant Activities of the Leaf Extract and Fractions of Cola lepidota K. Schum (sterculiaceae). Nig J Biotech. 2013;25:31-6.

168. Karou D, Mamoudou HD, Simpore J, Traore AS. Antioxidant and antibacterial activities of polyphenols from ethnomedicinal plants of Burkina Faso. Afr J Biotechnol. 2005:8:823-8.

169. Tsado, N.A., Lawal, B. Ossa, P.C., Jagaba A., Kontagora, G.N., Gboke, J.A, et al. Antioxidants and Antimicrobial Activities of Methanol Extract of Newbouldia laevis and Crateva adansonii. J. Pharm Allied Health Sci. 2016b. DOI: 10. 3923/jpahs.2016

170. Kiendrebeogo M, Coulibaly AY, Nebie RCH, Zeba B, Lamien CE, Meda AL, et al. Antiacetylcholinesterase and antioxidant activity of essential oils from six medicinal plants from Burkina Faso. Braz J Pharmacog. 2011;21:63-9.
171. Tibiri A, Sawadogo RW, Ouedraogo N, Banzouzi JT, Guissou IP, Nacoulma GO. Evaluation of antioxidant activity, total phenolic and flavonoid contents of Entada africana Guill. et Perr. (Mimosaceae) Organ Extracts. Res J Med Sci. 2010;4:81-7.

172. Aliyu AB, Ibrahim MA, Ibrahim H, Musa AM, Lawal AY, Oshanimi JA, et al. Free radical scavenging and total antioxidant capacity of Methanol extract of Ethulia conyzoides growing in Nigeria. Rom Biotechnol Letters. 2012;17:7458-65.

173. Ashafa AOT, Grierson DS, Afolayan AJ. In vitro Antioxidant Activity of Extracts from the Leaves of Felicia Muricata Thunb. An Underutilized Medicinal Plant in the Eastern Cape Province, South Africa. Afr J Tradit Compl Altern Med. 2010;7:296-302.

174. Ojo OA, Akintayo CO. Assessment of antioxidant activity of Ficus asperifolia Miq aqueous extract - In vitro studies. J Phytopharmacol. 2014;3:16-21.

175. Hamzah RU, Jigam AA, Makun HA, Egwim EC. Phytochemical Screening and In vitro Antioxidant Activity of Methanolic Extract Of Selected Nigerian Vegetables. Asian J Basis and Appl Sci. 2014;1:1-14.

176. Chinedu OJ, Ibrahim S, Chukwuemeka NH, Uwadiegwu AA. Effects of fractionated methanolic leaf extract of Gongronema latifoliumon $\mathrm{CCl}_{4}$ induced Wistar Albino Rats. J Pharmacol Clin Res. 2015;1:551-5.

177. Adetutu A, Owoade AO. Hepatoprotective and antioxidant effect of Hibiscus polyphenol rich extract (HPE) against carbon tetrachloride $\left(\mathrm{CCL}_{4}\right)$ induced damage in rats. B J Med Medical Res. 2013;3:1574-86.

178. Agyare C, Dwobeng AS, Agyepong N, Boakye YD, Mensah KB, Ayande PG, et al. Antimicrobial, antioxidant, and wound healing properties of Kigelia africana (Lam.) Beneth. and Strophanthus hispidus DC. Adv Pharmacol Sci. 2013. doi:10.1155/2013/692613.

179. Okereke SC, Elekwa I. Studies on the In vitro Antioxidant Activity of Laported Aestuans Leaf Extract. IOSR J Env Sci, Toxicol Food Technol. 2014;8:33-41.

180. Agbafor, K.N., Nwachukwu, N. (2011). Phytochemical analysis and antioxidant property of leaf extracts of Vitex doniana and Mucuna pruriens. Biochem. Res. Int. 2011, doi:10.1155/2011/459839

181. Badu M, Mensah JK, Boadi NO. Antioxidant Activity of methanol and ethanol/w ater extracts of Tetrapleura tetraptera and parkia biglobosa. Int J Pharm Bio Sci. 2012;3:312-21.

182. Seidu KT, Osundahunsi OF, Olaleye MT, Oluwalana IB. Chemical Composition, Phytochemical Constituents and Antioxidant Potentials of Lima Bean Seeds Coat. Ann Food Sci Tech. 2014;15:288-98.

183. Ouédraogo N, Tibiri A, Sawadogo RW, Lompo M, Hay AE, Koudou J, et al. Antioxidant anti-inflammatory and analgesic activities of aqueous extract From stem bark of Pterocarpus erinaceus Poir. (Fabaceae). J Med Plants Res. 2011;5:2047-53.

184. Yougbaré-Ziébrou MN, Ouédraogo N, Lompo M, Bationo H, Yaro B, Gnoula $\mathrm{C}$, et al. Anti-inflammatory, analgesic and antioxidant activities of an aqueous extract of Saba senegalensis Pichon stems with leaves (Apocynaceae). Phytothérapie. 2015. doi:10.1007/s10298-015-0992-5.

185. Tsado NA, Lawal B, Kontagora GN, Muhammad BM, Yahaya MA, Gboke JA, et al. Antioxidants and Antimicrobial- Activities of Methanol Leaf Extract of Senna occidentalis. J Adv Med Pharma Sci. 2016;8(2):1-7.

186. Adu OB, Folorunso OS, Adeola SA, Godfrey C. Antioxidant and Antimicrobial properties of volatile oil of Terminalia catappa and its inhibition on the extracellular protease of Pseudomonas aeruginosa. Res J Life Sci. 2013;1:1-8.

187. Adesanoye OA, Farombi EO. In vitro Antioxidant Properties of methanolic leaf extract of Vernonia amygdalina Del. Niger. J Physiol Sci. 2014;29:091-101.

188. Elnour MA, Elegamy AA, Koko WS, Khalid A, Fadul E. Antioxidant Activity and Cytotoxicity of some Sudanese Medicinal Plants. Inter J Adv Indust Eng. 2013;1:20-3

189. Hala AAM. Quality of medicinal plants traditionally used in Sudan as affected by ionizing radi at ion treatments. Khartoum: A Phd thesis submitted to Faculty of Agriculture University of Khartoum; 2009.

190. Bakr RO, Omer EA, Abdel-Razik KA, Abuelnaga ASM, Danial EN, Elgindy AG. Antioxidant and anti-listerial activities of selected Egyptian medicinal plants. Afr J Microbiol Res. 2013;7:459 0-95.

191. Kabbashi AS, Koko WS, Mohammed EE, Musa AN, Osman EE, Dahab MM. In vitro amoebicidal, antimicrobial and antioxidant activities of the plants Adansonia digitata and Cucurbit maxima. Adv Med Plant Res. 2014;2:50-7.

192. Ali SK, Hamed AR, Soltan MM, Hegazy UM, Elgorashi EE, El-Garf IA, et al. Invitro evaluation of selected Egyptian traditional herbal medicines for treatment of Alzheimer disease. BMC Complement Altern Med. 2013:13:121.

193. Soumia K, Tahar D, Lynda L, Saida B, Chabane C, Hafidha M. Antioxidant and antimicrobial activities of selected medicinal plants from Algeria. J Coast Life Med. 2014;2:478-83. 
194. Elmestiri FM. Evaluation of selected Libyan medicinal plant extracts for their antioxidant and anticholinesterase activities. In: Thesis submitted for the degree of Doctor of Philosophy. Newcastle upon Tyne: School of Biology and Psychology University of Newcastle upon Tyne; 2011. NE 1 7RU.

195. Ezejiofor AN, Udowelle NA, Orisakwe OE. Nephroprotective and antioxidant effect of aqueous leaf extract of Costus Afer Ker gawl on cyclosporin-a (Csa) induced nephrotoxicity. Clinical Phytoscience. 2016;2:11.

196. Hamid SY, Elegami AA, Koko WS, Abdelwahab SI, Bostman A. Anticancer and Antioxidant Activities of Three Sudanese Medicinal Plants Belong To The Family Combretaceae. Asian Acad Res J Multidiscipl. 2014;1:281-9.

197. Elhaj AM, Osman EE, Koko WS, Garbi MI, Kabbashi AS. Antioxidant activity, phytochemical screening and cytotoxicity of ethanolic leaves extract of Antigonon leptopus. Res J Agric Environm Manage. 2015;4:202-7.

198. Sami A, Abdulmottaleb Z, Mohamed S, Rmeli N, Fatah GA. Antioxidant Activity of Eight Libyan Medicinal Plants Extracted Using the Microwave Technique.Book of abstract.The 3rd International symposium on medicinal plants, their cultivationand aspects of uses. Jordan: Beitzaman hotel and resort Petra; 2012.

199. Guendouze-Bouchefa N, Madani K, Chibane M, Boulekbache-Makhlouf L Hauchard D, Kiendrebeogo E, et al. Phenolic compounds, antioxidant and antibacterial activities of three Ericaceae from Algeria. Ind Crop Prod. 2015; 70(2015):459-66

200. Abushama MF, Hilmi Yl, AbdAlgadir HM, Fadul E, Khalid HE. Lethality and antioxidant activity of some Sudanese medicinal plants' fixed oils. Eur J Med Plants. 2014;5:563-70.

201. Rashed K, Guder A. Comparative Study of Antioxidant Activity from some Egyptian Plants and Phytochemical Composition. Res J Med Plant. 2015;4: 146-59.

202. Nassr-Allah AA, Aboul-Enein AM, Aboul-Enein KM, Lightfoot DA, Cocchetto A, El-Shemy HA. Anti-cancer and anti-oxidant activity of some Egyptian medicinal plants. J Med Plants Res. 2009;3:799-808.

203. Garbi MI, Kabbashi AS, Osman EE, Dahab MM, Koko WS, Ahmed IF. Antioxidant activity and phytochemical screening of the methanolic leaves extract of B. Rufescens (LAM). Inter J Biol Pharma, Res. 2015;6:930-4.

204. Mariem BJ, Ghaith H, Maurizio B, Elyes KM. Antioxidant Activities in Calycotome villosa L. (Fabacées) from National Park of Bou Kornine, Tunisia. Book of abstract.The 3rd International symposium on medicinal plants, their cultivationand aspects of uses. Jordan: Beitzaman hotel and resort Petra; 2012.

205. Kaabour F, Belambri SA, Bouriche $H$, Senator A. Antioxidant Activity of Aqueous Tea Extracts. Book of abstract.The 3rd International symposium on medicinal plants, their cultivation and aspects of uses. Jordan: Beitzaman hotel and resort Petra; 2012.

206. Dudonn SE, Vitrac X, Coutiere P, Woillez M, Merillon JM. Comparative study of antioxidant properties and total phenolic content of 30 plant extracts of industrial interest using DPPH, ABTS, FRAP, SOD, and ORAC Assays. J Agric Food Chem. 2009:57:1768-74.

207. Oumar YS, Nathalie GK, Souleymane M, Karamoko O, Alexis BG, David GJ, et al. In vitro antioxidant activity of extracts of the root Cochlospermum planchonii Hook. f. ex. Planch (Cochlospermaceae). J Pharmacog Phytochemist. 2014;3(4):164-70.

208. Osman ME, Yassen HH, Deng JD, Mustafa RO, Hussein SM. General Phytochemical Screening and Antioxidant Activity of Some Sudanese Medicinal Plants. J forest produ Ind. 2014;3:292-5.

209. Alhadi EA, Khalid HS, Alhassan MS, Ali AA, Babiker SG, Alabdeen EMZ, et al, Antioxidant and cytotoxicity activity of Cordia Africana in Sudan. Adv Med Plant Res. 2015;3:29-32.

210. Mohamed B, Amar D, Zohra M, Hadda G, Mohamed Y. Antioxidant activity of phenolic extracts from some local pumpkin seeds (Cucurbita pepo). Book of abstract.The 3rd International symposium on medicinal plants, their cultivationand aspects of uses. Jordan: Beitzaman hotel and resort Petra; 2012.

211. Alghazeer R, El-Saltani H, Saleh NA, Al-Najjar A, Mahboba B, Hebail NF, et al. Antioxidant and antimicrobial activities of Cynara scolymus L. Rhizomes. Modern Appl Sci. 2012;6:54-63.

212. Hanane B, Lilia B, Khodir M, Mohamed K. Eucalyptus globulus: Polyphenols Extraction and Antioxidant Effect. Book of abstract.The 3rd International symposium on medicinal plants, their cultivationand aspects of uses. Jordan: Beitzaman hotel and resort Petra; 2012.

213. Alghazeer R, El-Saltani H, Saleh N, Al-Najjar A, Hebail F. Antioxidant and antimicrobial properties of five medicinal Libyan plants extracts. Nat Sci. 2012;4:324-35. http://dx.doi.org/10.4236/ns.2012.45045.
214. Yasmina L, Sebaihi S, Remila SM, Chaher N, Debache N, Ayouni K, et al. Antioxidant Activity of Extracts of Fraxinus angustifolia. Book of abstract.The 3rd International symposium on medicinal plants, their cultivation and aspects of uses. Jordan: Beitzaman hotel and resort Petra; 2012.

215. Derrafa I, Benchikh F, Amira S, Khennouf S, Dahamna S. Antioxidant and antiulcerogenic effects of Globularia alypum L. Extracts. Book of abstract. The 3rd International symposium on medicinal plants, their cultivation and aspects of uses. Jordan: Beitzaman hotel and resort Petra; 2012.

216. Atef C, Anouar F, El-Hadda A, Azzedine C. Phytochemicals study, antioxidant and antimicrobial activities of Helianthemum lippii (L.) pers. in different stages of growth (somatic, flowering and fruiting). World J Pharm Pharm Sci. 2015;4:338-49.

217. Kraouche NN, Kharfallah Y, Bejou F. Antioxidant Activity of Essential Oils Isolated from Selected Algerian Medicinal Plants. Book of abstract.The 3rd International symposium on medicinal plants, their cultivation and aspects of uses. Jordan: Beitzaman hotel and resort Petra; 2012.

218. El Diwani G, El Rafie SH, Hawash S. Antioxidant activity of extracts obtained from residues of nodes leaves stem and root of Egyptian Jatropha curcas. African J Pharm Pharmacol. 2009;3:521-30.

219. Fatiha B, Didier H, Naima G, Khodir M, Martin K, Léocadie K, et al. Phenolic composition, in vitro antioxidant effects and tyrosinase inhibitory activity of three Algerian Mentha species: M. spicata (L.), M. pulegium (L.) and M. rotundifolia (L.) Huds (Lamiaceae). Ind. Crops Prod. 2015:74:722-30.

220. Seddik K, Saliha D, Dalila B, Saliha D, Noureddine C, Abderahmane B, et al. Polyphenols and Antioxidant Properties of Extracts from Menthapulegium L. and Matricaria camomilla L. Book of abstract.The 3rd International symposium on medicinal plants, their cultivationand aspects of uses. Jordan: Beitzaman hotel and resort Petra; 2012.

221. Belmimoun A, Meddah B, Meddah AT, Sonnet P. Antibacterial and antioxidant activities of the essential oils and phenolic extracts of Myrtus communis and Zygophylum album from Algeria. J Fundam Appl Sci. 2016; $8(2): 510-24$

222. Kabbashi AS, Eltayeb OM, Abuzeid NM, Garbi MI, Koko WS. Antioxidant activity and Cytotoxicity of Ethanolic Seeds Extract of Nigella sativa (Linn) in Sudan. Merit Res J Agric Sci Soil Sci. 2015;3:1-10.

223. Djarmouni S, Abderrahmane B, Naouel B, Hayet T, Sabah B, Farida B, Ameni D, Fatima Z, Lekhmici A. Studies of Anti Bacterial and Antioxidant Potential of Methanol Extract/Fractions of Peganum harmala. Book of abstract.The 3rd International symposium on medicinal plants, their cultivationand aspects of uses. Jordan: Beitzaman hotel and resort Petra; 2012

224. Saliha D, Abir R, Mounira M, Dalila B, Daoud H, Assia B, Soulef B, Karima Y, Khadidja D. Antioxidant Activity of the Aqueous and Methanolic Extracts from Peganum harmala Seeds. Book of abstract.The 3rd International symposium on medicinal plants, their cultivationand aspects of uses. Jordan: Beitzaman hotel and resort Petra; 2012.

225. Sifi I, Dzoyem JP, Ouinten M, Yousfi M, McGaw LJ, Eloff JN. Antimycobacterial, antioxidant and cytotoxic activities of essential oil of gall of pistacia atlantica desf. from Algeria. Afr J Tradit Complement Altern Med. 2015;12(3):150-5.

226. Saliha D, Seddik K, Djamila A, Abdrrahmane B, Lekhmici A, Noureddine C. Antioxidant Proprieties of Pistacia lentiscus I. Leaves Extracts. Book of abstract. The 3rd International symposium on medicinal plants, their cultivation and aspects of uses. Jordan: Beitzaman hotel and resort Petra; 2012.

227. Nadia Z, Rachid M. Antioxidant Activity of Flavonoids Isolated from Rosmarinus officinalis L. J Plant Sci Res. 2016:3(1):142.

228. Ameni D, Baghiani A, Djidel S, Boumerfeg S, Khennouf S, Arrar L. The Antioxidant and Lipid Peroxidation Activities of Rubus idaeus L. Extracts. Book of abstract.The 3rd International symposium on medicinal plants, their cultivation and aspects of uses. Jordan: Beitzaman hotel and resort Petra; 2012.

229. Hamama B, Soumia B, Abderrahmane S. Total Polyphenolic Contents and Antioxidant Activity of Santolina chamaecyparissus. Book of abstract.The 3rd International symposium on medicinal plants, their cultivation and aspects of uses. Jordan: Beitzaman hotel and resort Petra; 2012.

230. Giweli A, Džamić AM, Soković M, Mihailo S, Ristić Petar DM. Antimicrobial and antioxidant activities of essential oils of Satureja thymbra Growing Wild in Libya. Molecules. 2012;17:4836-50. doi:10.3390/molecules17054836.

231. Sabah A, Fatiha B. Antioxidant Activity of Thapsia garganica Leaves and Roots Extracts. Book of abstract.The 3rd International symposium on medicinal plants, their cultivation and aspects of uses. Jordan: Beitzaman hotel and resort Petra; 2012 
232. El-Shora HM, El-Amier YA, Awad MH. Antioxidant Activity of Leaf Extracts from Zygophyllum coccineum L. Collected from Desert and Coastal Habitats of Egypt. Int J Curr Microbiol App Sci. 2016;5(4):635-41.

233. Adedapo AA, Jimoh FO, Afolayan AJ, Masika PJ. Antioxidant activities and phenolic contents of the methanol extracts of the stems of Acokanthera oppositifolia and Adenia gummifera. BMC Complement Altern Med. 2008:8:54.

234. Adewusi EA, Steenkamp V. In vitro screening for acetylcholinesterase inhibition and antioxidant activity of medicinal plants from southern Africa. Asian Pac J Trop Med. 2011;11:60203-4.

235. Wintola OA, Afolayan AJ. Phytochemical constituents and antioxidant activities of the whole leaf extract of Aloe ferox Mill. Pharmacog Mag. 2011;7:325-33.

236. Ahmed AS, Elgorashi EE, Moodley N, McGaw L, Naidoo V, Eloff JN. The antimicrobial, antioxidative, anti-inflammatory activity and cytotoxicity of different fractions of four South African Bauhinia species used traditionally to treat diarrhea. J Ethnopharmacol. 2012;143:826-39.

237. Adamu M, Naidoo V, Eloff JN. The antibacterial activity, antioxidant activity and selectivity index of leaf extracts of thirteen South African tree species used in ethnoveterinary medicine to treat helminth infections. BMC Vet Res. 2014;10:52.

238. Yusuf L, Oladunmoye MK, Ogundare AO, Akinyosoye FA, Daudu OAY, Hassan GA. Antimicrobial and antioxidant properties of mistletoe (viscum album) growing on cola (cola nitida) tree in Akure North, Nigeria. J MicrobiolRes Rev. 2013;1(3):35-41.

239. Olaokun OO, McGaw LJ, Eloff Jacobus JN, Naidoo V. Evaluation of the inhibition of carbohydrate hydrolysing enzymes, antioxidant activity and polyphenolic content of extracts of ten African Ficus species (Moraceae) used traditionally to treat diabetes. BMC Complement Altern Med. 2013;13:94.

240. Adebayo SA, Dzoyem JP, Shai LJ, Eloff JN. The anti-inflammatory and antioxidant activity of 25 plant species used traditionally to treat pain in southern African. BMC Complement Altern Med. 2015;15:159. doi:10.1186/ s12906-015-0669-5.

241. Katerere DR, Eloff JN. Antibacterial and Antioxidant Activity of Sutherlandia frutescens (Fabaceae), A Reputed Anti-HIV/AIDS Phytomedicine. Phytother Res. 2005;19:779-81.

242. Mokgotho, M.P., Gololo, S.C., Masoko, P., Mdee, L.K., Mbazima, V., Shai, L.J. et al., (2013). Isolation and Chemical Structural Characterisation of a Compound with Antioxidant Activity from the Roots of Senna italic. Evidence-Based Complementary and Alternative Medicine, 2013, http://dx. doi.org/10.1155/2013/519174.

243. Komape NPM, Aderogba M, Bagla VP, Masoko PM, Eloff JN. Anti-bacterial and anti-oxidant activities of leaf extracts of Combretum vendee (combretecacea) and the isolation of an anti-bacterial compound. Afr J Tradit Complement Altern Med. 2014;11(5):73-7.

244. Naidoo V, Chikoto H, Bekker LC, Eloff JN. Antioxidant compounds in Rhoicissus tridentata extracts may explain their antibabesial activity. S Afr J Sci. 2006;102:198-200.

245. Dzoyem JP, McGaw LJ, Eloff JN. In vitro antibacterial, antioxidant and cytotoxic activity of acetone leaf extracts of nine under-investigated Fabaceae tree species leads to potentially useful extracts in animal health and productivity. BMC Compl Alter Med. 2014;14:147.

246. Ahmed AS, McGaw LJ, Eloff JN. Evaluation of pharmacological activities, cytotoxicity and phenolic composition of four Maytenus species used in southern African traditional medicine to treat intestinal infections and diarrhoeal diseases. BMC Complem Alter Med. 2013;13:100.

247. Awouafack MD, Tane P, Eloff JN. Two new antioxidant flavones from the twigs of Eriosema robustum (Fabaceae). Phytochem Lett. 2013; 6(2013):62-6

248. Shai LJ, Masoko P, Mokgotho MP, Magano SR, Mogale AM, Boaduo N Yeast alpha glucosidase inhibitory and antioxidant activities of six medicinal plants collected in Phalaborwa, South Africa. South Afri J Bot. 2010;76:6.

249. Aderogba MA, Kgatle DT, McGaw LJ, Eloff JN. Isolation of antioxidant constituents from Combretum apiculatum subsp. Apiculatum. S Afr J Bot. 2012. doi:10.1016/j.sajb.2011.10.004.

250. Jimoh FO, Adedapo AA, Aliero AA, Koduru S, Afolayan AJ. Evaluation of the Polyphenolic, Nutritive and Biological Activities of the Acetone, Methanol and W at er Extracts of Amaranthus asper. Open Complem Med J. 2010;2:7-14.

251. Magama S, Lieta MI, Asita AO. Antioxidant and free radical scavenging properties of four plant species used in traditional medicine in Lesotho. Int J Med Plants Res. 2013;2:170-8.
252. Adedapo A, Jimoh F, Afolayan A. Comparison of the nutritive value and biological activities of the acetone, methanol and water extracts of the leaves of Bidens pilosa and Chenopodium album. Acta Pol Pharma Drug Res. 2011;68:83-92.

253. Omoruyi BE, Bradley G, Afolayan AJ. Antioxidant and phytochemical properties of Carpobrotus edulis (L.) bolus leaf used for the management of common infections in HIV/AIDS patients in Eastern Cape Province. BMC Complement Altern Med. 2012;12:215.

254. Adedapo AA, Jimoh FO, Afolayan AJ, Masika PJ. Antioxidant Properties of the Methanol Extracts of the Leaves and Stems of Celtis Africana. Rec Nat Prod. 2009;3:23-31.

255. Wintola OA, Afolayan AJ. The antibacterial, phytochemicals and antioxidants Evaluation of the root extracts of Hydnora african at hunb. Used as antidysenteric in Eastern Cape Province, South Africa. BMC Complement Altern Med. 2015;15:307.

256. Adewusi EA, Afolayan AJ. Antibacterial, antifungal and antioxidant activity of the roots and leaves of Pelargonium reniforme Curtis (Geraniaceae). Afr J Biotechnol. 2009;8:6425-33.

257. Ntsoelinyane PH, Mashele SS, Manduna IT. The anticancer, antioxidant and phytochemical screening of Philenoptera violacea and Xanthocercis zambesiaca leaf, flower and twig extracts. Inter J Pharmacol Res. 2014;4:100.

258. Nemudzivhadi, V., Masoko, P. (2014). In vitro Assessment of Cytotoxicity, Antioxidant, and Anti-Inflammatory Activities of Ricinus communis (Euphorbiaceae) Leaf Extracts. Evid. Based Complement. Altern. Med. 2014, http://dx.doi.org/10.1155/2014/625961.

259. Jimoh FO, Adedapo AA, Aliero AA, Afolayan AJ. Polyphenolic Contents and Biological Activities of Rumex ecklonianus. Pharma Biol. 2008;46(5):333-40.

260. Oyedemi SO, Afolayan AJ. Antibacterial and antioxidant activities of hydroalcoholic stem bark extract of Schotia latifolia Jacq. Asian Pac J Trop Med. 2011;4:952-8.

261. Jimoh FO, Adedapo AA, Afolayan AJ. Comparison of the nutritive value, antioxidant and antibacterial activities of Sonchus asper and Sonchus oleraceus. Rec Nat Prod. 2011;5:29-42.

262. Oyedemi SO, Bradley G, Afolayan AJ. In -vitro and -vivo antioxidant activities of aqueous extract of Strychnos henningsii Gilg. Afri J Pharm Pharmacol. 2010;4:070-8.

263. Olorunnisola OS, Bradley G, Afolayan AJ. Chemical composition, antioxidant activity and toxicity Evaluation of essential oil of Tulbaghia violacea Harv. J Med Plants Res. 2012:6:2340-7.

264. Noumedem JAK, Tamokou JD, Teke GN, Momo RCD, Kuete V, Kuiate JR. Phytochemical analysis, antimicrobial and radical-scavenging properties of Acalypha manniana leaves. SpringerPlus. 2013;2:503.

265. Ndjateu FST, Tsafack RBN, Nganou BK, Awouafack MD, Wabo HK, Tene M, et al. Antimicrobial and antioxidant activities of extracts and ten compounds from three Cameroonian medicinal plants: Dissotis perkinsiae (Melastomaceae), Adenocarpus mannii (Fabaceae) and Barteria fistulosa (Passifloraceae). S Afri J Bot. 2014;91(2014):37-42.

266. Kuete V, Azebaze AGB, Mbaveng AT, Nguemfo EL, Tshikalange ET, Chalard P, Nkengfack AE. Antioxidant, antitumor and antimicrobial activities of the crude extract and compounds of the root bark of Allanblackia floribunda. Pharma Biol. 2011;49(1):57-65. doi:10.3109/ 13880209.2010 .494673$.

267. Ngbolua, K.N., Mubindukila, R.E.N., Mpiana, P.T., Ashande, M.C., Baholy, R., F at iany, P.R., et. al. (2014). In vitro Assessment of antibacterial and antioxidant activities of a Congolese medicinal plant species Anthocleista schweinfurthii Gilg (Gentianaceae). J. Mod. Drug Disc. Drug Deliv. Res. 13,. DOI: 10.15297/JMDDR.V113.03.

268. Kuete $V$, Mbaveng AT, Maurice T, Benga VP, Etoa F, Nkengfack AE, et al. Antitumor, antioxidant and antimicrobial activities of Bersama engleriana (Melianthaceae). J Ethnopharmacolo. 2008:115:494-501.

269. Tagne RS, Telefo BP, Nyemb JN, Yemele DM, Njina SN, Goka SMC, et al. Anticancer and antioxidant activities of Methanol extracts and fractions of some Cameroonian medicinal plants. Asian Pac J Trop Med. 2014;7:442-7.

270. Fouedjou, R.T., Nguelefack-Mbuyo, E.P., Ponou, B.K., Nguelefack, T. B., Barboni L.,Tapondjou, L.A. (2016). Antioxidant Activities and chemical constituents of extracts from Cordyline fruticosa (L.) A. Chev. (Agavaceae) and Eriobotrya japonica (Thunb) Lindl, (Rosaceae). DOI: 10. 5567/pharmacologia.2016.103.113

271. Soares MO, Rita C, Alves AC, Pedro C, Pires BDM, Beatriz PP, et al. Angolan Cymbopogon citratus used for therapeutic benefits: Nutritional composition and influence of solvents in phytochemicals content and antioxidant activity of leaf extracts. Food Chem Toxicol. 2013;60:413-8. 
272. Tamokou JD, Chouna JR, Fischer-Fodor E, Chereches G, Barbos O, Damian G, et al. Anticancer and Antimicrobial Activities of Some Antioxidant-Rich Cameroonian Medicinal Plants. Plos ONE. 2013;8:2.

273. Donfack JH, Nico FN, Ngameni B, Tchana A, Chuisseu PD, Finzi PV, et al. In vitro hepatoprotective and antioxidant activities of diprenylated isoflavonoids from Erythrina senegalensis (Fabaceae). Asian J Trad Med. 2008:5:172-8.

274. Atsamo AD, Néné-Bi SA, Kouakou KL, Fofie KC, Nyadjeu P, Watcho P, et al. Cardiovascular and antioxidant effects of the methanol extract from the stem bark of Erythrina Senegalensis DC (Fabaceae). J Phys Pharm Adv. 2013;3:110-20.

275. Matsinkou RS, Ngondi JL, Kuate D, Mbofung C, Oben JE. Antioxidant and anti-hyperglycemic potential of pulp extracts of Irvingia wombolu fruits. Biol Med. 2012;4:10-9.

276. Pieme CA, Ngoupayo J, Nkoulou CHK, Moukette BM, Nono BL, Moor VJA, et al. Syzyguim guineense Extracts Show Antioxidant Activities and Beneficial Activities on Oxidative Stress Induced by Ferric Chloride in the Liver Homogenate. Antioxidants. 2014;3:618-35.

277. Sishu R, Yonathan M, Seyoum A, Asres K. Radical Scavenging Activity of Volatile Oils Of Herbs Traditionaly Used To Spice Cooking Butter In Ethiopia. Ethiop pharm J. 2005:23:7-14

278. Tibuhwa DD. A Comparative Study of Antioxidant Activities between Fresh and Dry Mushrooms in the Genera Cantharellus and Afrocantharellus from Tanzania. Food Nut Sci. 2014;5:212-21. http://dx.doi.org/10.4236/fns.2014.5202.

279. Asamenew G, Bisrat D, Mazumder A, Asres K. In vitro Antimicrobial and Antioxidant Activities of Anthrone and Chromone from the Latex of Aloe harlana Reynolds. Phytother Res. 2011;25:1756-60.

280. Asamenew G, Tadesse S, Asres K, Mazumder A, Bucar F. Study on the Composition, Antimicrobial and Antioxidant Activities of the Leaf Essential Oil of Apium leptophylum (Pers.) Benth. Growing in Ethiopia. Ethiop Pharm J. 2008; 26:95-102.

281. Burits M, Asres K, Bucar F. The Antioxidant Activity of the Essential Oils of Artemisia afra, Artemisia abyssinica and Juniperus procera. Phytother Res. 2001;15:103-8

282. Amabye TG, Bezabh AM, Mekonen F. Phytochemical Constituents and Antioxidant Activity of Delonix elata L. in Flower Extract. J Anal Pharm Res. 2016;2(1):00006. doi:10.15406/japlr.2016.02.00006.

283. Onyancha JM, Cherongis CN, Nzivo JM, Muriithi Gl, Njuguna DG, Mwalukumbi JM. Phytochemical screening and Evaluation of antioxidant activity of methanolic extract of Kenyan Hydnora abyssinica A. Braun (Hydnoraceae). J Innov Pharm Biol Sci. 2015;2:1-6.

284. Vagionas K, Ngassapa O, Runyoro D, Graikou K, Gortzi O, Chinou I. Chemical analysis of edible aromatic plants growing in Tanzania. Food Chem. 2007;105:1711-7.

285. Asres F, Bucar F. Lippia adoensis var. adoensis: studies on the essential oil composition and antioxidant activity. Ethiop pharm j. 2002;20:31-5.

286. Getahun Z, Asres K, Mazumder A, Bucar F. Essential Oil Composition, Antibacterial and Antioxidant Activities of Mentha aquatica Growing in Ethiopia. Ethiop Pharm J. 2008:26:9-16.

287. Karau GM, Njagi EM, Machocho AK, Wangai LN, Nthinga MJ. Chemical Composition and in vitro Antioxidant Activities of Ocimum americanum. Adv Anal Chem. 2015;5:42-9.

288. Sishu R, Taddesse D, Bucar F, Asres K. Chemical composition and antioxidan activity of the essential oils of Ocimum americanum and Ocimum basillicum var. thyrsiflorum. Intern J Ess Oil Therape. 2010;4:64-8.

289. Tadesse S, Asres K, Veeresham C. Antioxidant Activities of Three Rubus Species Growing in Ethiopia. Ethiop Pharm J. 2007;25:103-10.

290. Asfaha H, Asres K, Mazumder A, Bucar F. Leaf Essential oils of Salvia nilotica and Salvia schimperi: Their Antimicrobial and Antioxidant Activities. Ethiop Pharm J. 2008;26:49-58.

291. Wolde T, Engidawork E, Asres K, Eregete W. Evaluation of Hepatoprotective Activities of $S$ at ureja punctata Benth Briq and Solanecio angulatus Vahl Jeffrey in ferric nitrillotriacetate induced hepatotoxicity in Rats. Ethiop Pharm J. 2010;28:63-74.

292. Gebrelibanos M, Asres K, Veeresham C. In vitro Radical Scavenging Activity of the Leaf and Bark Extracts of Senna sinqueana (Del). Lock. Ethiop Pharm J. 2007;25:77-84

293. Chakraborty A, Asres K, Stipstis S, Eibl U, Brantnez AH. Biological Properties of Stephania abyssinica Roots. Pharmaceutical And Pharmacological Letters. 2000;10:19-21.

294. Tabopda TK, Ngoupayo J, Liu J, Mitaine-Offer AC, Tanoli SA, Khan SN, et al. Bioactive aristolactams from Piper umbellatum. Phytochemistry. 2008;69: $1726-31$.
295. Donfack JH, Njayou FN, Rodrigue TK, Chuisseu DDP, Tchana NA, Vita FP, et al. Study of a hepatoprotective and antioxidant fraction from Erythrina Senegalensis stem bark extract: in vitro and in vivo. Pharmacologyonline. 2008;1:120-30.

296. Donfack JH, Wabo Fotso G, Ngameni CF, Tsofack ND, Ambassa B, Moundipa PF, et al. In vitro Hepatoprotective and antioxidant activities of the crude extract and Isolated compounds from Irvingia gabonensis. Asian J Trad Med. 2010;5:79-88

297. Cesari M, Hoerle C, Simoes-Pires P, Grisoli EF, Queiroz C, Dacarro L, Marcourt PF, et al. Anti-inflammatory, antimicrobial and antioxidant activities of Diospyros bipindensis ( $\mathrm{G}$ urke) extracts and its main constituents. J Ethnopharmacol. 2013;146:264-70.

298. Mohamed LE, El Nur EE, Choudhary MI, Khan SN. Bioactive Natural Products from Two Sudanese Medicinal Plants Diospyros mespiliformis and Croton zambesicus. Rec Nat Prod. 2009;3(4):198-203.

299. Akimanya A, Midiwo JO, Matasyoh J, Okanga F, Masila VM, Walker L, et al. Two polymethoxylated flavonoids with antioxidant activities and a rearranged clerodane diterpenoid from the leaf exudates of Microglossa pyrifolia. Phytochem Lett. 2015;11:183-7.

300. Kouam SF, Ngadjui BT, Krohn K, Wafo P, Ajaz A, Choudhary MI. Prenylated anthronoid antioxidants from the stem bark of Harungana madagascariensis. Phytochemistry. 2005;66:1174-9.

301. Waffo AFK, Mulholland D, Wansi JD, Mbaze LM, Powo R, Mpondo TN, et al. Afzeliixanthones A and B, two new prenylated xanthones from Garcinia afzelii Engl. (Guttiferae). Chem Pharm Bull. 2006;54:448-51.

302. Lannang AM, Komguem J, Ngninzeko FN, Tangmouo JG, Lontsi D, Ajaz A, et al. Bangangxanthone $A$ and $B$, two xanthones from the stem bark of Garcinia polyantha Oliv. Phytochemistry. 2005;66:2351-5.

303. Nzowa LK, Barboni L, Teponno RB, Ricciutelli M, Lupidi G, Quassinti L, et al. Rheediinosides $A$ and $B$, two antiproliferative and antioxidant triterpene saponins from Entada rheedii. Phytochemistry. 2010;71:254-61.

304. Kebede W, Bisrat D, Asres K. Free Radical Scavenging Activity-Guided Isolation of a Diterpenoid from Plectranthus punuctatus. Nat prod Comm. 2011;6:1229-32.

305. Tangmouo JG, Raimana Ho R, Lannang AL, Komguem J, Lontsi TA, Lontsi D, et al. Norbergenin derivatives from the stem bark of Diospyros sanzaminika (Ebenaceae) and their radical scavenging activity. Phytochem Lett. 2009;2: 192-5.

306. Bhebhe M, Muchuweti M, Chipurura B, Kasiyamhuru A. A comparative study of total phenolic content and antioxidant activity in Zimbabwean indigenous and exotic herbal teas. Biochem Pharmacol. 2013;2:4. http://dx. doi.org/10.4172/2167-0501.S1.004.

307. Muchuweti M, Nyamukonda L, Chagonda LS, Ndhlala AR, Mupure C, Benhura M. Total phenolic content and antioxidant activity in selected medicinal plants of Zimbabwe. Int Food Sci Technol. 2006;41:33-8.

308. Udu-Ibiam OE, Ogbu O, Ibiam UA, Nnachi AU, Agah MV, Ukaegbu CO, et al. Phytochemical and Antioxidant Analyses of Selected Edible Mushrooms, Ginger and Garlic from Ebonyi State, Nigeria. IOSR J Pharm Biol Sci. 2014;9: 86-91.

309. Adesuyi OA, Awosanya AO, Adaramola FB, Omeonu Al. Nutritional and Phytochemical Screening of Aloe barbadensis. Curr Res J Biol Sci. 2012:4:4-9.

310. Kone, D., Diop, B., Diallo, D., Djilani, A., Dicko, D. (2012) IdentifiCAT ion, Quantit at ive Determin at ion, and Antioxidant Properties of Polyphenols of Some Malian Medicinal Plant Parts Used in Folk Medicine. InTech, Available from: http://www.intechopen.com/books/macro-to-nano-pectroscopy/ identification quantitat ive-determination-and-antioxidant-properties-ofpolyphenols-of-some-mali

311. Hamzah RU, Egwim EC, Kabiru AY, Muazu MB. Phytochemical and in vitro antioxidant properties of the Methanolic extract of fruits of Blighia sapida, Vitellaria paradoxa and Vitex doniana. Oxid Antioxid Med Sci. 2013;2:215-21.

312. Iniaghe OM, Malomo SO, Adebayo JO. Hepatoprotective effect of the aqueous extract of leaves of Acalypha racemosa in carbon tetrachloride treated rats. J Med Plants Res. 2008;2:301-5.

313. Ikewuchi JC, Uwakwe AA, Onyeike EN, Ikewuchi CC. Hepatoprotective effect of an aqueous extract of the leaves of Acalypha Wilkesiana 'Godseffiana' Muell Arg (Euphorbiaceae) against carbon tetrachloride induced liver injury in rats. EXCLI J. 2011:10:280-9.

314. Nwozo SO, Oyinloye BE. Hepatoprotective effect of aqueous extract of Aframomum melegueta on ethanol-induced toxicity in rats. ACTA Biochemica Polonica. 2011;58:355-8. 
315. EL-Hawary S, EL-Shabrawy A, Ezzat S, EL-Shibany F. Gas chromatographymass spectrometry analysis, hepatoprotective and antioxidant activities of the essential oils of four Libyan herbs. J Med Plants Res. 2013;7:1746-53.

316. Ikyembe D, Pwavodi C, Agbon AN. Hepatoprotective effect of Methanolic leaf extract of anacardium occidentale (cashew) on carbon-tetrachlorideinduced liver toxicity in wistar rats. Sub-Saharan Afr J Med. 2014;1:124-31.

317. Nasir A, Abubakar MG, Shehu RA, Aliyu U, Toge BK. Hepatoprotective Effect of the Aqueous Leaf Extract of Andrographis panicul at a Nees against Carbon Tetrachloride - Induced Hepatotoxicity in Rats. Nig J Basic Appl Sci. 2013;21:45-54

318. Oyedepo TA. Hepatoprotective Activity of Annona muricata leaf extract against paracetamol induced hepatotoxicity. In: A Quarterly Publication of the Faculty of Science. 1st ed. Ede, State of Osun: Adeleke University; 2014 p. $115-20$

319. Johnson M, Olufunmilayo LA, Anthony DO, Olusoji EO. Hepatoprotective Effect of Ethanolic Leaf Extract of Vernonia amygdalina and Azadirachta indica against Acetaminophen-Induced Hepatotoxicity in Sprague-Dawley Male Albino Rats. Amer J Pharmacol Sci. 2015;3:79-86.

320. Ojo OO, Nadro MS, Tella IO. Protection of rats by extracts of some common Nigerian trees against acetaminophen-induced Hep at otoxicity. Afr J Biotechnol. 2006:5:755-60.

321. El-Beshbishy HA. Hepatoprotective Effect of Green Tea (Camellia sinensis) Extract against Tamoxifen-induced Liver Injury in Rats. J Biochem Mol Biol. 2005;38:563-70.

322. Awodele $\mathrm{O}$, Yemitan $\mathrm{O}$, Ise PU, Ikumawoyi VO. Modulatory potentials of aqueous leaf and unripe fruit extracts of Carica papaya Linn. (Caricaceae) against carbon tetrachloride and acetaminophen-induced hepatotoxicity in rats. J Intercult Ethnopharmacol. 2016;5:27-35.

323. Nadro MS, Onoagbe 1O. Protective effects of aqueous and ethanolic extracts of the leaf of Cassia italica in CCl4-induced liver damage in rats. Amer J Res Comm. 2014;2:122-30.

324. Uzzi HO, Grillo DB. The hepato-protective potentials of aqueous leaf extract of Cassia occidentalis against paracetamol induced hepatotoxicity in adult wistar rats. Inter J Herbs Pharmacol Res. 2013;2:6-13.

325. Ottu OJ, Atawodi SE, Onyike E. Antioxidant, Hepatoprotective and hypolipidemic effects of methanolic root extract of Cassia singueana in rats following acute and chronic carbon tetrachloride intoxication. Asian Pac J Trop Med. 2013;6:609-15.

326. Adebayo AH, Abolaji AO, Kela R. Hepatoprotective activity of Chrysophyllum albidum against carbon tetrachloride induced hepatic damage in rats. SENRA Acad Pub Bur Brit Col. 2011;5:1597-602.

327. Ayakeme T, Essien ES, Akaninwor JO. Evaluation of hepatoprotective and in vivo Antioxidant Activity of the Methanolic stem extract of Costus afer (Bush Cane) in alcohol induced liver Cirrhosis in rats. J Biol Food Sci Res. 2014;3: 29-34.

328. Ezeonwu VU, Dahiru D. Protective Effect of bi-herbal formulation of Ocimum grat issimum and Gongronema latifolium Aqueous Leaf Extracts on Acetaminophen-induced Hep at o-Nephrotoxicity in Rats. Amer J Biochem. 2013;3:18-23.

329. Adeneye AA, Olagunju JA, Elias SO, Olatunbosun DO, Mustafa AO, Adeshile $\mathrm{Ol}$, et al. Protective activities of the aqueous root extract of Harungana madagascariensis in acute and repeated acetaminophen hepatotoxic rats. Inter J Appl Res Nat Prod. 2008:1:29-42.

330. Agbor GA, Oben JE, Nkegoum B, Takala JP, Ngogang JY. Hepatoprotective Activity of Hibiscus cannabinus (Linn.) Against carbon tetrachloride and paracetamol induced liver damage in rats. Pak J Biol Sci. 2005;8:1397-401.

331. Usoh IF, Itemobong S, Ekaidem OE, Etim E, Akpan HD, Akpan EJ, et al. Antioxidant and hepatoprotective effects of dried flower extracts of Hibiscus sabdariffa L. on rats treated with carbon tetrachloride. J Appl Pharm Sci. 2012;02:186-9.

332. Famurewa AC, Kanu SC, Uzoegwu PN, Ogugua VN. Ameliorative effects of Hibiscus Sabdariffa extract against carbon tetrachloride-induced lipid peroxidation, oxidative stress and hepatic damage in Rats. J Pharm Biomed Sci. 2015:5:725-32.

333. Omotayo MA, Ogundare OC, Longe AO, Adenekan S. Hepatoprotective effect of Mangifera-indica stem bark extracts on paracetamol-induced oxidative stress in albino rats. Eur Sci J. 2015;11:1857-7431.

334. Effiong GS, Udoh IE, Udo NM, Asuquo EN, Wilson LA, Ntukidem IU, Nwoke IB. Assessment of Hepatoprotective and antioxidant activity of nauclea latifolia leaf extract against acetaminophen induced hepatotoxicity in rats. Inter Res J Plant Sci. 2013;4:55-63.
335. Hassan SW, Salawu K, Ladan MJ, Hassan LG, Umar RA, Fatihu MY. Hepatoprotective, antioxidant and phytochemical properties of leaf extracts of Newbouldia Laevies. Inter J Pharm Tech Res. 2010;2:573-84.

336. Udem S, Nwaogu I, Onyejekwe O. Evaluation of Hepatoprotective Activity of Aqeous Leaf Extract of Swietenia Mahogani (Maliaceae) in Chronic AlcoholInduced Liver Injury in Rats. Maced J Med Sci. 2011;15:31-6.

337. Danladi J, Abayomi KB, Mairiga AA, Dahiru AU. Comparative study of the hepatoprotective effect of ethanolic extract of Telfairia occidentalis (Ugu) leaves and silymarin on paracetamol induced liver damage in wistar rats. Inter J Anim Veter Adva. 2012;4:235-9.

338. Minari JB. Hepatoprotective effect of methanolic extract of Vernonia amygdalina Leaf. J Nat Prod. 2012;5:188-92.

339. Adewale OB, Adekeye AO, Akintayo CO, Onikanni A, Sabiu S. Carbon tetrachloride $\left(\mathrm{CCl}_{4}\right)$-induced hepatic damage in experimental Sprague Dawley rats: Antioxidant potential of Xylopia aethiopica. J Phytopharmacol. 2014;3:118-23.

340. Sintayehu B, Bucar F, Veeresham C, Asres K. Hepatoprotective and Free Radical Scavenging Activities of Extracts and a Major Compound Isolated from the Leaves of Cineraria abyssinica Sch Bip exA Rich. Pharmacog J. 2012;4:40-6.

\section{Submit your manuscript to a SpringerOpen ${ }^{\circ}$ journal and benefit from:}

- Convenient online submission

- Rigorous peer review

- Immediate publication on acceptance

- Open access: articles freely available online

- High visibility within the field

- Retaining the copyright to your article

Submit your next manuscript at $>$ springeropen.com 